FINAL REPORT

FHWA/IN/JTRP-2005/31

\title{
ITS Strategies for Minimization of Fine Particulates
}

\author{
By \\ Ahmed Soliman \\ Research Assistant \\ School of Civil Engineering \\ Purdue University \\ Robert B. Jacko \\ Principal Investigator \\ Professor of Civil Engineering \\ Purdue University \\ Barry K. Partridge \\ Manager, Office of Research and Development \\ Indiana Department of Transportation \\ Joint Transportation Research Program \\ Project No. C-36-67BBBB \\ File No. 9-10-79 \\ SPR-2926 \\ Conducted in Cooperation with the \\ Indiana Department of Transportation \\ and the U.S. Department of Transportation \\ Federal Highway Administration
}

The contents of this report reflect the views of the authors who are responsible for the facts and accuracy of the data presented herein. The contents do not necessarily reflect the official views or policies of the Indiana Department of Transportation and the Federal Highway Administration.

This report does not constitute a standard, specification, or regulation.

Purdue University

West Lafayette, Indiana

December 2005 


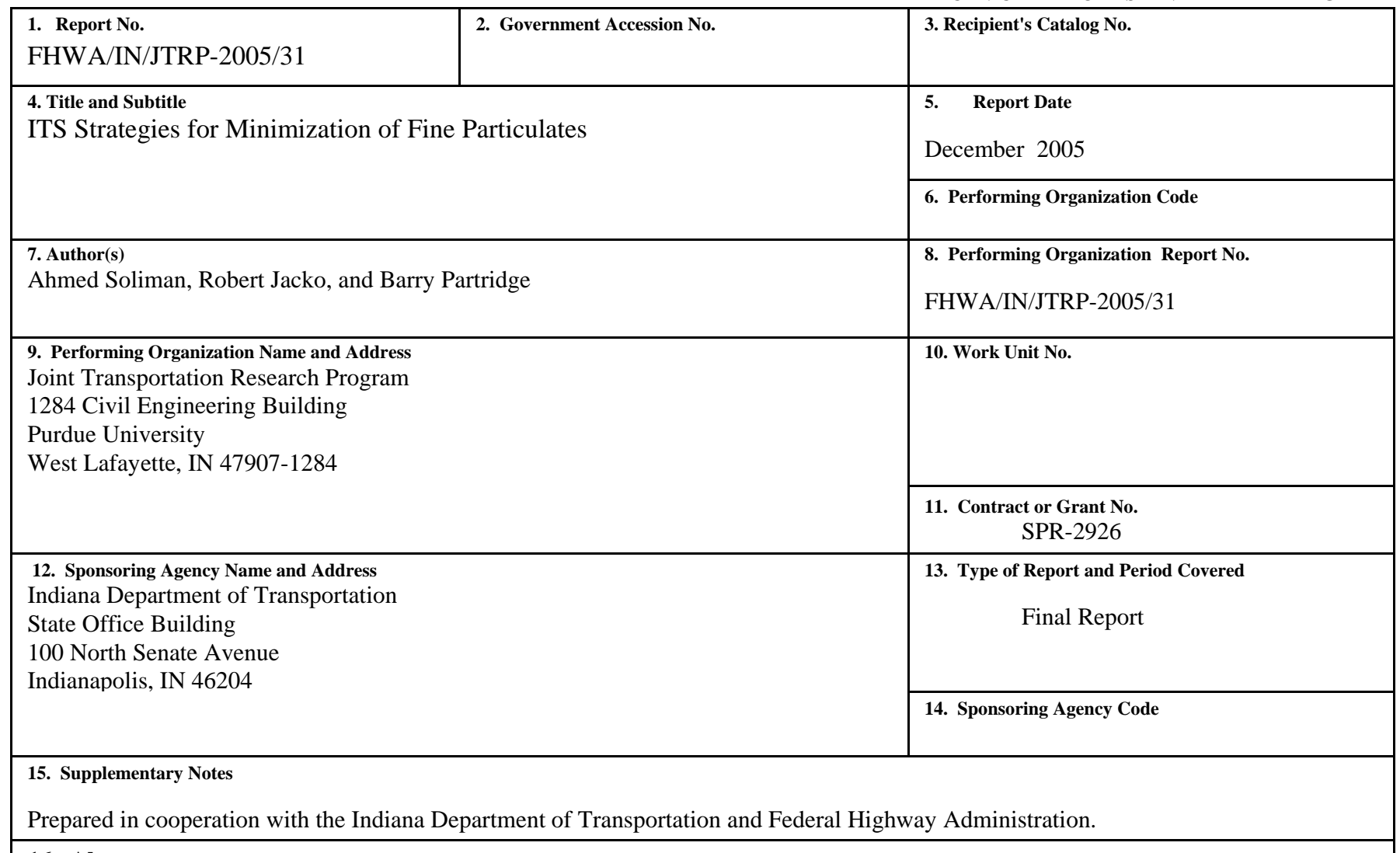

\section{Abstract}

The purpose of the study was to quantify the impact of traffic conditions such as free flow and congestion on local air quality. The Borman Expressway in Northwest Indiana is considered a test-bed for this research due to the high volume of class-9-truck traffic traveling on it, as well as the existing and continuing installation of the Intelligent Transportation System (ITS) to improve the traffic management along the highway stretch.

An empirical Traffic-Air-Quality model (TAQ model) was developed to estimate the $\mathrm{PM}_{2.5}$ emission factors (g/mi) based solely on the measured traffic parameters such as average speed, average acceleration and truck density. The TAQ model has shown better predictions that matched the measured emission factor values more than the EPA-PART5 model. During congestion (speeds $<30 \mathrm{mi} / \mathrm{h}$ ), the TAQ model, on average, over predicted the measured values by 1.2 fold, in comparison to the 4.0 fold under predictions of the EPA-PART5 model. On the other hand, during free flow (speeds $>50$ $\mathrm{mi} / \mathrm{h}$ ), the TAQ model, on average, over predicted the measured values only by 1.5 fold.

The measured values as well as the TAQ model have shown that the $\mathrm{PM}_{2.5}$ emission factors change more aggressively with respect to the average truck speeds on the Borman Expressway than the EPA-PART5 model predictions which assume constant emission values with respect to speed. On average, a $74 \%$ improvement in $\mathrm{PM}_{2.5}$ air quality is expected when the average Borman speed range is improved from $<30 \mathrm{mi} / \mathrm{h}$ to $>50 \mathrm{mi} / \mathrm{h}$ (based on reduction of mass emitted per mile [g/mi]). Additional 39\% (on average) improvement in the $\mathrm{PM}_{2.5}$ emissions on the Borman Expressway were found when traffic flow speeds increased from $55 \mathrm{mi} / \mathrm{h}$ to $75 \mathrm{mi} / \mathrm{h}$.

An autoregressive (AR) model was also developed to forecast hourly averaged emission factors using the TAQ model. The AR-TAQ model has shown the ability to predict $\mathrm{PM}_{2.5}$ emission factors based on traffic parameters..

17. Key Words

ITS, Intelligent, Transportation, Systems, Environmental, Air Pollution, Database, $\mathrm{PM}_{2.5}$, Fine, Particulate, Matter, Borman, Expressway, Ambient Monitoring, Traffic
18. Distribution Statement

No restrictions. This document is available to the public through the National Technical Information Service, Springfield, VA 22161

\begin{tabular}{|c|c|c|c|}
\hline $\begin{array}{c}\text { 19. Security Classif. (of this report) } \\
\text { Unclassified }\end{array}$ & $\begin{array}{c}\text { 20. Security Classif. (of this page) } \\
\text { Unclassified }\end{array}$ & 21. No. of Pages & 147 \\
\hline
\end{tabular}




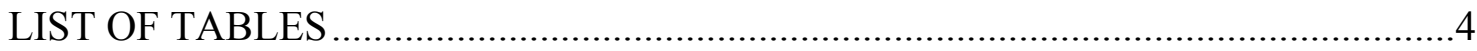

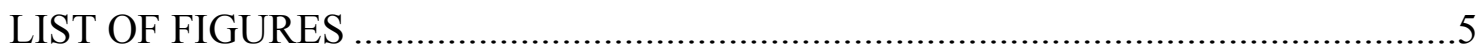

LIST OF SYMBOLS, ABBREVIATION, AND NOMENCLATURE .........................12

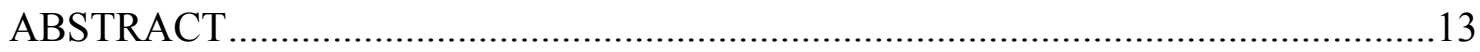

\section{CHAPTER 1. PREFACE AND OBJECTIVES}

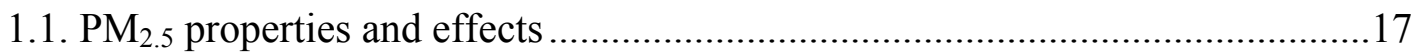

1.2. Introduction to Traffic-Air Quality Analysis..................................................19

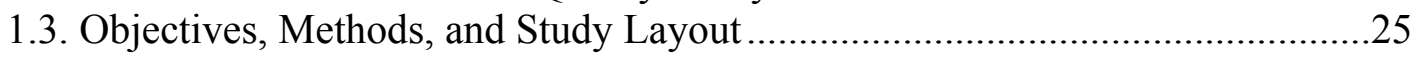

\section{CHAPTER 2. THE BORMAN EXPRESSWAY PROJECT}

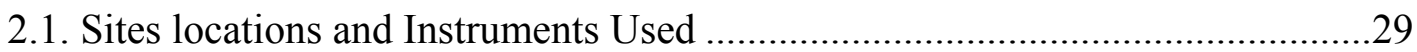

2.2. $\mathrm{PM}_{2.5}$ Background Modeling Analysis ................................................................

2.3. Borman Construction Effect on Local Air Quality ..............................................39

\section{CHAPTER 3. BORMAN TRAFFIC ANALYSIS}

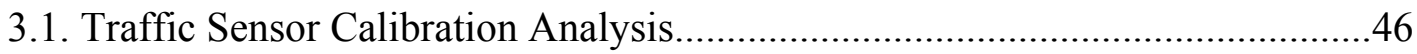

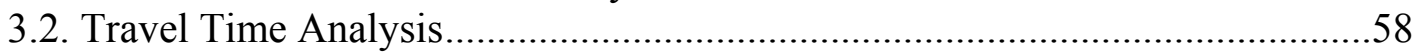

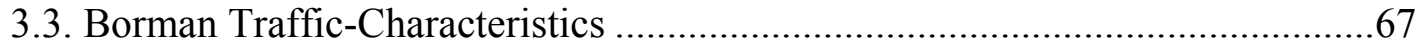

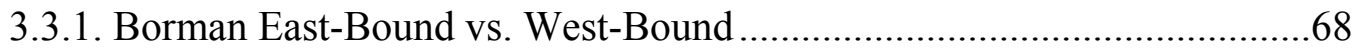

3.3.2. Borman Traffic Characteristics.............................................................

\section{CHAPTER 4. TRAFFIC-AIR QUALITY REGRESSION ANALYSIS}

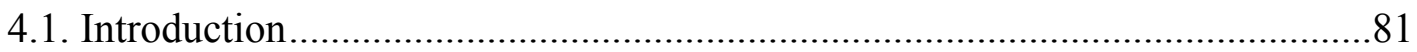

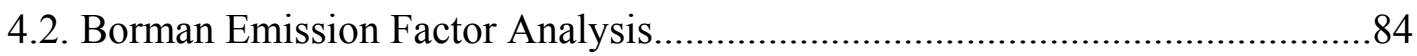


CHAPTER 5. TRUCK-MECHANICAL TURBULENCE ANALYSIS

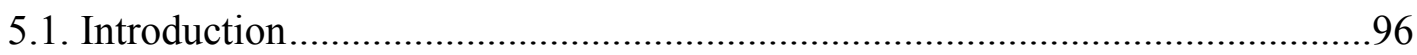

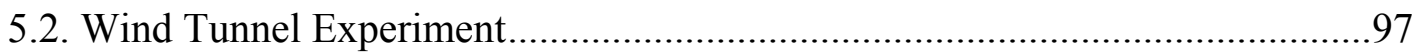

5.3. Turbulent Mixing Volume and the Borman Emission Factors..........................104

CHAPTER 6. TRAFFIC-AIR QUALITY TIME SERIES ANALYSIS

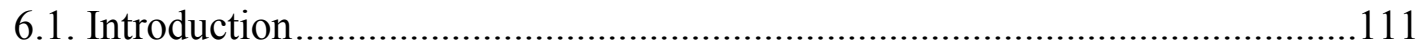

6.2. Traffic Time Series Properties ...............................................................116

6.3. Traffic-Air Quality Forecasting Model.........................................................118

CHAPTER 7. SUMMARY AND IMPLEMENTATION

7.1. Summary and Conclusion of the Borman Study ..............................................130

7.2. Implementation and Future Research …………….....................................137

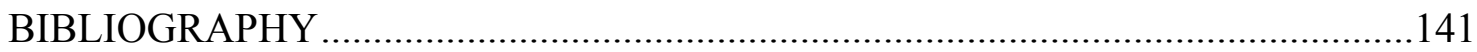




\section{LIST OF TABLES}

Table

$3.1 \%$ of trucks to total vehicles on the Borman Expressway ..................................73

$3.2 \%$ of trucks to total vehicles, for day and night on the Borman Expressway ........76

7.1 Measured $\mathrm{E}_{2}$ values for the different average Borman speed ranges..................134

7.2 \% Improvement in PM2.5 emission when speeds are changed from $55 \mathrm{mi} / \mathrm{h}$ to $75 \mathrm{mi} / \mathrm{h}$ on the Borman Expressway................................................134

7.3 The average ratios of the TAQ model and PART5 model compared to the measured $E_{2}$ values, a) during congestions, and $b$ ) during free flow 


\section{LIST OF FIGURES}

Figure

Page

$1.1 \%$ Variation of $\mathrm{CO}$ emission factor with speed in Beirut, Lebanon .24

2.1 Major roads and highways in Lake County, IN with respect to the PU-Hessville and the Kennedy Sites

2.2.a Effect of the Borman Expressway configuration with respect to the PUHessville Site on the measured concentration at the PU-Hessville Site with respect to North. North is at $0^{\circ}$

2.2.b Wind directions with respect to the PU-Hessville Site

2.3 A schematic diagram to explain the effect of wind vectors on the concentration of $\mathrm{CO}$ and $\mathrm{PM}_{2.5}$ at the PU-Hessville Site.

2.4 $\mathrm{PM}_{2.5}$ Sources, and the PU-Hessville Site, Lake County, IN, 1999

2.5 The modeled portion of the Borman Expressway with respect to the PU-Hessville Site.

2.6 Measured, CALINE4, and ISCST3 $\mathrm{PM}_{2.5}$ data at the PU-Hessville Site as a function of wind direction with respect to the PU-Hessville Site, 7:00 AM June-Sept 2001. $0^{\circ}$ is North

2.7 Measured, CALINE4 and ISCST3 $\mathrm{PM}_{2.5}$ concentration probability graph, June to September 2001

$2.8 \%$ Mass accumulation of $\mathrm{PM}_{2.5}$ as a function of time for the period of $10 / 2003$ to $5 / 2005$

2.9 Mass accumulation rate of $\mathrm{PM}_{2.5}$ (slopes of Figure 2-4 lines) for the periods of before, during and after the Borman construction for the period of 10/2003 to $5 / 2005$

2.10 Average mass accumulation rate on the Borman expressway for the periods of before, during and after the Borman construction for the period of 10/2003 to $5 / 2005$

2.11 $\mathrm{PM}_{2.5}$ concentration before, during and after construction for the periods of $1 / 11 / 03$ to $11 / 20 / 03,6 / 2 / 04$ to $6 / 18 / 04$ and $11 / 4 / 04$ to $11 / 18 / 04$, respectively......42 
Figure

2.12 $\mathrm{PM}_{2.5}$ concentration distribution for the period of $1 / 11 / 03$ to $11 / 20 / 03$ (before

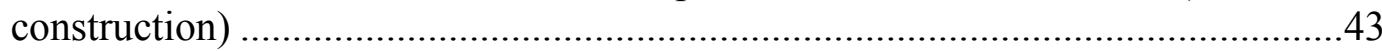

2.13 $\mathrm{PM}_{2.5}$ concentration distribution for the period of $6 / 2 / 04$ to $6 / 18 / 04$ (during construction) .44

2.14 $\mathrm{PM}_{2.5}$ concentration distribution for the period of $11 / 4 / 04$ to $11 / 18 / 04$ (after construction)

3.1 A photograph of the traffic monitoring station while being tested on the Northwestern Ave, West Lafayette, IN, May 2004

3.2 A sample of 5-min averaged traffic volume on Northwestern Ave, West Lafayette, IN. May 24 to May 28, 2004 .48

3.3 A sample of 5-min averaged traffic occupancy on Northwestern Ave, West Lafayette, IN. May 24 to May 28, 2004

3.4 A sample of 5-min averaged traffic time-mean-speed on Northwestern Ave, West Lafayette, IN. May 24 to May 28, 2004

3.5 A photograph of the PU-Hessville monitoring station, located south of the Borman Expressway, at mm 4.1

3.6 A photograph of the Kennedy monitoring station, located north of the Borman Expressway, at $\mathrm{mm} 3.3$

3.7 East bound manual and sensor speeds of lane 2 as a function of time, March 15, 2005, for the periods of 10:00 to 11:00 AM, and 2:30 to 3:30 PM

3.8 Correlation of the east bound manual and sensor speeds of lane 2, March 15, 2005, for the periods of 10:00 to 11:00 AM, and 2:30 to 3:30 PM.

3.9 Correlation of the east bound manual and sensor truck volume of lane 2, March 15, 2005, for the periods of 10:00 to 11:00 AM, and 2:30 to 3:30 PM. .53

3.10 The cumulative truck count for the east bound for both the congested and free flow periods, lane 2, March 15, 2005 
Figure

Page

$3.11 \%$ error of the cumulative truck count for the east bound for both the congested and free flow periods, lane 2, March 15, 2005

3.12 West bound manual and sensor speeds of lane 2 as a function of time, March 15, 2005, for the periods of 10:00 to 11:00 AM, and 2:30 to 3:30 PM

3.13 Correlation of the west bound manual and sensor speeds of lane 2, March 15, 2005, for the periods of 10:00 to 11:00 AM, and 2:30 to 3:30 PM.

3.14 Correlation of the west bound manual and sensor truck volume of lane 2 , March 15, 2005, for the periods of 10:00 to 11:00 AM, and 2:30 to 3:30 PM. 57

3.15 The cumulative truck count for the west bound for both the congested and free flow periods, lane 2, March 15, 2005

$3.16 \%$ error of the cumulative truck count for the west bound for both the congested and free flow periods, lane 2, March 15, 2005

3.17 Sum of Squares (S2) of Travel Time vs. Uc. S2 is between Manual readings, Manual-Coif. Algorithm, and sensor readings (for a 0.1 mile segment)

3.18 Sum of Squares (S2) of Travel Time vs. Uc. S2 is between Manual readings, Sensor-Coif. Algorithm, and sensor readings (for a 0.1 mile segment)

$3.19 \%$ change in output travel time values compared to $\mathrm{Uc}=12 \mathrm{mi} / \mathrm{h} \mathrm{vs}$. Uc

$3.20 \%$ change in output travel time values compared to. \% change in input timestamped-speeds

3.21 Normalized travel time (TRN) as a function of time during congestion and free flow for the west bound central lane of the Borman Expressway, March 15, 2005

$3.22 \%$ frequency distribution of speed on the Borman Expressway. (a) East Bound away from Chicago, (b) West bound towards Chicago, November 2004

$3.23 \%$ frequency distribution of speed on the Borman Expressway. (a) East Bound, (b) West bound, December 2004 
Figure

$3.24 \%$ frequency distribution of speed on the Borman Expressway. (a) East Bound, (b) West bound, January 2005.

$3.25 \%$ frequency distribution of speed on the Borman Expressway. (a) East Bound, (b) West bound, February 2005.

$3.26 \%$ frequency distribution of speed on the Borman Expressway. (a) East bound-day, (b) West bound-day, (c) East bound-night, (d) West bound-night, November 2004. Day is between 8:00 AM to 8:00 PM, and night is between 8:00 PM to 8:00 AM

$3.27 \%$ frequency distribution of speed on the Borman Expressway. (a) East bound-day, (b) West bound-day, (c) East bound-night, (d) West bound-night, December 2004. Day is between 8:00 AM to 8:00 PM, and night is between 8:00 PM to 8:00 AM

$3.28 \%$ frequency distribution of speed on the Borman Expressway. (a) East bound-day, (b) West bound-day, (c) East bound-night, (d) West bound-night, January 2005. Day is between 8:00 AM to 8:00 PM, and night is between 8:00 PM to 8:00 AM

$3.29 \%$ frequency distribution of speed on the Borman Expressway. (a) East bound-day, (b) West bound-day, (c) East bound-night, (d) West bound-night, February 2005. Day is between 8:00 AM to 8:00 PM, and night is between 8:00 PM to 8:00 AM

3.30 The flow-density relation of the Borman Expressway, February 2005 .78

3.31 The flow-Occupancy relation of the Borman Expressway, February 2005. .79

3.32 Acceleration frequency distribution of the Borman Expressway, for occupancy greater than 20\%. February 2005

3.33 Normalized travel time (TRN) as a function of the overall Borman Expressway occupancy, February 2005.

4.1 Microscopic emission factor $\mathrm{E}_{1}$ as a function of average speed for at a zero acceleration $(-0.01<\mathrm{a}<0.01)$. February 2005

4.2 Microscopic emission factor $\mathrm{E}_{1}$ as a function of average acceleration, February 2005 
Figure

4.3 A schematic diagram showing the process of estimating E2 from traffic data .....90

4.4 The measured, estimated and EPA-PART5-estimated macroscopic $\mathrm{PM}_{2.5}$ emission factor $E_{2}$ as a function of the Borman average speed, November 2004

4.5 The measured, estimated and EPA-PART5-estimated macroscopic $\mathrm{PM}_{2.5}$ emission factor $E_{2}$ as a function of the Borman average speed, December 2004

4.6 The measured, estimated and EPA-PART5-estimated macroscopic $\mathrm{PM}_{2.5}$ emission factor $\mathrm{E}_{2}$ as a function of the Borman average speed, January 2005

4.7 The ratio between the measured and estimated values of $E_{2}$ by both equation 4-7 and the EPA-PART5 model. a) November 2004, b) December 2004 and c) January 2005

4.8 The change in the $\mathrm{PM}_{2.5}-\mathrm{E}_{2}$ output as a function of the change in the input parameters, a) speed, and b) acceleration

5.1 A schematic diagram of the wind tunnel used in the experiments

5.2 The wind tunnel velocity profile at wind speed of $112 \mathrm{mi} / \mathrm{h}$ without the platform or models.

5.3 a) the 11-inch high, 54-inch wide wooden frame mounted inside the wind tunnel, b) the 4-inch long tufts attached to the screen at the back of the platform.

5.4 the screen tufts at $54 \mathrm{mi} / \mathrm{h}$ for two different truck location from the screen, a) at 2.5 inches ( 0.36 truck height), b) at 10 inches (1.43 truck height)

5.5 Change in area behind the truck $\left[\mathrm{in}^{2}\right]$ as a function of the distance (normalized with respect to the truck height) from the trefftz plane at constant wind speeds of $34 \mathrm{mi} / \mathrm{h}$ and $54 \mathrm{mi} / \mathrm{h}$ 101

5.6 Turbulent area $\left[\mathrm{in}^{2}\right]$ behind a single truck as a function of wind speed $[\mathrm{mi} / \mathrm{h}] \ldots .102$

5.7 Photographs of a) two-truck setup, and b) three-truck setup used in the wind tunnel experiment. 
Figure

5.8 Turbulent area $\left[\mathrm{in}^{2}\right]$ behind two trucks as a function of wind speed $[\mathrm{mi} / \mathrm{h}] \ldots \ldots . .103$

5.9 Turbulent area $\left[\mathrm{in}^{2}\right]$ behind three trucks as a function of wind speed $[\mathrm{mi} / \mathrm{h}] \ldots . .103$

5.10 Microscopic emission factor $\mathrm{E}_{1}$ as a function of average speed for at a zero acceleration $(-0.01<\mathrm{a}<0.01)$, using the modified mixing volume $\mathrm{V}(\mathrm{SPD})$. February 2005

5.11 Microscopic emission factor $\mathrm{E}_{1}$ as a function of average acceleration for a modified mixing volume V(SPD), February 2005.

5.12 The measured, estimated (modified TAQ-model) and PART5-estimated macroscopic $\mathrm{PM}_{2.5}$ emission factor $\mathrm{E}_{2}$ as a function of the Borman average speed, November 2004.

5.13 The measured, estimated (modified TAQ-model) and PART5-estimated macroscopic $\mathrm{PM}_{2.5}$ emission factor $\mathrm{E}_{2}$ as a function of the Borman average speed, December 2004

5.14 The measured, estimated (modified TAQ-model) and PART5-estimated macroscopic $\mathrm{PM}_{2.5}$ emission factor $\mathrm{E}_{2}$ as a function of the Borman average speed, January 2005 .

5.15 The ratio between the measured and estimated values of $E_{2}$ by both TAQ-model and the EPA-PART5 model. a) November 2004,

b) December 2004 and c) January 2005

6.1 A hypothetical representation of an additive time series model....

6.2 1-hour averages of the traffic data: a) average Borman speed [mi/h], b) average class 9-truck-density [vehicle/mi], c) total class 9-truck volume [vehicle/h], and d) average fleet-mix [\%]. November 8 to November 14, 2004.

6.3 Spectral analysis of the traffic data: a) FFT of average Borman speed, b) FFT of average class 9-truck-density, c) FFT of total class 9-truck volume, and d) FFT of average fleet-mix. November 8 to November 14, 2004 118

6.4 The sum-of-squares $\left(\mathrm{S}^{2}\right)$ as a function of the AR-model order " $p$ " for: a) Speed, b) Acceleration and c) class 9-truck density. November 8 to November 14, 2004 
Figure

6.5 a) Measured speed values, and b) estimated speed values using the AR-model of order $3 \mathrm{c}$ ) estimated speed vs. measured speed.

November 8 to November 14, 2004

6.6 a) Measured acceleration values, and b) estimated acceleration values using the AR-model of order 8. November 8 to November 14, 2004

6.7 a) Measured truck density values, b) estimated truck density values using the AR-model of order 2, and c) estimated (forecasted) vs. measured class 9-truck density. November 8 to November 14, 2004

6.8 Measured and forecasted/estimated $\mathrm{E}_{2}$ values as a function of time for the period of November 8 to November 14, 2004

6.9 Measured normalized-travel-time (TRN) as a function of time for the period of November 8 to November 14, 2004

6.10 a) Measured, b) forecasted emission factors $\left(E_{2}\right)$ and c) The TRN values of the Borman Expressway. February 10 and 11, 2005

7.1 A schematic diagram showing the process of estimating E2 from traffic data ...132

7.2 a) The measured, estimated (modified TAQ-model) and PART5-estimated macroscopic $\mathrm{PM}_{2.5}$ emission factor $\mathrm{E}_{2}$ as a function of the Borman average speed, and b) TAQ-model-estimated $E_{2}$ vs. the measured values of $E_{2}$, January 2005

7.3 Measured and forecasted (estimated) emission factors $\left(E_{2}, \mathrm{~g} / \mathrm{mi}\right)$ of the Borman Expressway. February 10 and 11, 2005 136

7.4 Air pollution sources in urban areas and their control measures 138 


\section{LIST OF SYMBOLS, ABBREVIATION, AND NOMENCLATURE}

$\begin{array}{ll}\text { Acc } & \text { Acceleration }\left[\mathrm{m} / \mathrm{s}^{2}\right] \\ \mathrm{CO} & \text { Carbon Monoxide } \\ \mathrm{E}_{1} & \text { Microscopic } \mathrm{PM}_{2.5} \text { emission factor }[\mathrm{g} / \mathrm{veh}] \\ \mathrm{E}_{2} & \text { Macroscopic } \mathrm{PM}_{2.5} \text { emission factor }[\mathrm{g} / \mathrm{mi}] \\ \mathrm{g} & \text { Gram } \\ \mathrm{h} & \text { Hour } \\ \mathrm{m} & \text { Meter } \\ \mathrm{mi} & \text { Mile } \\ \mathrm{PM} & \text { Particulate Matter } 2.5 \text { micrometer in diameter or less } \\ \mathrm{s} & \text { Second } \\ \mathrm{S} 2 & \text { Sum of Squares } \\ \mathrm{SPD} & \text { Speed }[\mathrm{mi} / \mathrm{h}] \\ \text { veh } & \text { Vehicle }\end{array}$




\begin{abstract}
The purpose of the study was to quantify the impact of traffic conditions such as free flow and congestion on local air quality. The Borman Expressway in Northwest Indiana is considered a test-bed for this research due to the high volume of class-9-truck traffic traveling on it, as well as the existing and continuing installation of the Intelligent Transportation System (ITS) to improve the traffic management along the highway stretch.
\end{abstract}

An empirical Traffic-Air-Quality model (TAQ model) was developed to estimate the $\mathrm{PM}_{2.5}$ emission factors $(\mathrm{g} / \mathrm{mi})$ based solely on the measured traffic parameters such as average speed, average acceleration and truck density. The TAQ model has shown better predictions that matched the measured emission factor values more than the EPA-PART5 model. During congestion (speeds $<30 \mathrm{mi} / \mathrm{h}$ ), the TAQ model, on average, over predicted the measured values by 1.2 fold, in comparison to the 4.0 fold under predictions of the EPA-PART5 model. On the other hand, during free flow (speeds $>50 \mathrm{mi} / \mathrm{h}$ ), the TAQ model, on average, over predicted the measured values only by 1.5 fold.

The measured values as well as the TAQ model have shown that the $\mathrm{PM}_{2.5}$ emission factors change more aggressively with respect to the average truck speeds on the Borman Expressway than the EPA-PART5 model predictions which assume constant emission values with respect to speed. On average, a $74 \%$ improvement in $\mathrm{PM}_{2.5}$ air quality is expected when the average Borman speed range is improved from $<30 \mathrm{mi} / \mathrm{h}$ to $>50 \mathrm{mi} / \mathrm{h}$ (based on reduction of mass emitted per mile $[\mathrm{g} / \mathrm{mi}]$ ). Additional $39 \%$ (on 
average) improvement in the $\mathrm{PM}_{2.5}$ emissions on the Borman Expressway were found when traffic flow speeds increased from $55 \mathrm{mi} / \mathrm{h}$ to $75 \mathrm{mi} / \mathrm{h}$.

An autoregressive (AR) model was also developed to forecast hourly averaged emission factors using the TAQ model. The AR-TAQ model has shown the ability to predict $\mathrm{PM}_{2.5}$ emission factors based on traffic parameters. 


\section{CHAPTER ONE}

\section{PREFACE AND OBJECTIVES}

The study of meteorology and air pollution of urban areas is of importance due to the harmful effects of the excess air pollutants on the environment and human health. Dispersion and dilution of air pollutants in urban areas are strongly influenced by meteorological conditions as well as the terrain. Buildings and high rises contribute to the change in wind speed and direction, as well as turbulence and the thermal properties of the surface. These changes are due to the change in both the surface roughness and the amount of solar radiation reaching the ground in comparison to rural areas. Several individual air pollution sources can be found in urban areas, ranging from motor vehicles, and small individual households or businesses to large sources such as commercial industrial plants and power plants. Such factors contribute to the complexity of analyzing and modeling air pollution in urban areas and mega-cities (Mayer 1999, and Mage et. al. 1991).

Air pollution regimes can be divided into three main classes based on the horizontal pollution concentration gradient (Noll et. al. 1977):

1- Micro-scale: This regime is characterized by a change in the ground level air pollution concentrations by values greater than $20 \%$ over a horizontal distance less than $100 \mathrm{~m}$. In other words, it is a regime where a major change in ground level concentration 
occurs over a small distance. This usually occurs very near to the sources of air pollution; for example, high-traffic expressways, and large industrial sources.

2- Meso-scale: This regime is characterized by a change in the ground level air pollution concentrations by values less than $20 \%$ over a horizontal distance ranging from $100 \mathrm{~m}$ to $10,000 \mathrm{~m}$. This regime represents a community size air mass with fairly homogeneous ground level air pollution concentration, i.e. local background for urban areas, which includes, local streets, residential and commercial space heating furnaces, and small industrial sources. Industrial and mobile sources, such as motor vehicles also contribute to the meso-scale air pollution that contaminates the ambient air in urban areas.

3- Macro-scale: This regime is characterized by a change in the ground level air pollution concentrations by values less than $20 \%$ over a horizontal distance greater than $10,000 \mathrm{~m}$. This regime represents a regional background which is characterized by fairly homogeneous air pollution concentration over long distances ranging from tens to hundreds of kilometers.

The objective of this project is to analytically develop a model using both regression analysis as well as Time Series Analysis (TSA) to correlate traffic conditions on the Borman Expressway, such as free-flow and congested conditions, to the local air quality adjacent to the Borman Expressway. Such a model may be used as an air-quality index or parameter that can be included in the Intelligent Transportation System (ITS) protocols that are currently being installed an implemented in Northwest Indiana to improve local traffic-air quality levels. 


\section{1. $\mathrm{PM}_{2.5}$ Properties and Effects:}

There are different types of air pollutants that have significant impact on human's health and the environment, such as carbon monoxide (CO), hazardous air pollutants (HAPs), lead $(\mathrm{Pb})$, nitrogen oxides $\left(\mathrm{NO}_{\mathrm{x}}\right)$, particulate matter $\left(\mathrm{PM}_{10}\right.$, and $\left.\mathrm{PM}_{2.5}\right)$ and sulfur oxides $\left(\mathrm{SO}_{\mathrm{x}}\right)$. This review will focus mainly on particulate matter 2.5 micrometer in diameter or less $\left(\mathrm{PM}_{2.5}\right)$.

Particulate matter is the term used for a mixture of solid particles and liquid droplets found in the air such as sea salt, soil dust, smoke, sulfates, nitrates, some organic compounds, and exhaust of diesel engines. In general, are particles with sizes ranging from 0.001 to $500 \mu \mathrm{m}$ in diameter (Wark et. al, 1998). The bulk particulate size distribution in the atmosphere ranges from 0.1 to $10 \mu \mathrm{m}$. Particles with diameters ranging from 1 to $20 \mu \mathrm{m}$ have settling velocities, yet these velocities are considerably small compared to the wind velocities and therefore these particles tend to follow the motion of the gas (air) in which they are born (Wark et. al, 1998). Settling velocities are basically the constant-terminal velocities of these particles in the direction parallel to the earth's gravitational field. The terminal velocities are reached after the weight of the particles reach equilibrium with the forces caused by buoyancy and frictional drag. The average settling velocities of the particulate matter with sizes between 1 and $10 \mu \mathrm{m}$ in diameter range from $4 \times 10^{-5}$ to $300 \times 10^{-5} \mathrm{~m} / \mathrm{s}$ (Wark et. al, 1998) (the average wind speeds observed in this study ranged from 0.5 to $4.5 \mathrm{~m} / \mathrm{s}$ ). Therefore, $\mathrm{PM}_{2.5}$ can travel long distances affecting other areas away from their source.

Several sources can contribute to the $\mathrm{PM}_{2.5}$ found in the atmosphere. Such sources include fuel combustion from automobiles, power plants, wood burning, industrial 
processes, and diesel powered vehicles such as buses and trucks. $\mathrm{PM}_{2.5}$ may also be formed in the atmosphere when products of fuel combustion such as sulfur dioxide, nitrogen oxides, and volatile organic compounds (VOC's) are transformed in the air by chemical reactions.

Particulate matter has significant effects on the environment and human health. It may cause mortality in sensitive groups such as children and the elderly even if the air quality standards were respected (Ebelt et. al, 2000, Dab et. al, 2001). These particulates present a health hazard to the lungs due to their small size (respirable particulates, less than $10 \mu \mathrm{m}$ in diameter) and can find passage from the ambient air into the respiratory system. In a study conducted by Künzli et al. (2002) in urban areas in France, Austria and Switzerland, $6 \%$ of mortality of the population exposed to particulates $\mathrm{PM}_{10}(10 \mu \mathrm{m}$ in diameter or less) was attributed to the $\mathrm{PM}_{10}$, where $3 \%$ of these deaths were attributed to traffic sources (Künzli et al, 2002).

With respect to the environment, $\mathrm{PM}_{2.5}$ reduces visibility, increases the possibility of precipitation, acid-rain, fog and cloud. They may also reduce solar radiation, and therefore may cause changes to the environmental temperatures and biological rates of plant growth. The National Ambient Air Quality Primary Standard (set to protect human health) for $\mathrm{PM}_{10}$ is $150 \mu \mathrm{g} / \mathrm{m}^{3}$ for an average time of 24 hours, and for $\mathrm{PM}_{2.5}$ is $65 \mu \mathrm{g} / \mathrm{m}^{3}$ for the same averaging time period (Wark et. al, 1998).

One of the major $\mathrm{PM}_{2.5}$ sources in urban areas is vehicle traffic (especially Heavy Duty Diesel Trucks -HDDV). Diesel emissions contribute to the development of cancer, cardiovascular and respiratory health problems as well as reductions in visibility and solar radiation as mentioned earlier and hence may contribute to the global climate 
change (Lloyed et. al, 2001). It has been found that outdoor as well as indoor $\mathrm{PM}_{10}$ and $\mathrm{PM}_{2.5}$ concentrations increased in high traffic urban areas by $15 \%$ to $20 \%$ in comparison to low traffic areas in the Netherlands (Fischer et. al, 2000). Such increase in indoor/outdoor concentration was found to be strongly correlated to personal exposure to these particulates; hence increasing the chances of respiratory diseases for the sensitive groups (Janssen et. al., 2000). Therefore, it is of importance to analyze and quantify the traffic-air quality relation in urban areas adjacent to major highways.

\subsection{Introduction to Traffic-Air Quality Analysis:}

The impact of traffic on air quality has been frequently studied using two different methods: theoretical and empirical approaches. The first is, the theoretical approach, where traffic factors such as traffic flow (traffic-volume), traffic speed, and fleet mix as well as environmental parameters such as temperature, mixing height, emission factor (from emission factor-models such as PART5, and MOBILE6), and wind speeds are input to a model such as CALINE4 to calculate the pollutant concentration for the different traffic scenarios. The second is the empirical approach, where pollutant concentrations are first measured along with the different traffic parameters, then the emission factors are calculated based on the measured values as in the case of tunnel studies (Kristensson et. al, 2004, and John et. al, 1999). The first approach is good in the case of urban-traffic planning. It provides an estimation of the relative change in the air quality in urban areas caused by building extra roads, overpasses, etc. However, since the emission factors are estimated based on dynamometer measurements, they may not necessarily represent the real world-emissions (Robinson, et. al, 1996); hence may produce errors when output concentrations are compared to measured values. On the 
other hand, the empirical approach has the advantage of representing the real-world conditions. However, if results are not generalized, the final analysis may be biased or in other words, site specific.

The following is a general review of studies performed in different areas for different air pollutants using the theoretical modeling approach. Several studies have been concerned with modeling the pollution in the streets of urban areas using different diffusion models, as well as in street canyons (Parsons, et. al, 2003, and Vardoulkis, et. al, 2003). These studies ranged from the comparison between the real-time instruments used to monitor airborne particulate matter (Chuersuwan et. al, 2000, Chung et. al, 2001, Pang et. al, 2001, and Bortnick et. al, 2002) to modeling the particulate dispersion in the wake of vehicles (Hider et. al, 1997) as well as the environmental impact of diesel engines (an important mobile-source of particulate matter) (Lloyed et. al, 2001).

The Operational Street Pollution Model (OSPM) has been developed by the National Environmental Research Institute in Denmark (NERI) to predict the $\mathrm{CO}, \mathrm{NO}_{\mathrm{x}}$ and $\mathrm{SO}_{2}$ concentration in street canyons. Street canyons are streets with a relatively narrow width and where the buildings are relatively high (average height of 25 meters) (Fu et. al, 2000). The OSPM computes the concentrations at a receptor height of only 2 meters. The pollutant concentration calculated by the model has two components; the first is from the direct contribution of the traffic on the road that is calculated using simple Gaussian diffusion equations, while the second is from the re-circulation component, which is due to the transport and dispersion of pollutants by the wind vortices created by the buildings in the street canyons. A study on the traffic-related air 
pollution in street canyons of Beijing, China has used the OSPM to predict the $\mathrm{CO}, \mathrm{NO}_{\mathrm{x}}$ and $\mathrm{SO}_{2}$ concentration at a receptor located in a street canyon. The study has shown that the OSPM has predicted concentrations systematically higher than the measured values. This was attributed to the width of the street canyons. While OSPM was mainly developed for the narrow street canyons of Denmark, the Beijing street canyons were wider (around 68 meters wide). When the streets become more open (wider) the rooftop wind flow increases giving strength to the street canyon's vortices, and therefore increasing the wind speed in the street canyon. As a consequence, the exchange of the pollutants between the street canyons and the upper atmosphere becomes more intensive and therefore decreases the concentration re-circulation component. This wind speed modification was added to the model and the model was retested, resulting in reducing the difference between the modeled and measured values (Fu et. al, 2000).

A study that combined both traffic and environmental dispersion models has analyzed the extent to which traffic policies and future trends in engine technologies can affect air quality in urban areas (Chquetto et. al, 1995). The city of Chester, England was considered for this study due to its relatively high population (119,000 inhabitants; 687 population $/ \mathrm{mi}^{2}$ ) and due to the increasing use of private transport that caused problems such as congestions, delays, traffic queues, and air pollution especially during peak periods. The Simulation and Assignment of Traffic in Urban Road Networks model (SATURN) was used to simulate urban traffic assignment in Chester. The SATURN outputs are car and bus-traffic flows, travel times on the road links, and vehicle queues at road junctions. These outputs along with the exhaust emission coefficients of pollutants (mass of pollutants emitted per unit time per unit distance) were the input to a Gaussian 
dispersion model -developed by the Transport and Research Laboratory (TRL) in the UK- was used to calculate the pollutant concentrations under different traffic scenarios in downtown Chester. The study predicted that the implementation of a pedestrianisation scheme where traffic is diverted from routes and areas that are of predominant pedestrian use (central and high density areas along main shopping streets) to other local road networks in the central areas will result in a drop of air pollution in these areas by $79 \%$ for $\mathrm{CO}$ and $63 \%$ for PM. This scheme was also predicted to increase air pollution in the rest of the central area road network by $22 \%$ for $\mathrm{CO}$ and a drop of $1 \%$ for PM. The study also predicted that the increased use of diesel engine vehicles in the central area (market trends) will increase the $\mathrm{PM}$ and $\mathrm{CO}_{2}$ levels in these areas. However, a considerable decrease in CO levels (up to 50\%) will be achieved by the use of catalytic converters in vehicles (Chquetto et. al, 1995).

Another study on the factors affecting air quality at congested intersections in urban areas was conducted in Beirut, Lebanon (El-Fadel et. al, 2000). Air quality measurements were first obtained to define the existing levels of $\mathrm{CO}$ and $\mathrm{NO}_{2}$, and then mathematical models were used to define the change of pollutant concentrations under various scenarios at congested intersections. The different scenarios presented to reduce air pollution were: 1) the introduction of grade separation, 2) changing the vehicle fleet mix, and 3) the improvement of road level of service (LOS). Grade separation is a transportation strategy aimed at increasing the average cruising speed and thereby reducing traffic delays at intersections. This can be achieved by introducing overpasses (bridges) or underpasses (tunnels) at the different congested intersections. The fleet mix represents the different types of vehicles in a fleet, for example, passenger cars, trucks, 
and buses. Change in the fleet mix means a change in the ratio of the different types of vehicles in the fleet; for example, increasing the ratio of the number of buses to the passenger cars. The LOS describes the performance of the roadway which can be improved, for example, by adding extra lanes to the existing roads, to reduce the probability of congestion on the roadways and increasing cruising speeds. The mathematical models used in this air quality assessment were the Mobile Vehicle Emissions Inventory (MVEI7G) developed by the California Air Resources Board, and the California Line source dispersion model (CALINE4) developed by the California Department of Transportation (CALTRANS). The MVEI7G was used to estimate the emission factors (grams/kilometer) for the different types of vehicles and the fleet mixes in the greater Beirut area, while CALINE4 was used to estimate the pollutant concentration levels at specified receptor locations for the different road conditions and improvement scenarios. Figure 1-1 shows the variation of $\mathrm{CO}$ emission factors with speed predicted by MVEI7G. The study has shown that the introduction of grade separation has reduced the $\mathrm{CO}$ concentration by $56 \%$ and $86 \%$ for an overpass and an underpass respectively, assuming a $20 \mathrm{kph}$ (kilometers per hour) increase in speed. A decrease of $7 \%$ and $71 \%$ for $\mathrm{CO}$ concentration was also obtained with the assumption of no change in speed for an overpass and an underpass respectively. The change in the vehicle fleet mix by introducing public transportation and decreasing the number of private vehicles has resulted in the reduction of the traffic-volume and an increase in the cruising speeds. This scenario has resulted in the reduction of $\mathrm{CO}$ concentrations at the intersections by $29 \%$ and $52 \%$ for a speed increase of $5 \mathrm{kph}$ and $10 \mathrm{kph}$ respectively. The study has also shown that the improved LOS resulted in the increase of cruising speeds 
that in turn reduced the pollutants emission factors emitted by the specific fleet mixes. The best cruising speeds were predicted to be 75 to $80 \mathrm{kph}$ (El-Fadel et. al, 2000).

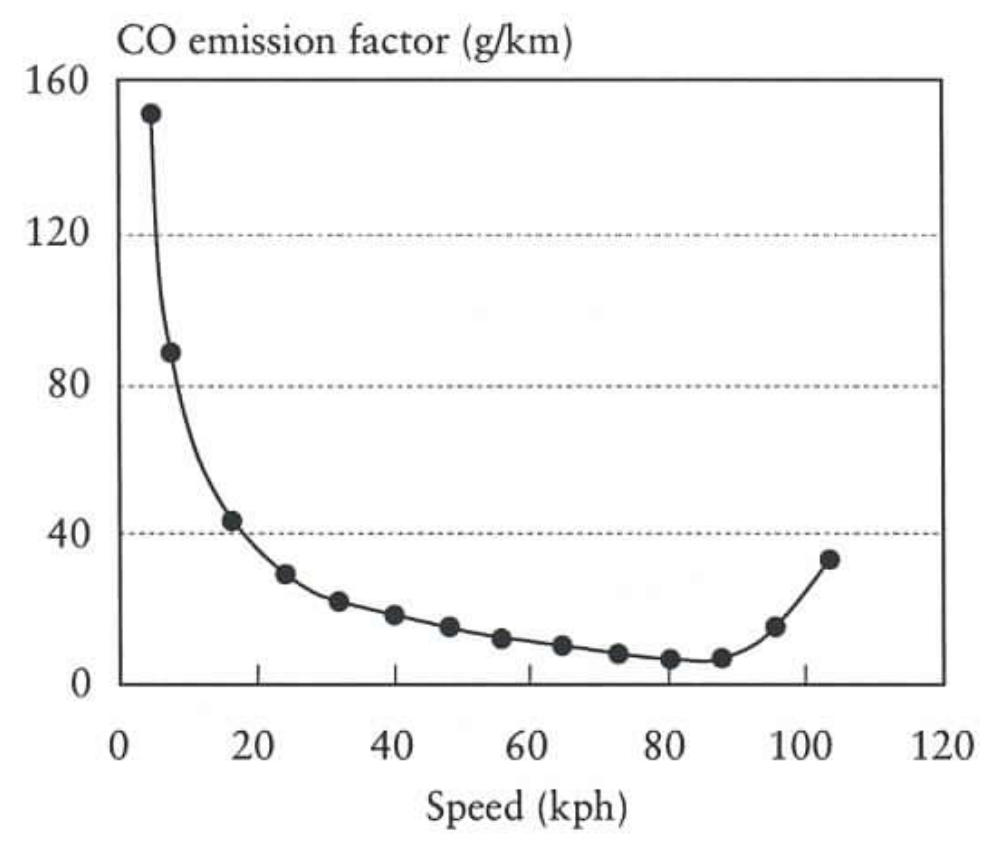

Figure 1-1. Variation of CO emission factor with speed in Beirut, Lebanon. (El-Fadel et al., 2000).

Another study in Kaohsiung, Taiwan was performed to determine the source contributions to ambient $\mathrm{PM}_{2.5}$ in the area using the Chemical Mass Balance model (CMB8) for the period of February and March 1999 (Chen et. al, 2001). The study has shown that the major contributors to ambient $\mathrm{PM}_{2.5}$ in Kaohsiung were traffic exhaust (18-54\%), secondary aerosols from chemical reactions in the atmosphere (30-41\% from $\mathrm{SO}_{4}{ }^{2-}$ and $\mathrm{NO}_{3}{ }^{-}$), and outdoor burning of agricultural waste (13-17\%).

Emission factor determination using the empirical approach has been studied by using regression analysis and by using Time Series Analysis (TSA) for forecasting. 
Literature review and detailed discussion of both techniques will be given in chapters four and six, respectively.

\subsection{Objectives, Methods, and Study Layout:}

Mobile sources on an expressway have been shown to be a major contributor to local air pollutants even in industrialized urban areas (Soliman et. al, 2004). The city of Gary, IN is a good example of such areas due to the existence of the Borman Expressway and nearby industrial plants. The Borman Expressway is a critical Interstate Highway link through the northwestern portion of Indiana that is heavily traveled by trucks and private vehicles. It carries the highest truck traffic volume in Indiana.

The objective of this project is to analytically develop a model (a set of equations or parameters) that correlate traffic conditions on the Borman Expressway, such as freeflow and congested conditions to the local air quality ( $\mathrm{PM}_{2.5}$ levels) adjacent to the Expressway. Such a model may be used as an air-quality index or parameter that can be included in the Intelligent Transportation System (ITS) protocols that are currently installed in Northwest Indiana to improve local traffic-air quality levels, further details on its applications are discussed in chapter seven.

Two techniques will be used in the analysis: 1) A regression analysis, and 2) A Time Series Analysis (TSA). The main focus of this study is on heavy duty diesel vehicles or HDDV (Class 9, diesel vehicles greater than 30 feet long) which are the primary $\mathrm{PM}_{2.5}$ sources in the near vicinity of the Borman Expressway.

The analysis will be used to determine two types of emission factors that will be calculated from the measured traffic and environmental data: 1- microscopic emission factor $\left(E_{1}\right)$, which is the vehicle emission factor measured in pollutant-mass per vehicle 
(g/truck), 2- macroscopic emission factor $\left(\mathrm{E}_{2}\right)$, which is the pollutant-mass emitted per road-link length $(\mathrm{g} / \mathrm{mile})$. This approach using these two factors will help in generalizing the developed model (i.e. non-site specific model).

Regression analysis will provide an insight on the effect of acceleration/deceleration as well as speed on $\mathrm{E}_{1}$ (chapter four). While TSA will provide a model that will be used for forecasting the traffic parameters (auto-regression analysis, chapter six) and from it, forecast the emissions per road link. The macroscopic factor $\left(\mathrm{E}_{2}\right)$ will be used as an indicator to the improvement or degradation of air quality levels as a function of road traffic condition. Wind-tunnel experiments have been also conducted by the author to determine the actual turbulent mixing volume around a moving truck as a function of its speed. This provided an improvement to the commonly used assumptions in calculating the microscopic emission factor $\mathrm{E}_{1}$ as will be shown in chapter five.

This study is divided into seven relatively independent chapters:

1- Chapter 1: a general introduction.

2- Chapter 2: an overview on the Borman Expressway project as well as findings on the effect of road construction on local $\mathrm{PM}_{2.5}$ levels adjacent to the expressway.

3- Chapter 3: an overview on the Borman Expressway traffic characteristics.

4- Chapter 4: Traffic-air quality regression analysis to determine both the microscopic emission factor $E_{1}$ and the macroscopic emission factor $E_{2}$ as well as comparisons to the currently used EPA-PART5 emission model.

5- Chapter 5: An analysis on a wind tunnel experiment that is used to calculate the mechanical turbulent mixing volume on an expressway caused by moving trucks. 
6- Chapter 6: Traffic-air quality time series analysis to provide a forecasting model for the needed traffic parameters.

7- Chapter 7: A summary of the study findings as well as a discussion on the application and implementation of such findings to the Intelligent Transportation System (ITS) used in Northwestern Indiana.

This study is part of an ongoing project conducted by the School of Civil Engineering, Environmental and Hydraulic Engineering area, Purdue University in collaboration with the Indiana Department Of Transportation (INDOT). The project findings aim at assisting in determining the effect of the implementation of the ITS strategies -installed at the Borman Expressway- on the air quality in the Gary-Hammond area in northwest Indiana. 


\section{CHAPTER TWO}

\section{THE BORMAN EXPRESSWAY PROJECT}

The objective of the Borman Expressway project is to quantify the impact of highway traffic management systems and incident-counter-measure strategies on local air quality. The I-94 Expressway in Northwest Indiana (Lake Co., IN) is considered a testbed for this research due to the high volume of traffic traveling on it, as well as the existing and continuing installation of the Intelligent Transportation System (ITS) to improve the traffic management along this highway stretch. Lake Co., IN is known for its several major stationary industrial sources, such as steel plants, municipal incinerators, and power plants as well as the Borman Expressway (I-80/94). The Borman Expressway is considered a critical east-west Interstate Highway link through the northwestern portion of Indiana that is heavily traveled by trucks and private vehicles. The truck traffic on this link is one of the highest in volume in the country, on average $50 \%$ for the east bound and $30 \%$ for the west bound. Due to the complexity of the pollutant sources in the Gary-Hammond area, IN, this project was divided into three parts. The first part was concerned with measuring the local concentrations of both Carbon Monoxide (CO) and Particulate Matter, $2.5 \mu \mathrm{m}$ in diameter and smaller $\left(\mathrm{PM}_{2.5}\right)$, in Lake County, northwest Indiana. Integrated 10 second samples of wind direction and speed; temperature, rain fall, $\mathrm{CO}$ and $\mathrm{PM}_{2.5}$ concentrations have been recorded since September 1999. One of the monitoring stations (sites) is located 50 meters south of the Borman Expressway and will be referred to as the Purdue University Hessville Site or "PU-Hessville-Site", while the second station is located 50 meters north of the expressway at mile marker 3.3 and will 
be referred to as the "Kennedy-Site". The second part of the project was concerned with identifying the major contributors to the measured concentration values (Soliman, 2002). This was done by modeling the impact on air quality caused by both the stationary industrial sources as well as the mobile sources along the Borman Expressway. Attention was paid to modeling results of the industrial stationary sources to determine their impact on the PU-Hessville Site relative to the impact of mobile sources moving along the Borman Expressway. The EPA-ISCST3 model was used to model the stationary sources, while EPA-CALINE4 was used to model the mobile sources along the Borman Expressway. Modeling results were then verified and compared to measured values obtained at the PU-Hessville monitoring station. The last part of the project started after it was verified that the measured pollutant concentrations are mainly caused by traffic (mobile sources); air pollution patterns are then compared to traffic patterns and incidents on the Borman Expressway to quantify the relation between traffic and air quality in order to produce a traffic-air quality model. Note that the traffic parameters were obtained using inductive loop detectors located along the Borman Expressway for the analysis period of June to September 2001, but obtained using WAVETRONIX ${ }^{\mathrm{TM}}$ microwave sensors for the analysis period of November 2004 to March 2005, as will be discussed later in the chapter.

\subsection{Sites Locations and Instruments Used:}

Figure 2-1 shows a map of the major roads and highways in Lake County, IN with respect to the PU-Hessville and the Kennedy Sites. The PU-Hessville Site is located approximately at the 4.1-mile marker on the Borman Expressway on a moderate S-curve and was installed in September 1999, while the Kennedy Site is located at the 3.3-mile 
marker and was installed on October 2004. The $\mathbf{X}$ marks on the map indicate the portion used for modeling the Borman Expressway (approximately from the IL/IN border from the west to the 10.1-mile marker from the east).

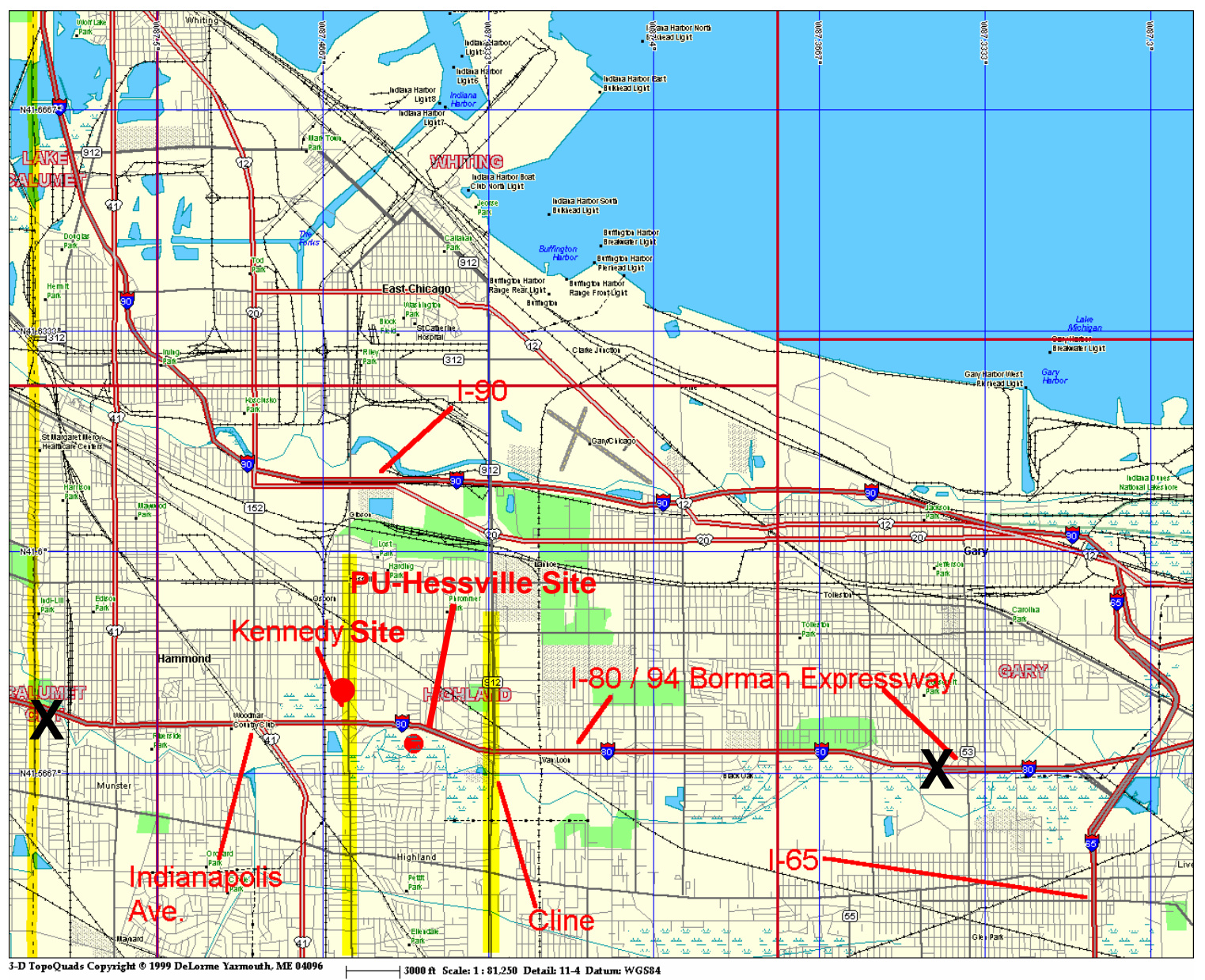

Figure 2-1. Major roads and highways in Lake County, IN with respect to the PUHessville and the Kennedy Sites.

The meteorological data at the PU-Hessville Site were collected by the Purdue University Department of Civil Engineering monitoring station located adjacent to the Borman Expressway. These data included ambient temperature, wind direction, and wind 
speed since 1999. The meteorological instrument used at the PU-Hessville Site is a MetOne-Meteorological instrument set.

Carbon monoxide concentrations at the PU-Hessville Site were measured using a Thermo-Environmental Instruments Model 48C, while $\mathrm{PM}_{2.5}$ concentrations were measured using a Rupperecht \& Patashnick Tapered Element Oscillating Microbalance (TEOM) at both sites. Concentration data were measured every 10 (ten) secondsintegrated to be able to monitor the dynamic behavior of the pollutants caused by mobile sources on the Borman Expressway. Some hourly-averaged-data points represent averages of approximately 43,000 (forty three thousand) measured data points. With such a large number of measured data points in the averaged values, it is expected that the measured average values would represent the true (total) population with minimal error.

Traffic data were collected using inductive loop detectors located along the Borman Expressway for the modeling analysis period of June to September 2001. However, due to the ongoing construction and improvements to the Borman expressway, these loop-detectors were removed for a significant period of time, therefore, a different technology had to be used to obtain the needed traffic data. Similar to the new technology used by the Indiana Department Of Transportation (INDOT) in northwest Indiana; two WAVETRONIX $^{\mathrm{TM}}$ SIDEFIRE $^{\circledR}$ microwave traffic sensors were installed at both the PUHessville and Kennedy sites, to monitor traffic on both bounds of the expressway. As will be shown later in Chapter three, these traffic sensors have been tested and calibrated on a local road near Purdue University, West Lafayette, IN before being installed at the Borman Expressway. They were also calibrated and tested again when installed on the 
expressway. The 10-second-averaged traffic data obtained from the microwave sensors where used for the analysis period of November 2004 to March 2005.

EPA-CALINE4 model was run to determine the effect of the asymmetrical layout of the expressway with respect to the PU-Hessville site on the measured concentrations. The model was run for a hypothetical case where all the meteorological and traffic parameters were kept constant while changing the wind direction to see the effect of the Borman Expressway on the PU-Hessville Site measured concentrations relative to the North $\left(0^{\circ}\right.$ wind direction $)$ as a function of wind direction only. As shown in figure 2-2-a, maximum changes in concentrations were predicted to be for wind sectors $97^{\circ}$ to $103^{\circ}$ and $280^{\circ}$ to $290^{\circ}$. This predicted wind sector was consistent with what has been reported in the literature with regards to worst wind directions for this specific S-shape road-Site configuration (Noll et. al, 1977). Figure 2-2-b shows a schematic diagram of the wind direction with respect to the PU-Hessville Site.

Figure 2-3 is a schematic diagram to graphically explain the peaks in figure 2-2-a. As shown in the figure, the angle of exposure to the Borman changes with the wind vector. For wind vector $\mathbf{B}\left(0^{\circ}\right.$ to $\left.60^{\circ}\right)$, there is a minimum exposure to the Borman since the PU-Hessville Site is affected by transverse winds crossing over a small section on the Borman. While for wind vectors $\mathbf{A}$ and $\mathbf{C}\left(97^{\circ}\right.$ to $103^{\circ}$ and $280^{\circ}$ to $290^{\circ}$, respectively), the PU-Hessville Site is exposed to a larger portion of the Borman, and therefore higher pollutant concentration was expected from these two wind sectors (under constant wind speed, and fixed traffic and meteorological parameters). Pollutant concentrations at the PU-Hessville Site dropped rapidly for wind vectors between $103^{\circ}$ and $280^{\circ}$ since the PUHessville Site is not directly exposed to the Borman Expressway for these wind sectors. 
The analysis in chapters four through six will be performed for wind sectors equal to or smaller than $300^{\circ}$ to $60^{\circ}$ for the PU-Hessville Site and $120^{\circ}$ to $240^{\circ}$ for the Kennedy Site, hence minimizing the effect of the road configuration on analyzed data (Jamriska et. al, 2001).

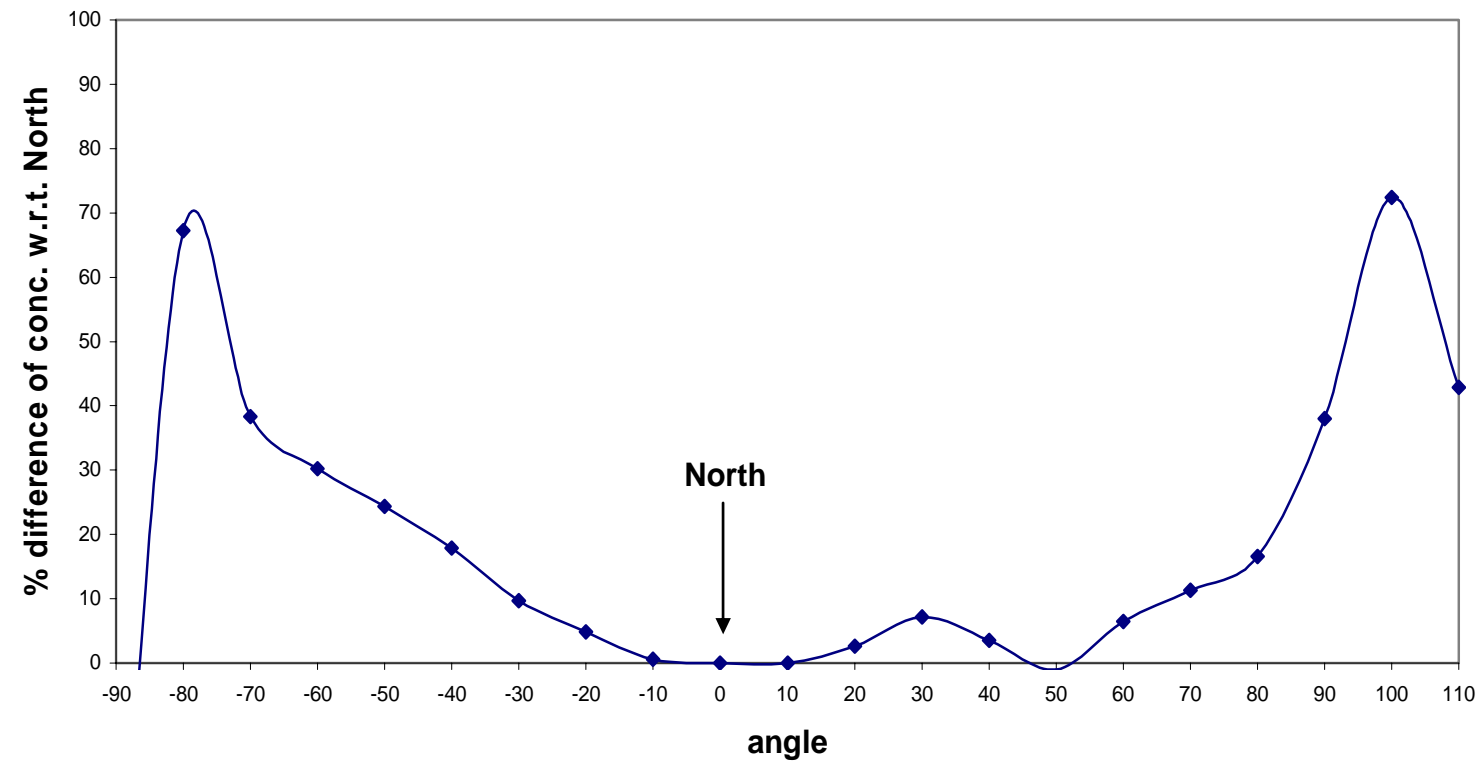

Figure 2-2-a. Effect of the Borman Expressway configuration with respect to the PUHessville Site on the measured concentration at the PU-Hessville Site with respect to North. North is at $0^{\circ}$.

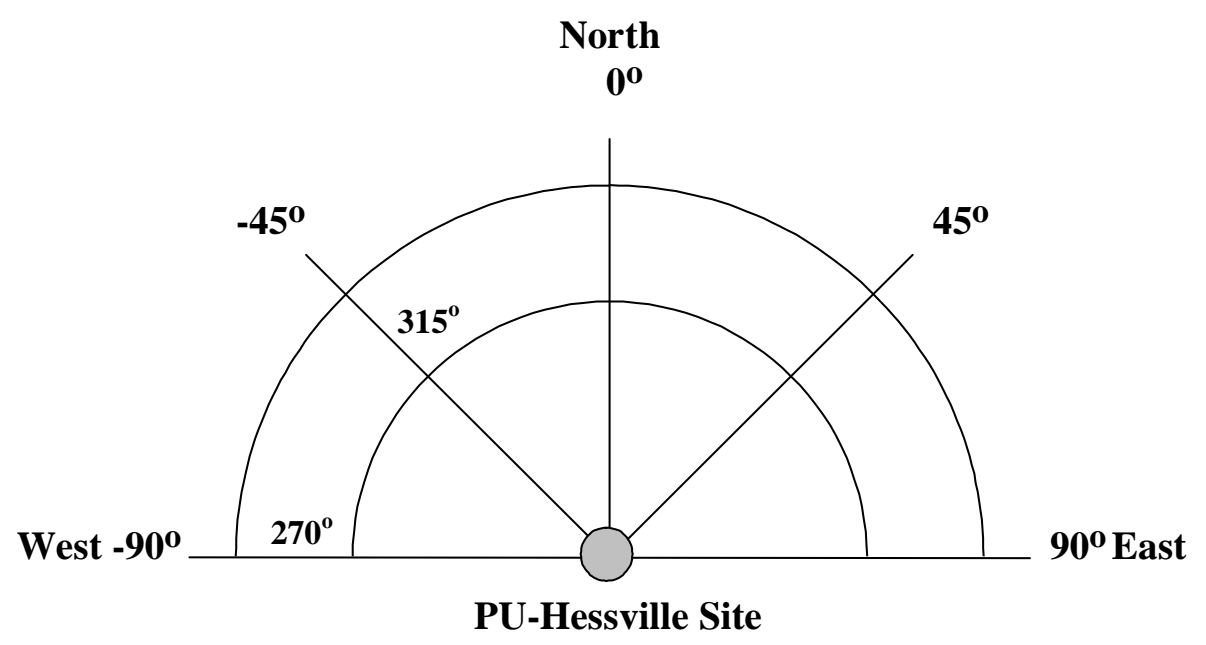

Figure 2-2-b. Wind directions with respect to the PU-Hessville Site. 


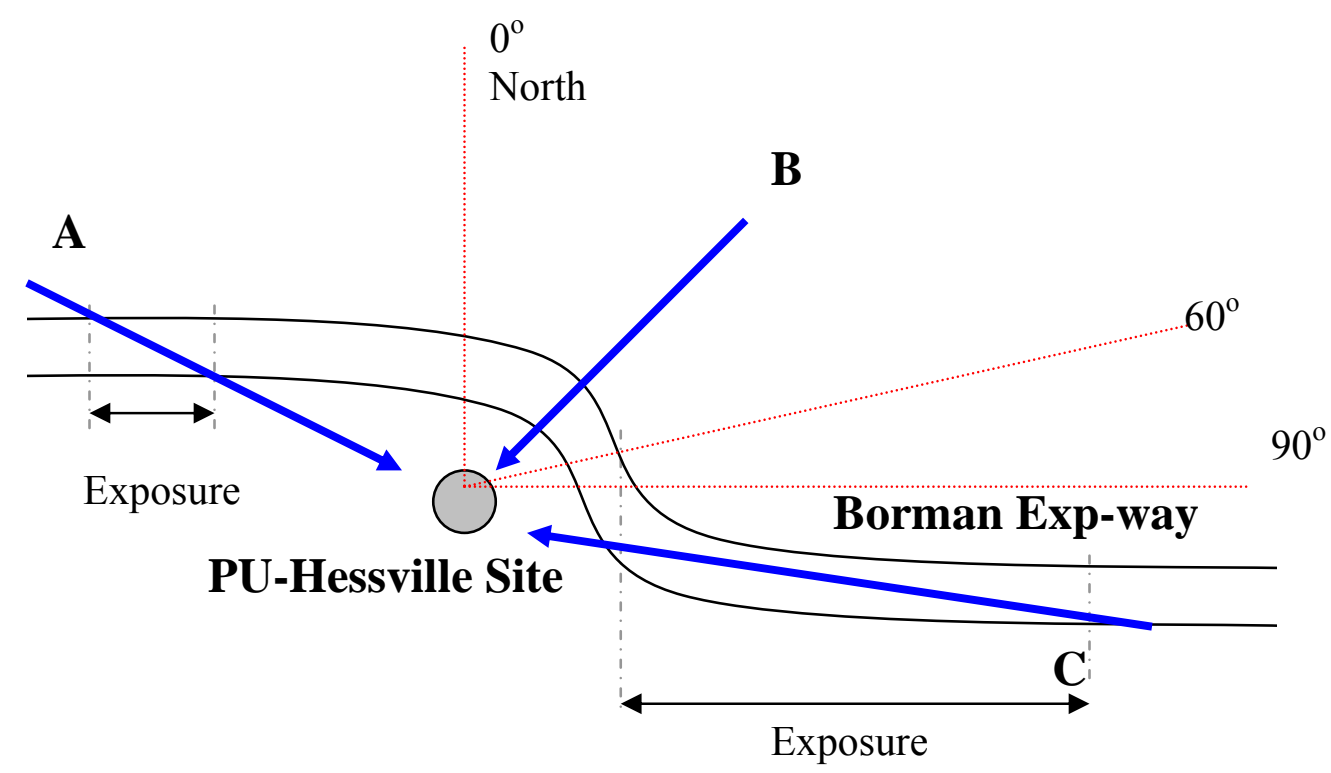

Figure 2-3. A schematic diagram to explain the effect of wind vectors on the concentration of $\mathrm{CO}$ and $\mathrm{PM}_{2.5}$ at the PU-Hessville Site.

The following sections will focus solely on the $\mathrm{PM}_{2.5}$ findings, since $\mathrm{PM}_{2.5}$ concentration levels are the primary focus of this report. Further details on the $\mathrm{CO}$ modeling and findings can be found in Soliman, 2002.

\section{2. $\mathrm{PM}_{2.5}$ Background Modeling Analysis:}

Northwest Indiana is noted for its heavy industry density. Therefore, to assess the contribution of traffic sources to local air quality in comparison with the industrial stationary sources, forty two industrial stationary $\mathrm{PM}_{2.5}$ sources were modeled in Lake Co., IN, in addition to 10.1 miles of the Borman Expressway. The major $\mathrm{PM}_{2.5}$ source in Lake County, IN is US Steel Co. which emits 101.4 grams per second $\mathrm{PM}_{2.5}$ in the ambient air, which is $62.9 \%$ of the total $\mathrm{PM}_{2.5}$ emissions. The largest six $\mathrm{PM}_{2.5}$ industrial stationary sources in Lake Co., IN emit a total of 158.5 grams per second of $\mathrm{PM}_{2.5}$, which is $98.48 \%$ of the total $\mathrm{CO}$ emission in Lake Co., IN. Figure 2-4 shows the location of 
each of the $\mathrm{PM}_{2.5}$ sources with respect to the PU-Hessville Site in the UTM coordinate system.

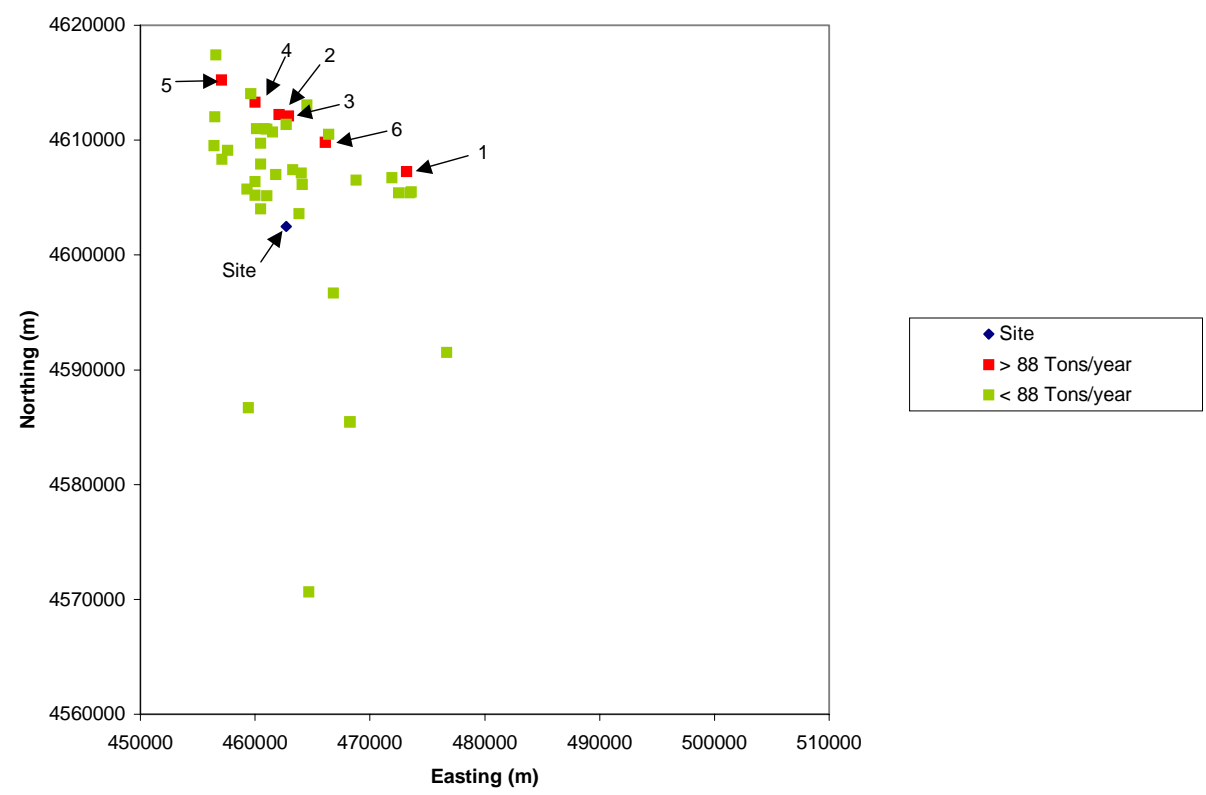

Figure 2-4. $\mathrm{PM}_{2.5}$ Sources, and the PU-Hessville Site, Lake County, IN, 1999.

Since particles with diameters ranging from 1 to $20 \mu \mathrm{m}$ have settling velocity, that are considerably small (between $4 \times 10^{-5}$ and $300 \times 10^{-5} \mathrm{~m} / \mathrm{s}$ ) compared to the measured wind velocities (ranging from 0.5 to $4.5 \mathrm{~m} / \mathrm{s}$ ), these particles tend to follow the motion of the gas (air) in which they are born (Wark et. al, 1998). Therefore, for practical purposes, $\mathrm{PM}_{2.5}$ is treated like a gas (as $\mathrm{CO}$ ) on the ISCST3 runs and so any formation of new $\mathrm{PM}_{2.5}$ particles via nucleation has been neglected (Seigneur, 2001).

Analyses were done for only the northern wind sector with respect to the PUHessville Site for winds exposing the Borman Expressway from $270^{\circ}\left(-90^{\circ}\right.$ west) to $110^{\circ}$ 
east of the Site for the period of June to September 2001. North is at $0^{\circ}$ with respect to the PU-Hessville Site. The EPA-ISCST3 model was used to evaluate the stationary sources, while EPA-CALINE4 was used to evaluate the mobile sources along the Borman Expressway. Figure 2-5 shows the portion of the expressway used in the $\mathrm{PM}_{2.5}$ CALINE4 modeling in UTM coordinates.

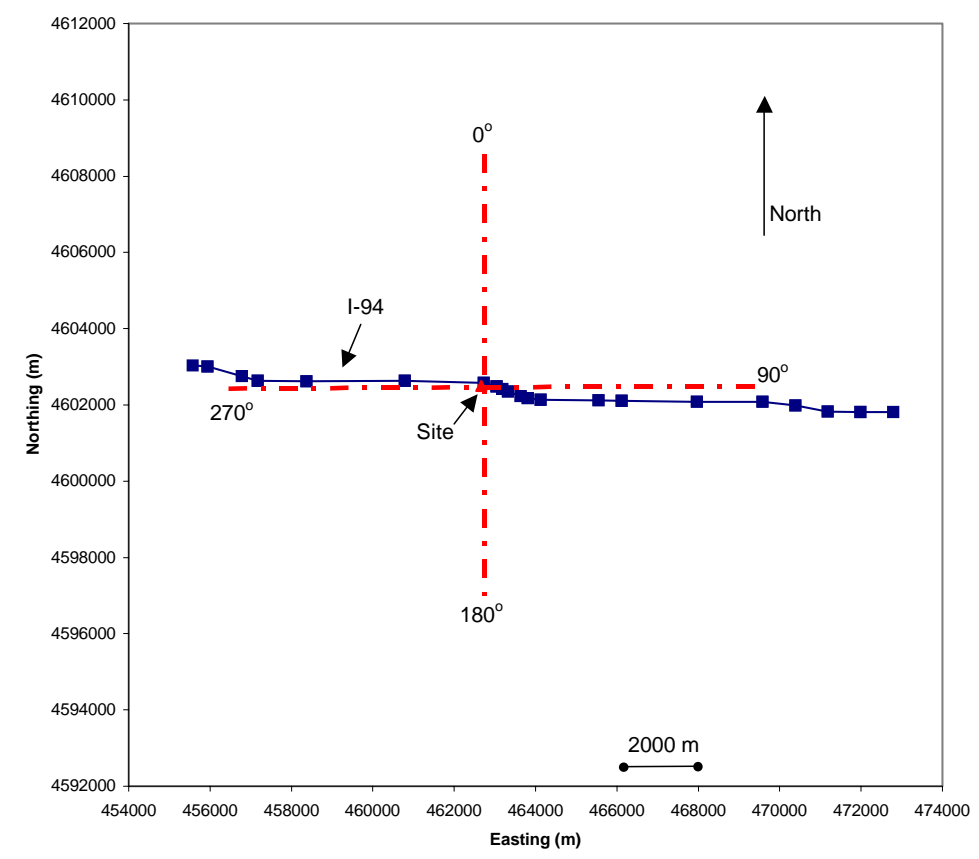

Figure 2-5. The modeled portion of the Borman Expressway with respect to the PUHessville Site.

Traffic emission factors for $\mathrm{PM}_{2.5}$ were calculated using the EPA-PART5 model and were found to be constant with respect to speed for the fleet mix on the Borman Expressway at 0.268 grams $/ \mathrm{mile}(\mathrm{g} / \mathrm{mi})$ (Soliman, 2002). Figure 2-6 shows a comparison between the predictions of the two models for $\mathrm{PM}_{2.5}$ and the measured values as a function of wind direction. The measured $\mathrm{PM}_{2.5}$ values relatively mirror the CALINE4 predictions more than the ISCST3 predictions. This was also seen from the slope of the 
lines on figure 2-7, where the slope of the line produced by CALINE4 is similar to the one produced by the measured data. Therefore, the $\mathrm{PM}_{2.5}$ measured data at the PUHessville Site are mainly from the contribution of the mobile sources on the Borman Expressway, not from the industrial stationary sources.

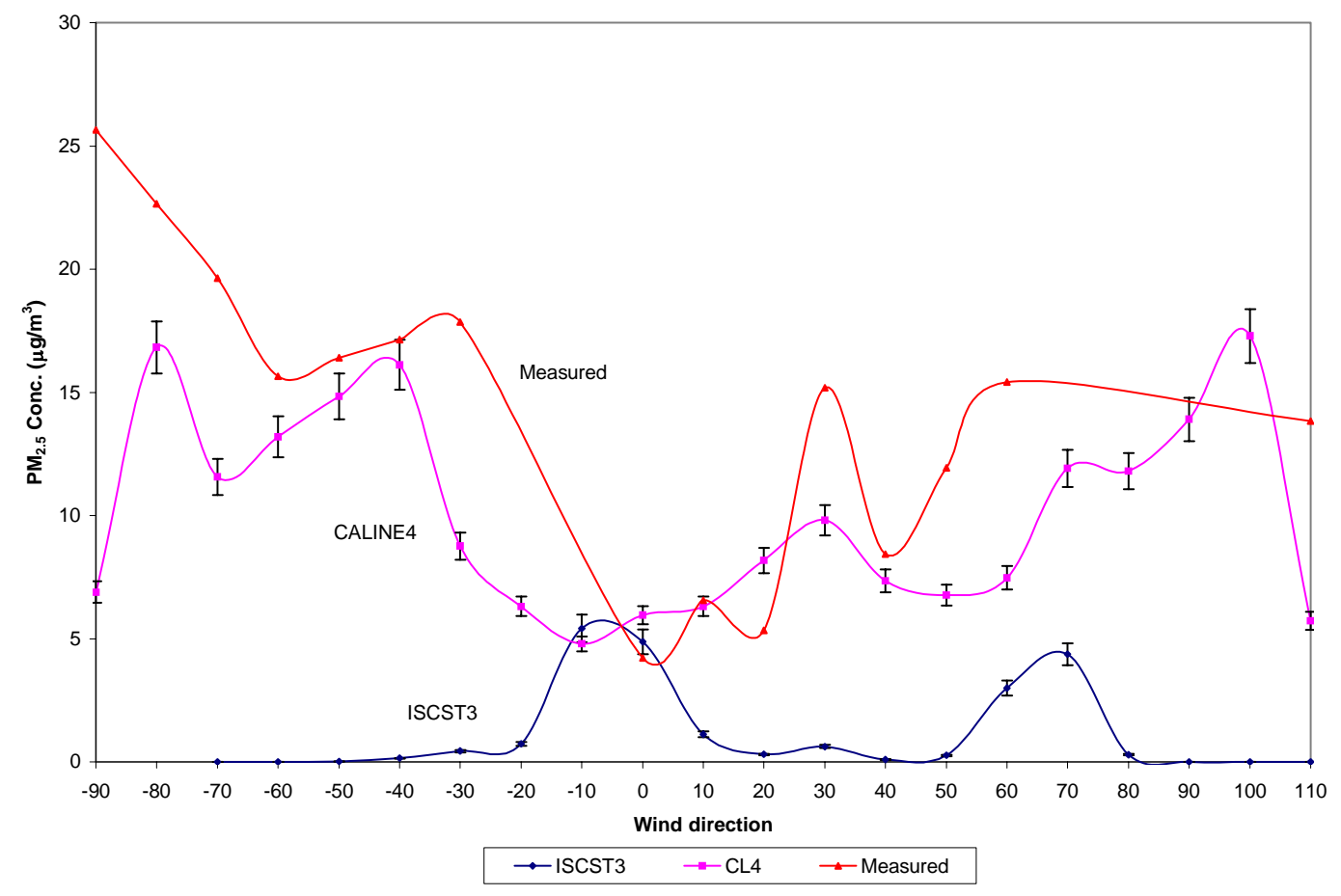

Figure 2-6. Measured, CALINE4, and ISCST3 $\mathrm{PM}_{2.5}$ data at the PU-Hessville Site as a function of wind direction with respect to the PU-Hessville Site, 7:00 AM June-Sept 2001. $0^{\circ}$ is North. 


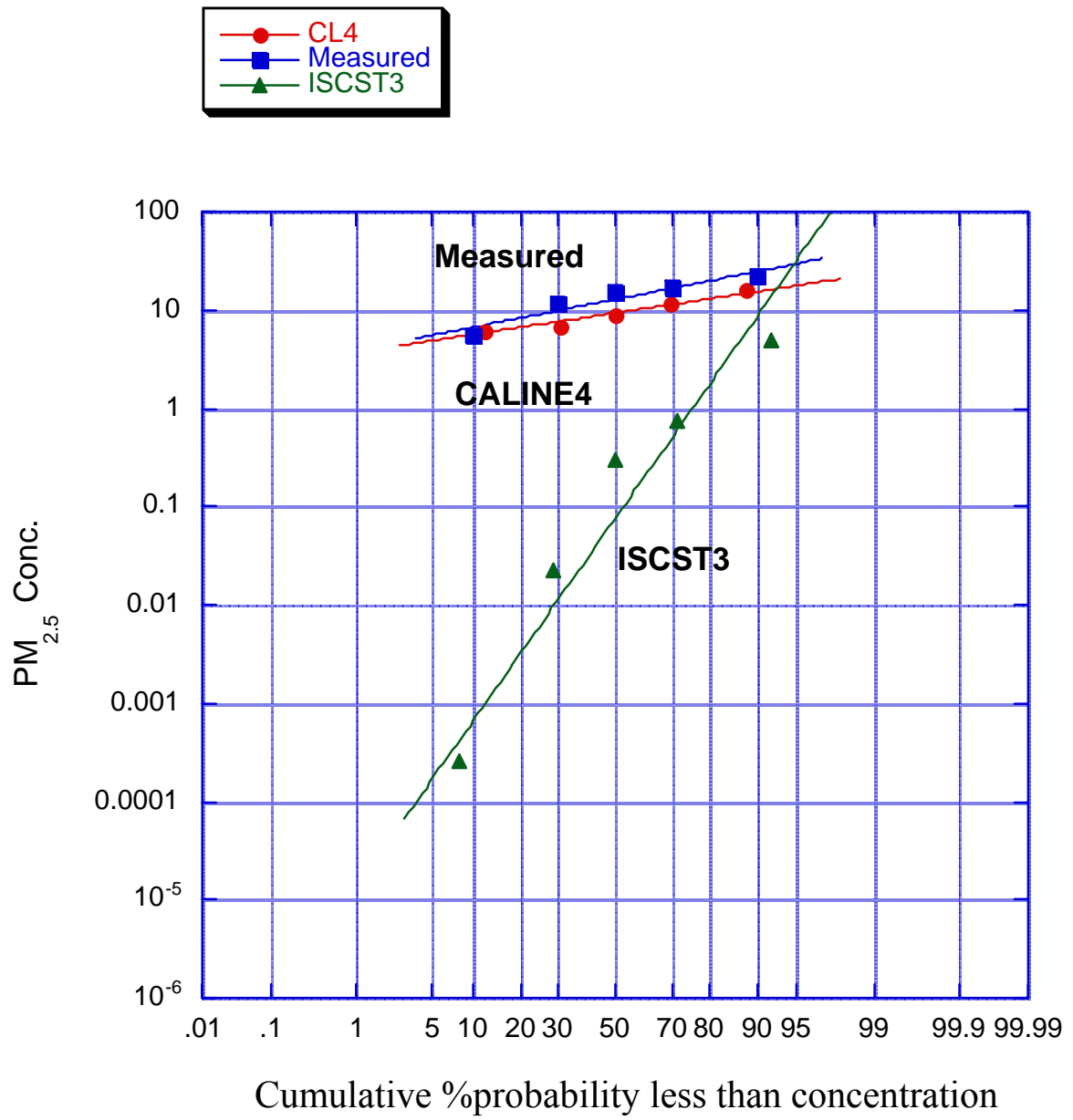

Figure 2-7. Measured, CALINE4 and ISCST3 $\mathrm{PM}_{2.5}$ concentration probability graph, June to September 2001.

The installation of the second $\mathrm{PM}_{2.5} /$ traffic monitoring station north of the Borman Expressway (the Kennedy Site) in October of 2004 assisted in estimating the background levels of $\mathrm{PM}_{2.5}$ concentration measured locally adjacent to the Borman. When the winds are form the north $\left(300^{\circ}\right.$ to $60^{\circ}$ wind-arc), the Kennedy site measures the background $\mathrm{PM}_{2.5}$ from the City of Gary, while the PU-Hessville site measures the combined Borman and background emissions, and vice versa when the wind blow from the south $\left(120^{\circ}\right.$ to $240^{\circ}$ wind arc). The analysis has shown that on average the background 
$\mathrm{PM}_{2.5}$ emission constitutes $30 \%$ of the measured $\mathrm{PM}_{2.5}$ concentration adjacent to the Borman Expressway, which is in agreement with previously estimated findings by Schneider (2001) and Soliman (2002).

\subsection{Borman Construction Effect on Local Air Quality:}

The data collection technique used for the Borman Expressway project has shown the ability to capture the dynamic nature of traffic-air quality on the road (Soliman et. al, 2004). Hence, the technique can be used to quantify the effect of different traffic scenarios as well as the effect of road construction on local air quality.

The following is an analysis of the air-quality data obtained before, during and after road construction to reconfigure exit-ramps on the Borman Expressway. It is important to note that the active number of lanes on the Borman remained the same for both the before and after construction operations ( 3 active lanes for each bound). The analysis is based on comparing the mass-accumulation rate (\% mass/day) as well as the concentration distribution for the periods mentioned above.

Figure 2-8 shows the mass accumulation rate (\% mass/day) represented by the slopes of the lines shown in the figure for the period of October 2003 to May 2005, which covers the construction period in summer 2004. As shown in figures 2-8, the slope of the line during the construction period is steeper than the before and after slopes. This is shown in both figures 2-9 and 2-10. The mass accumulation rate before and after construction on the Borman were of an average of $1.189 \pm 0.187$ and $1.4 \pm 0.285$ $\%$ mass/day, respectively (based on $95 \%$ confidence level). However, the mass accumulation rate during construction has shown a high value of $3.590 \%$ mass/day, 
which corresponds to approximately a three times increase in the mass accumulation rate during the construction period.

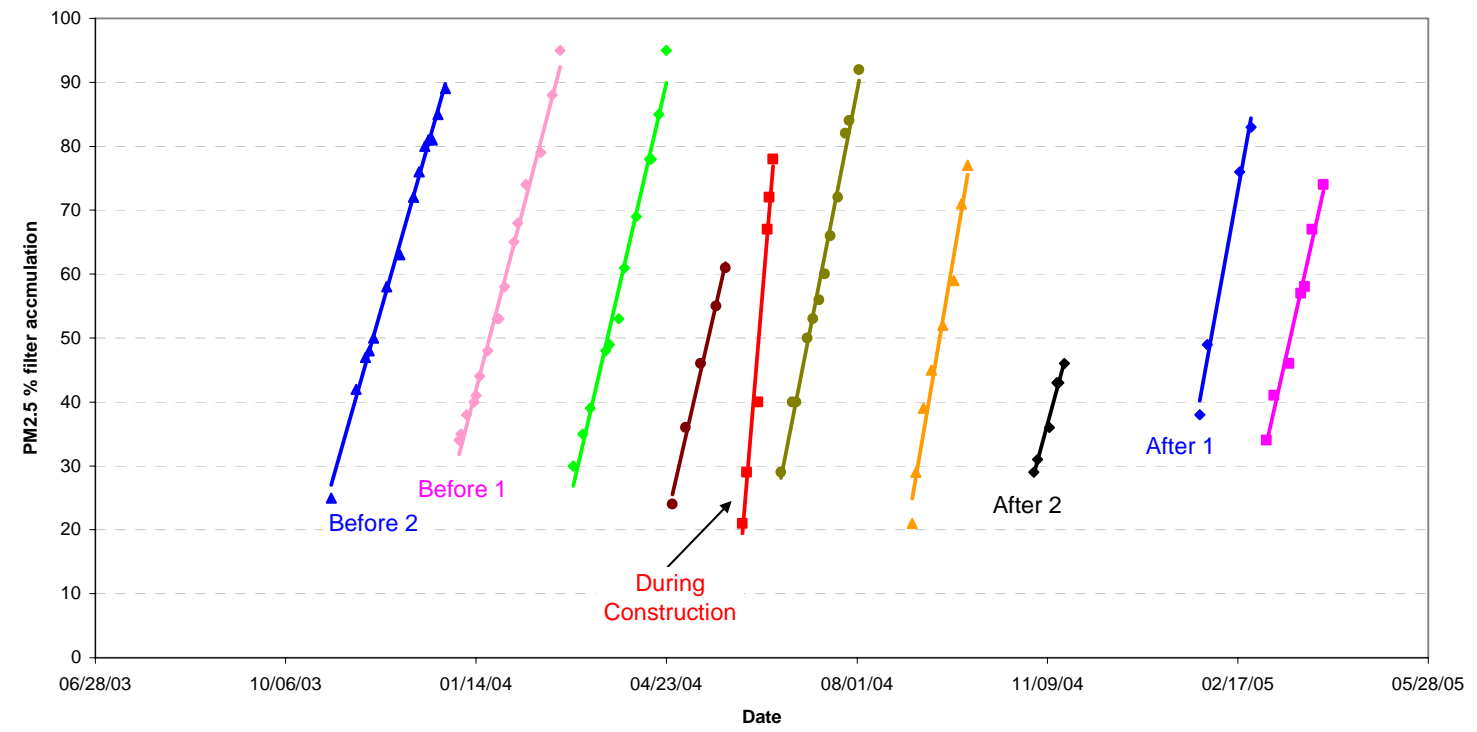

Figure 2-8. \% Mass accumulation of $\mathrm{PM}_{2.5}$ as a function of time for the period of 10/2003 to $5 / 2005$. 


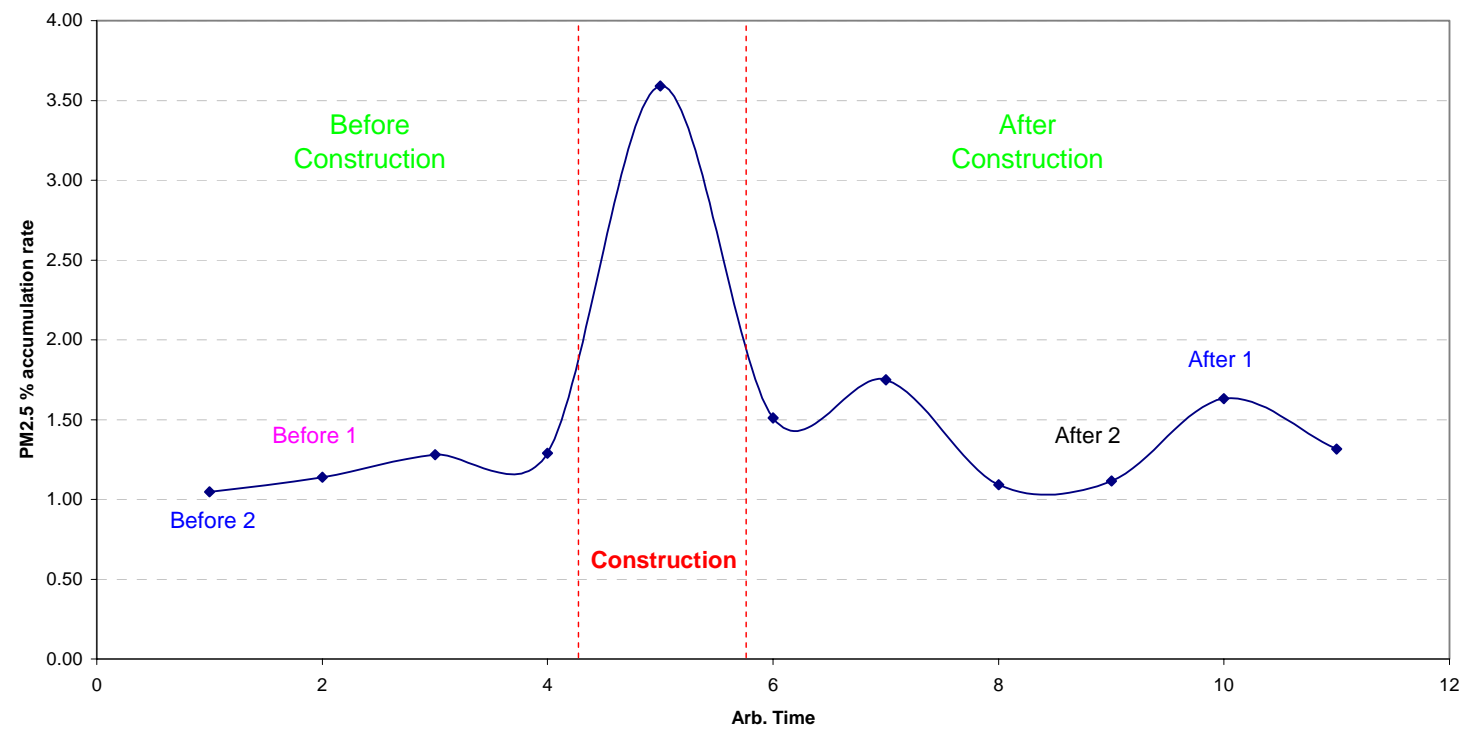

Figure 2-9. Mass accumulation rate of $\mathrm{PM}_{2.5}$ (slopes of Figure 2-4 lines) for the periods of before, during and after the Borman construction for the period of 10/2003 to 5/2005.

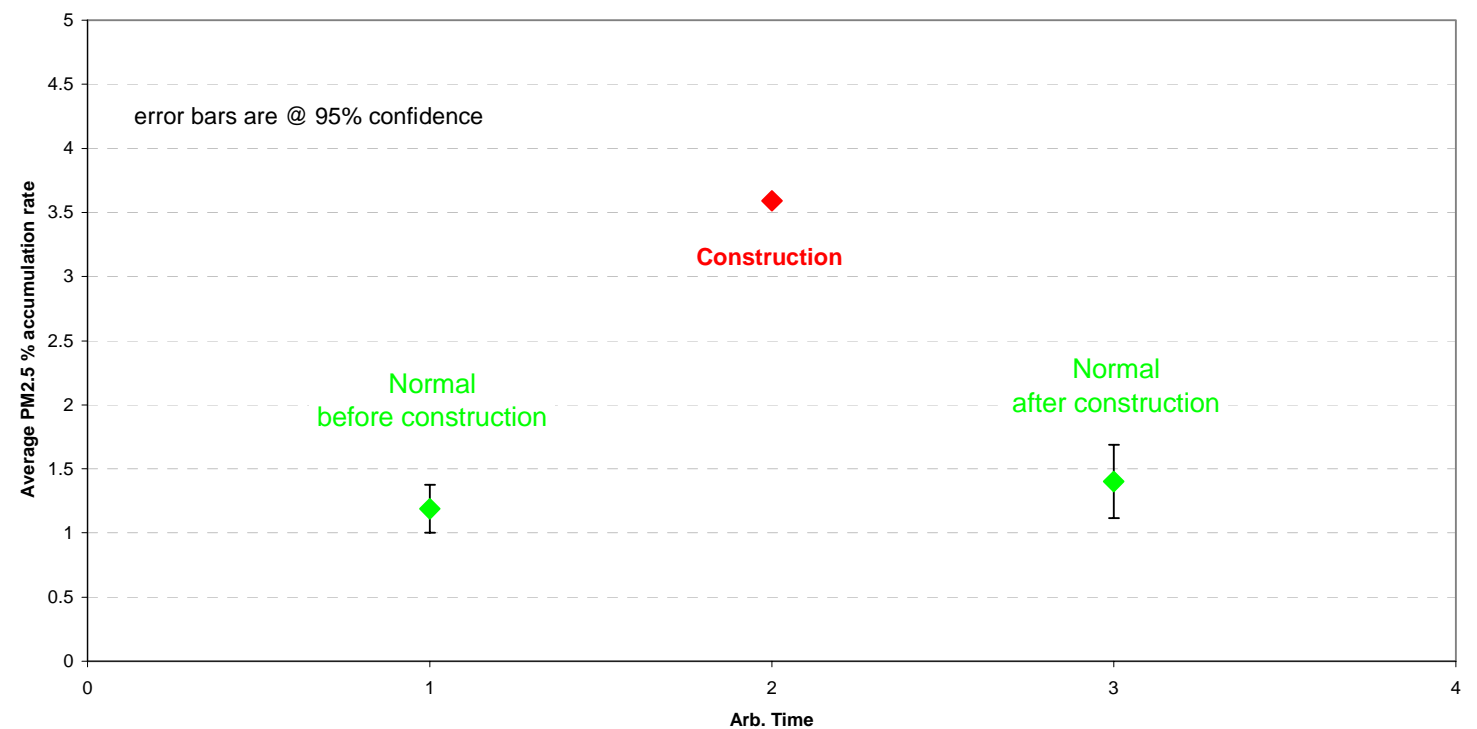

Figure 2-10. Average mass accumulation rate on the Borman expressway for the periods of before, during and after the Borman construction for the period of 10/2003 to 5/2005. 
With respect to the $\mathrm{PM}_{2.5}$ average concentration $\left(\mu \mathrm{g} / \mathrm{m}^{3}\right)$, the data have shown a significant increase (at 95\% confidence level) of the concentration levels during the construction period relative to the before and after data. Figure 2-11 shows the change of the average $\mathrm{PM}_{2.5}$ concentration before, during and after construction for the periods of $1 / 11 / 03$ to $11 / 20 / 03,6 / 2 / 04$ to $6 / 18 / 04$ and $11 / 4 / 04$ to $11 / 18 / 04$, respectively. The figure shows there is no major difference between the before and after construction concentration levels and reflects the significantly higher $\mathrm{PM}_{2.5}$ during construction. This is expected since the number of active lanes on the Borman have not changed before and after the construction, as previously mentioned.

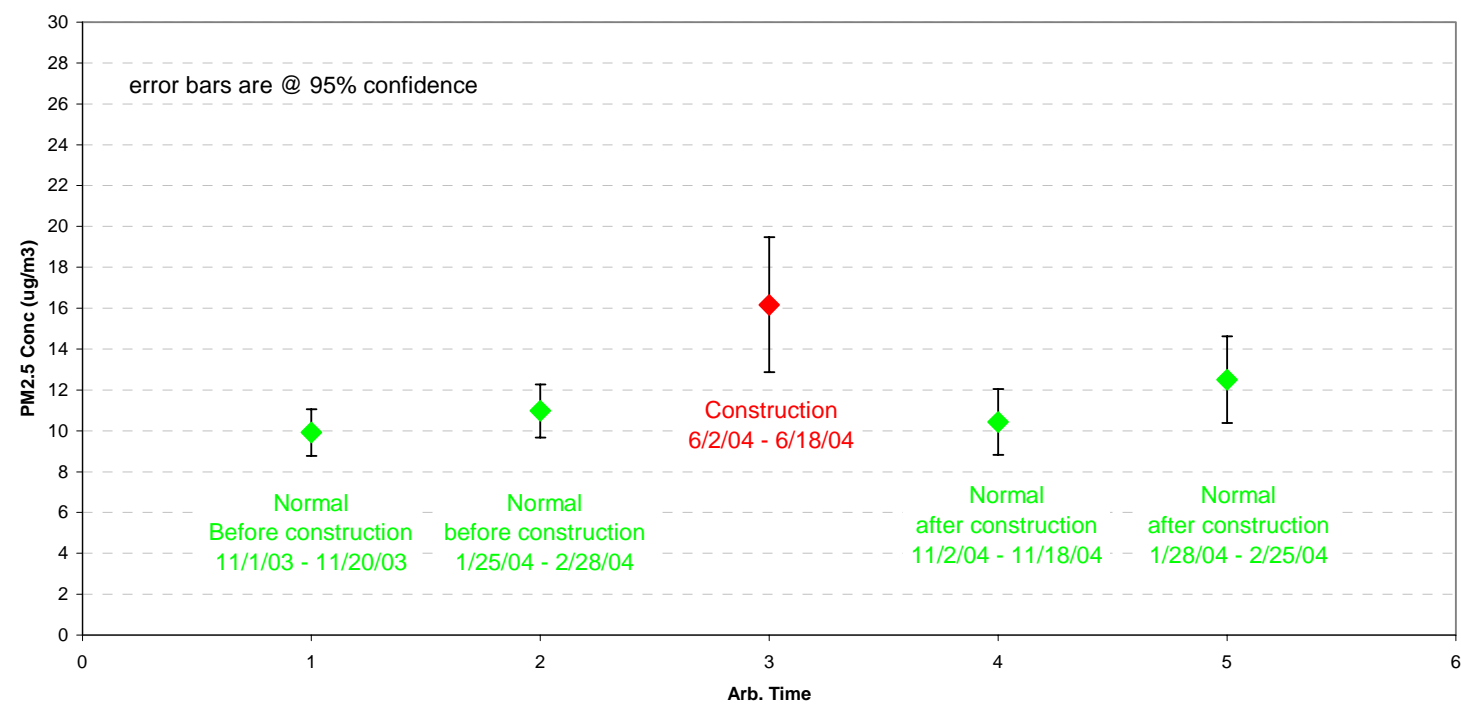

Figure 2-11. $\mathrm{PM}_{2.5}$ concentration before, during and after construction for the periods of $1 / 11 / 03$ to $11 / 20 / 03,6 / 2 / 04$ to $6 / 18 / 04$ and $11 / 4 / 04$ to $11 / 18 / 04$, respectively.

Figures 2-12 through 2-14 show the $\mathrm{PM}_{2.5}$ average concentration frequency distribution for the periods of concentration before, during and after construction $(1 / 11 / 03$ to $11 / 20 / 03,6 / 2 / 04$ to $6 / 18 / 04$ and $11 / 4 / 04$ to $11 / 18 / 04$ ), respectively. 
As shown in figure 2-12; the most frequent distribution occurred at low concentration values, between 6.2 and $11.12 \mu \mathrm{g} / \mathrm{m}^{3}$, with a maximum distribution at 9.9 $\mu \mathrm{g} / \mathrm{m}^{3}$. The $80^{\text {th }}$ percentile concentration value was about $13 \mu \mathrm{g} / \mathrm{m}^{3}$. Figure $2-13$ shows the shift of the concentration distribution during construction to higher concentration values, between 9.8 and $23.24 \mu \mathrm{g} / \mathrm{m}^{3}$, with a maximum distribution at $17.86 \mu \mathrm{g} / \mathrm{m}^{3}$. The $80^{\text {th }}$ percentile concentration value for this distribution was at about $23 \mu \mathrm{g} / \mathrm{m}^{3}$. Figure 214 shows the distribution of the $\mathrm{PM}_{2.5}$ concentration values for the period after the road construction on the Borman. The figure shows that the most frequent distribution has dropped to the range of 6.2 to $14.4 \mu \mathrm{g} / \mathrm{m}^{3}$, with a maximum distribution at $10.3 \mu \mathrm{g} / \mathrm{m}^{3}$. The $80^{\text {th }}$ percentile concentration value has also dropped to about $14 \mu \mathrm{g} / \mathrm{m}^{3}$, which is close to the values observed before the construction took place.

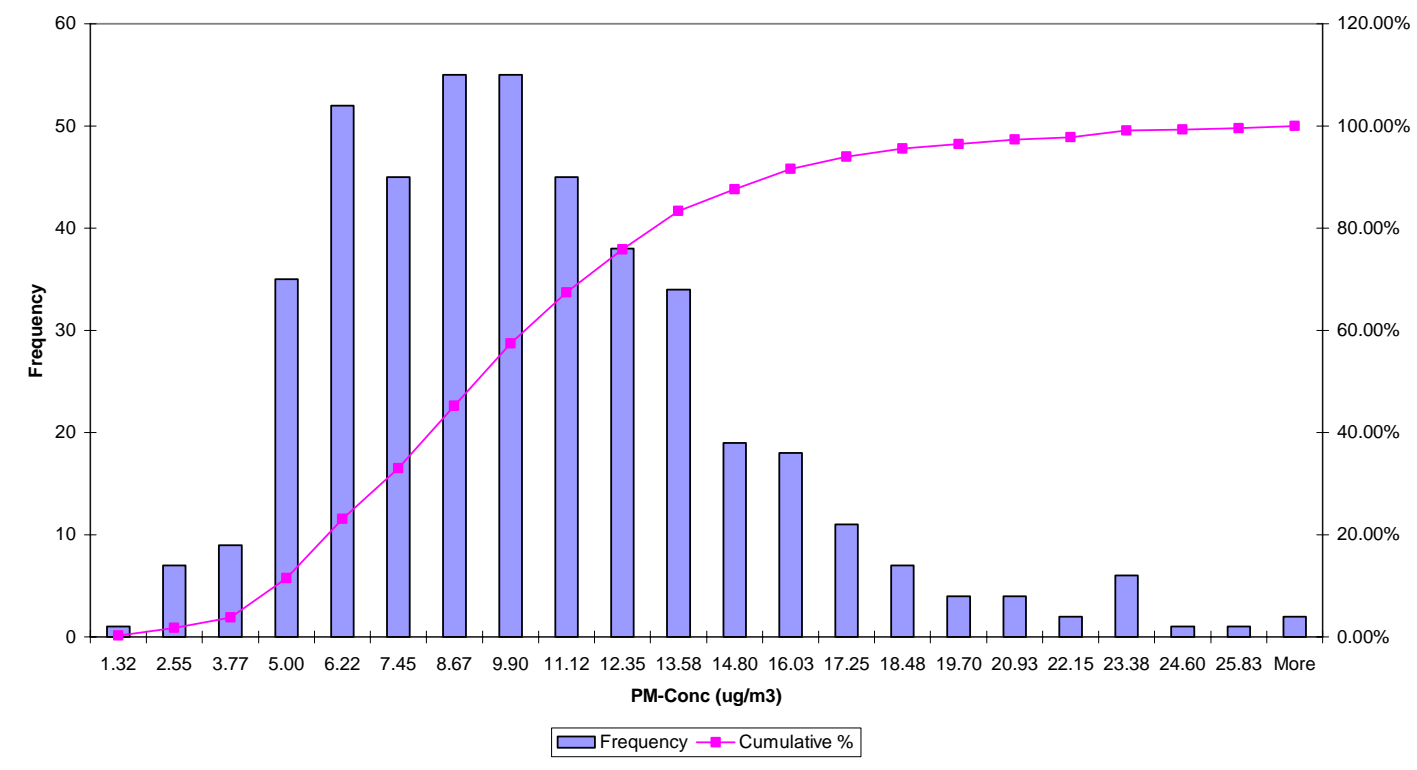

Figure 2-12. $\mathrm{PM}_{2.5}$ concentration distribution for the period of $1 / 11 / 03$ to $11 / 20 / 03$ (before construction). 


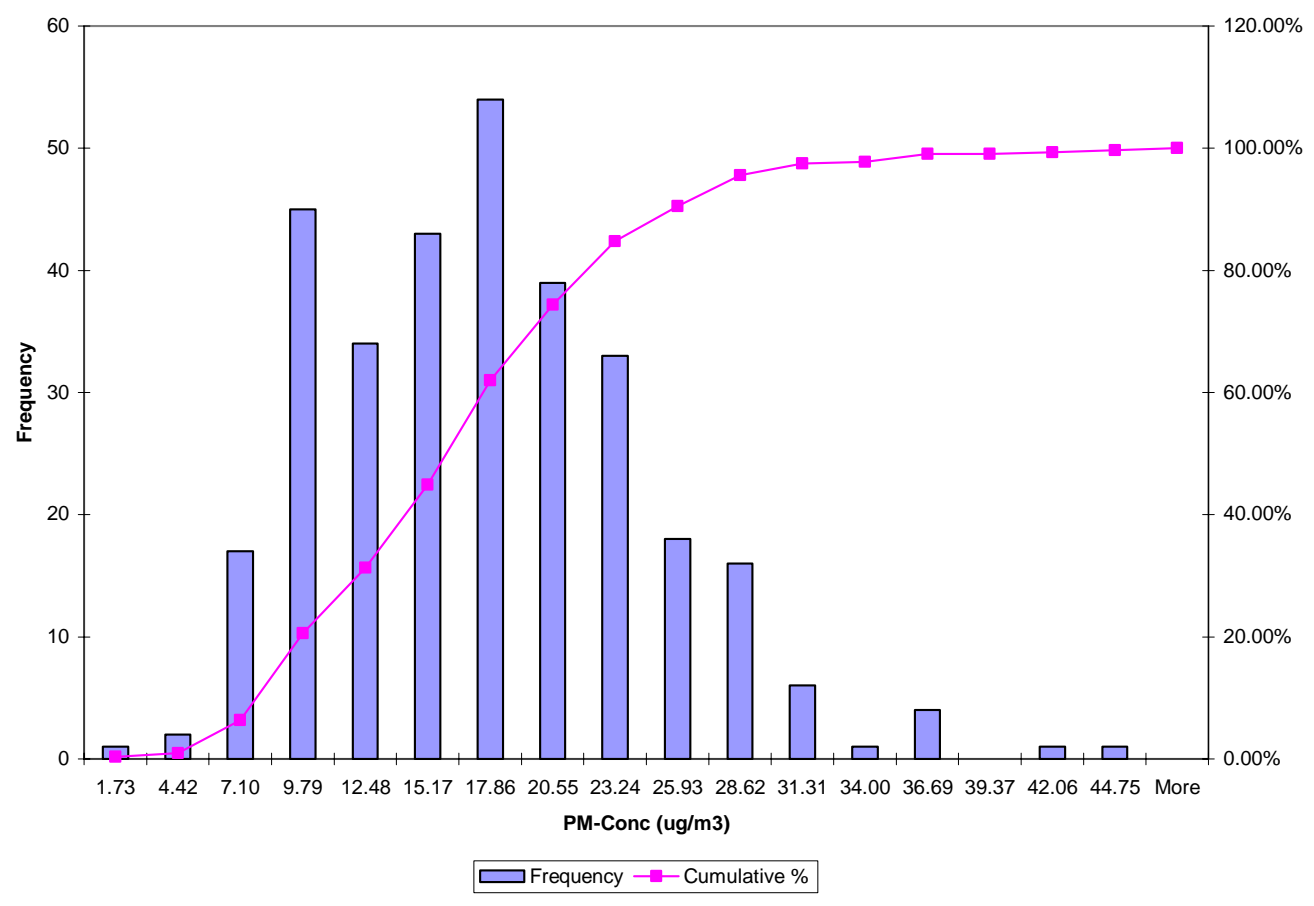

Figure 2-13. $\mathrm{PM}_{2.5}$ concentration distribution for the period of $6 / 2 / 04$ to $6 / 18 / 04$ (during construction).

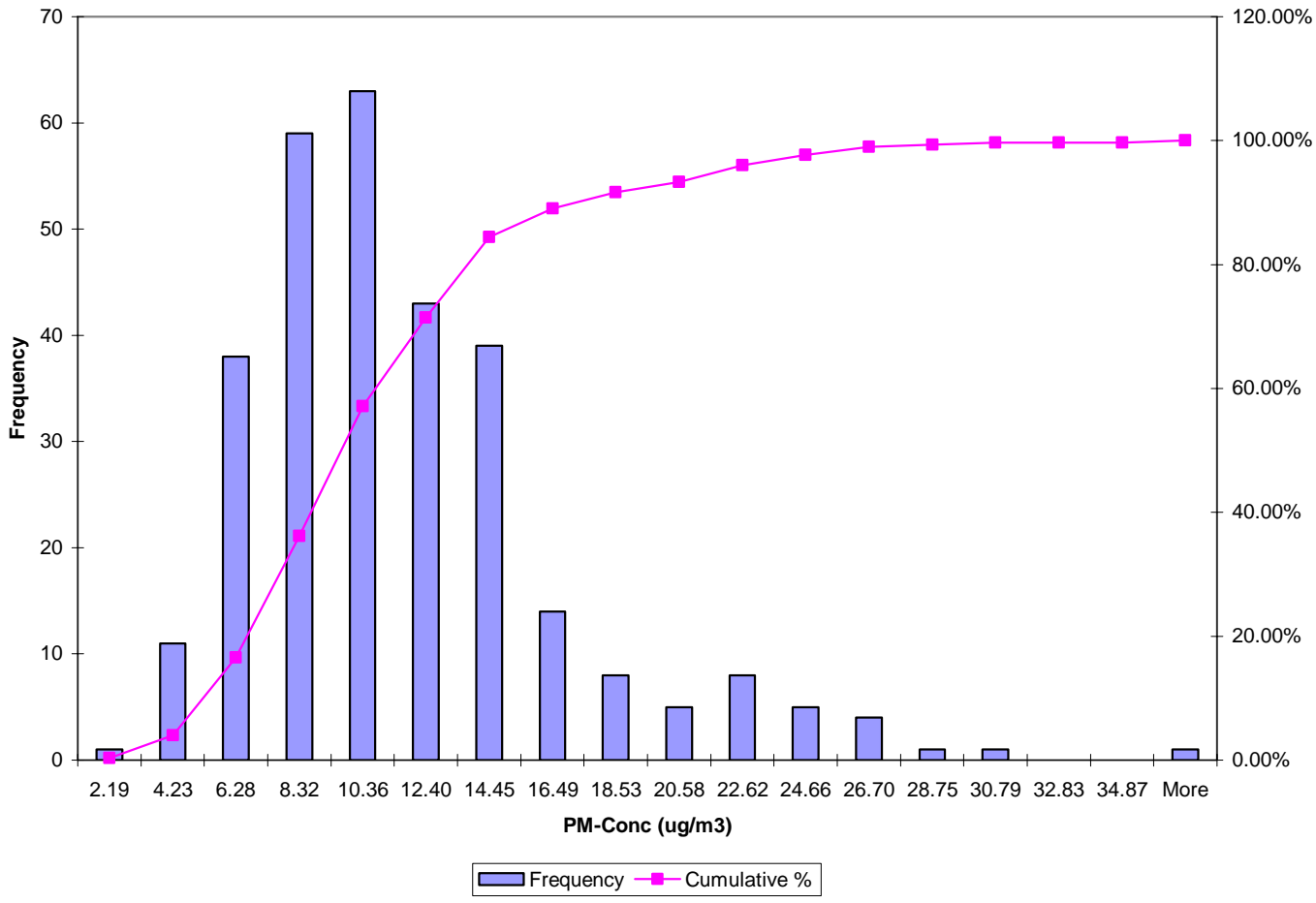

Figure 2-14. $\mathrm{PM}_{2.5}$ concentration distribution for the period of 11/4/04 to $11 / 18 / 04$ (after construction). 
The lack of reliable traffic data for the before and during construction periods (1/11/03 to $11 / 20 / 03$, and $6 / 2 / 04$ to $6 / 18 / 04$, respectively) has caused limitation on the data analysis in terms of quantifying the relative impact of the different sources on the $\mathrm{PM}_{2.5}$ levels adjacent to the expressway. In other words, it is hard to identify whether the increase of the $\mathrm{PM}_{2.5}$ levels was caused by the traffic queues formed at the construction site or caused by the heavy diesel machinery used during construction.

In spite of such limitations, however, the data collection technique has shown the ability to capture the dynamic nature of the traffic-air quality. Together with traffic data, this air-quality methodology and analysis can be normalized with respect to the traffic volumes, giving a better indication of the air-quality impact due to the reconfiguration of the expressways, whether by adding lanes, removing lanes or changing the traffic flow by implementing the different ITS strategies. 


\section{CHAPTER THREE \\ BORMAN TRAFFIC ANALYSIS}

Traffic data were collected using inductive loop detectors located along the Borman Expressway for the modeling analysis period of June to September 2001. However, due to the ongoing construction and improvements to the Borman expressway, these loop-detectors were removed for a significant period of time; therefore, a different technology had to be used to obtain the needed traffic data. Two WAVETRONIX ${ }^{\mathrm{TM}}$ SIDEFIRE $^{\circledR}$ microwave traffic sensors were installed at both the PU-Hessville and Kennedy sites, to monitor traffic on both bounds of the expressway. These traffic sensors have been tested on a local road near Purdue University, West Lafayette, IN before installing them at the Borman Expressway as well as calibrated after installation on the expressway. The 10-second-averaged traffic data obtained from the microwave sensors were traffic volume (Flow, vehicle/time), traffic speed (mi/hour), occupancy, and vehicle classification. These data were used for the analysis period of November 2004 to March 2005.

\subsection{Traffic Sensor Calibration Analysis:}

The capabilities of the SIDEFIRE-SMART-SENSOR ${ }^{\circledR}$ have been tested on Northwestern Ave, which is a local road in West Lafayette, IN for a period of 3 weeks in May 2004. The sensors have shown the ability to provide both event and interval traffic 
data continuously. This testing period allowed for the unit speed calibration (for a 35 mi/hour speed limit zone) and the debugging of the operating software, figure 3-1.

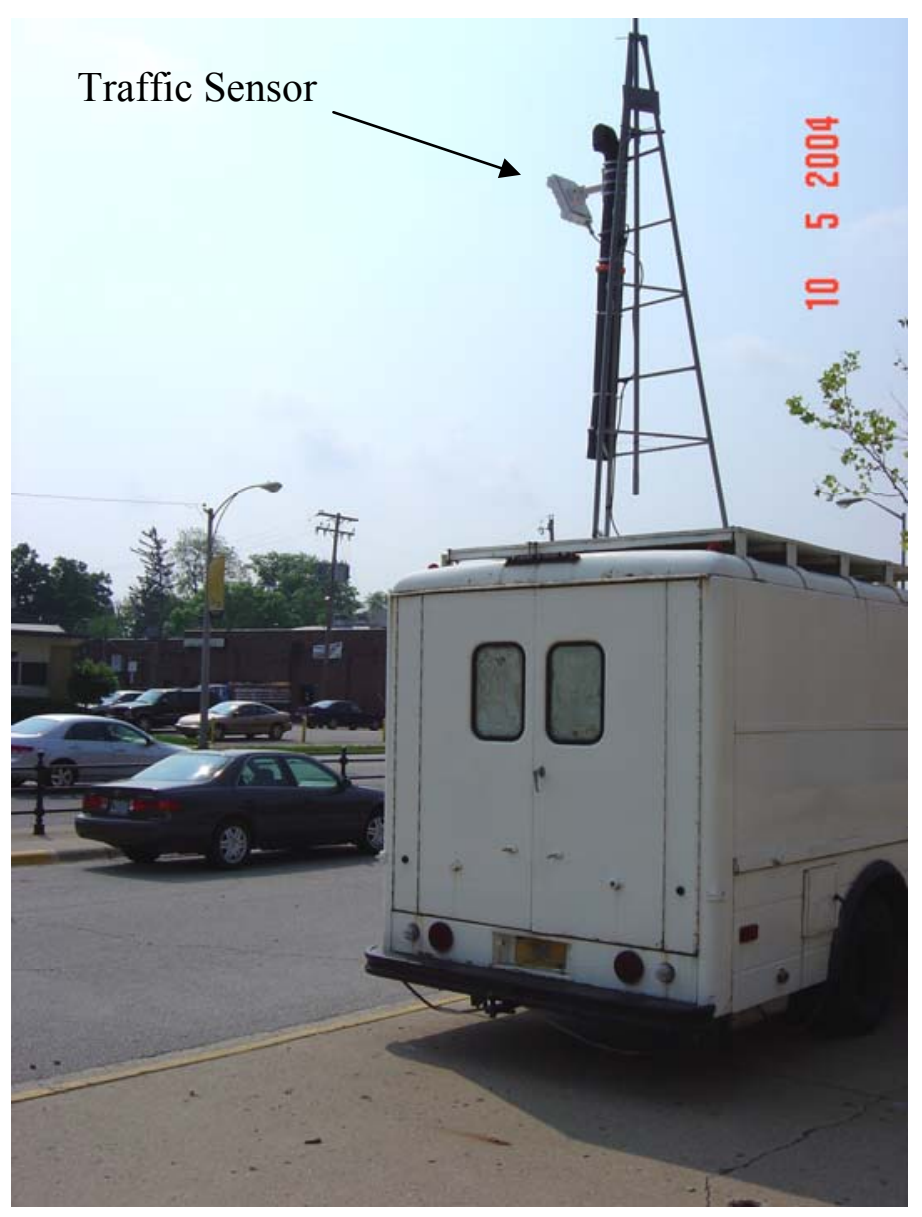

Figure 3-1. A photograph of the traffic monitoring station while being tested on the Northwestern Ave, West Lafayette, IN, May 2004.

Interval data log files provide time/date stamped traffic volume, occupancy, and time-mean-speeds as shown on figures 3-2 through 3-4. Vehicle classifications were also obtained by the sensors. The vehicles are classified into three categories, Small, Medium, and Large. This classification is setup by the user; and is set to: Small for vehicles 0 to 17 
$\mathrm{ft}$ long, Medium for vehicles 18 to $30 \mathrm{ft}$ long, and Large for vehicles 31 to $328 \mathrm{ft}$ long. The small and medium ranges mainly covers the Gas-Light-Duty-Vehicles (GLDV), while the large range covers the Heavy-Duty-Diesel-Vehicles (HDDV, Class 9) which are the primary $\mathrm{PM}_{2.5}$ polluters on the Borman Expressway.

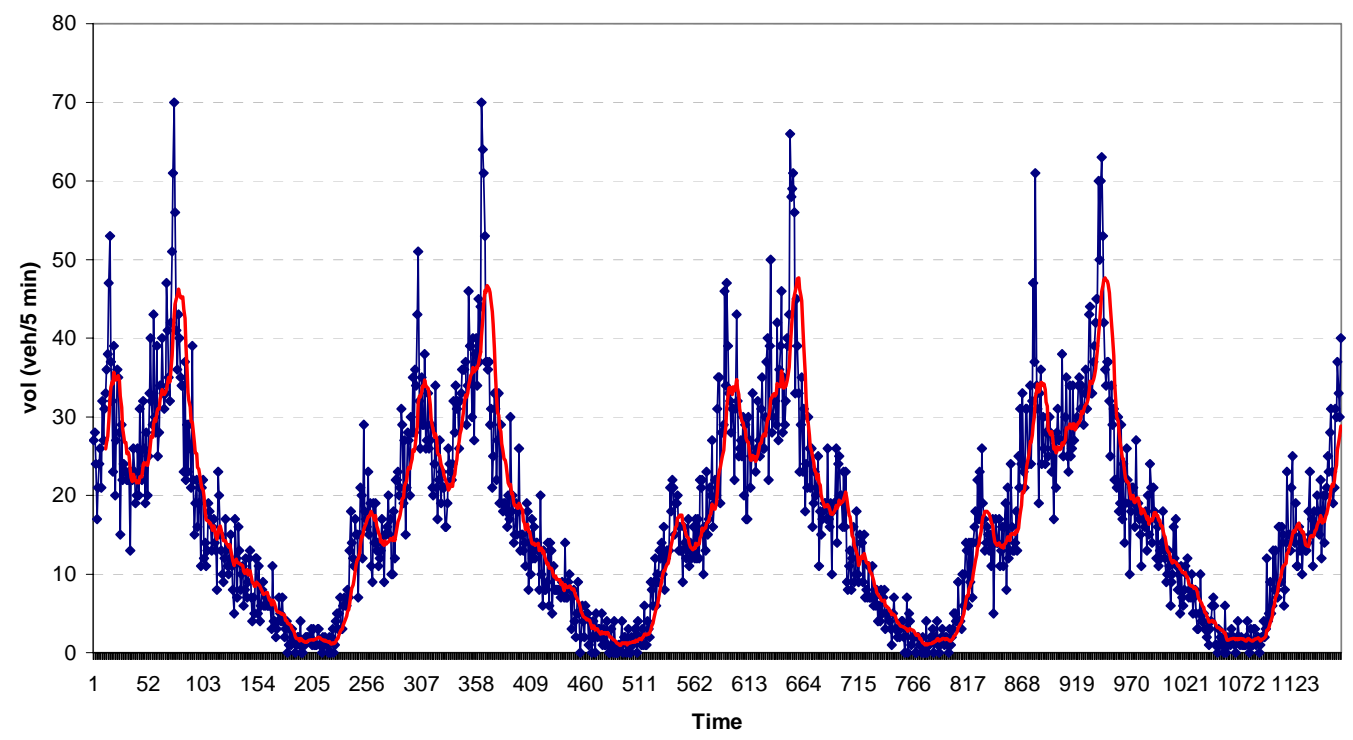

Figure 3-2. A sample of 5-min averaged traffic volume on Northwestern Ave, West Lafayette, IN. May 24 to May 28, 2004.

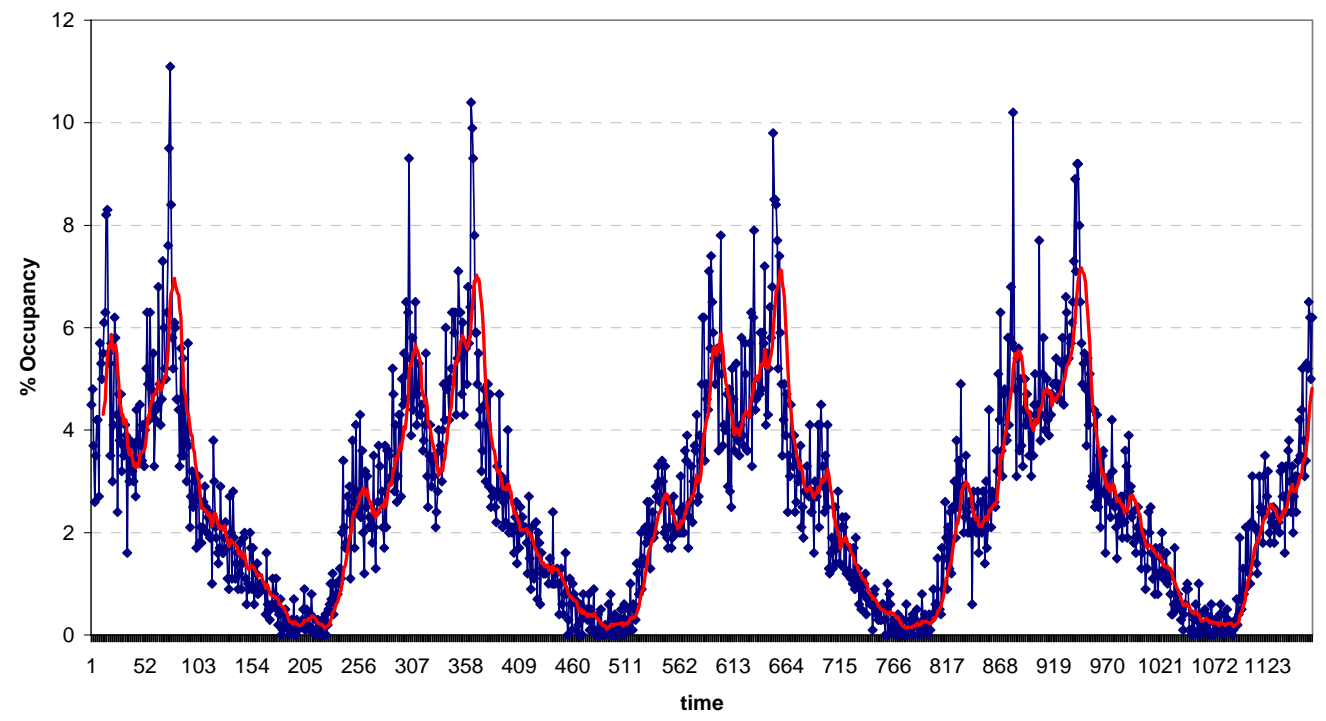

Figure 3-3. A sample of 5-min averaged traffic occupancy on Northwestern Ave, West Lafayette, IN. May 24 to May 28, 2004. 


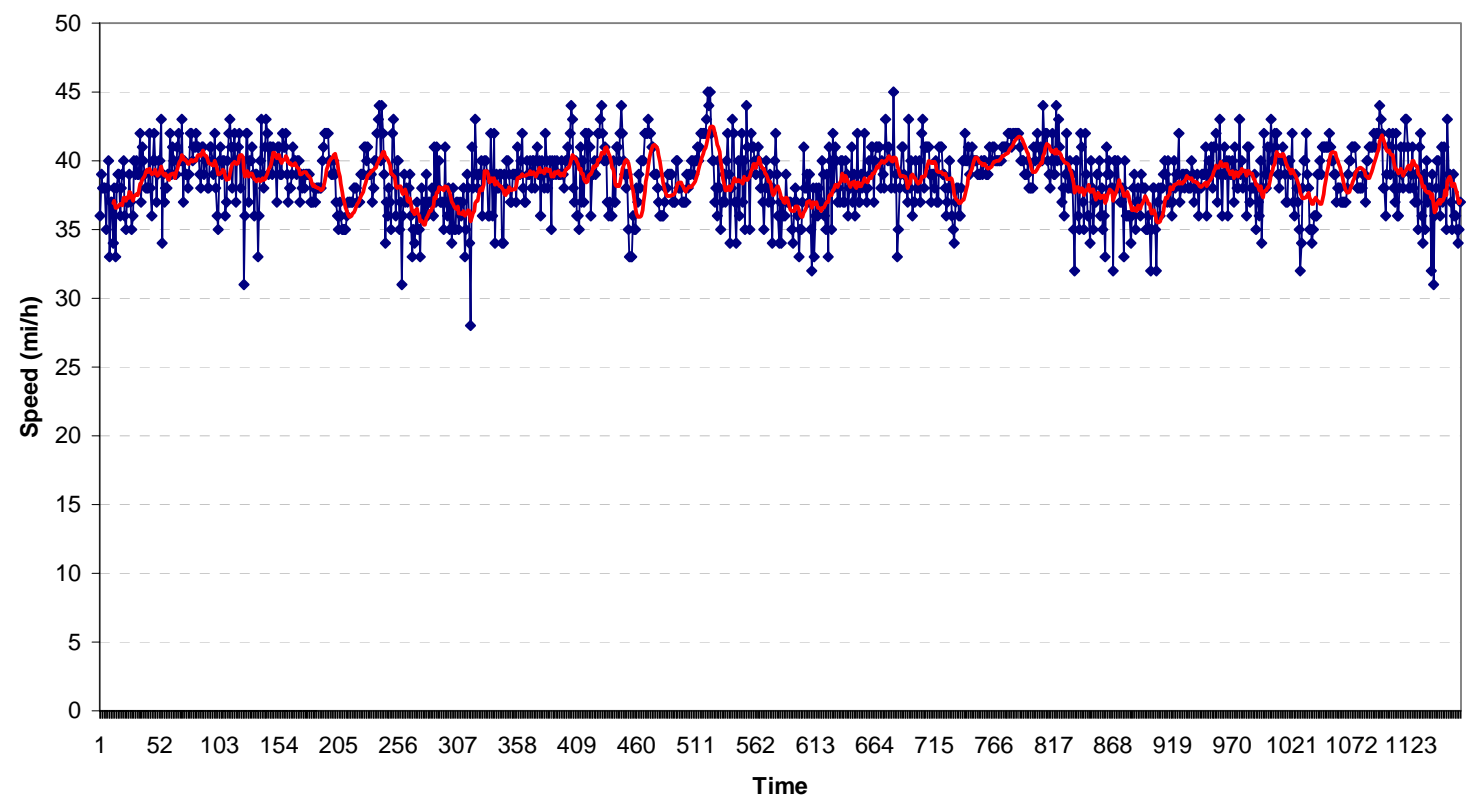

Figure 3-4. A sample of 5-min averaged traffic time-mean-speed on Northwestern Ave, West Lafayette, IN. May 24 to May 28, 2004.

Event data log files on the other hand, provide time stamped vehicle speeds as well as classification whenever a vehicle passes through the sensor field-of-view. This type of data set is useful in providing travel time estimates on a road segment using Coifman's dual-loop algorithm (Coifman, 2002). However, due to the instruments memory limitation, only integrated 10-second-interval data are collected and used for both the traffic-air quality analysis and the travel time estimation which functioned well in the this project's analysis.

After the testing period, the traffic sensors were installed at both the PU-Hessville (mm 4.1) and Kennedy sites (mm 3.3) at the Borman Expressway in October 2004, figures 3-5 and 3-6 show the installed sensors at both of these locations, respectively. Figure 3-5 shows the traffic sensor, $\mathrm{PM}_{2.5}$ inlet and meteorological tower at the PU- 
Hessville station. Figure 3-6 shows the traffic sensor and the $\mathrm{PM}_{2.5}$ inlet at the Kennedy Site.

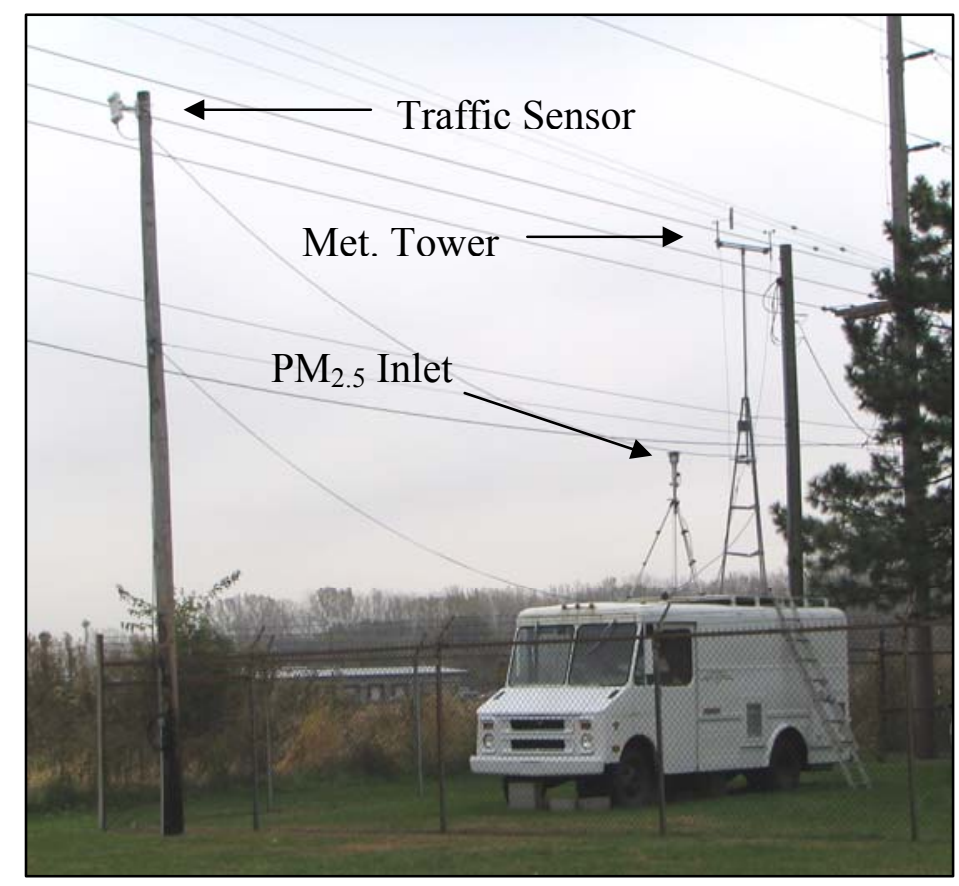

Figure 3-5. A photograph of the PU-Hessville monitoring station, located south of the Borman Expressway, at mm 4.1.

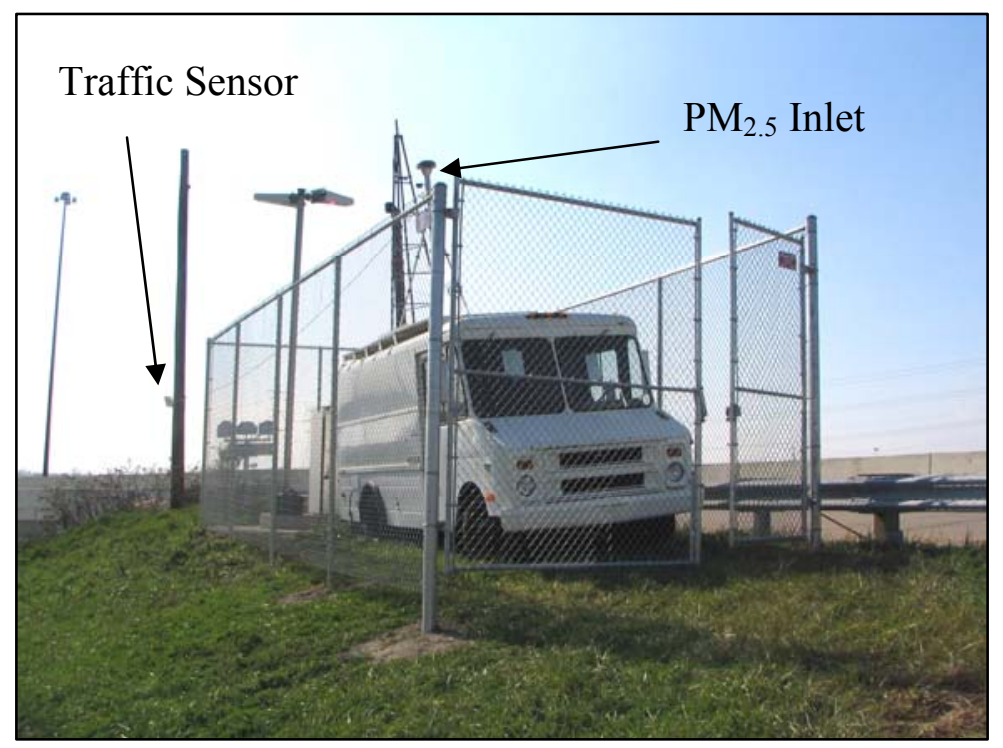

Figure 3-6. A photograph of the Kennedy monitoring station, located north of the Borman Expressway, at $\mathrm{mm}$ 3.3. 
The WAVETRONIX ${ }^{\mathrm{TM}}$ traffic sensors were calibrated again at the Borman Expressway on March 15, 2005. The test was performed by video recording traffic for approximately 10 hours for both the east and the west bounds of the Borman. The data obtained from the sensors were then compared to the data obtained from video recordings. The video recordings started at 8:00 $\mathrm{AM}$ and ended at 6:00 PM. The recordings were then reviewed and 2 hours were chosen representing free flow and congested conditions on both bounds of the Borman Expressway. Analysis was performed for vehicle speeds and Class 9 truck-volume (truck/time); hence calibrating the vehicle speeds, vehicle counts, as well as vehicle classification. Travel times as well as truck counts were measured manually from the video recordings for the center-lane (lane 2) of both bounds between mile markers 3.1 and 3.2 on the expressway. The manual data were then compared with the data recorded by both traffic sensors for the same center lanes. Through out this study, the "manual" readings will always refer to data measured from the video recordings, while "sensor" readings will refer to data measured by the WAVETRONIX ${ }^{\mathrm{TM}}$ sensors.

Figure 3-7 shows both 30-second averaged "manual speeds" (actual speeds measured form the video recordings) and the "sensor speeds" (speeds measured by the sensors) as a function of time for the east-bound-traffic. As shown in figure, during the traffic-free flow condition (10:00 to 11:00 AM), the sensor speeds followed the actual speeds. However, during the traffic congestion period (2:30 to $3: 30 \mathrm{PM})$, there is a 5.5 minute lag between the actual and sensor readings. This lag is due to the of the 0.9 miles location difference between the measured values since the camera measurements are at mile marker 3.2 and the sensor is located at mile marker 4.1. The discrepancy in the speed values between the two measurement methods is expected due to the fact that 
during congestion, traffic at the front of the queue may be moving at a different speed than that at the end of the queue, which is 0.9 mile apart in this case. This fact is reflected on the calibration graph of figure $3-8$, where the 5-minute average of manual speeds showed poor correlation with the 5-minute sensor speeds. Note the data scatter is pronounced below $35 \mathrm{mi} / \mathrm{h}$ but not at cruising speeds above $50 \mathrm{mi} / \mathrm{h}$.

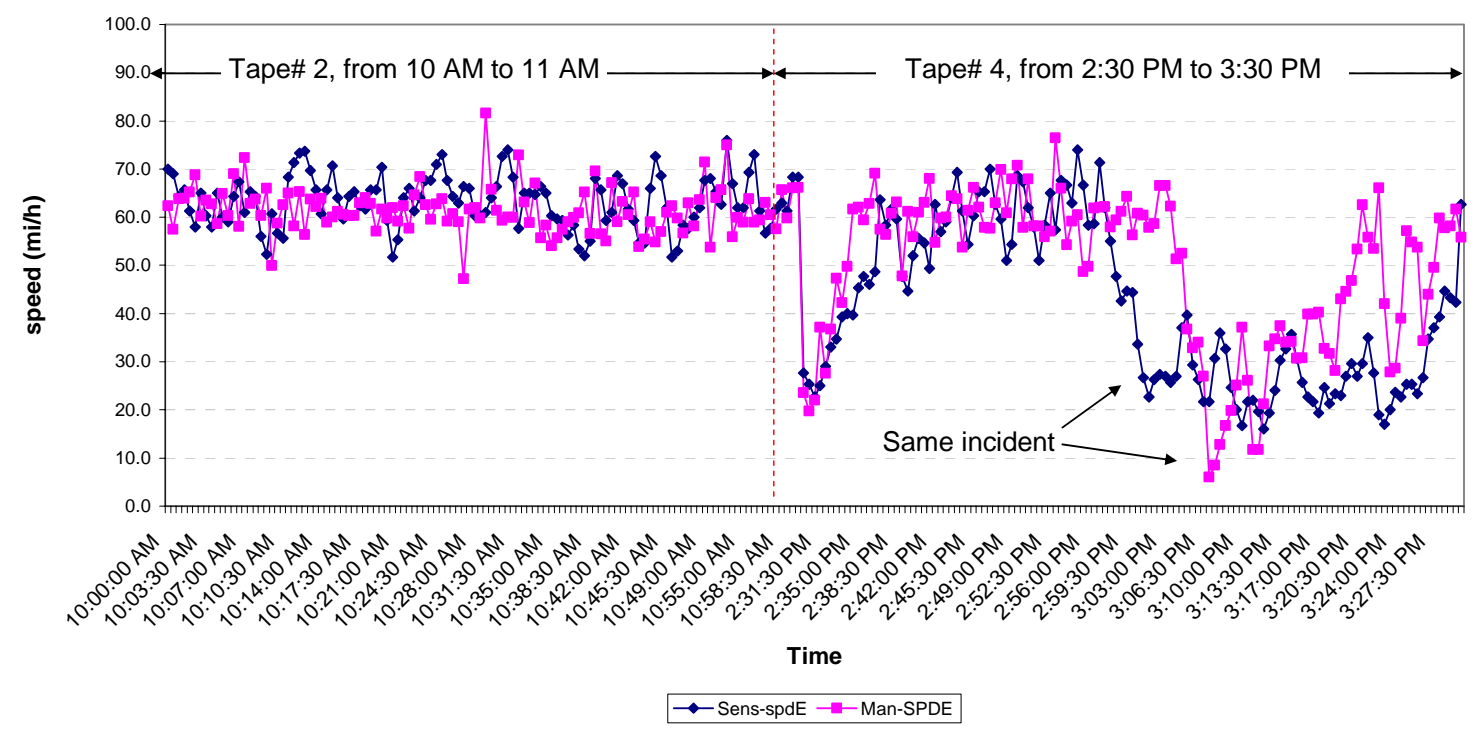

Figure 3-7. East bound manual and sensor speeds of lane 2 as a function of time, March 15,2005 , for the periods of 10:00 to 11:00 AM, and 2:30 to 3:30 PM.

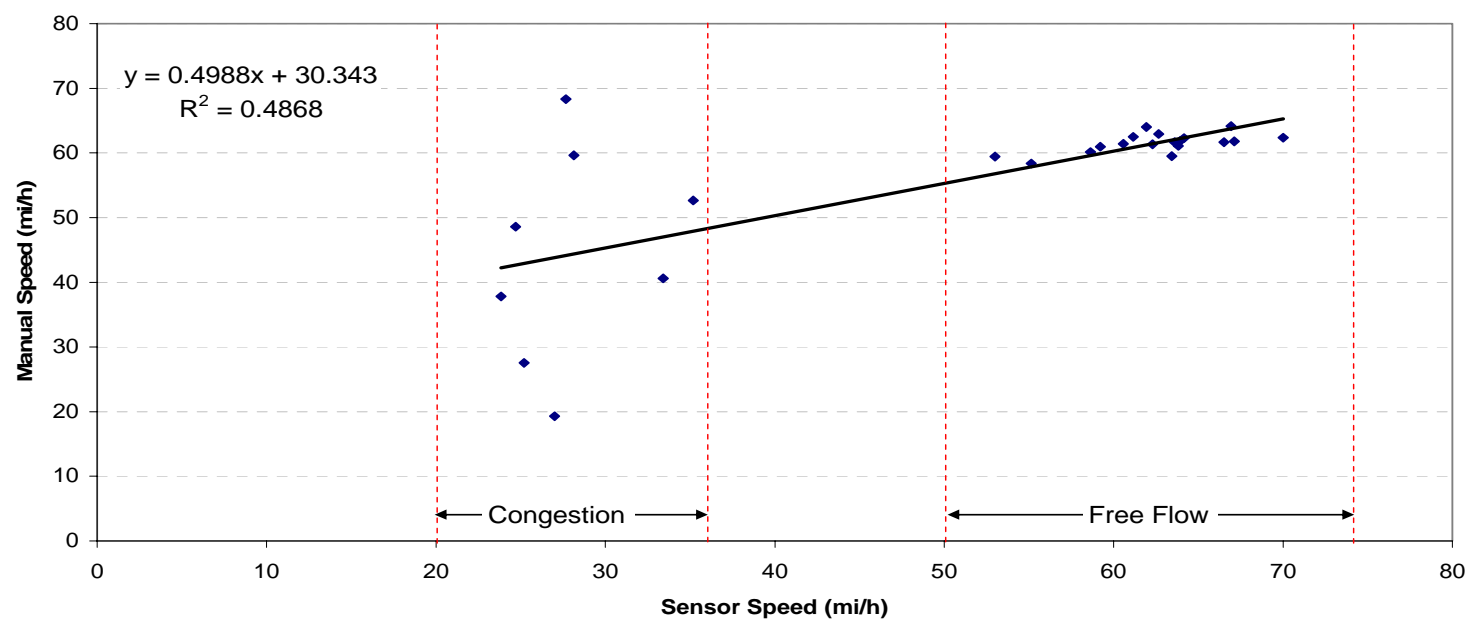

Figure 3-8. Correlation of the east bound manual and sensor speeds of lane 2, March 15, 2005, for the periods of 10:00 to 11:00 AM, and 2:30 to 3:30 PM. 
With respect to the truck volume (truck count), unlike east bound speeds, truck count is independent of the location difference for this experiment ( 0.9 miles) since the system is closed with no major exit ramps, and therefore no trucks exiting or entering the Borman within this distance. This fact is reflected on the calibration graph of the 5minute truck volume shown in figure 3-9 where sensor truck count shows good correlation $\left(\mathrm{R}^{2}=0.81\right.$, slope $\left.=1.02\right)$ with the manual truck count readings.

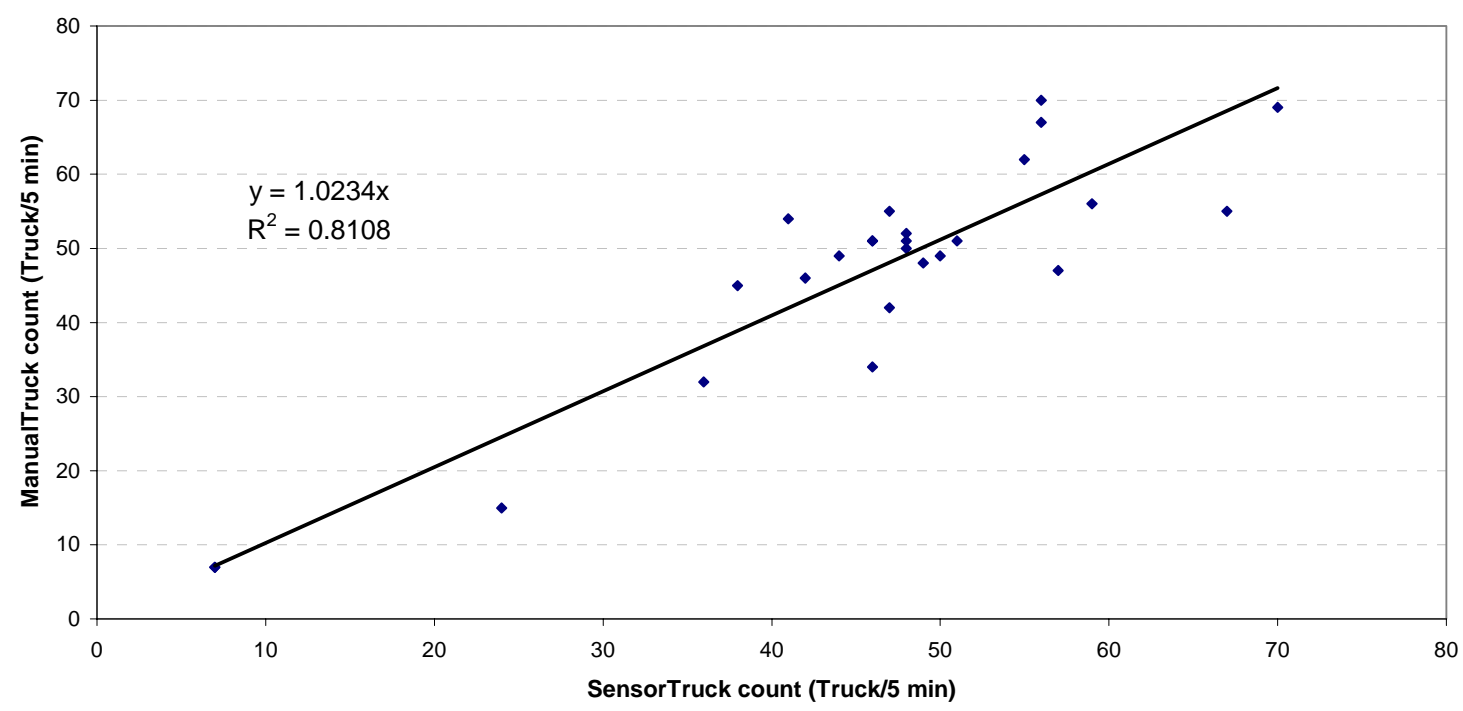

Figure 3-9. Correlation of the east bound manual and sensor truck volume of lane 2, March 15, 2005, for the periods of 10:00 to 11:00 AM, and 2:30 to 3:30 PM.

Cumulative-truck count error was also analyzed for the sensors, i.e. analyzing if the sensors will over- or under-count the truck volume as the time-period (in which trucks are counted) increases from 30 seconds to 1 hour.

Figure 3-10 shows the cumulative truck count for the east bound for both the congested and free flow periods. As shown in figure 3-10, both truck counts were almost identical for the free-flow region (around 2.5\% error for the 1-hour period, refer to figure 
3-11), while during congestion, the sensor was under-counting the trucks by $6.8 \%$ for the 1-hour period, refer to figure 3-11.

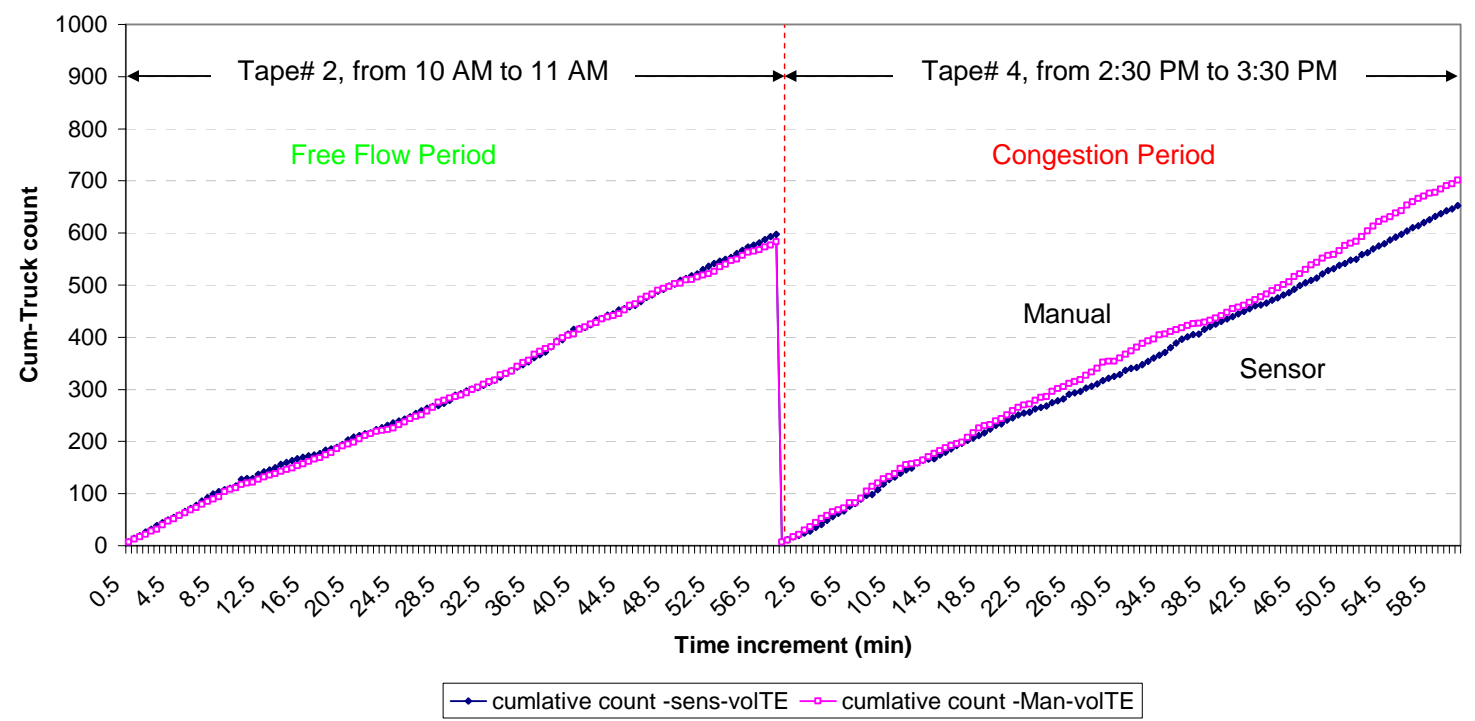

Figure 3-10. The cumulative truck count for the east bound for both the congested and free flow periods, lane 2, March 15, 2005.

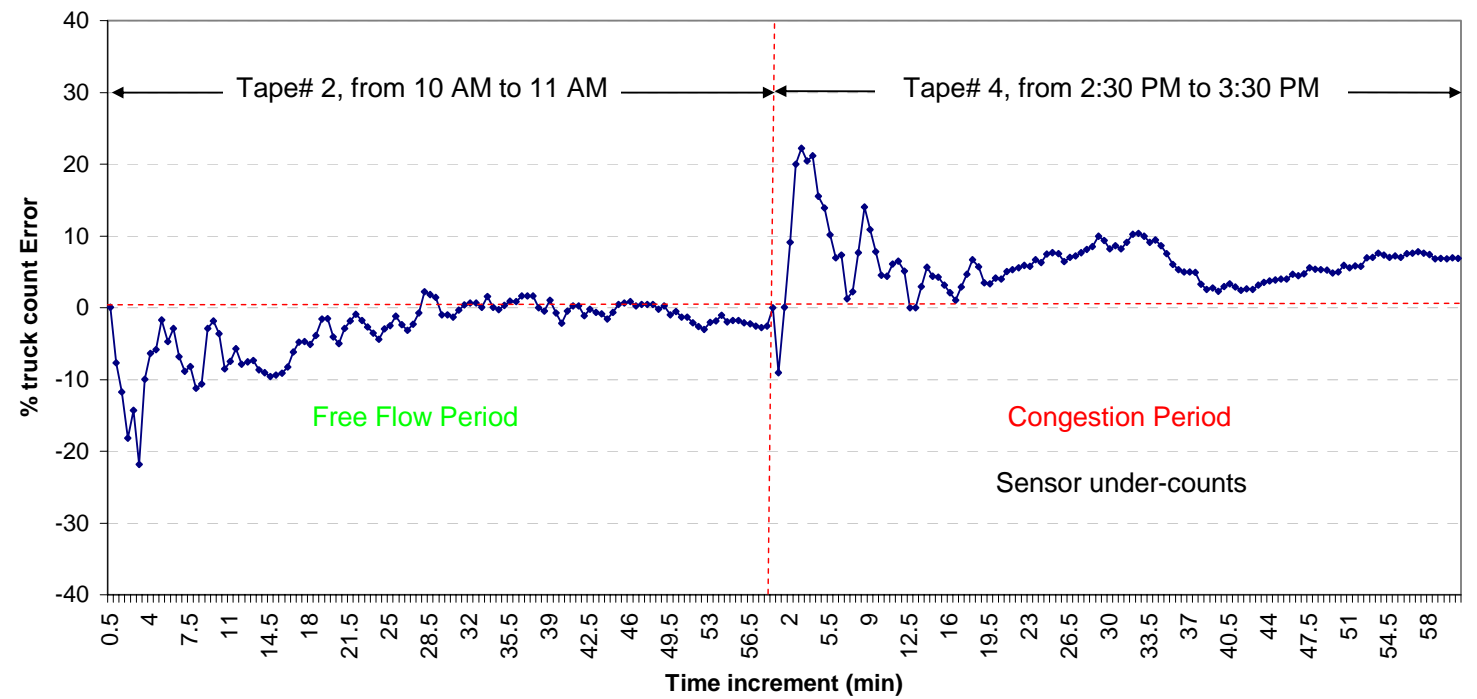

Figure 3-11. \% error of the cumulative truck count for the east bound for both the congested and free flow periods, lane 2, March 15, 2005. 
A similar analysis was performed for the west bound measurements. Figure 3-12 shows both 30-second averaged "manual speeds" (actual speeds measured form the video recordings) and the "sensor speeds" (speeds measured by the sensors) as a function of time for the west-bound-traffic. Since measurements are taken at almost the same locations (traffic sensor at mile marker 3.3, and manual measurements are at mile marker 3.2), the delay (time lag) between the values is found to be minimal (unlike the case of the east bound measurements, figure 3-7). Note that at low speeds (below $15 \mathrm{mi} / \mathrm{h}$ ), the sensor tends to read speeds higher than the actual readings. WAVETRONIX ${ }^{\mathrm{TM}}$ Corporation suggested that the sensor becomes "noisy" for speed values less than $15 \mathrm{mi} / \mathrm{h}$ which is considered a limitation of the instrument at such speeds compared to the inductive loop detectors. However, this does not affect the 5 minute averages of speeds as shown in figure 3-13. Due to the short distance between the location of the sensor and the manual measurements, good correlation of the 5-minute averaged speeds $\left(\mathrm{R}^{2}=0.83\right.$, slope $=1.05)$ is shown in figure 3-13.

With respect to the west bound truck volume (truck count), the calibration graph of the 5-minute truck volume shown in figure 3-14 showed good correlation $\left(R^{2}=0.82\right.$, slope $=0.96)$ between manual and sensor truck count readings.

Figure 3-15 shows the cumulative truck count for the west bound for both congested and free flow periods. As shown in figure 3-15, both truck counts were almost identical for the free-flow region (around 4.7\% error for the 1-hour period, refer to figure $3-16$ ), while during congestion, the sensor was over-counting the trucks by $14.5 \%$ for the 1-hour period, refer to figure 3-16. 
Overall, the WAVETRONIX ${ }^{\mathrm{TM}}$ traffic sensors have performed well through the calibration test done on March 15, 2005.

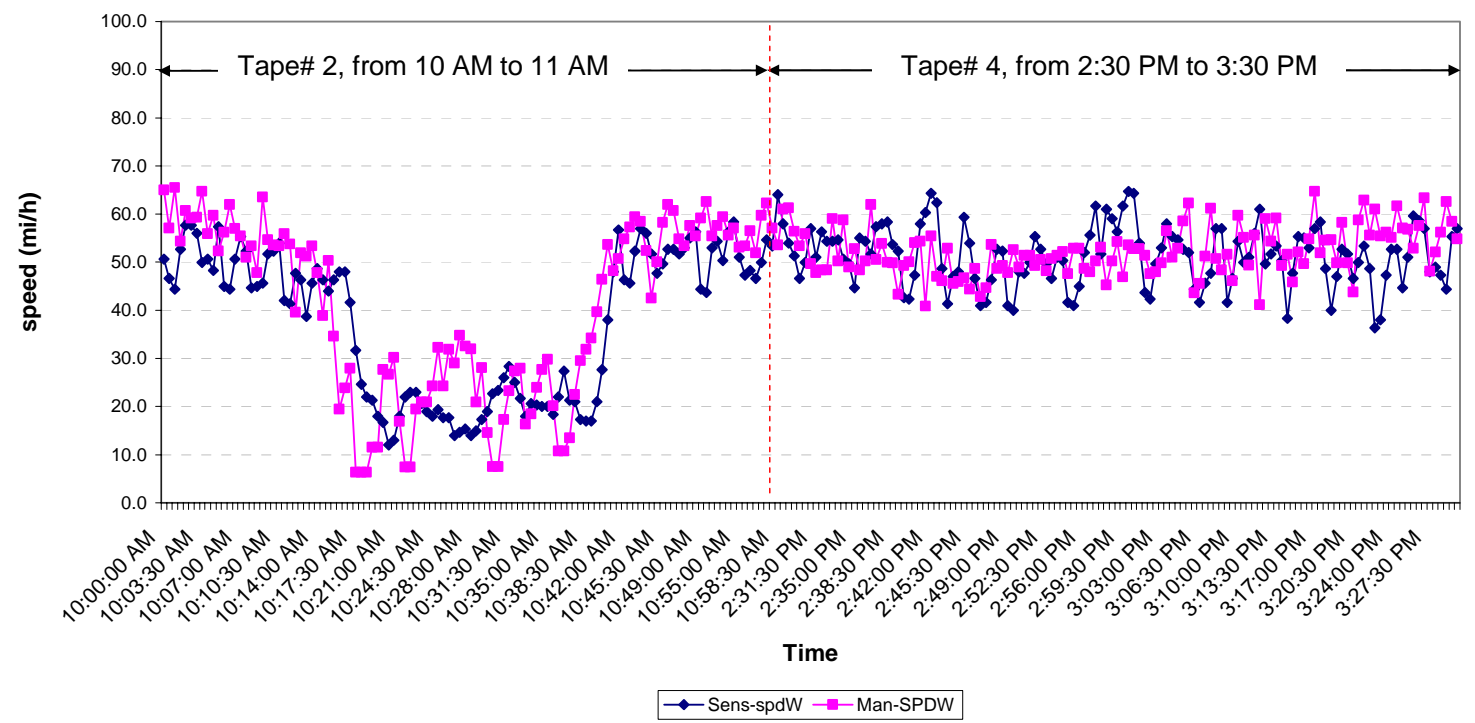

Figure 3-12. West bound manual and sensor speeds of lane 2 as a function of time, March 15,2005 , for the periods of 10:00 to 11:00 AM, and 2:30 to 3:30 PM.

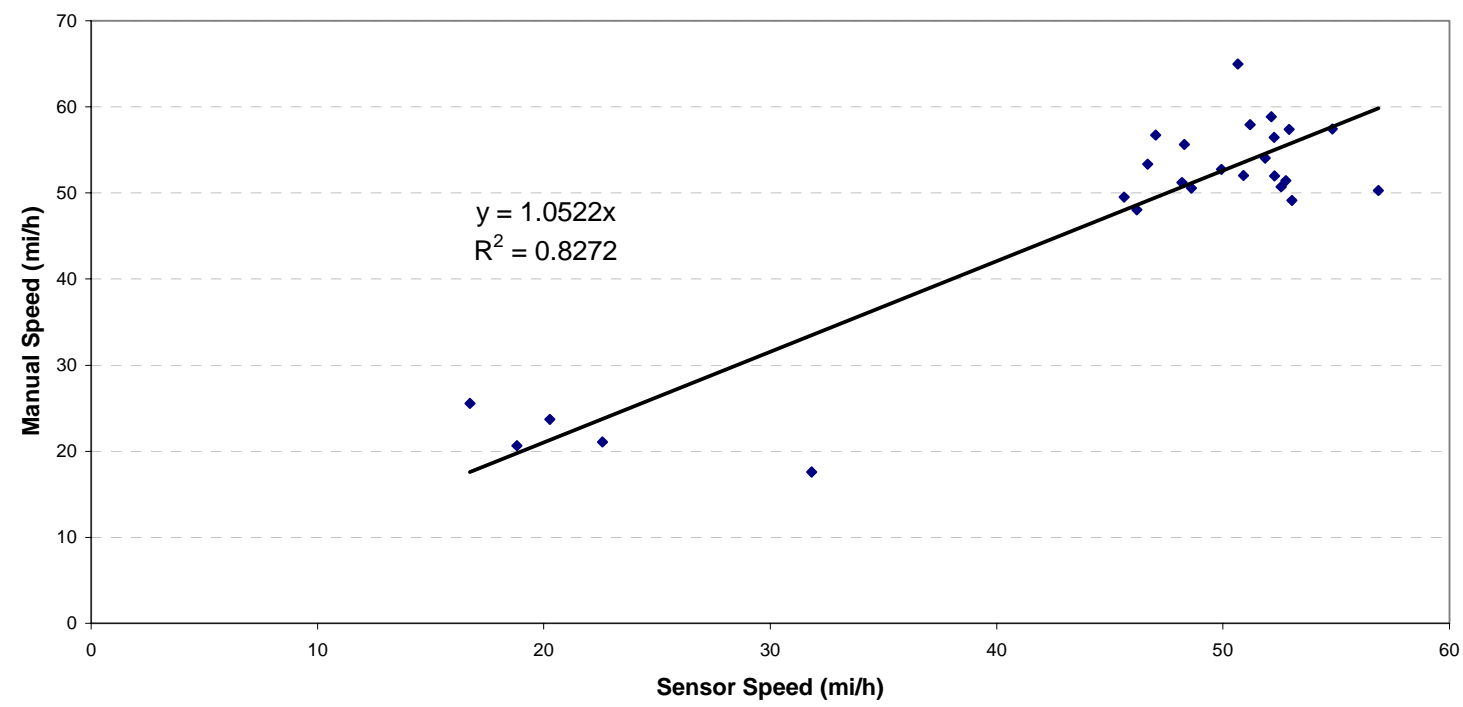

Figure 3-13. Correlation of the west bound manual and sensor speeds of lane 2, March 15, 2005, for the periods of 10:00 to 11:00 AM, and 2:30 to 3:30 PM. 


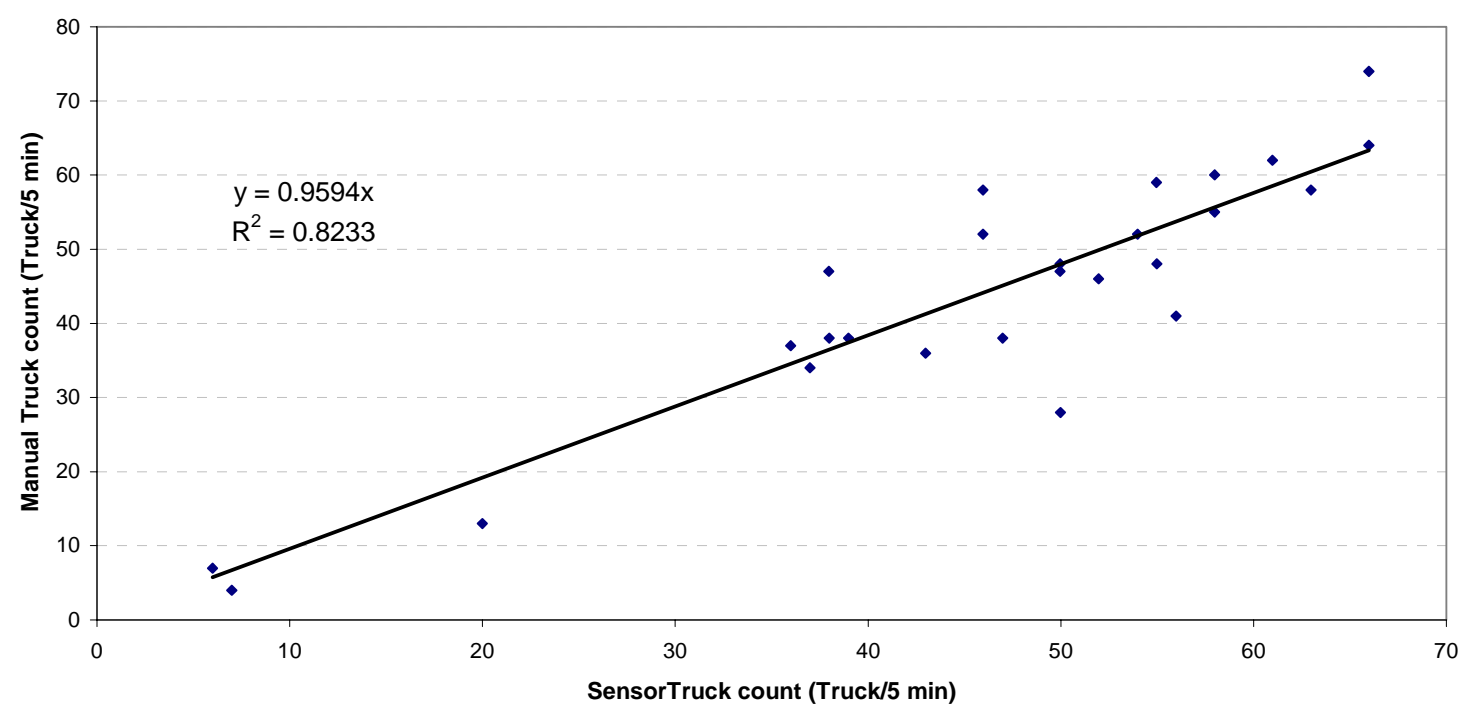

Figure 3-14. Correlation of the west bound manual and sensor truck volume of lane 2, March 15, 2005, for the periods of 10:00 to 11:00 AM, and 2:30 to 3:30 PM.

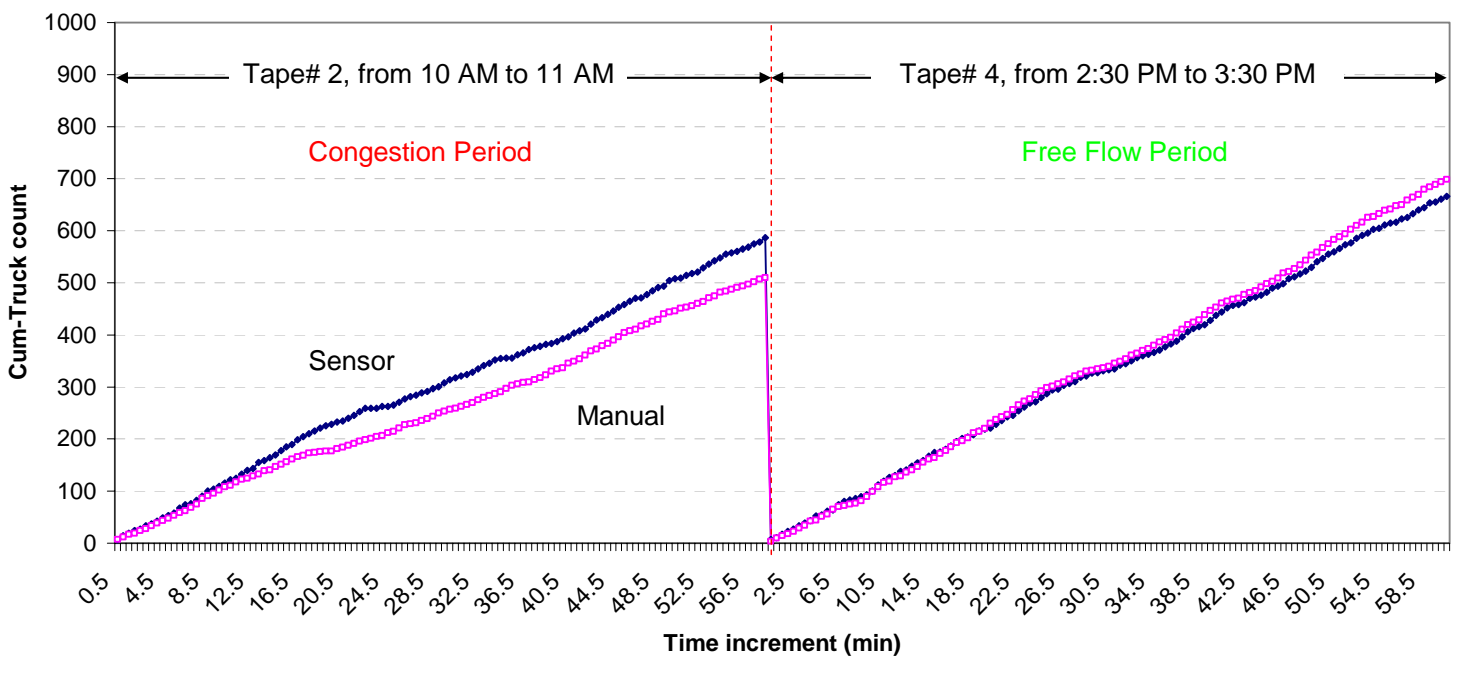

$\rightarrow$ cumlative count -sens-volTW - a- cumlative count -Man-volTW

Figure 3-15. The cumulative truck count for the west bound for both the congested and free flow periods, lane 2, March 15, 2005. 


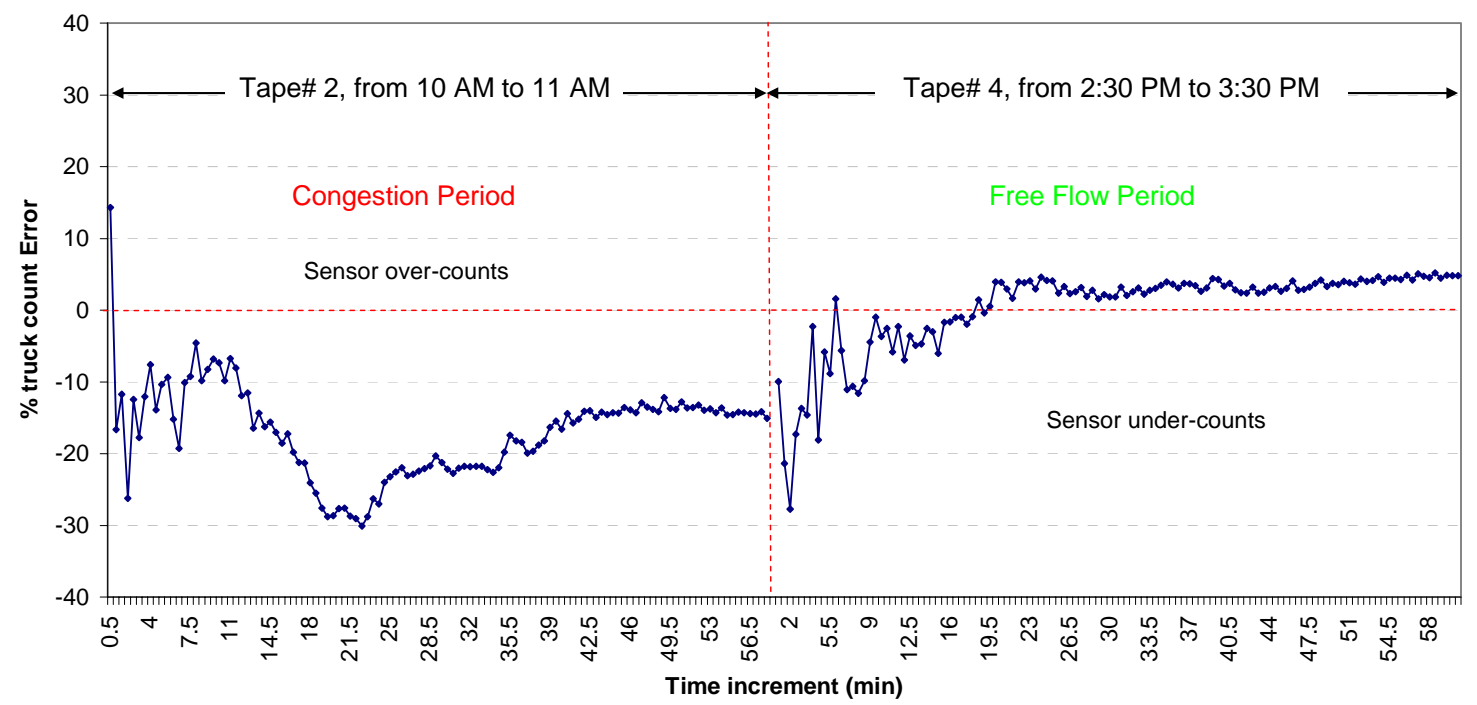

Figure 3-16. \% error of the cumulative truck count for the west bound for both the congested and free flow periods, lane 2, March 15, 2005.

\subsection{Travel Time Analysis:}

Travel time is an important measure of how the traffic flows along a road segment. It provides more accurate information than the "point-measurements" of velocity and volume about the degree of the congestion along a known road link. Travel time is simply defined as the time needed for a vehicle to travel a certain distance on the road:

$$
\tau=\frac{d}{v_{s}}
$$

Where: $\tau=$ travel time, $\mathrm{d}=$ road link length, and $\mathrm{v}_{\mathrm{s}}=$ space mean speed.

Space mean speed is defined as the average speed of vehicles over a road-link length during an interval of time. Space-mean speed is a more accurate measure of speeds than the time-mean speed (which is the average of speeds at a point-location over time) during congestions. The difference between the two speeds decreases as the absolute values of speeds increases (Garber et. al, 2002). 
There are several techniques to measure the delays and travel times on specific highway links, such as the floating-car technique, where observers drive along a road segment with the traffic several times (while balancing the number of passing cars) and calculate the average travel time for this segment (Garber et. al, 2002). The averagespeed technique is also used, where the observer travels at an average speed of the traffic at a specific link and hence calculates the travel time (Shimizo et. al, 2000). However, such techniques are not practical for continuous-real-time analysis of traffic on road links. Hence, traffic engineers relay more on traffic sensors to estimate travel times, as in the case of using models to estimates such travel times (Kachroo, et al, 2001). Some of the common techniques are based on using two dual-loop detectors located a known distance apart to determine the time which vehicles take to pass between these loops. Such technique requires vehicle-identification algorithms to be able to ensure that the travel time is measured for the same vehicle passing the two detectors. This is done by matching platoons rather than individual vehicles at the down-stream dual loop detector (Coifman et. al, 2002), and once a vehicle is identified through the algorithm, its arrival time at the detector is used in the calculation of its travel time. A similar technique is also used to estimate vehicle density on a highway segment (Coifman, 2003). Although these techniques provided good estimates of travel times, however, they require two or more dual loop detectors along the highway link in order to work. Another technique developed by Coifman (2002) uses only one dual loop detector to estimate travel times up or down stream for the range of 0.3 to 0.5 miles, with a shockwave estimation range of 12 to $16 \mathrm{mi} /$ hour (Windover, 1998). This algorithm is used in the Borman Expressway study to estimate the travel times and hence the vehicle densities along a road segment down- 
stream from the monitoring station. Although the technique reported by Coifman (2002) required a dual loop traffic detector as well as event-traffic speed data, however, the microwave traffic sensors along with short-term interval-traffic speed data (10-second integrated speed data) have proved to be also successful in estimating travel times along the expressway links as discovered by this author and described in the following text.

Coifman's travel time algorithm (Coifman, 2002) was calibrated and tested for the Borman Expressway. The calibration was done based on the observed travel time values measured during the traffic sensor test period of March 15, 2005. Travel times were measured for vehicles between mile markers 3.1 and 3.2 which were then compared to the travel times estimated by Coifman's algorithm. Coifman's algorithm is simple and requires only time-stamped vehicle speeds, as well as an estimated value of the traffic shockwave which is reported to be constant with a value between 12 and $16 \mathrm{mi} /$ hour for highways (Windover, 1998, Windover et. al, 2001). In order to estimate the proper shockwave speed for the Borman Expressway, the algorithm had to be tested by comparing the sum-of-squares $\left(\mathrm{S}^{2}\right)$ of the difference between the manually measured travel times and the values obtained by the algorithm. The algorithm was tested twice; the first was by using the manual-velocity readings obtained by the video recordings of March 15, 2005 as an input and the second was by using the speeds recorded by the sensors for the same period of time as an input to the algorithm. Both tests were also compared to travel times obtained by the naïve-approach of generalizing point-speed measurements taken by the sensor over an entire link, i.e. assuming that the vehicles will maintain their speed (measured at the sensor location) over the entire link length (0.1 miles). 
The sum-of-squares were then plotted as a function of the shockwave speeds, in the 12 to $16 \mathrm{mi} /$ hour range for the free-flow condition, congested condition and the total sum-of-squares for both cases. Based on the sensor calibration analysis, west bound data were used to calculate the sum-of-squares.

Figure 3-17 shows the sum-of-squares (S2-1, S2-2, and S2-Total) as a function of shockwave velocity $\left(U_{c}\right)$ as well as the sensor's naïve-approach for the first case.

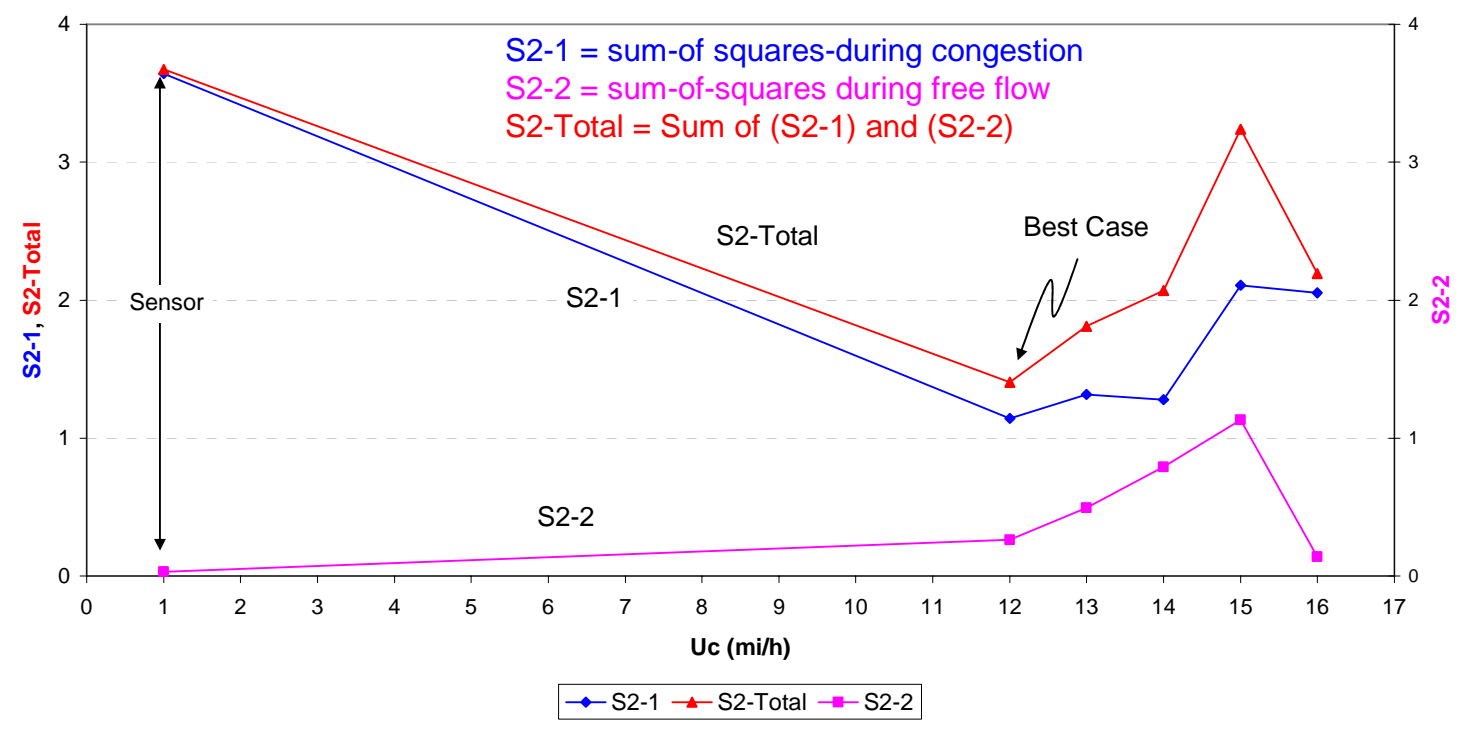

Figure 3-17. Sum of Squares (S2) of Travel Time vs. Uc. S2 is between Manual readings, Manual-Coif. Algorithm, and sensor readings (for a 0.1 mile segment).

As shown in figure 3-17, the sensor performed well for the free flow condition, while -as expected- it failed during the congested flow condition. This is due to the fact that speeds measured at a point location can not be generalized to the entire link during congestions since vehicles may reduce their speeds based on their interaction with the other vehicles forming the queue downstream from the sensor. The figure also shows that the best case for the total-sum-of-squares was for shockwave value of $12 \mathrm{mi} /$ hour. 
A similar outcome was obtained for the second case where sensor readings were used as an input to the Coifman's algorithm as shown in figure 3-18.

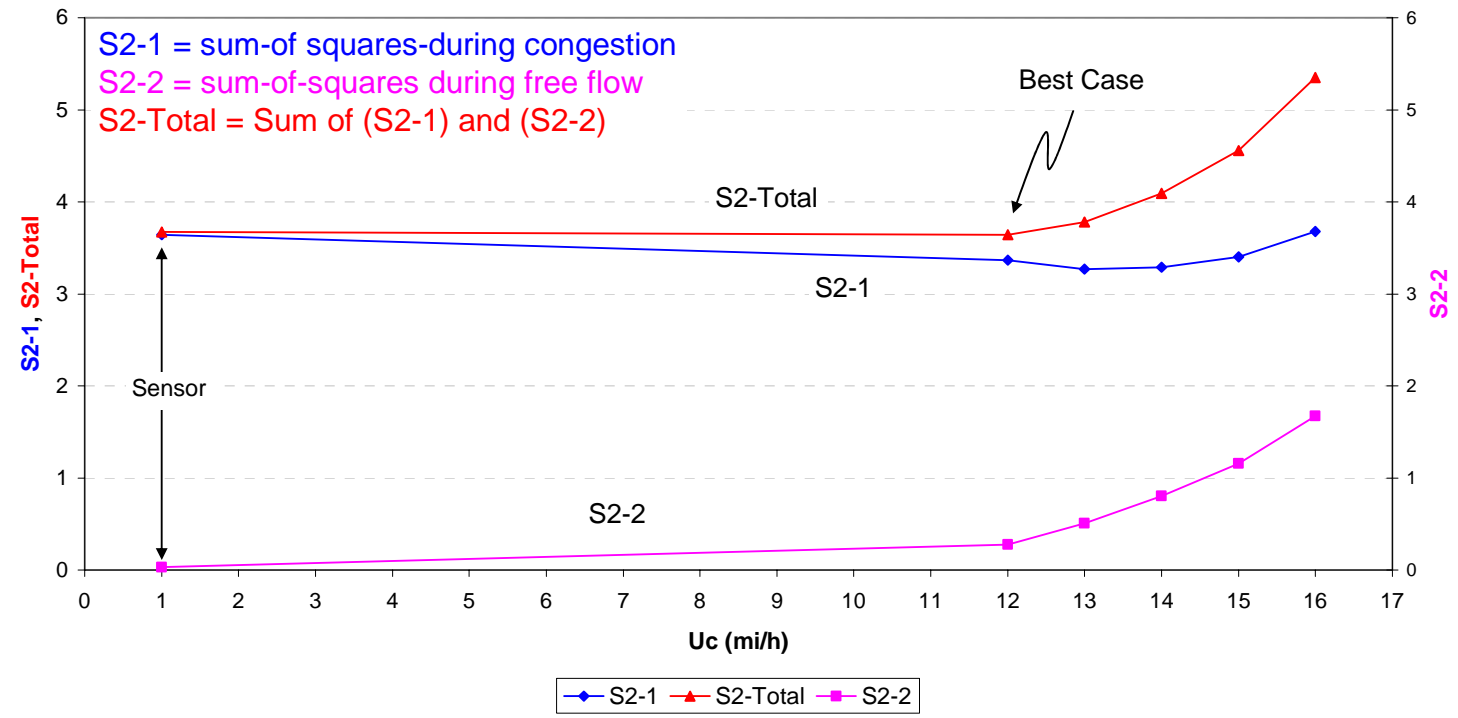

Figure 3-18. Sum of Squares (S2) of Travel Time vs. Uc. S2 is between Manual readings, Sensor-Coif. Algorithm, and sensor readings (for a 0.1 mile segment).

Sensitivity tests were run on the algorithm to check how would the output change based on percent-change in the input parameters namely the time-stamped speed, and shockwave speed (Uc) values. A randomly chosen data set (over 2000 data points) of time-stamped speeds measured by the sensor in November 2004 was used for this sensitivity test. It was found that the output percentile difference of the average travel time would change between $1.4 \%$ and $4.5 \%$ if Uc values were to be chosen other than Uc $=12 \mathrm{mi} / \mathrm{h}$, as shown in figure 3-19. 
For the case of percentile change of the time-stamped input speeds, it was found that the output percentage error in the average travel time was given by the following equation:

$$
\begin{gathered}
\% \text { diff- } T r=-0.0018 \text { (\%diff-spd })^{2}+0.6761 \text { (\%diff-spd) } \\
\mathrm{R}^{2}=0.99
\end{gathered}
$$

Where: \%diff-Tr is percentage difference in the average output-travel-time, and \%diffspd is the percentage difference in the time-stamped input speeds.

Figure 3-20 shows the relationship given by equation 3-2. As shown in figure 320 , an error of $30 \%$ in the input speed data will result in an error of about $19 \%$ of the output travel time values.

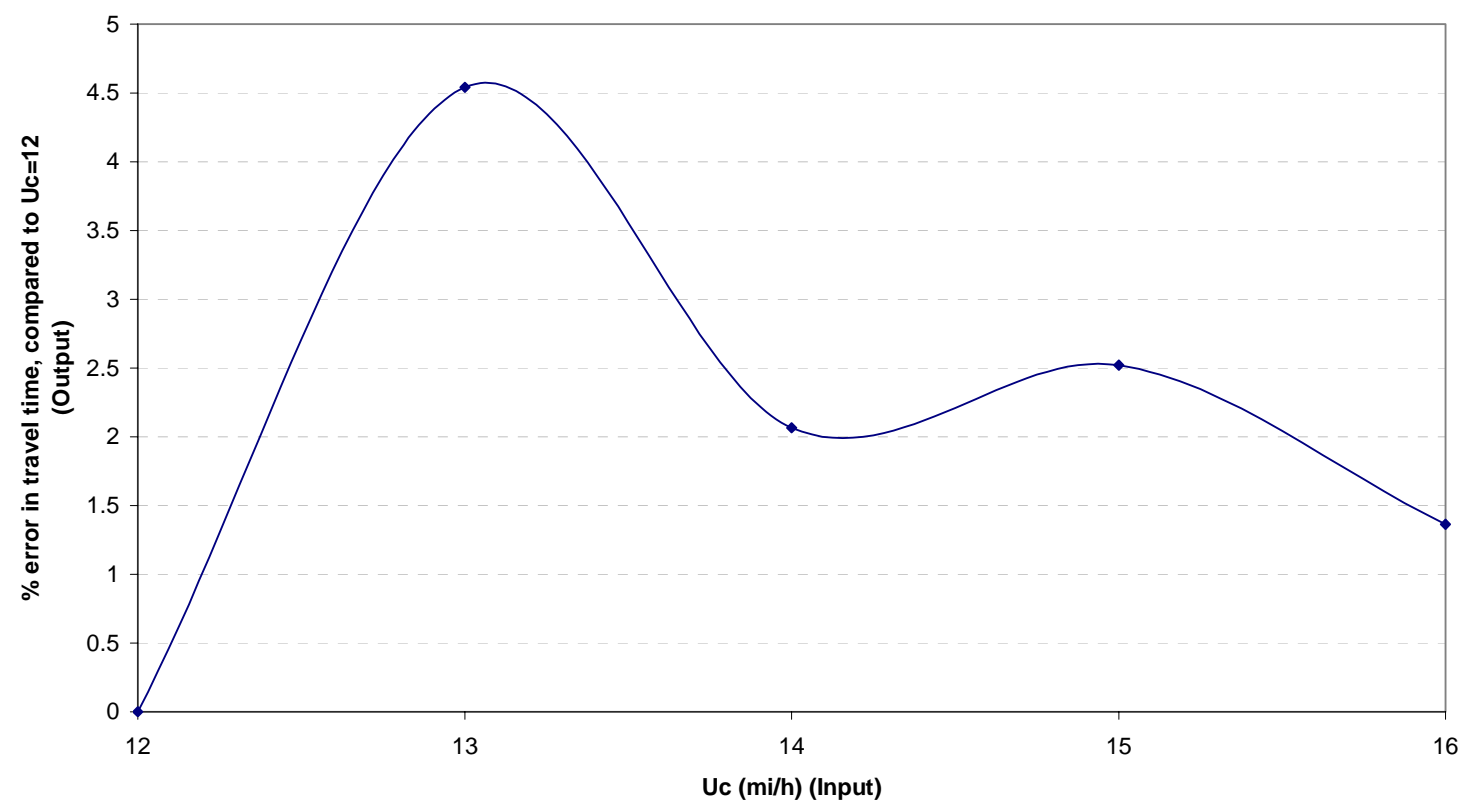

Figure 3-19. \%change in output travel time values compared to $\mathrm{Uc}=12 \mathrm{mi} / \mathrm{h}$ vs. Uc. 


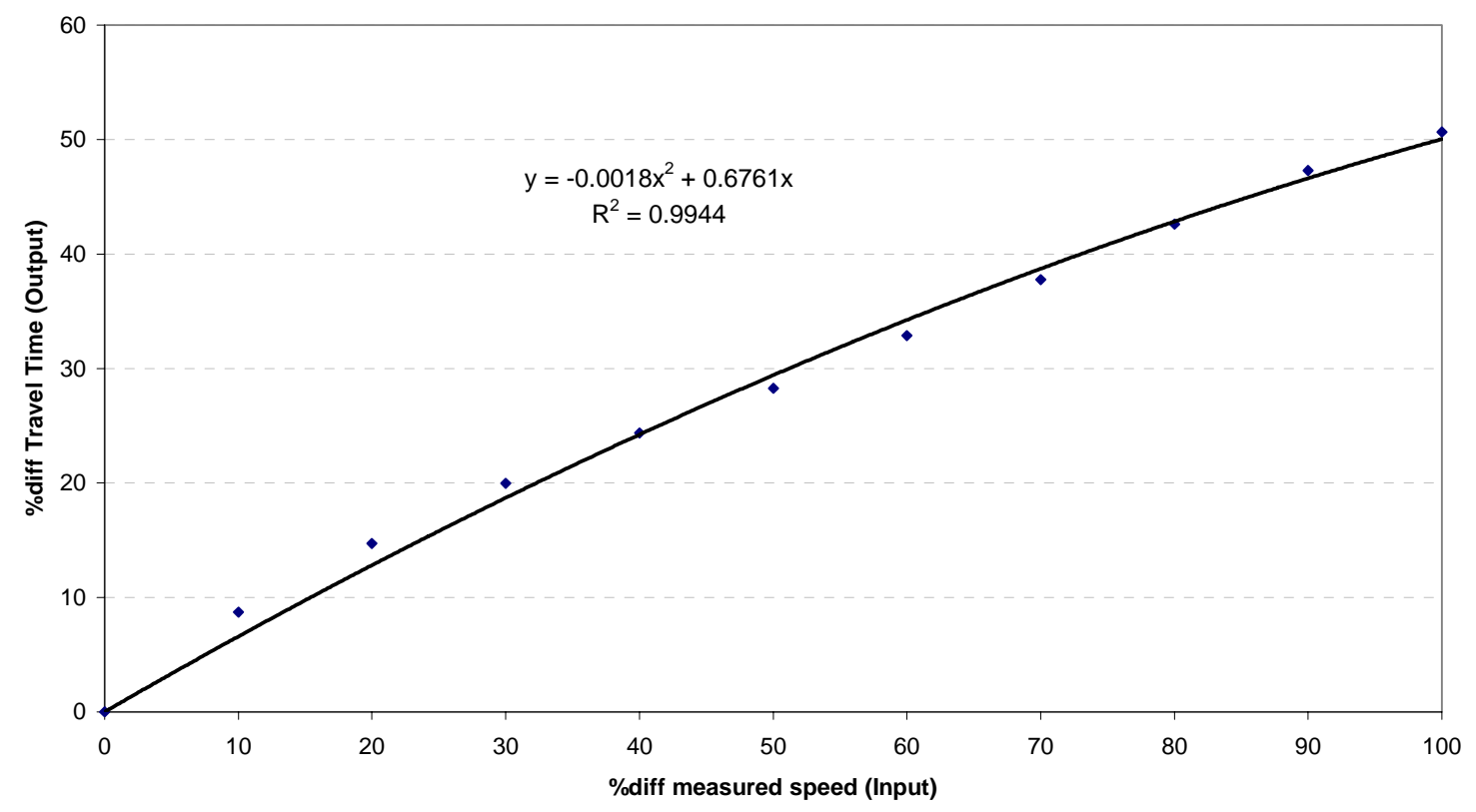

Figure $3-20 . \%$ change in output travel time values compared to. $\%$ change in input timestamped-speeds.

Traffic condition in general can be quantified by using the Highway Capacity Manual (HCM2000) that identifies the Level Of Service (LOS) of the highway, which is a "quantized" parameter, based on the density of passenger vehicles per lane, their speed, and flow rate. The LOS is divided into the following "quantized" levels (Garber et. al, 2002):

Level A: Complete free flow conditions, where vehicles are unimpaired in their ability to maneuver.

Level B: Slight restrictions on the road, while vehicles maintain their free flow speeds, an overall reasonable free flow condition.

Level C: Speeds are at or slightly lower than the free flow speeds, however, there is a noticeable restriction to vehicles' ability to maneuver. 
Level D: Speeds are decreased compared to free flow speeds with a major increase in vehicle densities due to the rapid increase in the vehicle flow; gaps (space headways) decrease significantly at this level.

Level E: Low speeds, where there are virtually no usable gaps in the highway, therefore any restriction to the traffic stream such as entering traffic or incidents may result in traffic-queuing.

Level F: Complete breakdown in the traffic flow; long-term queue formations occur.

Although such LOS traffic levels have been widely and successfully used, it is suggested for this Borman Expressway research to use a more "continuous" and simpler traffic parameter to describe the traffic flow along a segment of a highway rather than the quantized LOS. Such parameter is called "normalized-travel-time" or TRN.

The normalized travel time is estimated as follows:

$$
T R N=\frac{\text { traveltime }}{\text { traveltime@ flowspeed }}
$$

Where travel-time is the time needed to travel a segment length of the highway, and travel-time@flow-speed is the travel time of the same segment for vehicles traveling at the speed limit. Based on such definition (equation 3-3), for TRN values ranging $0<$ TRN $<1$, traffic is freely moving at speeds higher than the speed limit, where the faster the traffic moves, the smaller the TRN value. Signs of congestion as well as traffic jams occur for the TRN range of $1<\mathrm{TRN}$, where the slower the traffic moves, and hence the bigger the TRN value. At TRN $=1$, the traffic is moving exactly at the speed limit. The following schematic diagram summarizes the TRN description of the traffic flow: 


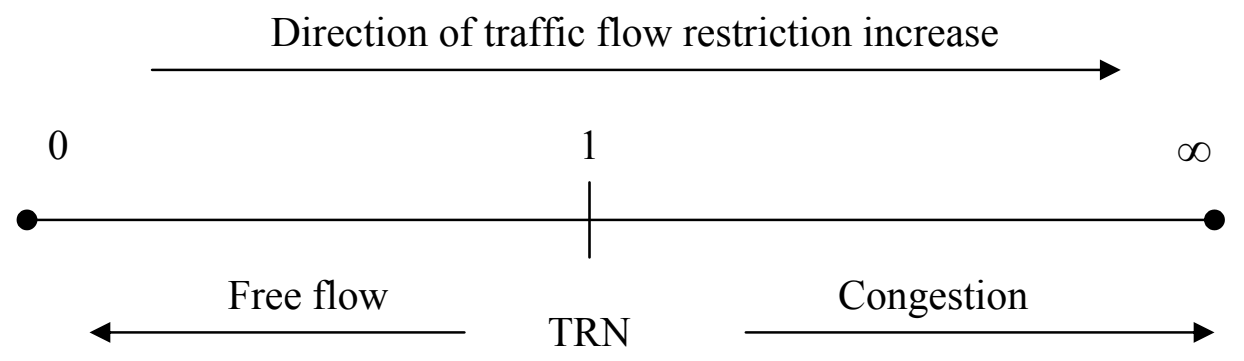

Figure 3-21 illustrates the TRN concept for the data collected during the sensors calibration tests of March 2005. The figure shows the TRN values for the data collected at the center lane of the west bound flow. As shown in the figure, congestion occurred between 10:00 AM and 11:00 AM, where the severity of the congestion reached up to 8.6 times worse than the case of speed-limit-flow (i.e. traffic is moving at about $6.4 \mathrm{mi} / \mathrm{h}$ ). On the other hand, traffic was flowing normally near the speed limit value during the period of 2:30 PM to 3:30 PM (14:30 to 15:30) (TRN between 0.89 and 1.3).

Unless stated otherwise, the travel times estimated in this Borman Expressway study will be based on time-stamped speeds measured by the WAVETRONIX ${ }^{\mathrm{TM}}$ microwave traffic sensors for a road link of 0.3 miles downstream from the sensors and for an estimated shockwave speed of $12 \mathrm{mi} /$ hour. 


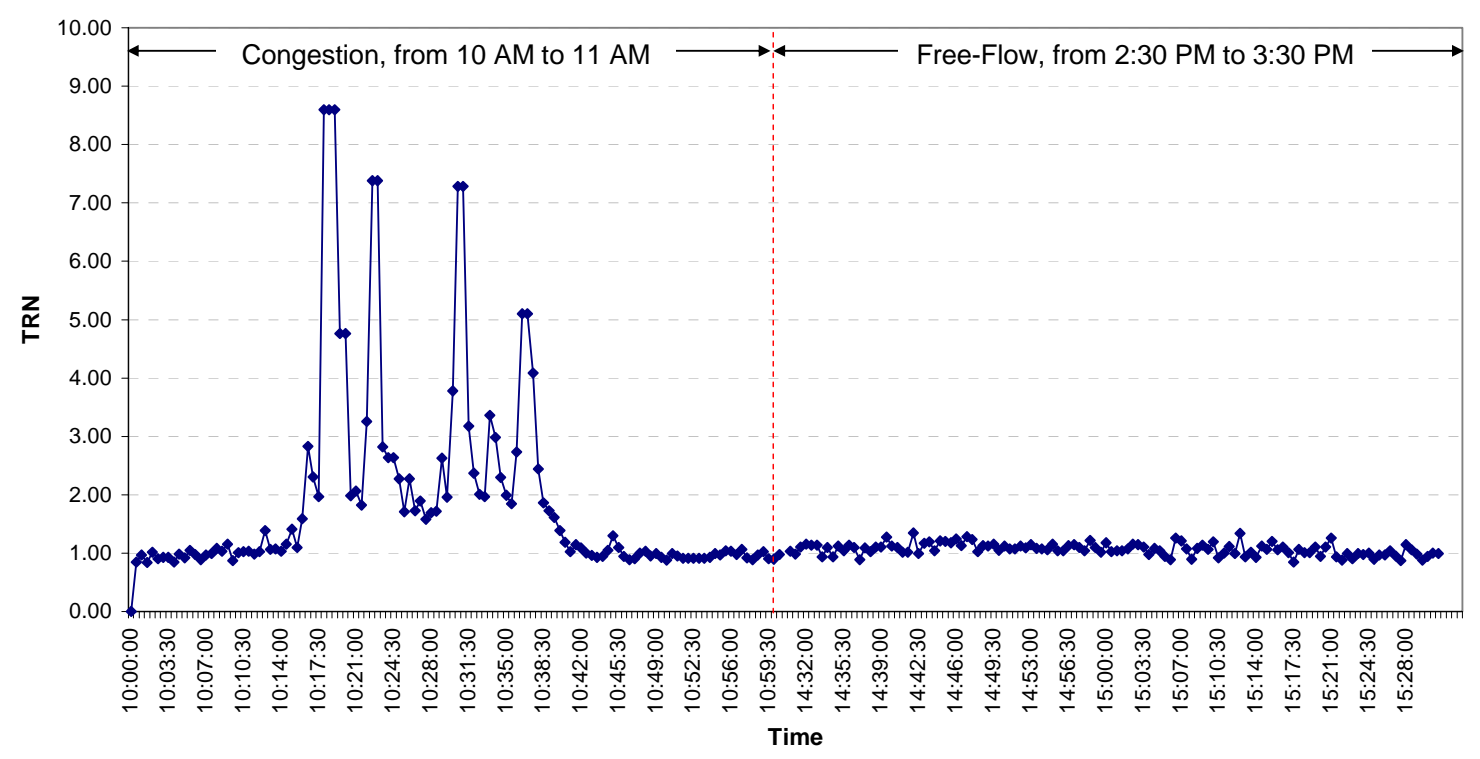

Figure 3-21. Normalized travel time (TRN) as a function of time during congestion and free flow for the west bound central lane of the Borman Expressway, March 15, 2005.

\subsection{Borman Traffic-Characteristics:}

This section of the study discusses the different traffic parameters collected by the microwave sensors as well as the general characteristics of both bounds of the Borman Expressway. The main parameters collected by the traffic sensors are: traffic volume (or traffic-flow) [vehicle/time], occupancy [\%], time-mean-speed [mi/hour]. These parameters are used to calculate other traffic factors that are needed in the traffic-airpollution analysis, such as travel-time [minutes], space-mean-speeds [mi/hour], traffic density [vehicle/mi], and acceleration $\left[\mathrm{mi} / \mathrm{h}^{2}\right]$. The units of these parameters may be converted to metric-units later on in the analysis whenever needed.

Traffic flow is divided into three categories; free flow, synchronized flow, and traffic jam (Kerner, et. al, 2004, and Lubashevsky, et al, 2002), as shown in the following diagram: 


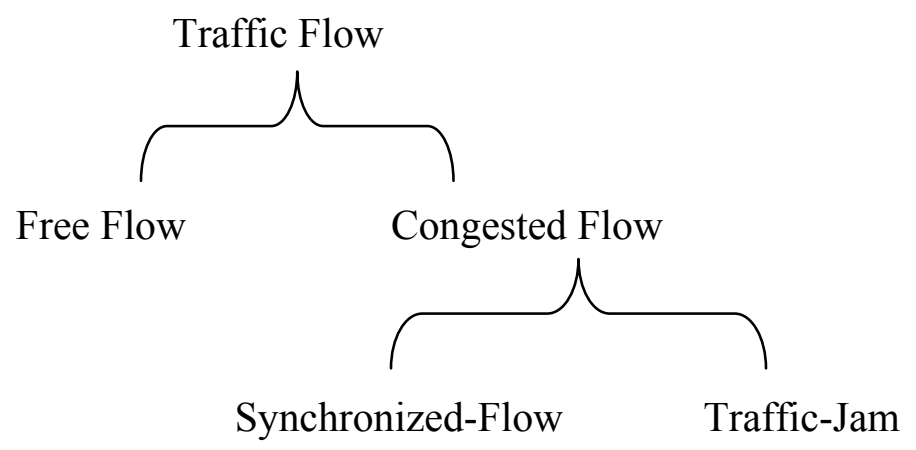

Free traffic flow occurs when vehicles are moving "freely" on the highway, i.e. there is no interaction between the vehicles on the road. This condition is analogues to compressible-fluid (gas) molecules in a pipe at low pressures. Vehicles at this stage usually move at the speed limit or even more in some cases. Such condition occurs at low traffic densities and occupancy. Congested flow, on the other hand, occurs at higher traffic densities when, at this stage, vehicles interact with each other and are forced to follow the stream-speed of the road. This condition is similar to gas molecules turning to non-compressible-fluid (liquid) moving in a pipe. The congested flow is divided into: synchronized flow; where vehicles are not able to pass due to the high density compared to free-flow. Traffic jam on the other hand describes a complete break-down in the traffic flow, where vehicles significantly slow down or stop (Kerner et. al, 1997).

\subsubsection{Borman East-Bound vs. West-Bound:}

The Borman Expressway (I-80/94) is a critical highway connecting east and west of the northern portion of the USA. The west bound portion of the expressway leads to the City of Chicago IL, while the east bound leads away from it to the east. Hence it is expected that traffic congestions would occur more frequently on the west bound than the east bound. Such hypothesis is supported by looking at the speed-frequency distribution 
of figures 3-22 through 3-25. On the following graphs, SPD will refer to the average speed measured on the Borman Expressway [mi/h].
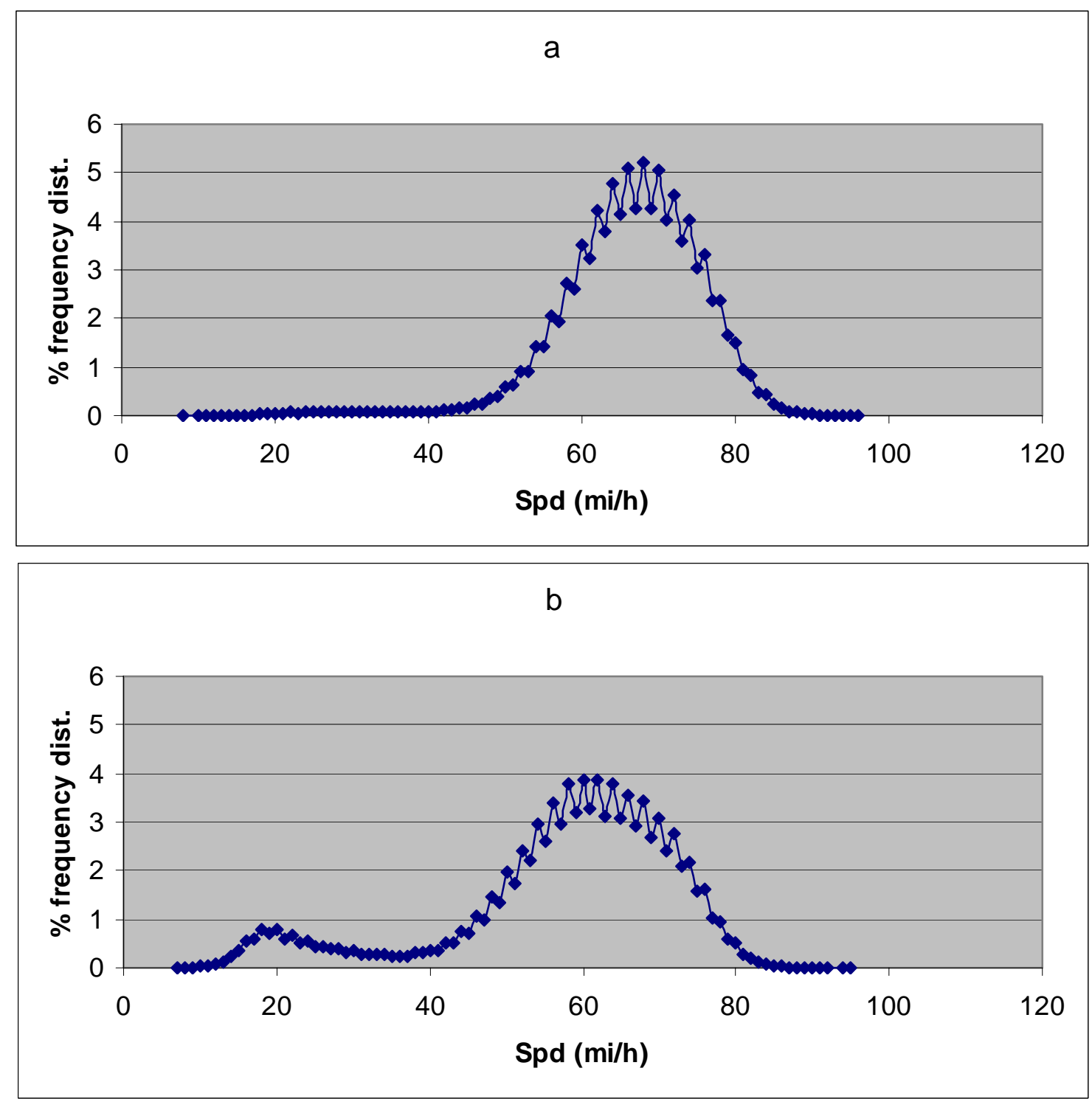

Figure 3-22. \% frequency distribution of speed on the Borman Expressway. (a) East Bound away from Chicago, (b) West bound towards Chicago, November 2004. 

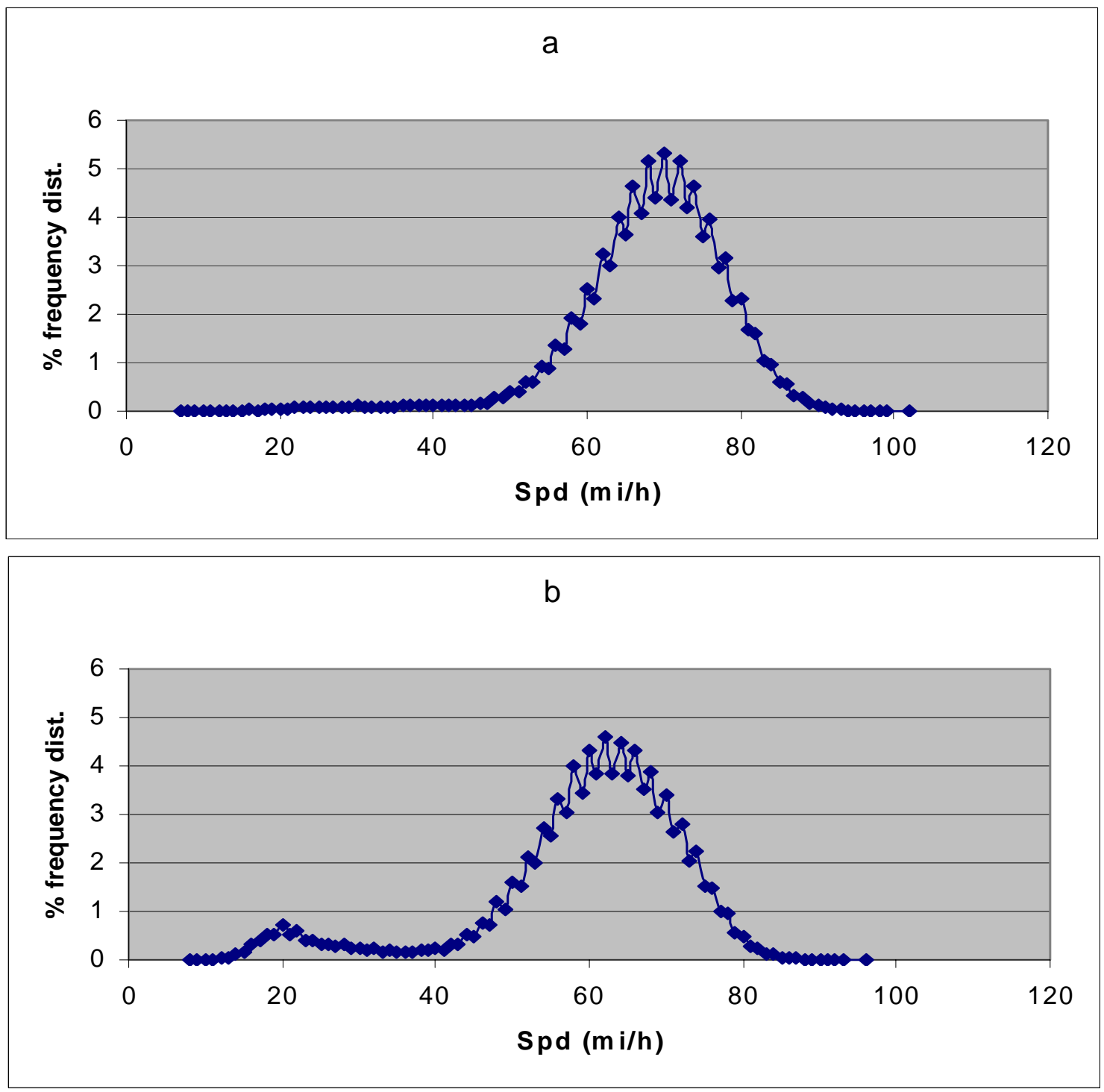

Figure 3-23. \%frequency distribution of speed on the Borman Expressway. (a) East Bound, (b) West bound, December 2004. 

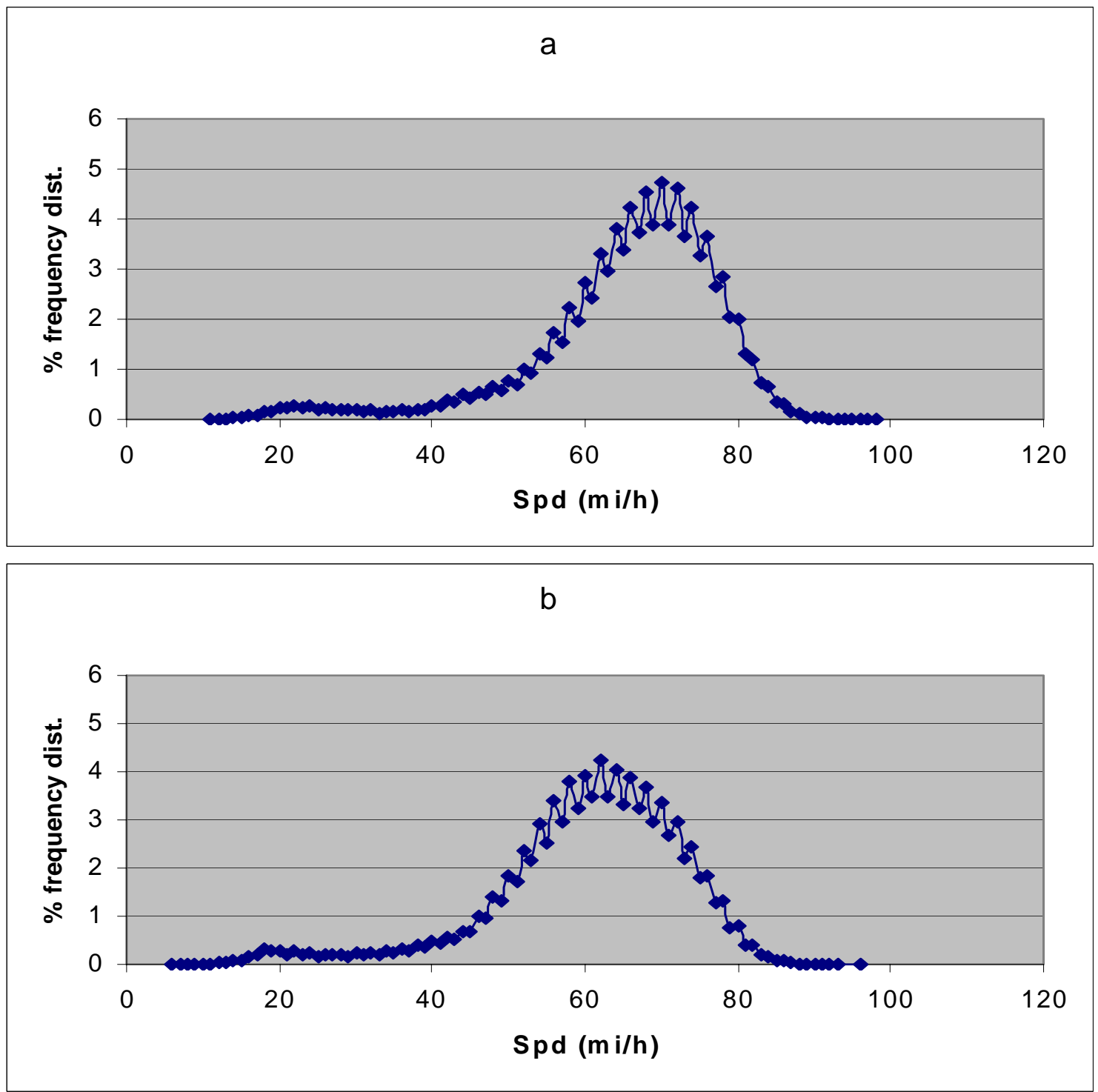

Figure 3-24. \%frequency distribution of speed on the Borman Expressway. (a) East Bound, (b) West bound, January 2005. 

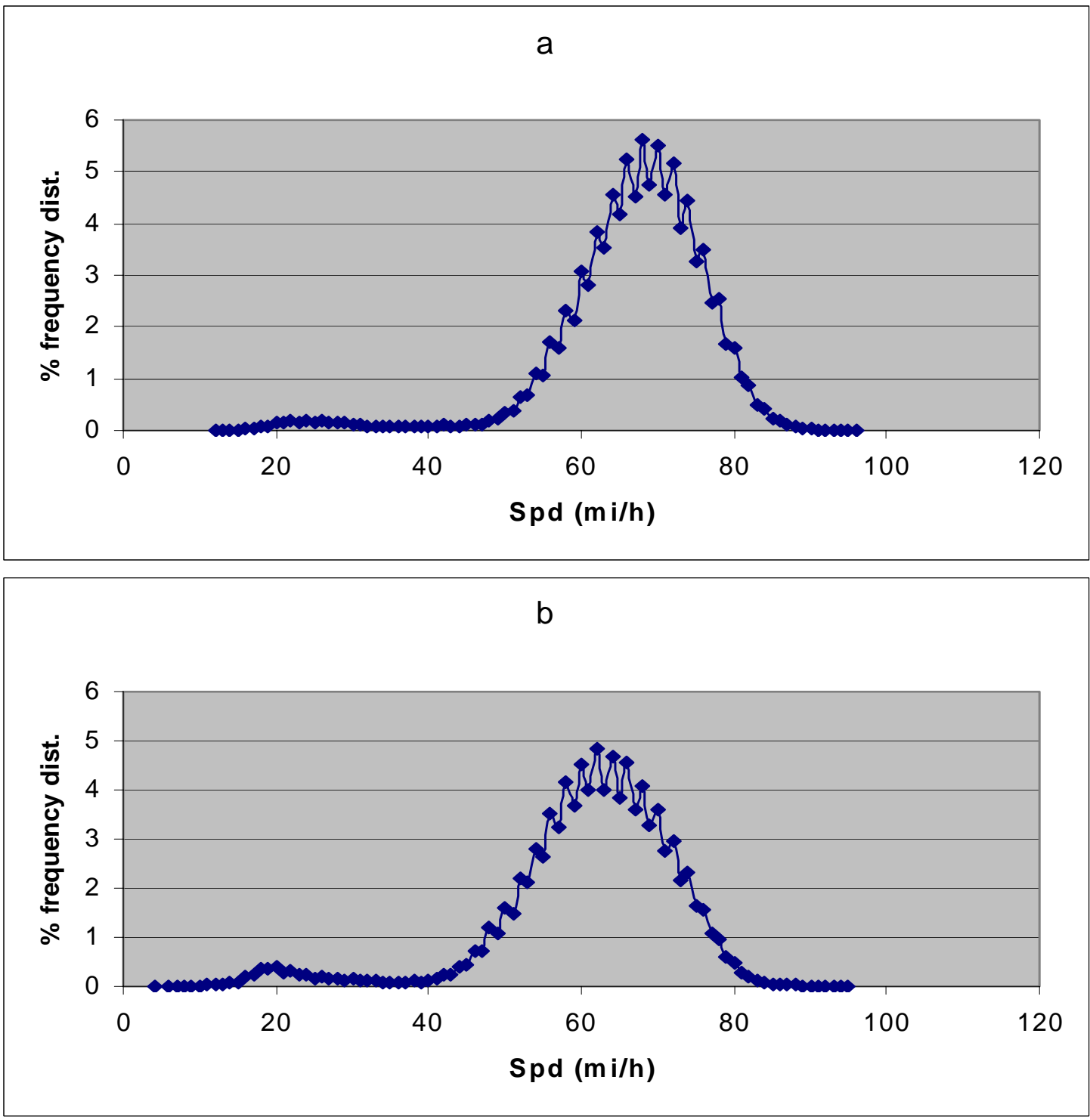

Figure 3-25. \%frequency distribution of speed on the Borman Expressway. (a) East Bound, (b) West bound, February 2005. 
Figures 3-22 and 3-23 show that the east bound has higher frequency distribution at high speeds (around $70 \mathrm{mi} / \mathrm{h}$ ), more than the west bound (around $60 \mathrm{mi} / \mathrm{h}$ ) for November, and December 2004. Also, there is another peak appearing on the west bound at low speeds of around $20 \mathrm{mi} / \mathrm{h}$, indicating more congested conditions on the west bound. January and February of 2005, on the other hand, showed the same frequency distribution at high speeds of the east and west bounds (around 70, and $60 \mathrm{mi} / \mathrm{h}$, respectively). However, the $20 \mathrm{mi} / \mathrm{h}$ peak started to appear on the east bound and disappear on the west bound.

This change could be attributed to construction on the east bound at mile marker 9.0, or may have been due to the implementation of the new Illinois-Tollway policy of increasing the toll on I-294 (around 3 miles west of the IN/IL border) by $100 \%$ for peak hours (8:00 AM to 8:00 PM) starting January $1^{\text {st }}, 2005$. Table 3-1 shows the $\%$ of trucks to total vehicles for the individual months starting November 2004 to February 2005.

Table 3-1. \% of trucks to total vehicles on the Borman Expressway.

\begin{tabular}{|c|c|c|}
\hline Month & East & West \\
\hline Nov & 40 & 30 \\
\hline Dec & 48 & 29 \\
\hline Jan & 48 & 30 \\
\hline Feb & 49 & 28 \\
\hline
\end{tabular}

Table 3-1, however, does not show major changes in the fleet mixes for both east and west bounds from November 2004 to February 2005. A detailed analysis was performed by investigating the vehicles speed distributions for day and night periods, 8:00 AM to 8:00 PM and 8:00 PM to 8:00 AM, respectively. 
Figures 3-26 to 3-29 show the frequency distribution of speeds for both the east and west bounds for day and night periods. Similar observations can be seen in the graphs showing the difference between night and day as well as between the east and west bounds. However, table 3-2 also shows no major change in the fleet mixes between day and night over the period of November 2004 to January 2005 and hence the change of the $20 \mathrm{mi} / \mathrm{h}$ peaks can not be attributed to the change of the fleet mix due to the IL-Tollway policy implemented on January $1^{\text {st }}$, 2005. Further analysis is needed though, to understand the reason behind the appearance of the $20 \mathrm{mi} / \mathrm{h}$ peak on the east bound and its decrease in size on the west bound starting January 2005. However, such analysis is beyond the scope of this phase of the project.
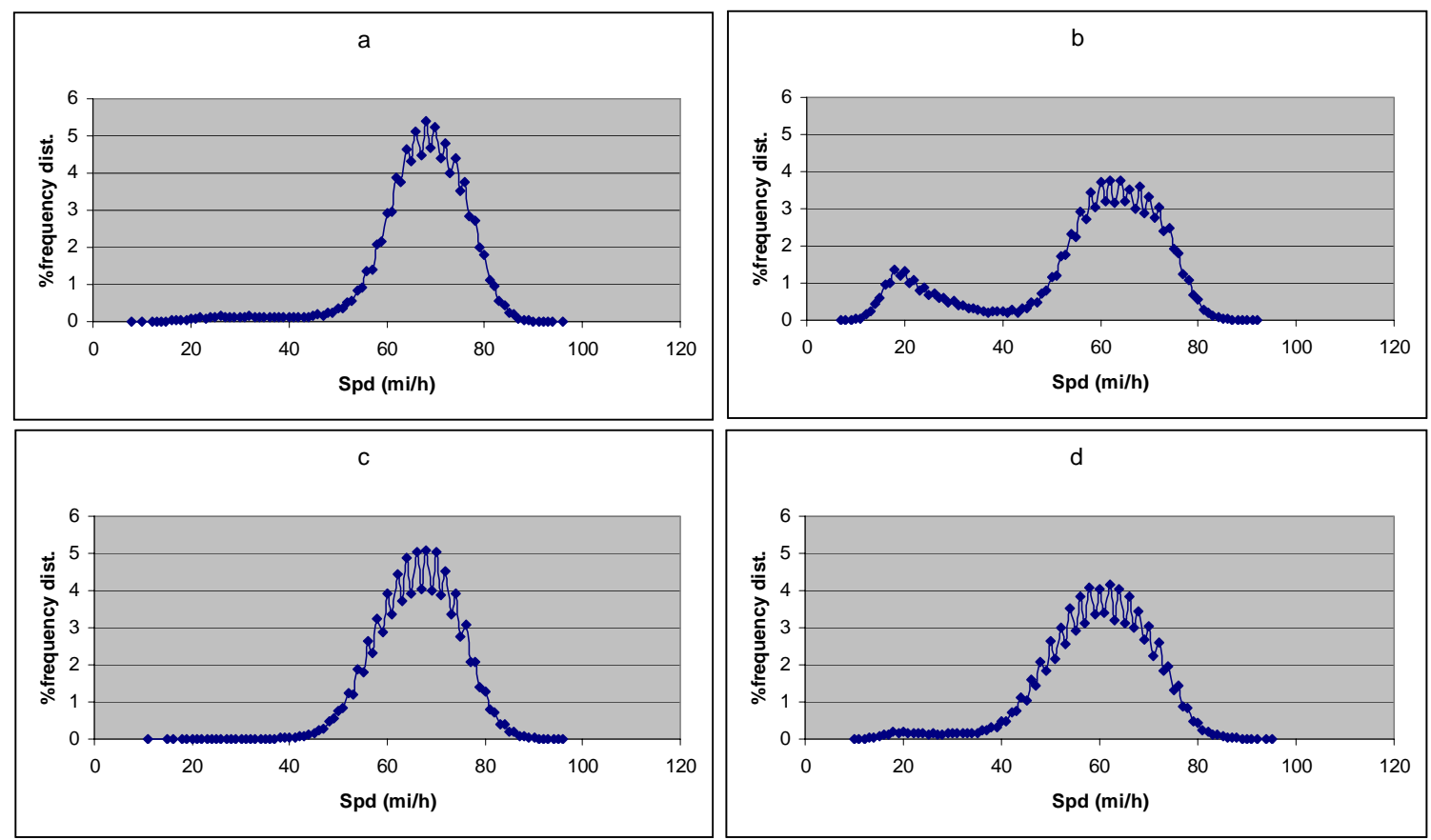

Figure 3-26. \%frequency distribution of speed on the Borman Expressway. (a) East bound-day, (b) West bound-day, (c) East bound-night, (d) West bound-night, November 2004. Day is between 8:00 AM to 8:00 PM, and night is between 8:00 PM to 8:00 AM. 

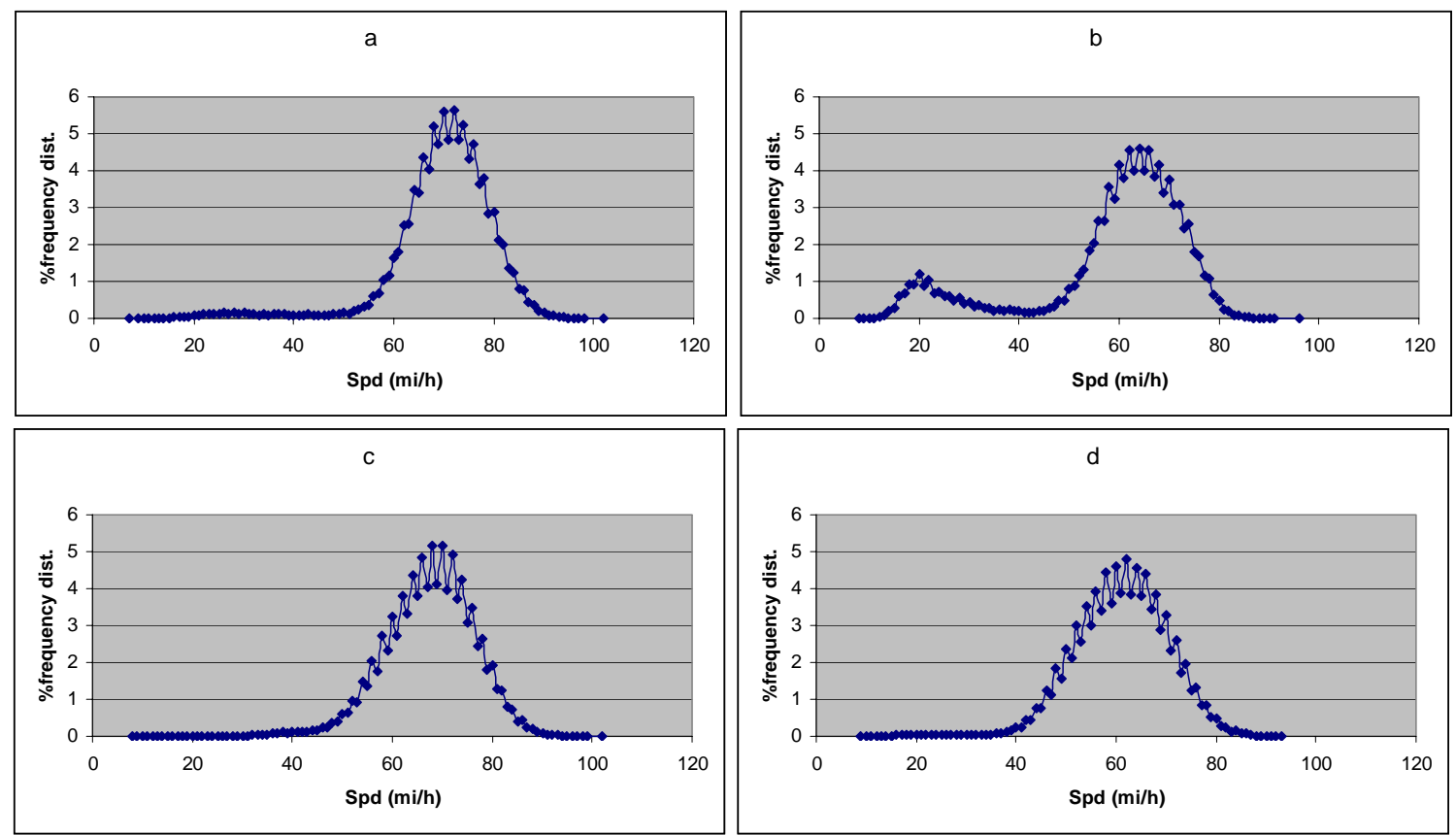

Figure 3-27. \%frequency distribution of speed on the Borman Expressway. (a) East bound-day, (b) West bound-day, (c) East bound-night, (d) West bound-night, December 2004. Day is between 8:00 AM to 8:00 PM, and night is between 8:00 PM to 8:00 AM.
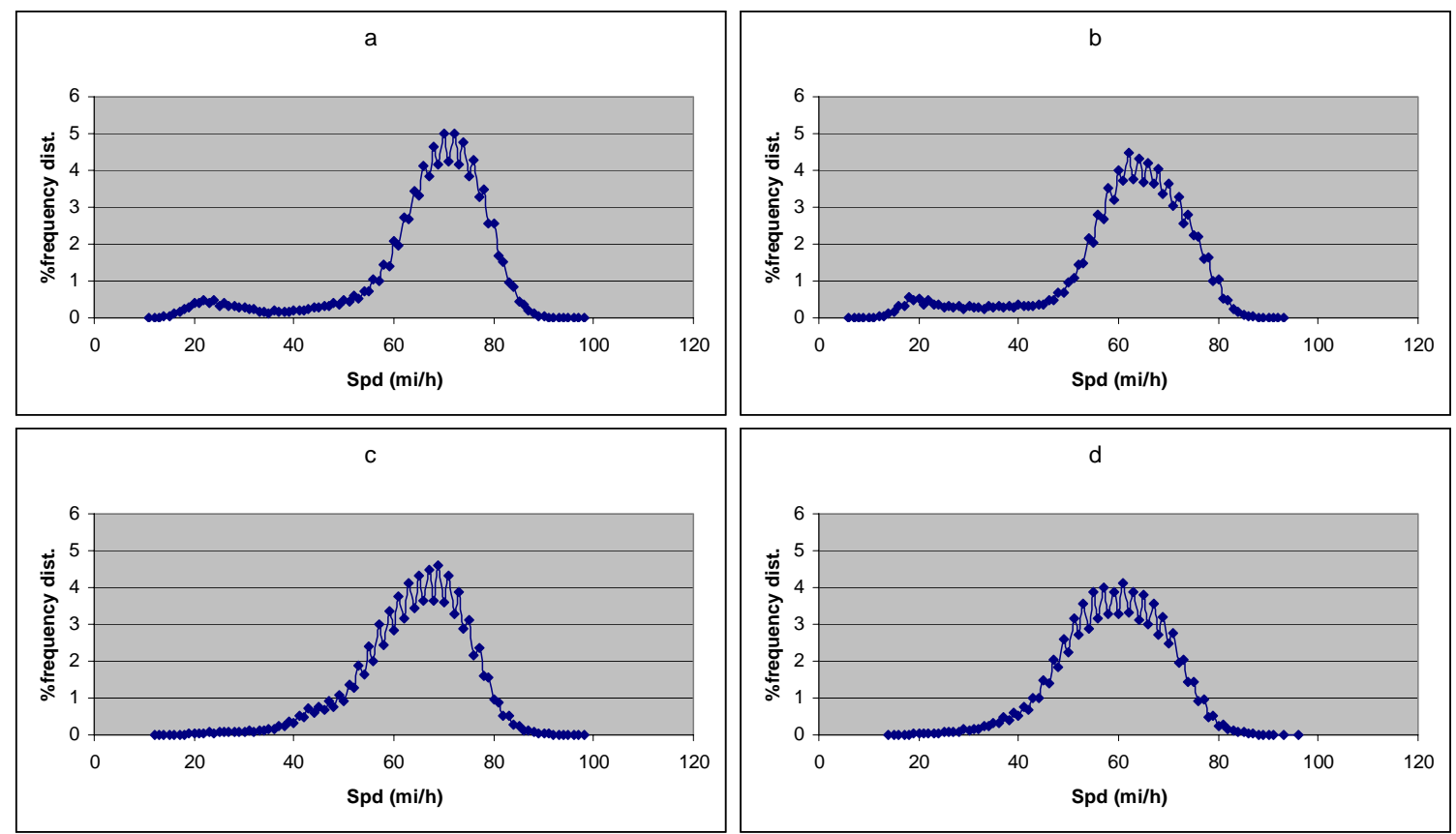

Figure 3-28. \%frequency distribution of speed on the Borman Expressway. (a) East bound-day, (b) West bound-day, (c) East bound-night, (d) West bound-night, January 2005. Day is between 8:00 AM to 8:00 PM, and night is between 8:00 PM to 8:00 AM. 

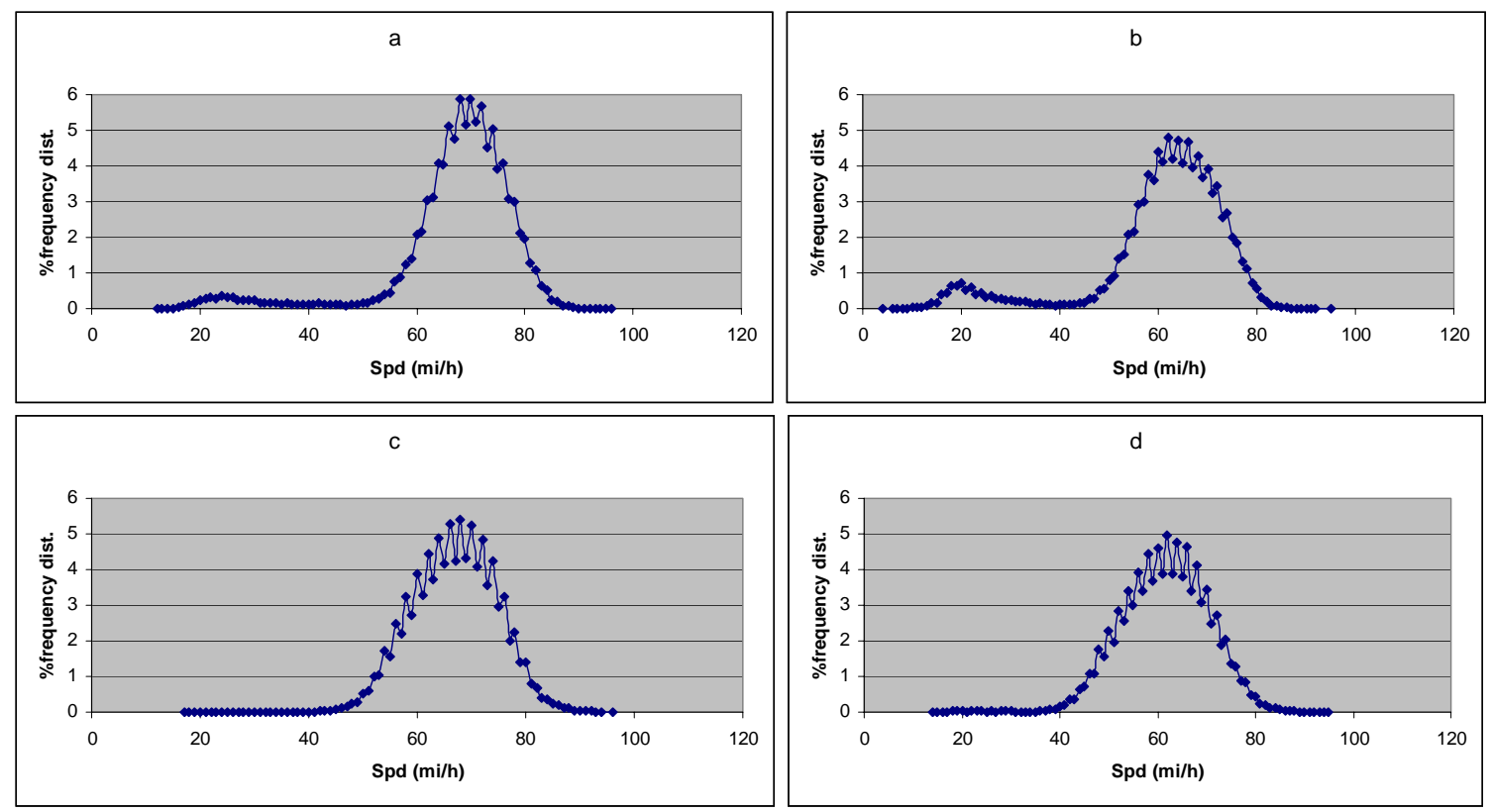

Figure 3-29. \%frequency distribution of speed on the Borman Expressway. (a) East bound-day, (b) West bound-day, (c) East bound-night, (d) West bound-night, February 2005. Day is between 8:00 AM to 8:00 PM, and night is between 8:00 PM to 8:00 AM.

Table 3-2. \% of trucks to total vehicles, for day and night on the Borman Expressway.

\begin{tabular}{|c|c|c|c|c|}
\hline Month & morning-E & Night-E & morning-W & Night-W \\
\hline Nov & 36 & 44 & 28 & 32 \\
\hline Dec & 44 & 51 & 27 & 30 \\
\hline Jan & 44 & 51 & 28 & 32 \\
\hline Feb & 45 & 53 & 27 & 30 \\
\hline
\end{tabular}

\subsubsection{Borman Traffic Characteristics:}

The average speed for a multilane highway is calculated by the following relation:

$$
S P D=\frac{\sum_{i=1}^{n} Q_{i} \times V_{i}}{\sum_{i=1}^{n} Q_{i}}
$$

Where "SPD" is the average speed of the highway (both east and west bounds), "Q" $\mathrm{Q}_{i}$ " is the traffic volume moving at speed " $\mathrm{V}_{\mathrm{i}}$ ", and " $\mathrm{n}$ " is the number of lanes of the highway. 
The last expression (equation 3-4) is generalized to:

$$
Y=\frac{\sum_{i=1}^{n} Q_{i} \times y_{i}}{\sum_{i=1}^{n} Q_{i}}
$$

Where "Y" is the average traffic parameter of the highway (both east and west bounds), " $\mathrm{Q}_{\mathrm{i}}$ " is the traffic volume moving at traffic parameter " $\mathrm{y}_{\mathrm{i}}$ ", and " $\mathrm{n}$ " is the number of lanes of the highway. "Y" can be speed (equation 3-4), acceleration, occupancy, or normalizedtravel-time.

To further test the traffic sensors and hence the validity of the traffic data, the fundamental diagrams such as the traffic-flow versus traffic-density were analyzed to check if they match the common ones reported in literature and traffic text books (e.g. Garber et. al, 2002). A sample of the data is presented here since all of the data have shown similar characteristics.

Figure 3-30 shows the fundamental diagram of the traffic flow-density relation for the month of February 2005. The figure shows that the flow density relation can be easily characterized in the free flow region, where it follows a quadratic relation of high correlation coefficient $\left(\mathrm{R}^{2}=0.9984\right)$ in agreement with the Greenshields model (Garber et. al, 2002). However, due to its complexity, the widely scattered states of the synchronized flow (congestion-region) require more sophisticated probabilistic models to describe it (Kerner et. al, 2004, and Helbing et. al, 2002). The overall Borman Expressway "capacity" can also be estimated from the graph, which is about 26 vehicles/10-seconds, 9360 vehicles/hour, or 1560 vehicles/hour/lane. 


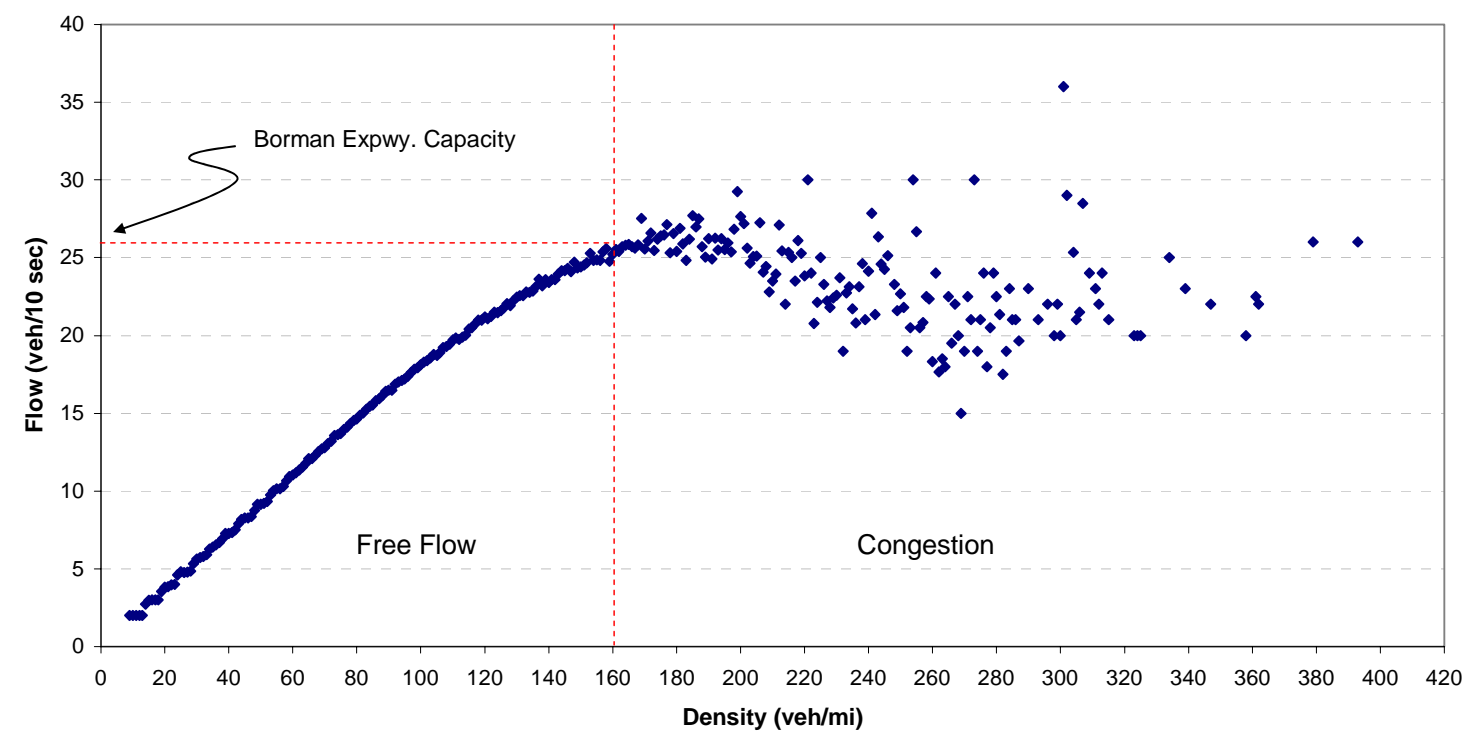

Figure 3-30. The flow-density relation of the Borman Expressway, February 2005.

Flow has also been plotted against the overall average occupancy of the Borman in order to identify the critical occupancy that separates the free flow from the congested flow on the highway. Figure 3-31 shows such relation with a critical occupancy value of $21 \%$ in agreement with results obtained by Schneider IV, 2003. The critical occupancy value is important in determining the vehicles acceleration on the Borman Expressway. Since the WAVETRONIX ${ }^{\mathrm{TM}}$ sensors are limited to only measuring speeds, the acceleration is then calculated by estimating the change in the measured speeds. However, during free flow, where there is no interaction between vehicles, there is no guarantee that the change of speed at time " $t$ " at the sensors point-location is due to the change in speed of vehicles " $\mathrm{x}$ " miles downstream from the sensor. Therefore, to insure an interaction between the vehicles, acceleration and deceleration is estimated only during the congestion periods, i.e. for traffic data above the critical occupancy value of $21 \%$. 


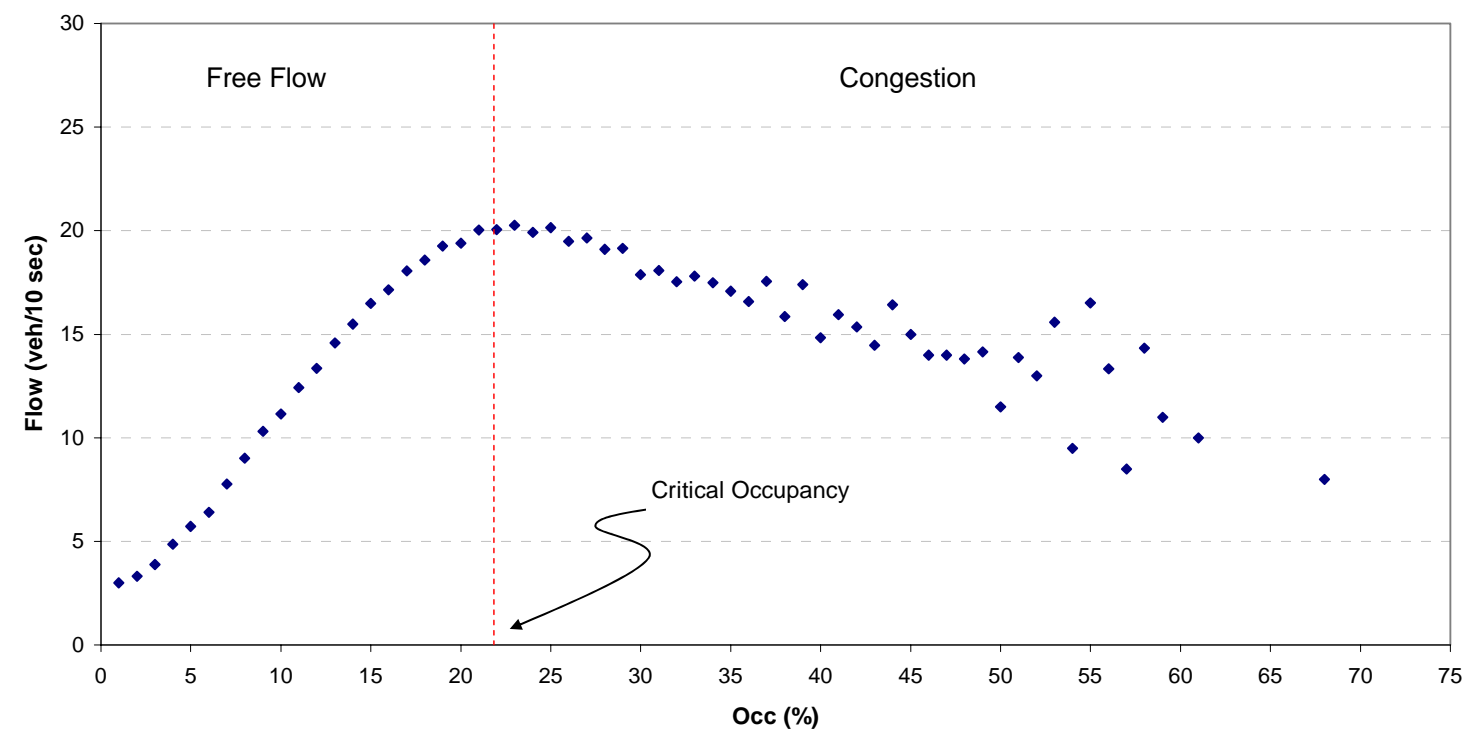

Figure 3-31. The flow-Occupancy relation of the Borman Expressway, February 2005.

The frequency distribution of the acceleration measured at the Borman Expressway has also shown agreement with what is reported in literature. Figure 3-32 shows the $\%$ frequency distribution estimated for the Borman Expressway for occupancies greater than $20 \%$. The figure shows that the distribution followed a positively-skewed Gaussian distribution similar to the findings on other highways.

With regards to the overall level of service on the Borman Expressway, figure 333 shows a significant increase in the normalized travel time on the expressway (and hence the travel time) for occupancies greater than the critical occupancy of $21 \%$.

In summary, the previous analysis has shown the validity of the collected traffic data of the Borman Expressway as well as the characteristics of these data. The collected traffic parameters such as time-mean-speed, occupancy, traffic volume and traffic mix, as well as the calculated traffic parameters such as space-mean-speed, travel times, traffic 
density, and acceleration will be used later on in the next two chapters to develop the traffic-air-quality model.

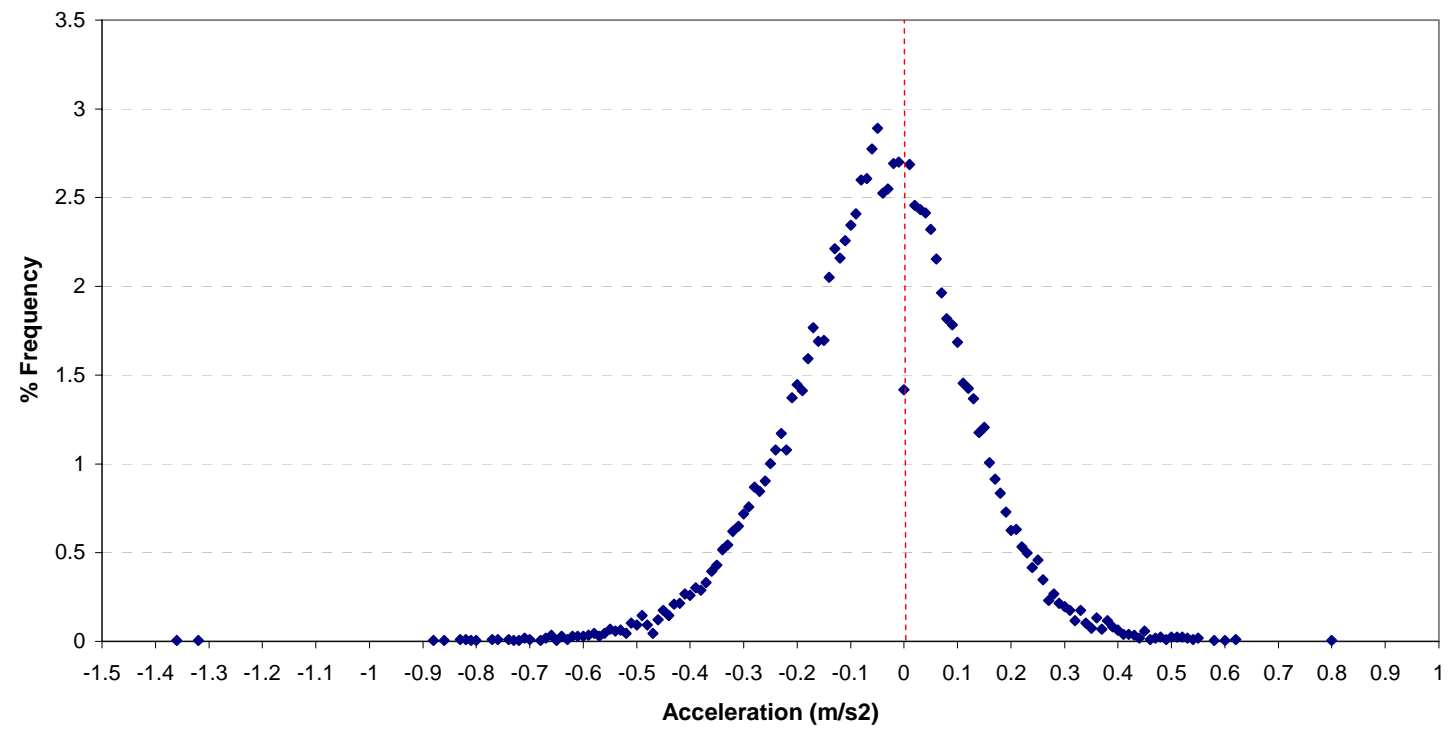

Figure 3-32. Acceleration frequency distribution of the Borman Expressway, for occupancy greater than 20\%. February 2005.

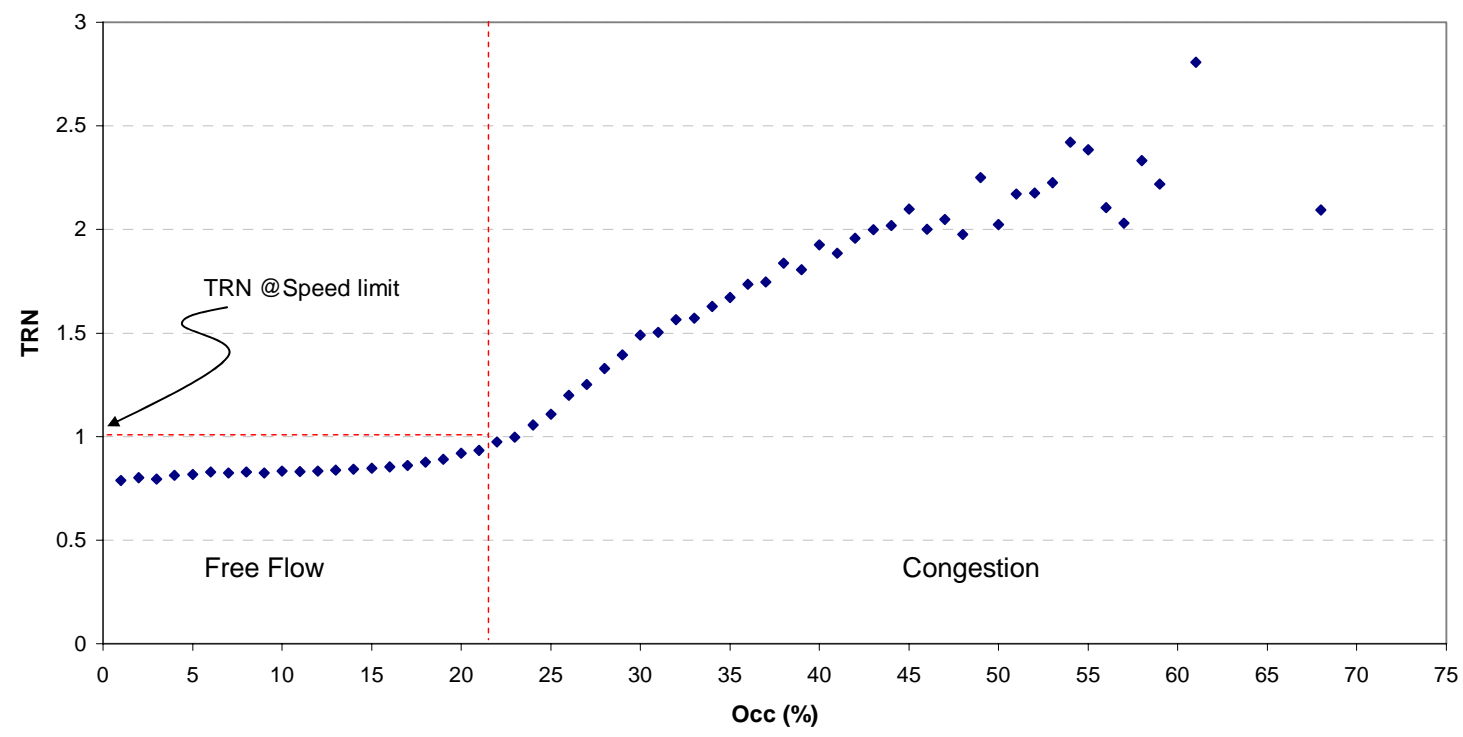

Figure 3-33. Normalized travel time (TRN) as a function of the overall Borman Expressway occupancy, February 2005. 


\section{CHAPTER FOUR}

\section{TRAFFIC-AIR QUALITY REGRESSION ANALYSIS}

\subsection{Introduction:}

Mobile sources are major contributors to air pollution in urban areas, therefore, it is important to characterize and quantify the impact of traffic on air quality. Such characterization can be done by analyzing the change in pollutant concentration as a function of the different traffic conditions. Pollutant concentration by itself, however, may give an unreliable indication of the emission-strength of the source. This is due to the fact that pollutant concentration is inversely proportional to wind speed; hence, a low concentration value might be due to either a small pollutant-emitter, or high-velocity winds. Pollutant-flux, on the other hand, is a pollutant concentration normalized with respect to wind speed, as shown in equation 4-1:

$$
F L U X=C \times U
$$

Where "FLUX" is the pollutant-flux, "C" is the pollutant concentration and " $U$ " is the wind speed. Although the pollutant-flux is a quantity that is proportional to the emitterstrength, it is more common to use "emission-factors" to give a detailed information on the emitter-strength. Emission factors can be expressed as the amount of pollutant-mass emitted per vehicle, per distance traveled, per volume of fuel consumption or per vehicledistance traveled. 
Several techniques have been used to empirically estimate the emission factors for vehicles, both the Light-Duty-Vehicles (LDV) and the Heavy-Duty-Vehicles (HDV). One of such techniques is the dynamometer-laboratory-tests which are performed by measuring emissions directly from the individual vehicles or mobile source exhaustsystem under different engine loads and temperatures as well as for the different fuel mixes (Tsai et. al, 2000, Durbin et. al, 2002, and Ubanwa et. al, 2003). However, since individual vehicles may have diverse emission profiles, they can not be fully representative of the whole fleet, therefore, such technique does not fully simulate the "real-world" driving condition and the emission factors may not completely reflect real emissions on the road.

To obtain a more comprehensive view of the real-world emission factors, a study of the emission factors of the whole fleet under "real" driving conditions needs to be performed. Such studies are normally performed in urban areas and emission factors can be obtained using three ways: 1) tunnel measurements (e.g. Kristensson et. al, 2004), 2) inverse-dispersion modeling of streets (Gramotnev et. al, 2003) and street canyons (e.g. Ketzel, et. al, 2003), and 3) mass conservation-box model of open road measurements (e.g. Jamriska et. al, 2001).

Kristensson et. al. (2004) studied the emission factors from road-tunnel measurements in Stockholm, Sweden. The fleet mix passing through the tunnel was divided into two categories, Light-Duty-Vehicles (LDV) which constituted $95 \%$ of the fleet and Heavy-Duty-Vehicles (HDV) which was $5 \%$ of the whole fleet. The study was performed for the period of December 1998 to February 1999 using two monitoring stations located inside the tunnel (1.5 km long), 595 meters apart. The study measured 
several traffic-related pollutants such as $\mathrm{CO}, \mathrm{NO}_{\mathrm{x}}$, Polycyclic Aromatic Hydrocarbons (PAH), and particulates $\left(\mathrm{PM}_{10}\right.$, and $\left.\mathrm{PM}_{2.5}\right)$. The study found that, on average, emission factors of $\mathrm{PM}_{10}$ and $\mathrm{PM}_{2.5}$ were $67 \pm 4 \mathrm{mg} / \mathrm{km}$ and $236 \pm 12 \mathrm{mg} / \mathrm{km}(0.112 \pm 0.006 \mathrm{~g} / \mathrm{mi}$, and $0.393 \pm 0.020 \mathrm{~g} / \mathrm{mi}$ ), respectively. Furthermore, the study found that PAH emission factors were 2 to 25 times higher than predicted by the dynamometer studies.

Inverse dispersion modeling has also been used to estimate the emission factors. Gramotnev et. al. used such an approach in a study done in Australia in 2003. The study used the EPA model CALINE4 to estimate the emission factors of fine particulates on an urban road by using the following steps: First, fine particulates and meteorological data were measured on the side of the road at different distances from the highway, while simultaneously measuring traffic parameters, such as traffic volume and speeds. Secondly, all the meteorological and traffic data were input to the CALINE4 model along with arbitrary emission factors to estimate the fine particulates concentration at the given distances. The input emission factors $\left(\mathrm{E}_{\mathrm{c}}\right)$ are then changed to adjust the CALINE4 output concentration to closely match the measured values. Thirdly, $E_{c}$ is fed into the CALINE4 model to estimate the concentration at different heights and at a known distance from the road. Finally, the pollutant flux $\left(F_{c}\right)$ is calculated using the concentration profile estimated by CALINE4 (using $\mathrm{E}_{\mathrm{c}}$ ) and compared to the measured pollutant flux $\left(\mathrm{F}_{\mathrm{m}}\right)$ from which an average emission factor $\mathrm{E}$ is calculated along with a coefficient $\eta=E c / E$ which a "correction-coefficient" for the CALINE4 model input (Gramotnev et. al, 2003).

Unlike tunnel studies, where the pollutant mixing volume may be estimated to be the same turbulent air volume of the tunnel caused by the vehicle movement (also known 
as the piston-effect (Bellasio, 1997)); open-street empirical emission factor estimation encounters the difficulty of estimating the turbulent mixing volume of the pollutants on the side of the road. A common solution is to assume a constant box volume, where the pollutants are well-mixed (Jamriska, et. al, 2001).

Other means of estimating the real-world emission factors include direct measurements of the tail-pipe emissions either by using remote-sensing techniques such as open path Fourier Transform Infrared Spectroscopy (FTIR), (Premo, 1998, and Chan et. al, 2004) or using on-board instruments to measure emissions (Veurman et. al, 2002).

\subsection{Borman Emission Factor Analysis:}

The purpose of the Borman Expressway project is to quantify and characterize the effect of traffic along the expressway on the local air quality adjacent to the road. Such characterization is done by analytically building a model to estimate the $\mathrm{PM}_{2.5}$ emission factors (mass of pollutant per unit length, g/mi) for the Borman Expressway under the different driving conditions. Such emission factors will indicate the pollution emissionstrength of a unit length of a road link on the expressway. The higher the emission factor the worse the expected air quality level adjacent to the road.

Traffic and air quality data have been collected simultaneously on both sides of the expressway for the period of November 2004 to February 2005 as mentioned in chapters two and three. The data collected were 10-second-integrated values of wind speed and direction, air quality data such as $\mathrm{PM}_{2.5}$ concentrations, as well as traffic data such as time-mean-speeds, occupancy, and traffic volume for each individual lane. The procedure of producing the empirical model to estimate the Borman emission factors is outlined as follows: 
1- The 10-second-integrated travel time " $\mathrm{t}$ " (measured in hours $[\mathrm{h}]$ ) is calculated for each lane using Coifman's algorithm (Coifman, 2002).

2- Travel times are used to calculate 10-second-integrated space-mean-speeds " $\mathrm{V}_{\mathrm{s}}$ " $(\mathrm{mi} / \mathrm{h})$ for each lane for a link distance of 0.3 miles downstream from the detectors, $\mathrm{v}_{\mathrm{s}}=0.3 / \mathrm{t}$.

3- 10-second-integrated traffic density "k" (vehicle/mi, or veh/mi) is calculated from the space mean speed values " $\mathrm{v}_{\mathrm{s}}$ " and the measured traffic volume " $\mathrm{q}$ ", $\mathrm{k}=\mathrm{q} / \mathrm{v}_{\mathrm{s}}$.

4- Time-stamped truck volume " $\mathrm{q}_{\mathrm{T}}$ " and densities " $\mathrm{k}_{\mathrm{T}}$ " are calculated using the fleet mix ratios measured by the traffic detectors.

5- Traffic data are then joined to the air quality and the meteorological data in the system's database.

6- $\mathrm{PM}_{2.5}$ emission factors are calculated on two levels; the microscopic, and the macroscopic levels:

a- The microscopic emission factor " $\mathrm{E}_{1}$ " is defined as the pollutant mass emitted per vehicle ( $\mathrm{g} / \mathrm{vehicle})$ and is given by:

$$
E_{1}=\frac{C \times U}{q_{T}} \times V^{2 / 3}
$$

Where, "C" is the $\mathrm{PM}_{2.5}$ concentration $\left[\mathrm{g} / \mathrm{m}^{3}\right]$, " $\mathrm{U}$ " is the wind speed $[\mathrm{m} / \mathrm{h}]$, " $\mathrm{q}_{\mathrm{T}}$ " is the truck volume $[\mathrm{veh} / \mathrm{h}]$, and $\mathrm{V}$ is the turbulent mixing volume $\left[\mathrm{m}^{3}\right]$ caused by traffic moving on the road. Note that the turbulent mixing volume at this stage of the analysis is assumed to be a box with a constant volume (Jamriska et. al, 2001). The dimensions of the box are assumed to be, the width of the mixing zone (width of the road, 3.65 meters/lane, 3 
lanes on each bound), a constant turbulent mixing height of an estimated value of 8.4 meters (Jamriska et. al, 2001), and finally a length equal to the portion of the expressway exposed to the air quality monitors which is 160 meters that covers the $120^{\circ}$ wind sectors used in the analysis, $300^{\circ}$ to $60^{\circ}$ for the PU-Hessville site, and $120^{\circ}$ to $240^{\circ}$ for the PU-Kennedy site. The total constant volume is then $\mathrm{V}=160 \times 21.95 \times 8.4=29500.8 \approx 29501 \mathrm{~m}^{3}$. Note, only the normal components of the wind speeds are used in the analysis, i.e. each wind direction is put in its components, the normal component (normal to the Borman expressway) and the parallel component (parallel to the expressway).

b- The macroscopic emission factor " $\mathrm{E}_{2}$ " is defined as the pollutant mass emitted per road-link-length $[\mathrm{g} / \mathrm{mi}]$ and is given by:

$$
E_{2}=E_{1} \times k_{T}
$$

Where $\mathrm{E}_{1}$ is the microscopic emission factor $[\mathrm{g} / \mathrm{veh}]$, and $\mathrm{k}_{\mathrm{T}}$ is truck density [veh/mi].

Equation 4-2 is used to calculate the microscopic emission factor $E_{1}$ from the measured concentration values. The microscopic emission factor $E_{1}$ is then regressed with respect to the average speed " $\mathrm{v}$ " $[\mathrm{mi} / \mathrm{h}]$ on the Borman expressway, as well as with respect to the average acceleration "a" $\left[\mathrm{m} / \mathrm{s}^{2}\right]$ in order to deduce the traffic-air-quality model $\left(\mathrm{E}_{1}(\mathrm{v}, \mathrm{a})\right)$. The regression analysis is commonly performed by grouping the measured values of $E_{1}$ and plotting them versus the average speed or acceleration (Ketzel, 2003). The macroscopic emission factor $E_{2}$ is then calculated according to equation (4-3). The macroscopic emission factor $\mathrm{E}_{2}$ can then be used to quantify the impact of traffic 
condition on local air quality. $E_{2}$ is then plotted versus average speeds on the road to show the effect of free flow and congestions on the air quality. It may also be plotted against the road condition defined by the road-average occupancy or normalized-traveltime. Data from February 2005 are used to develop the relations between the microscopic emission factor $E_{1}$ and speed as well as acceleration. The developed $E_{1}(v, a)$ model is then used to estimate the macroscopic emission factor $E_{2}$ and compared to the measured values of $E_{2}$ for the months November 2004 through January 2005. The units will be converted to the metric system (meters, grams, and seconds) wherever needed.

Figure 4-1 shows the measured values of $E_{1}$ as a function of average speed on the Borman Expressway for the month of February 2005. The speeds used in figure 4-1 analysis are for a constant velocity, $-0.01<$ acceleration $<0.01$. Such condition is needed in order to be able to combine the relation between $E_{1}$ and speed $\left(E_{1}(v)\right)$ with the relation between $E_{1}$ and acceleration $\left(E_{1}(a)\right)$ to produce $E_{1}(v, a)$ as will be shown later.

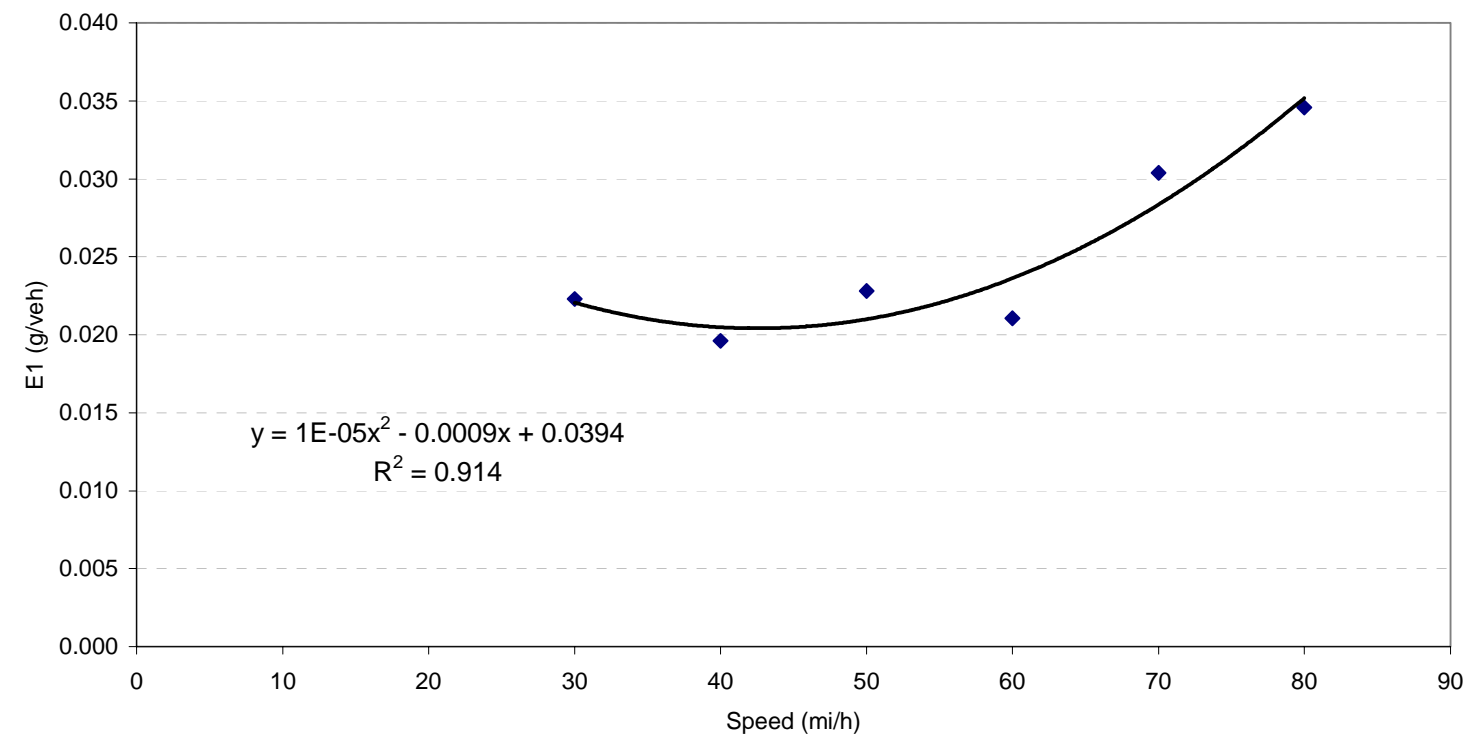

Figure 4-1. Microscopic emission factor $\mathrm{E}_{1}$ as a function of average speed for at a zero acceleration $(-0.01<\mathrm{a}<0.01)$. February 2005. 
Figure 4-1 shows a good relation between $E_{1}$ and the average speed $\left(R^{2}=0.914\right)$ and is given by equation 4-4:

$$
E_{1}=10^{-5} \times S P D^{2}-0.0009 \times S P D+0.0394
$$

Where " $\mathrm{E}_{1}$ " is the microscopic emission factor $[\mathrm{g} / \mathrm{veh}]$, and "SPD" is the average speed at constant acceleration $[\mathrm{mi} / \mathrm{h}]$. The average data points shown in figure 4-1 represent averages of data up to 1700 points per data-point indicating the robustness of the data used in the analysis.

The relation between $E_{1}$ and the average acceleration is shown in figure 4-2. Figure 4-2 shows a good relation between $E_{1}$ and the average acceleration $\left(R^{2}=0.955\right)$ and is given by equation 4-5:

$$
E_{1}=0.0213 \times A c c^{2}+0.008 \times A c c+0.0263
$$

Where " $\mathrm{E}_{1}$ " is the microscopic emission factor [g/veh], and "Acc" is the average acceleration $\left[\mathrm{m} / \mathrm{s}^{2}\right]$. The average data points shown in figure 4-2 represent averages of data up to 17000 points per data-point indicating the robustness of the data used in the analysis. 


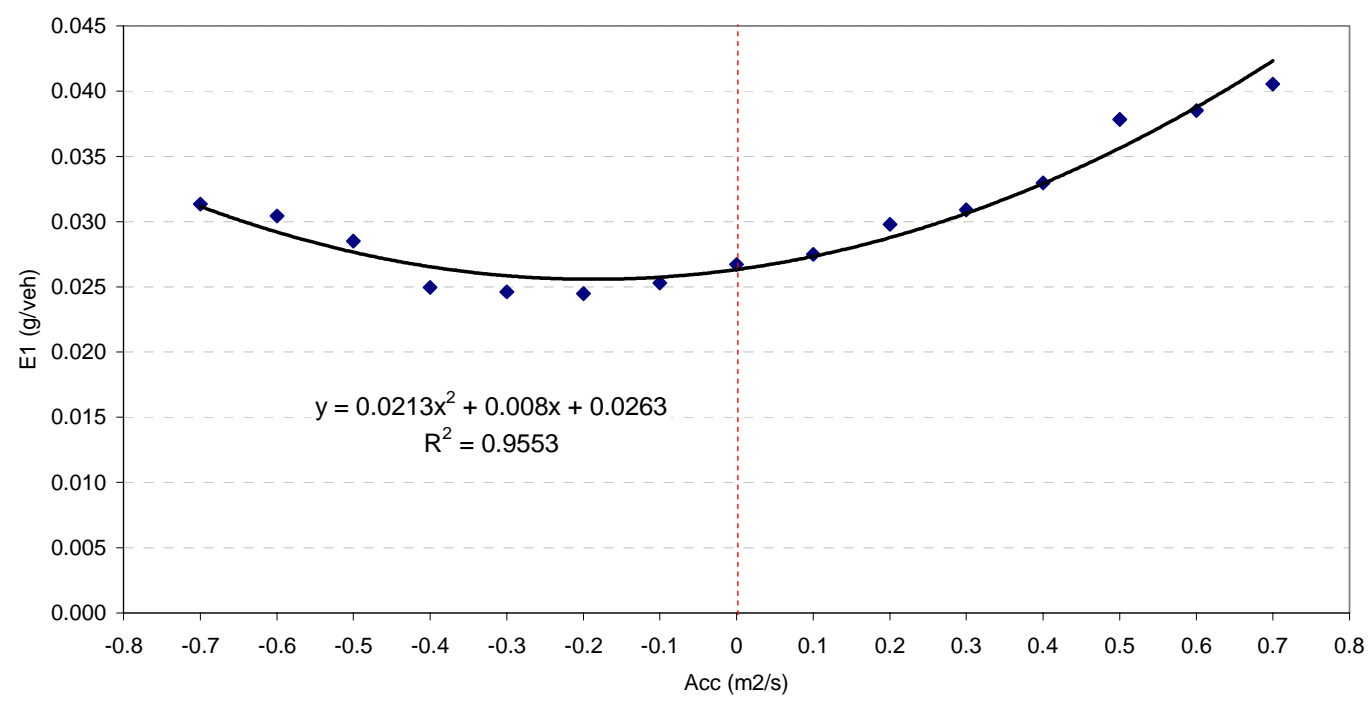

Figure 4-2. Microscopic emission factor $E_{1}$ as a function of average acceleration, February 2005.

The constant value shown in equation 4-5 (the 0.0263 value) represents the average value of $E_{1}$ at zero acceleration, i.e. the average $E_{1}$ value at the different constant speeds. In order to combine equations $4-4$ and $4-5$, the constant value of equation $4-5$ is replaced by the relation between $\mathrm{E}_{1}$ and speed at zero acceleration $(-0.01<\mathrm{a}<0.01)$. Accordingly, the traffic-air-quality model $\left(\mathrm{E}_{1}(\mathrm{v}, \mathrm{a})\right)$ is then given by:

$$
E_{1}=0.0213 \times A c c^{2}+0.008 \times A c c+10^{-5} \times S P D^{2}-0.0009 \times S P D+0.0394
$$

Equation 4-6 along with the truck density on the road $\left(\mathrm{k}_{\mathrm{T}}\right)$ is used to estimate the value of the macroscopic emission factor $\mathrm{E}_{2}$ according to equation 4-3.

$$
E_{2}=\left(0.0213 \times A c c^{2}+0.008 \times A c c+10^{-5} \times S P D^{2}-0.0009 \times S P D+0.0394\right) \times k_{T}
$$

The following schematic diagram (figure 4-3) summarizes the process used to estimate $E_{2}$ from only the measured traffic data on the Borman Expressway. The measured $E_{2}$ value on the other hand is calculated from the measured environmental and 
traffic values such as "C" $\left(\mathrm{PM}_{2.5}\right.$ concentration), "U" (wind speed), "Q $\mathrm{Q}_{\mathrm{T}}$ " (truck flow), and "V" (turbulent mixing volume) using equations 4-2 and 4-3.

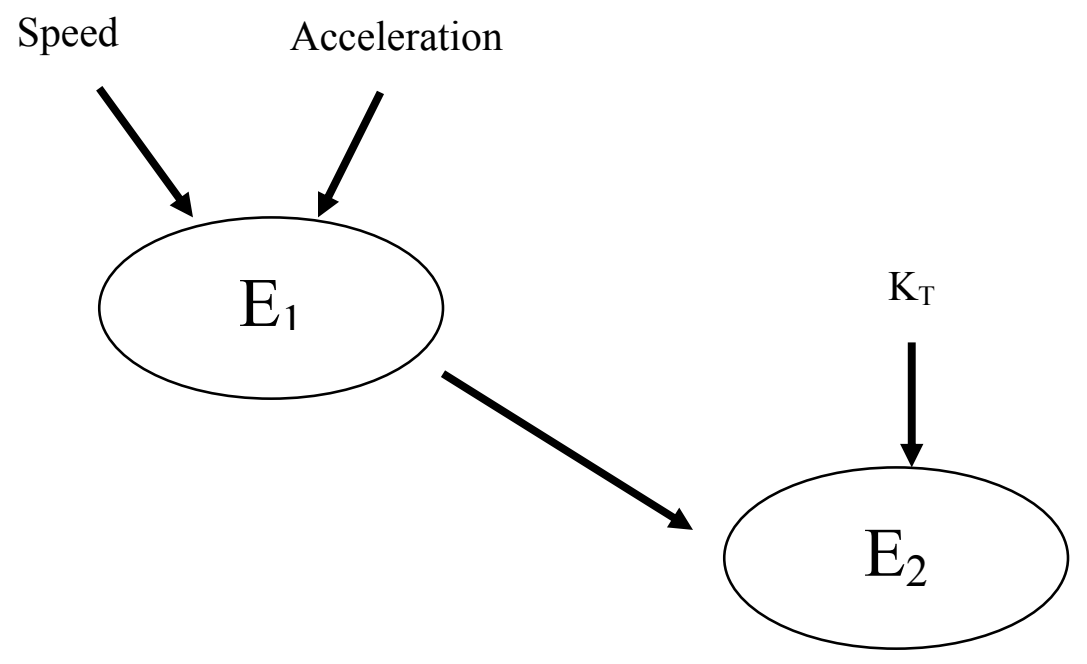

Figure 4-3. A schematic diagram showing the process of estimating E2 from traffic data.

The macroscopic emission factor $\mathrm{E}_{2}[\mathrm{~g} / \mathrm{mi}]$ is plotted versus average speeds on the road to show the effect of free flow and congestions on the air quality, the higher the $E_{2}$ the worse the expected local air quality around the expressway.

Figures 4-4 through 4-6 show a comparison for November, December 2004 and January 2005, respectively, between the measured values of $E_{2}$ and the $E_{2}$ values estimated by equation 4-7 as well as the constant $\mathrm{PM}_{2.5}$ emission factor estimated by the EPA-PART5 model for the Borman Expressway (Soliman et. al, 2004). 


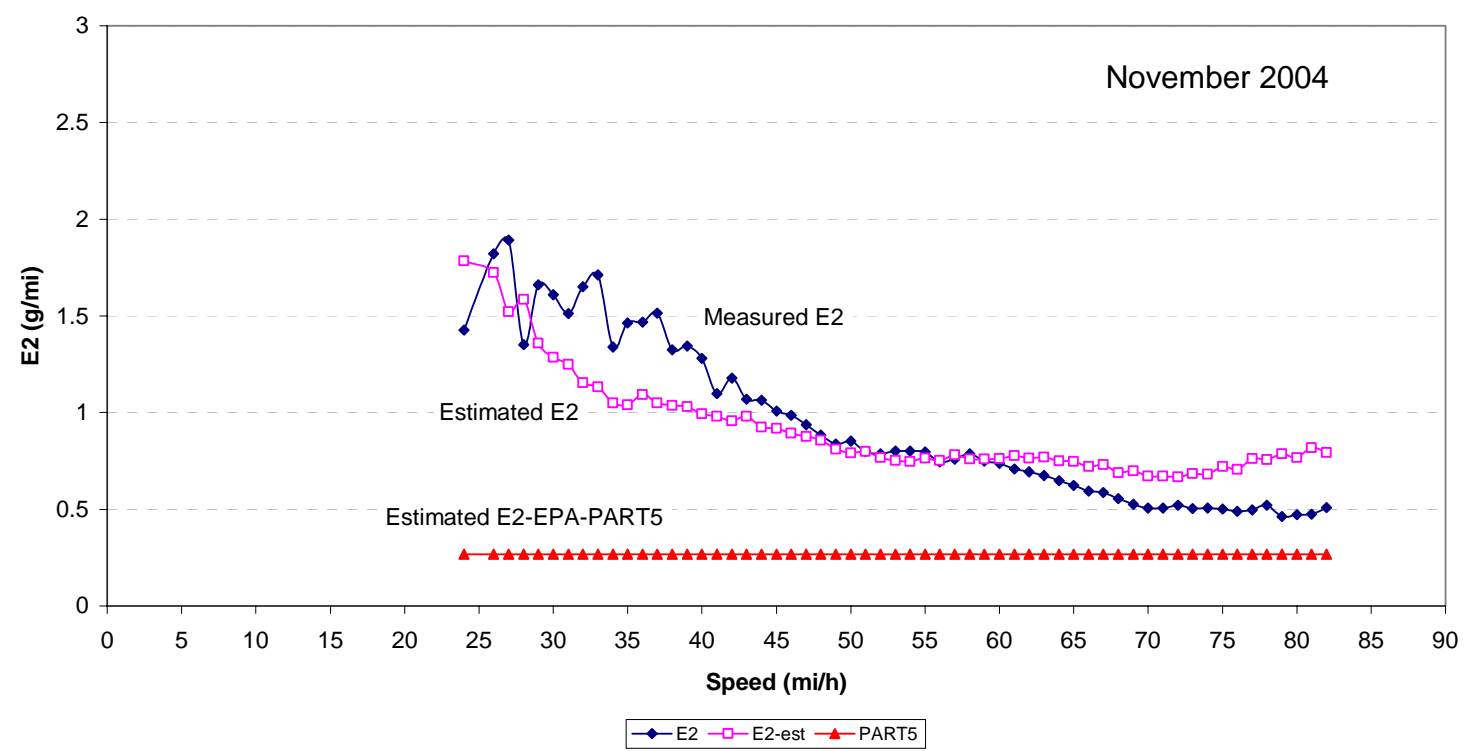

Figure 4-4. The measured, estimated and EPA-PART5-estimated macroscopic $\mathrm{PM}_{2.5}$ emission factor $\mathrm{E}_{2}$ as a function of the Borman average speed, November 2004.

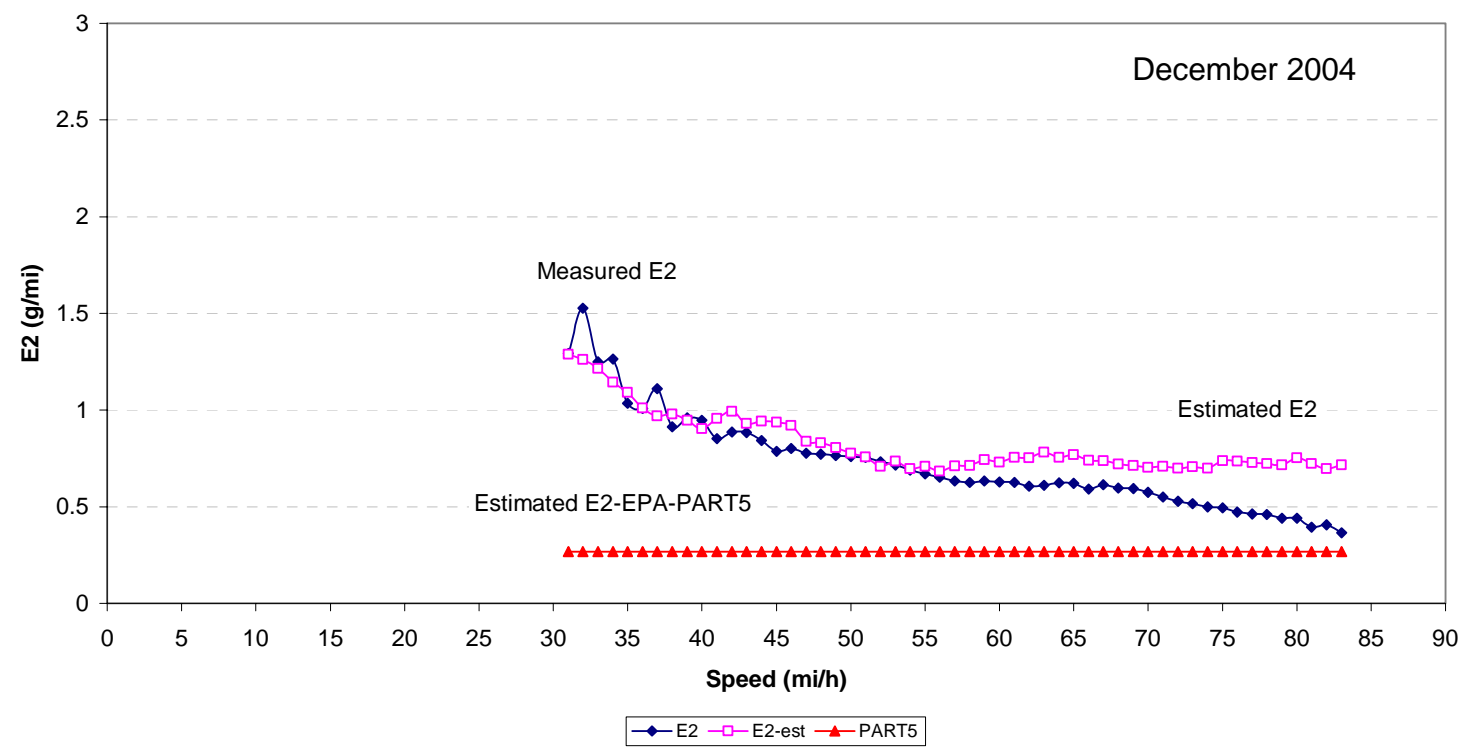

Figure 4-5. The measured, estimated and EPA-PART5-estimated macroscopic $\mathrm{PM}_{2.5}$ emission factor $\mathrm{E}_{2}$ as a function of the Borman average speed, December 2004. 


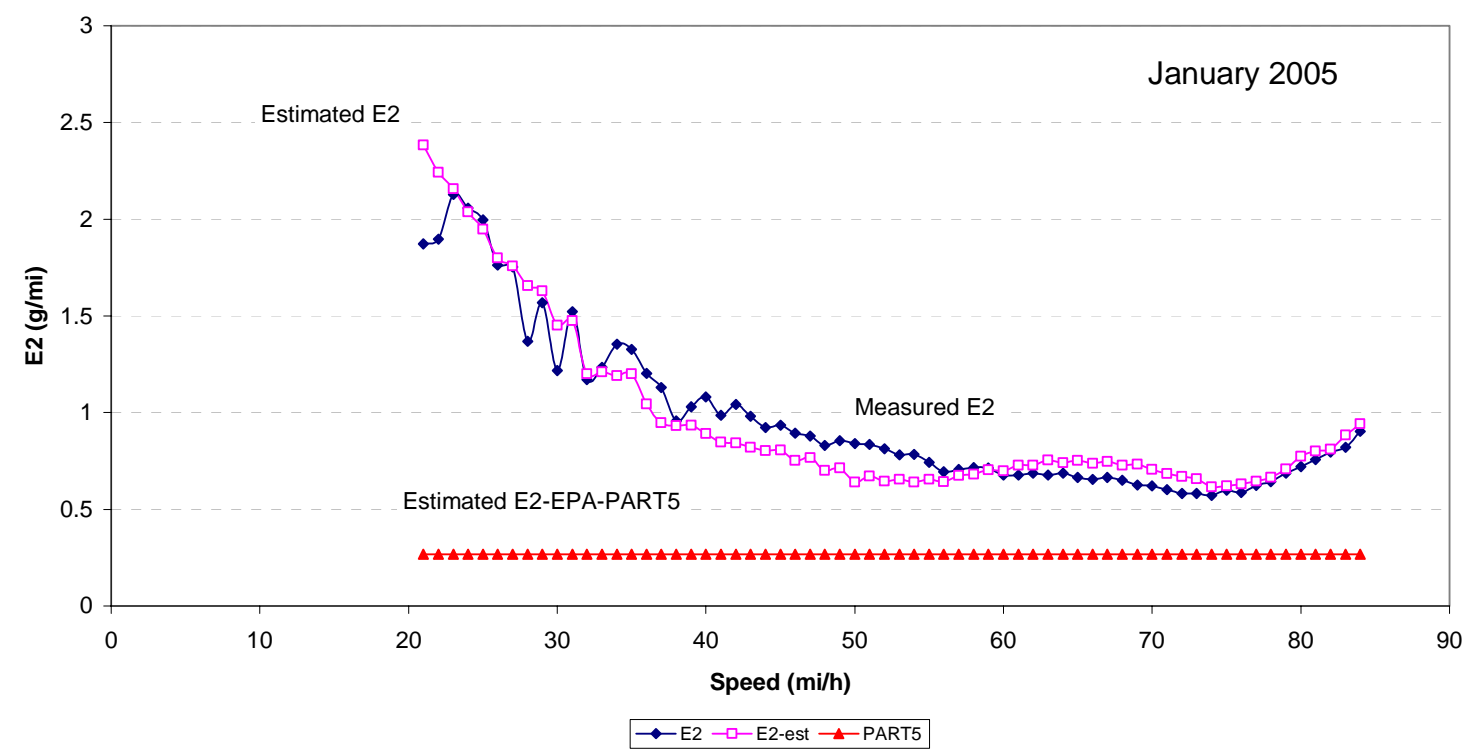

Figure 4-6. The measured, estimated and EPA-PART5-estimated macroscopic $\mathrm{PM}_{2.5}$ emission factor $E_{2}$ as a function of the Borman average speed, January 2005.

As shown in figures 4-4 through 4-6, the macroscopic $\mathrm{PM}_{2.5}$-emission factors $\left(\mathrm{E}_{2}\right)$ estimated by the traffic-air-quality model (equation 4-7) have shown better agreement with the measured values than $E_{2}$ estimated by the EPA-PART5 model $\left(E_{2}=0.268 \mathrm{~g} / \mathrm{mi}\right)$ for the Borman Expressway. Figure 4-7 shows the ratios between the measured and estimated values of $\mathrm{E}_{2}$ for both the model equation 4-7, and the EPA-PART5 model. The graphs are for November, December 2004 and January 2005.

As shown in figure 4-7, the traffic-air-quality model (equation 4-7) has performed better than the EPA-PART5 model. The discrepancy between the actual (measured) data versus the PART5-modeled $\mathrm{PM}_{2.5}$ emissions is generally attributed to the inadequate emissions data and outdated assumptions used in the EPA-PART5 model (Ubanwa, 2003). 
Sensitivity tests were run on the traffic air-quality model (equation 4-7) to determine how the output emission factor $\mathrm{E}_{2}$ would change as the input parameters change (speed, acceleration and truck density). Such analysis is performed by changing hypothetical input values of speed and acceleration by $10 \%$ increments. Figure $4-8$ "a" and "b" show the $\%$ change (or error) of the $\mathrm{PM}_{2.5}-\mathrm{E}_{2}$ output as a function of the $\%$ change in the input parameters, speed and acceleration, respectively.

As shown in Figure 4-8, the traffic-air-quality model (equation 4-7) is sensitive to the change in input parameters, a $20 \%$ change in the input speed will result in a $42 \%$ change in the output $\mathrm{PM}_{2.5}$ emission factor $\mathrm{E}_{2}$, similarly for the acceleration relation, a $20 \%$ change in the acceleration input will result in a $44 \%$ change in the $E_{2}$ output. The change in $E_{2}$ with respect to the change in the truck density is expected to be linear as indicated by equation 4-7.

Further improvement to the traffic-air-quality model may be achieved via accurately determining the turbulent mixing volume " $\mathrm{V}$ " in equation $4-2$, and showing how such turbulent mixing volume changes as a function of the truck speed on the highway. 

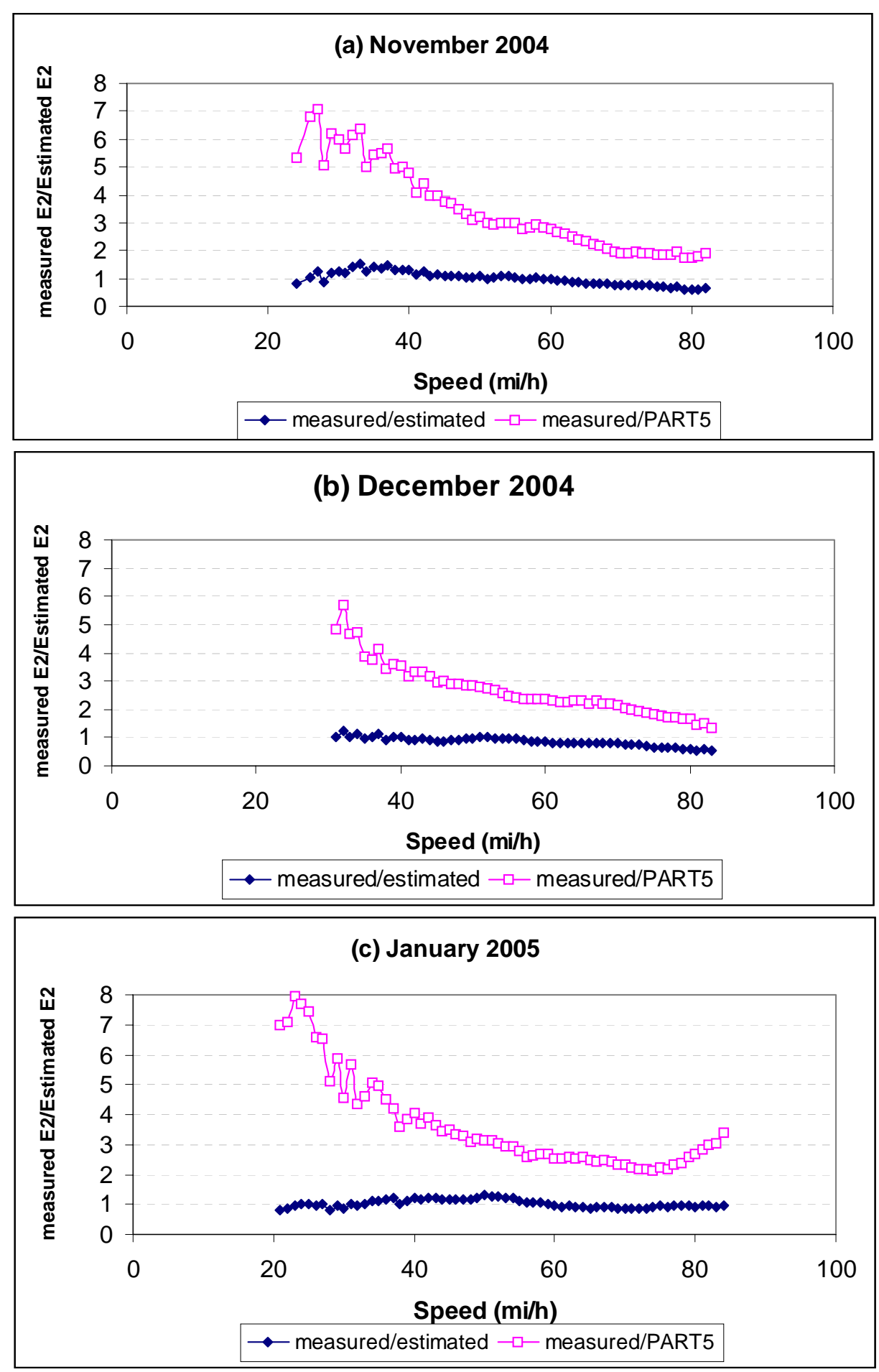

Figure 4-7. The ratio between the measured and estimated values of $E_{2}$ by both equation 4-7 and the EPA-PART5 model. a) November 2004, b) December 2004 and c) January 2005. 

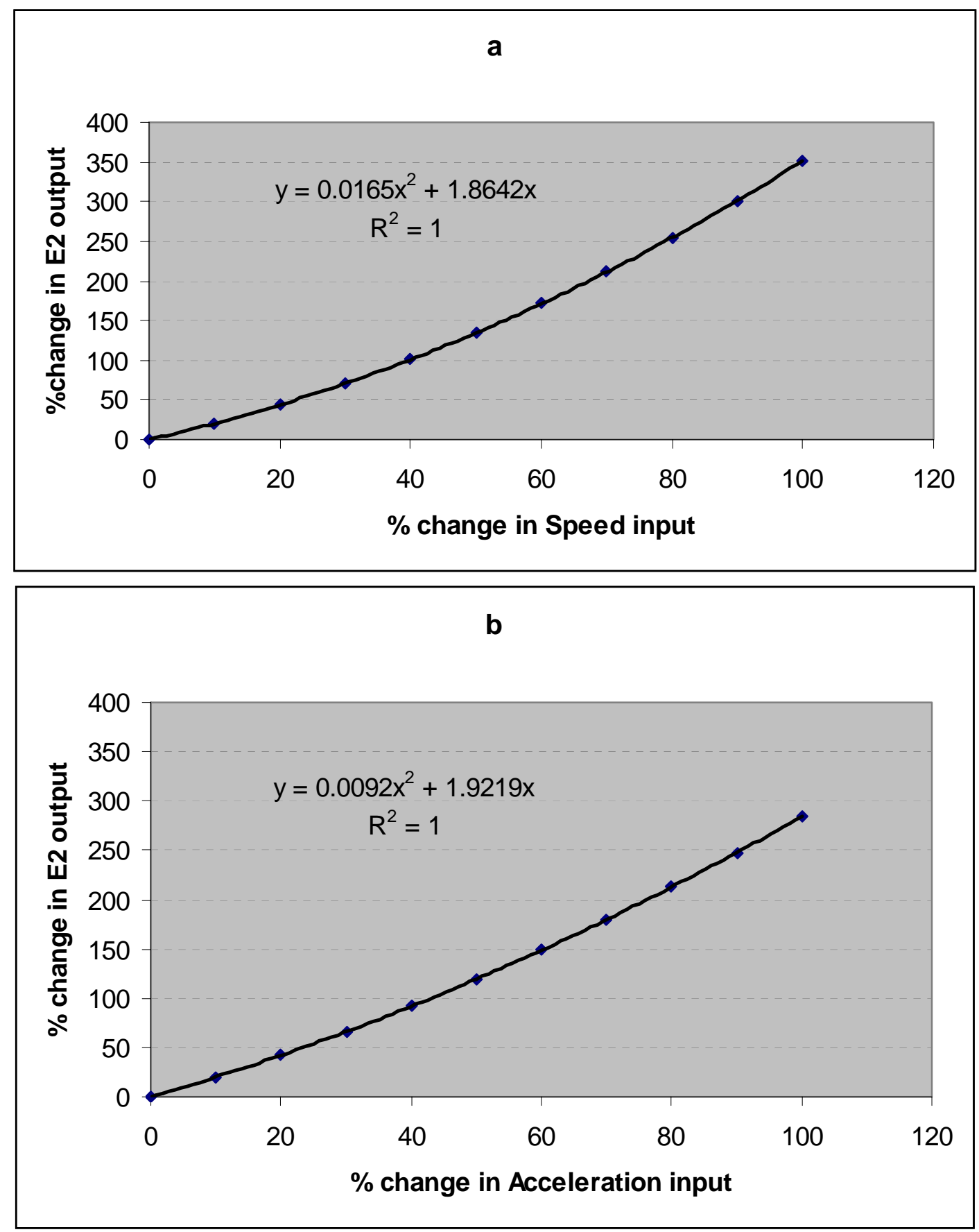

Figure 4-8. The change in the $\mathrm{PM}_{2.5}-\mathrm{E}_{2}$ output as a function of the change in the input parameters, a) speed, and b) acceleration. 


\section{CHAPTER FIVE}

\section{TRUCK-MECHANICAL TURBULENCE ANALYSIS}

\subsection{Introduction:}

Traffic-induced turbulence plays a major role in the dispersion of pollutants near highways. Several studies have been conducted to model the dispersion of different pollutants in the wake of vehicles (e.g. Eskridge et. al, 1979 and Hider et. al, 1997).Other research focused on the dispersion that is due to the turbulence adjacent to a major road (e.g. Eskridge et. al, 1983 and, Rao et. al, 2002). Wind-tunnel experiments have also been conducted to model the dispersion of the vehicular-emitted pollutants for cross winds to the road (Baker et. al, 2001). The main concern of these studies was to determine the strength of the turbulent flow in the wake of the vehicles as well as to model the pollutant concentrations near roadways dispersed by turbulent air due to moving vehicles. However, these studies did not provide the relation between the speed of the vehicles and the turbulent mixing volume needed for the emission factor estimation.

Unlike tunnel studies, where the pollutant mixing volume may be estimated to be the same turbulent air volume of the tunnel caused by the vehicle movement (also known as the piston-effect (Bellasio, 1997)); open-street empirical emission factor estimation encounters the difficulty of estimating the turbulent mixing volume of the pollutants on the side of the road. Based on concentration measurements near a road conducted by 
Jamriska et. al., it was found that pollutant concentration remained constant as a function of height, however, the concentration dropped of at a height of 8.4 meters above the ground. This height was then considered to be the turbulent mixing height used in the Box-Model to estimate the pollutant emission factors. Hence, the common solution was to assume a constant box volume where the pollutants are well-mixed (Jamriska, et. al, 2001). Chapter 4 has discussed the estimation of both the microscopic and macroscopic emission factors ( $E_{1}$ and $E_{2}$, respectively) using the Box-Model with the assumption of a constant turbulent-mixing box volume. A better estimation of the emission factors could be expected by studying the effect of truck speeds on the turbulent mixing volume around the trucks. This chapter will discuss a wind tunnel experiment that was run to study the truck-speed effect on the mixing volume of equation 4-2.

$$
E_{1}=\frac{C \times U}{q_{T}} \times V^{2 / 3}
$$

\subsection{Wind Tunnel Experiment:}

A wind tunnel experiment was run with three similar 1/24-scaled model class-9 trucks to study the effect of their speeds on the turbulent area behind them and hence the mixing volume needed for equation 4-2. The wind tunnel is located in the School of Civil Engineering, Purdue University.

The wind tunnel was operated at $112 \mathrm{mi} / \mathrm{h}$ and the wind speed was measured as a function of height from the bottom of the wind tunnel in order to create a wind-speed profile of the tunnel. A DWYER ${ }^{\mathrm{TM}}$ thermo-anemometer, model 471 was used to determine the vertical velocity profile in an empty-tunnel (without a ground-plane or 
trucks). Measurements were taken while the probe is going up, and while going down.

Figure 5-1 shows a schematic diagram of the wind tunnel used in the experiments.

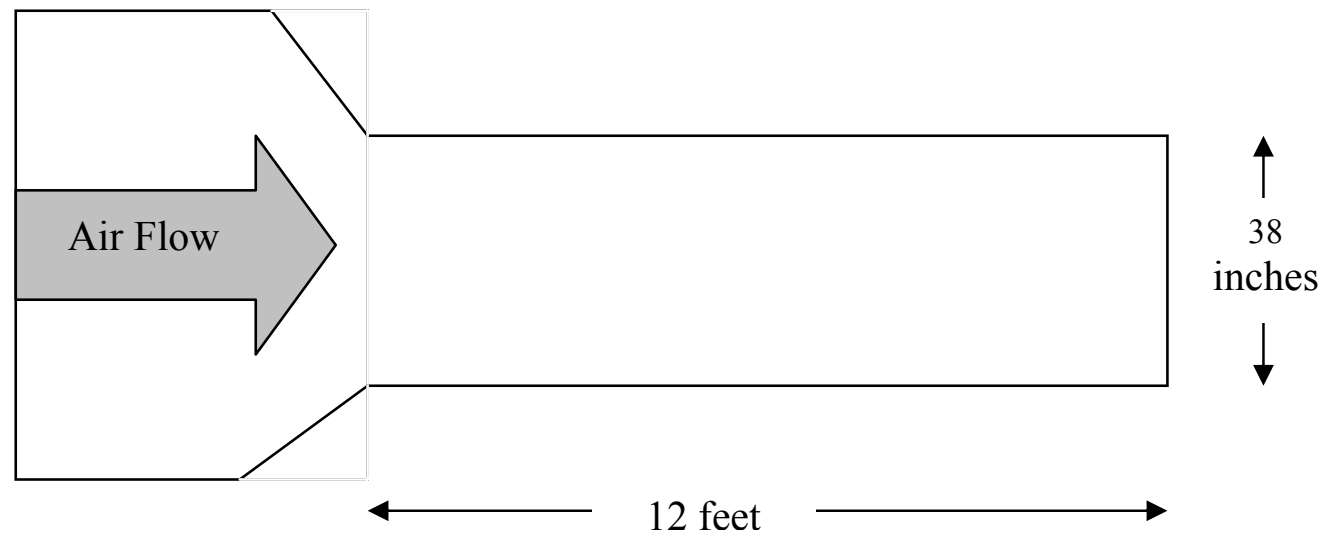

Figure 5-1. A schematic diagram of the wind tunnel used in the experiments.

Figure 5-2 shows the measured wind-velocity profile of the School of Civil Engineering wind tunnel at wind speed of $112 \mathrm{mi} / \mathrm{h}$.

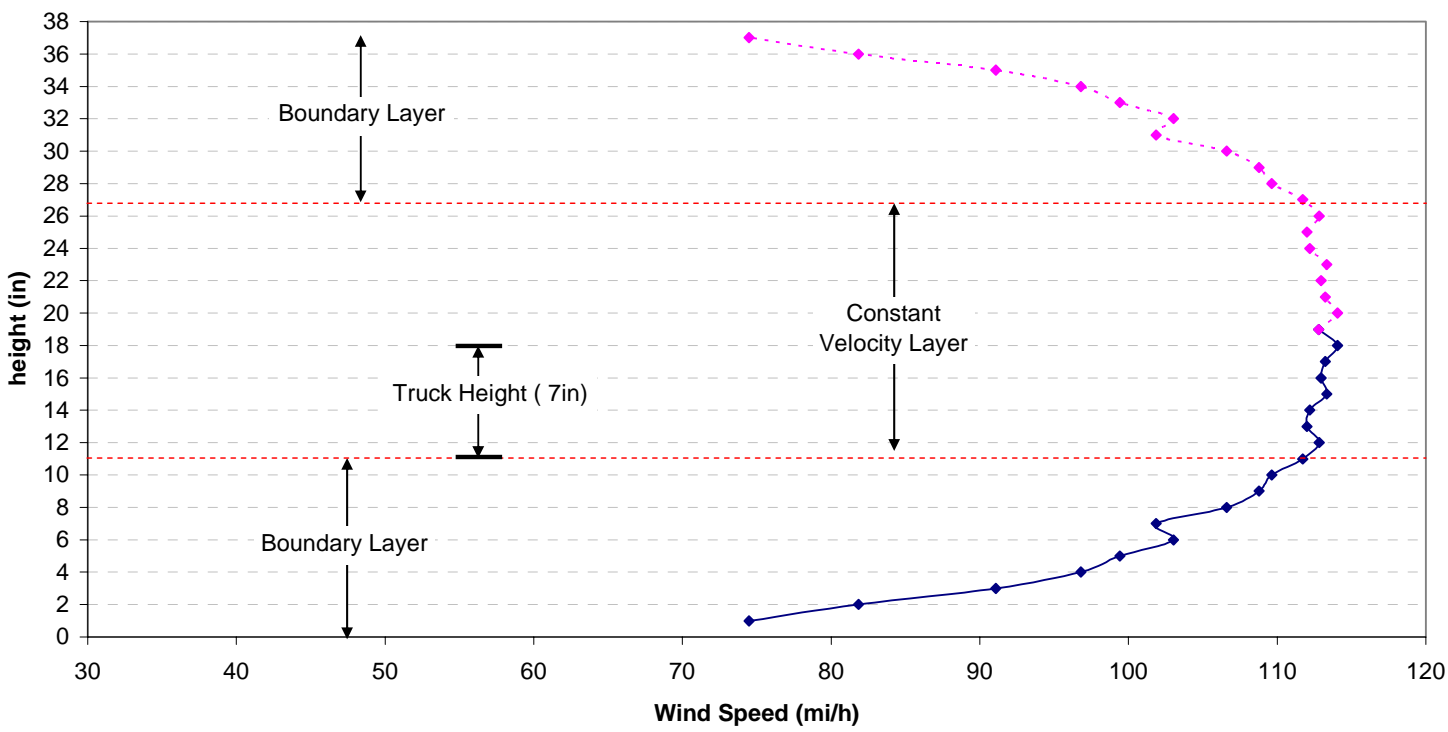

Figure 5-2. The wind tunnel velocity profile at wind speed of $112 \mathrm{mi} / \mathrm{h}$ without the ground-plane or models. 
As shown in figure 5-2, the boundary layer occupied the top and bottom 11 inches of the tunnel. The constant-speed layer was found to be located between 11 and 27 inches above the floor.

An 11 inches-high, 54 inches-wide wooden platform (ground-plane) was designed and installed in order to mount the model trucks within the constant wind-speed layer. The platform was equipped with a 1-inch mesh-screen (treffts plane) vertically located at the back the platform figure 5-3-a. Four inch long, six-strand white yarn-tufts were attached at 2-inch increments on the screen as shown in figure 3-5-b. The tufts are a low cost, and a fast setup to show and determine the location of the turbulent mixing area behind the truck at the different truck distances from the screen as well as at different wind speeds.
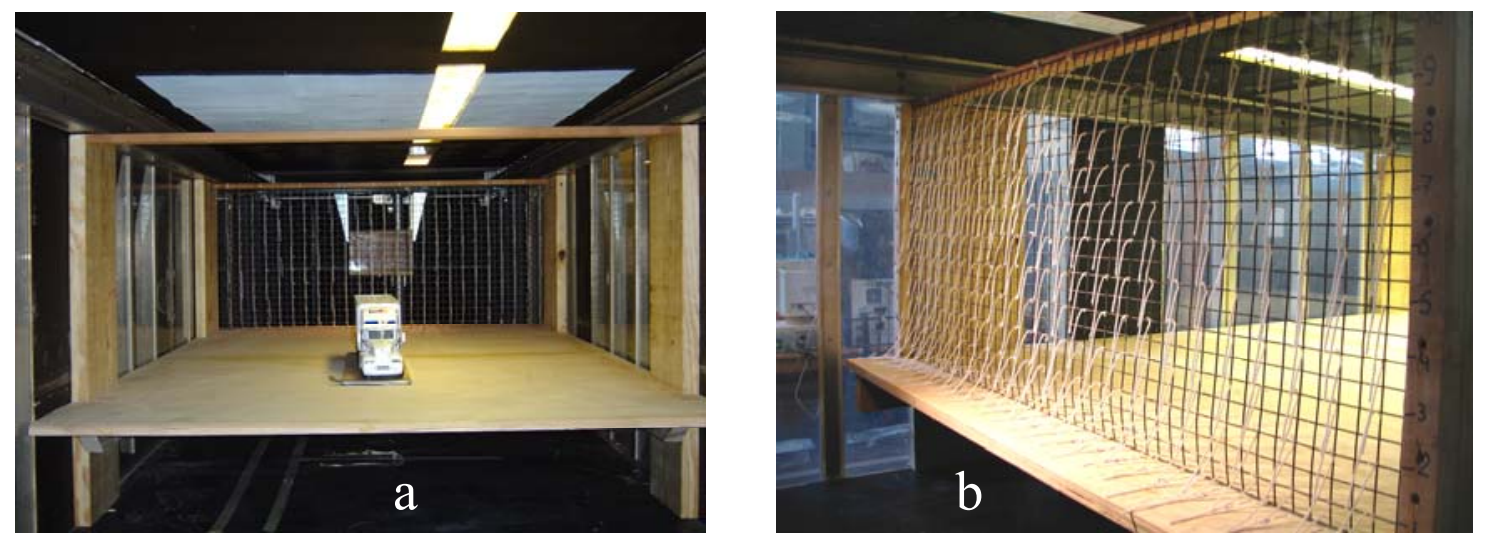

Figure 5-3. a) the 11-inch high, 54-inch wide wooden frame mounted inside the wind tunnel, b) the 4-inch long tufts attached to the screen at the back of the platform.

The experiment was divided into three parts; Part one: measuring the turbulent flow area "A" behind one truck as a function of the truck distance " $\mathrm{d}$ " from the screen at a constant wind speed, i.e. A(d). Part two: fixing the truck at the location that gave the largest turbulent area in part one, and studying the turbulent area as a function of wind 
speed "U", i.e. A(U). Part three: studying the effect of adding more trucks side by side on the turbulent area as a function of wind speed as could occur on an expressway.

Part One: A single truck model is used in this experiment. The wind speed was kept constant while changing the location of the truck by moving it upstream from the screen. The experiment was run at two different speeds, $34 \mathrm{mi} / \mathrm{h}$ and at $54 \mathrm{mi} / \mathrm{h}$. The area was measured in inches-squared $\left[\mathrm{in}^{2}\right]$ and will be changed to meters-squared $\left[\mathrm{m}^{2}\right]$ later on before using it in the traffic-air-quality model. Figure 5-5 shows a photograph of the tufts for two different truck locations, 2.5 , and 10 inches from the screen at the $54 \mathrm{mi} / \mathrm{h}$ setting. The figure shows the turbulence decrease in the tufts as the truck distance from the screen is increased.
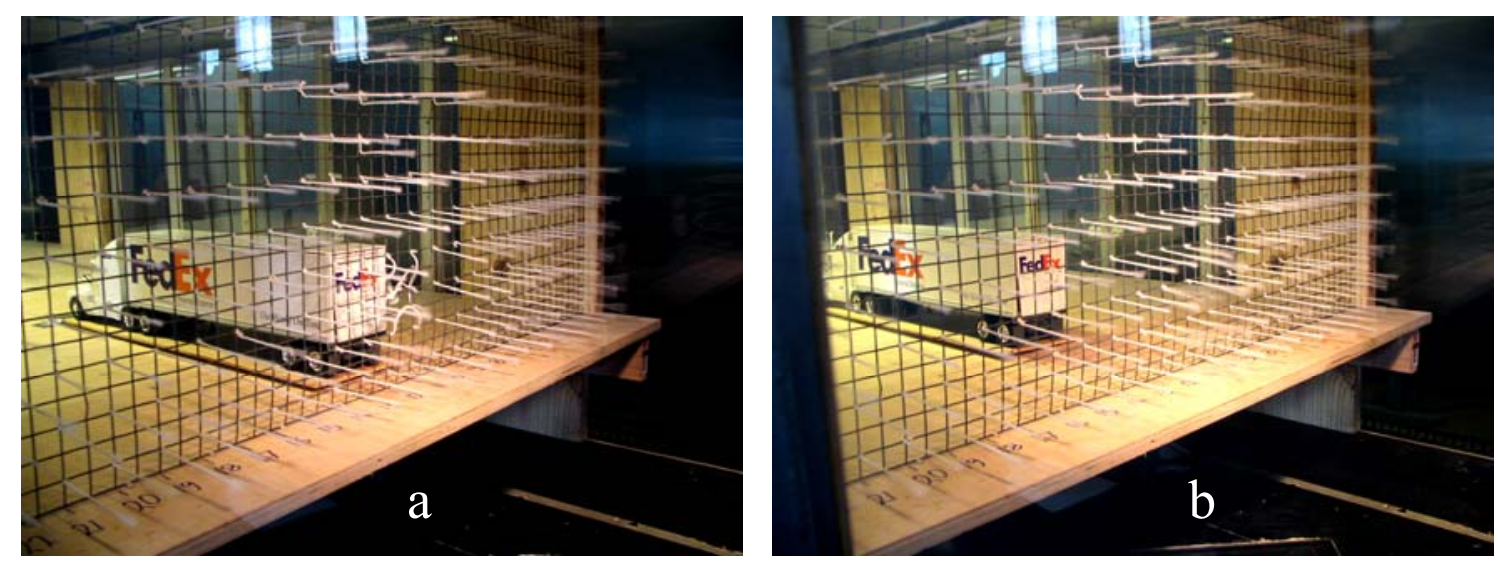

Figure 5-4. the screen tufts at $54 \mathrm{mi} / \mathrm{h}$ for two different truck location from the screen, a) at 2.5 inches ( 0.36 truck height), b) at 10 inches ( 1.43 truck height).

Figure 5-5 shows the change in area behind the truck $\left[\mathrm{in}^{2}\right]$ as a function of the distance from the screen at constant wind speeds of $34 \mathrm{mi} / \mathrm{h}$ and $54 \mathrm{mi} / \mathrm{h}$. 


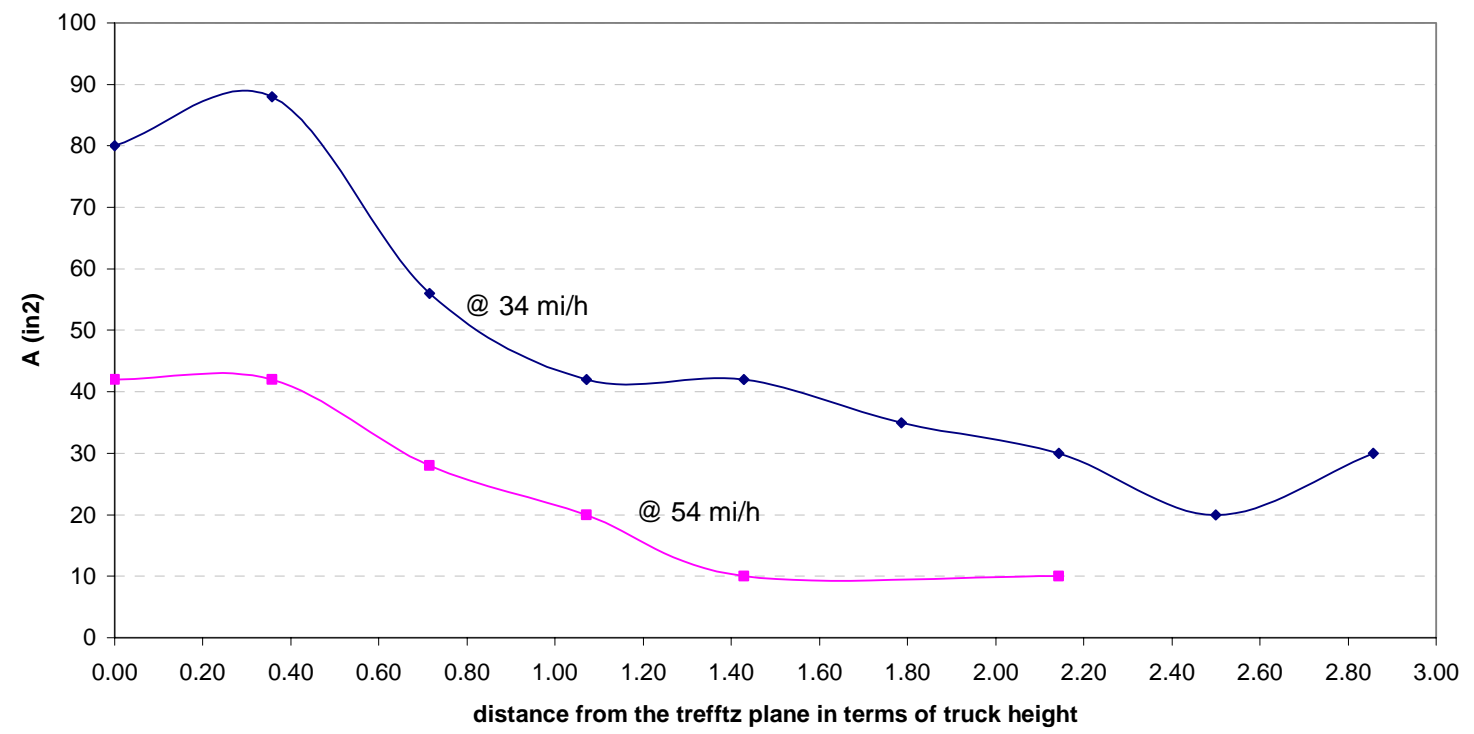

Figure 5-5 Change in disturbed flow area behind the truck $\left[\mathrm{in}^{2}\right]$ as a function of the distance (normalized with respect to the truck height) from the trefftz plane at constant wind speeds of $34 \mathrm{mi} / \mathrm{h}$ and $54 \mathrm{mi} / \mathrm{h}$.

Figure 5-5 shows that the largest disturbed flow area behind the truck occurred at 0.36 truck-height (2.5 inches) distance from the screen, beyond that point the area decreases in size as the distance increases.

Part Two: A single truck was fixed in location at the 0.36 truck-height ( 2.5 inches) marker on the platform. The wind speed was then increased and the turbulent area behind the truck measured. Three runs were performed and an average was taken to show the change in the disturbed flow area as a function of speed, figure 5-6.

Figure 5-6 shows that the area decreases behind the truck as the wind speed increases with a good fit quadratic relation, $\mathrm{R}^{2}=0.998$. The same experiment was repeated for two trucks and then three trucks side by side in part three. 


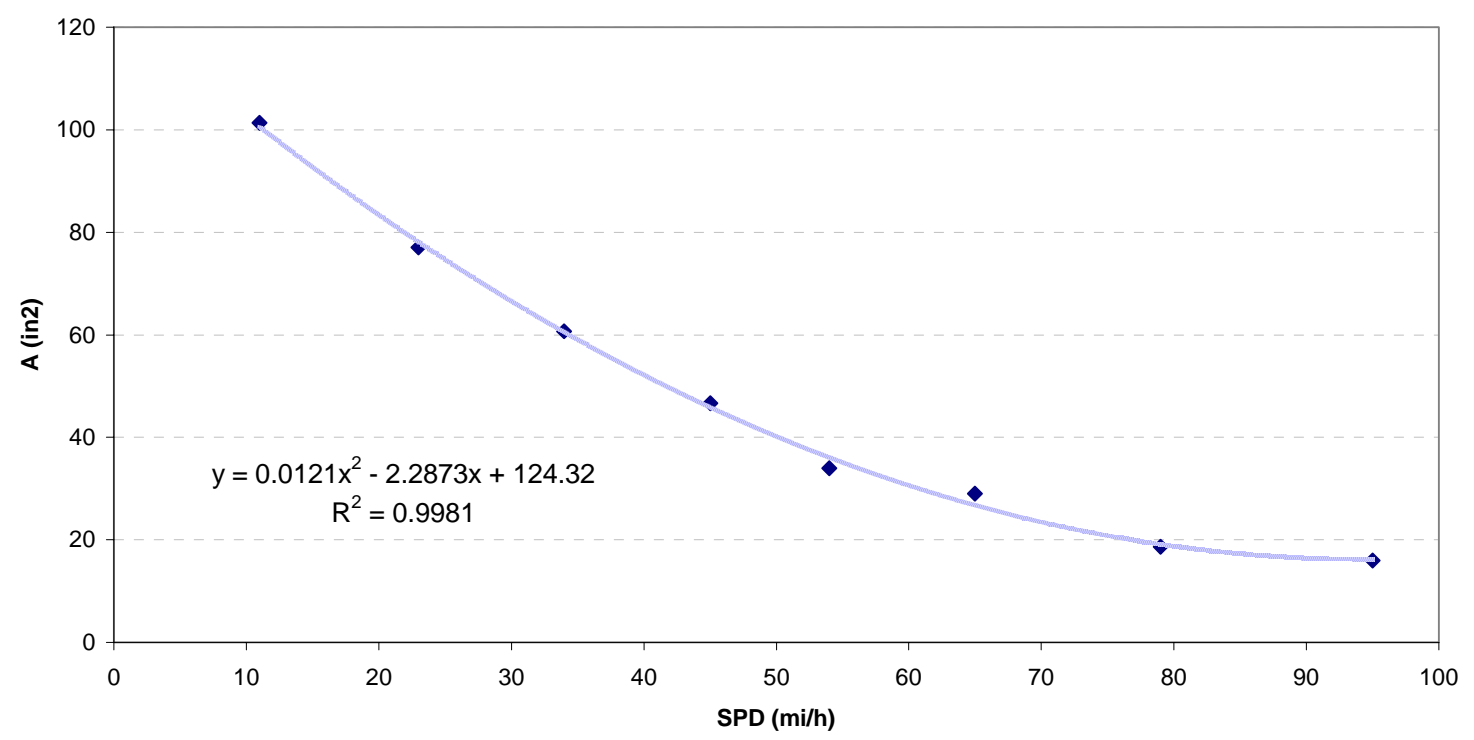

Figure 5-6. Disturbed flow area $\left[\mathrm{in}^{2}\right]$ behind a single truck as a function of wind speed $[\mathrm{mi} / \mathrm{h}]$.

Part Three: Similar to part two, one and two more trucks were added in this experiment. The turbulent area behind the trucks was measured as a function of wind speed. Figure 5-7 shows photographs of two- and three-truck setup used in the experiment.
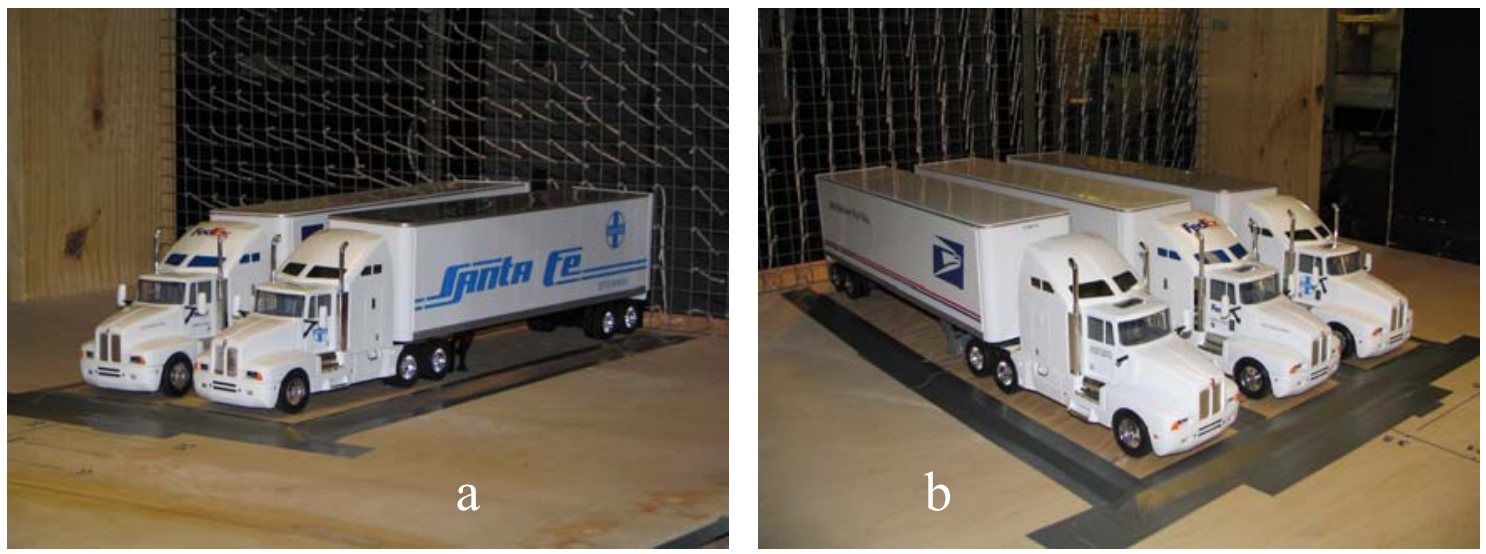

Figure 5-7. Photographs of a) two-truck setup, and b) three-truck setup used in the wind tunnel experiment. 
Figures 5-8 and 5-9 show the turbulent area behind the trucks as a function of wind speed for the two- and three-truck setups, respectively. As shown in the figures, the area followed a quadratic relation with the wind speeds showing good correlations, $\mathrm{R}^{2}=0.986$ and $\mathrm{R}^{2}=0.923$, respectively.

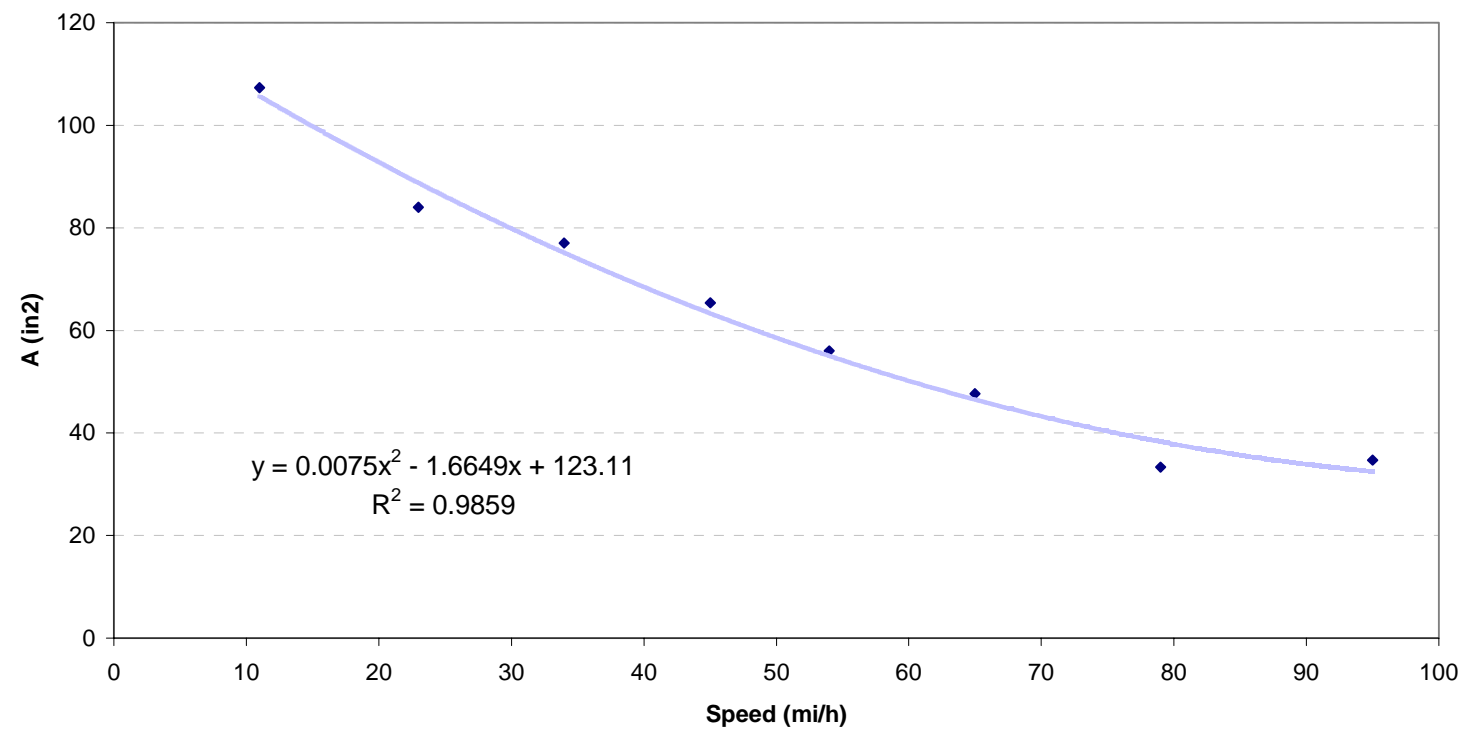

Figure 5-8. Turbulent area $\left[\mathrm{in}^{2}\right]$ behind two trucks as a function of wind speed $[\mathrm{mi} / \mathrm{h}]$.

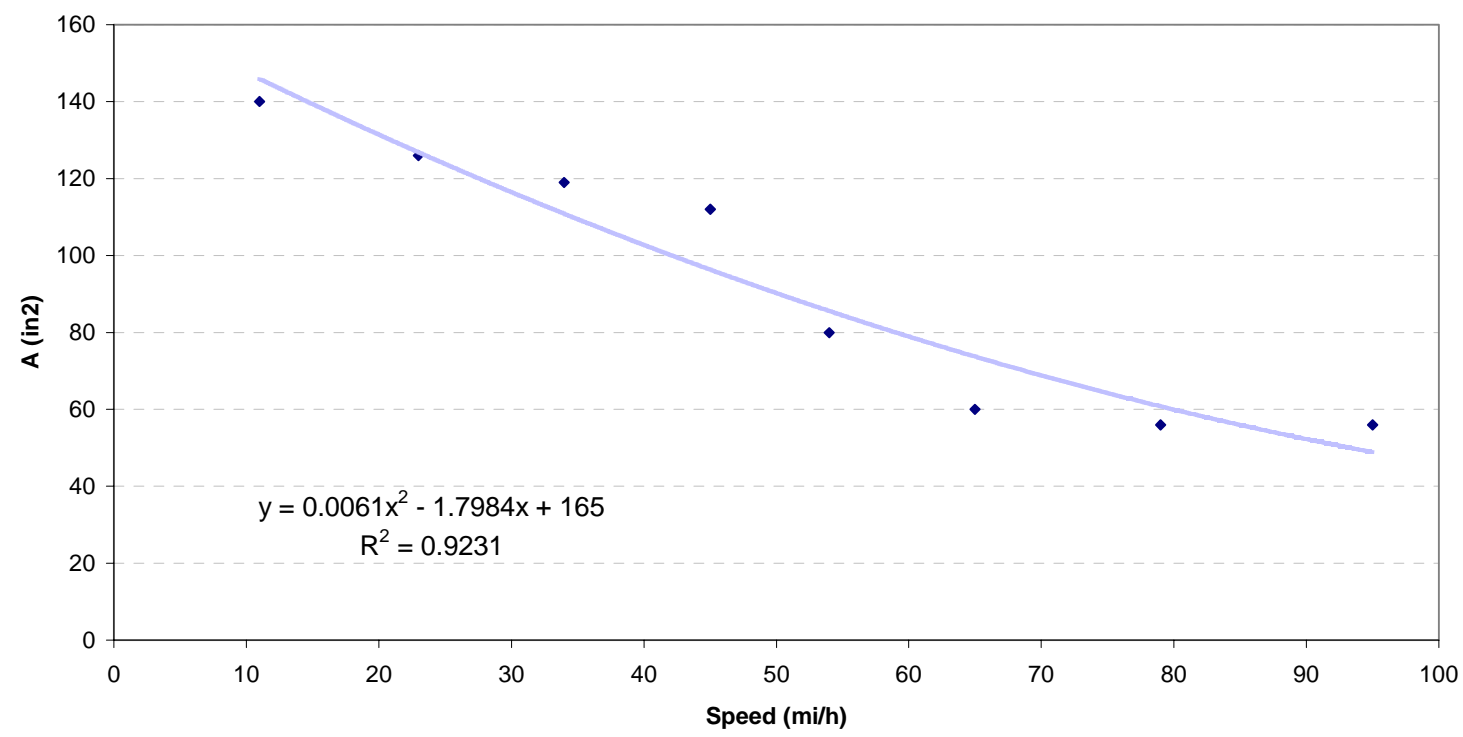

Figure 5-9. Turbulent area $\left[\mathrm{in}^{2}\right]$ behind three trucks as a function of wind speed $[\mathrm{mi} / \mathrm{h}]$. 
The area behind the trucks was scaled up and converted into meters-squared to be used in traffic-air-quality model. Therefore, the equation governing the relation between the turbulent mixing area and the wind speed for three trucks is given by equation 5-1:

$$
\mathrm{A}=0.0023 \times \mathrm{SPD}^{2}-0.6673 \times \mathrm{SPD}+61.224
$$

Where "A" is the turbulent mixing area (disturbed flow area) measured in meterssquared $\left[\mathrm{m}^{2}\right]$, and "SPD" is the wind speed (or truck speed) measured in miles per hour $[\mathrm{mi} / \mathrm{h}]$.

Due to the difficulty of determining the distribution of trucks on the Borman Expressway at a given time (i.e., the difficulty of determining how many trucks exist side by side on the road at a given instant of time) it will be assumed that the turbulent mixing volume is caused by three trucks existing side by side on each bound all the time during the measurements. Hence, the turbulent mixing volume used in the modified traffic-airquality model for an area A(SPD) for both bounds (three lanes per bound) and for an exposed length " $\mathrm{L}$ " of the Borman Expressway is given by equation 5-2:

$$
\mathrm{V}=\left(0.0023 \times \mathrm{SPD}^{2}-0.6673 \times \mathrm{SPD}+61.224\right) \times 2 \times \mathrm{L}
$$

Where "V" is the turbulent mixing volume $\left[\mathrm{m}^{3}\right]$, "SPD" is the average speed on the Borman Expressway at a given instant of time $[\mathrm{mi} / \mathrm{h}]$, and " $\mathrm{L}$ " is the exposed length of the Borman Expressway, $\mathrm{L}=160$ meters [m] as discussed in chapter 4 .

\subsection{Turbulent Mixing Volume and the Borman Emission Factors:}

Similar to the analysis performed in chapter four, the traffic-air-quality will be derived for the variable mixing volume $\mathrm{V}(\mathrm{SPD})$ obtained by equation $5-2$. The turbulent mixing volume of equation 4-2 is replaced with the volume V(SPD) estimated in equation 5-2. 


$$
E_{1}=\frac{C \times U}{q_{T}} \times V^{2 / 3}
$$

$E_{1}$ is then regressed against speed at constant acceleration $(-0.01<\mathrm{a}<0.01)$, and against acceleration.

Figure 5-10 shows the measured values of $E_{1}$ as a function of average speed on the Borman Expressway for the month of February 2005 calculated using the modified mixing volume $\mathrm{V}(\mathrm{SPD})$. The speeds used in figure 5-10 analysis are for a constant velocity, $-0.01<$ acceleration $<0.01$.

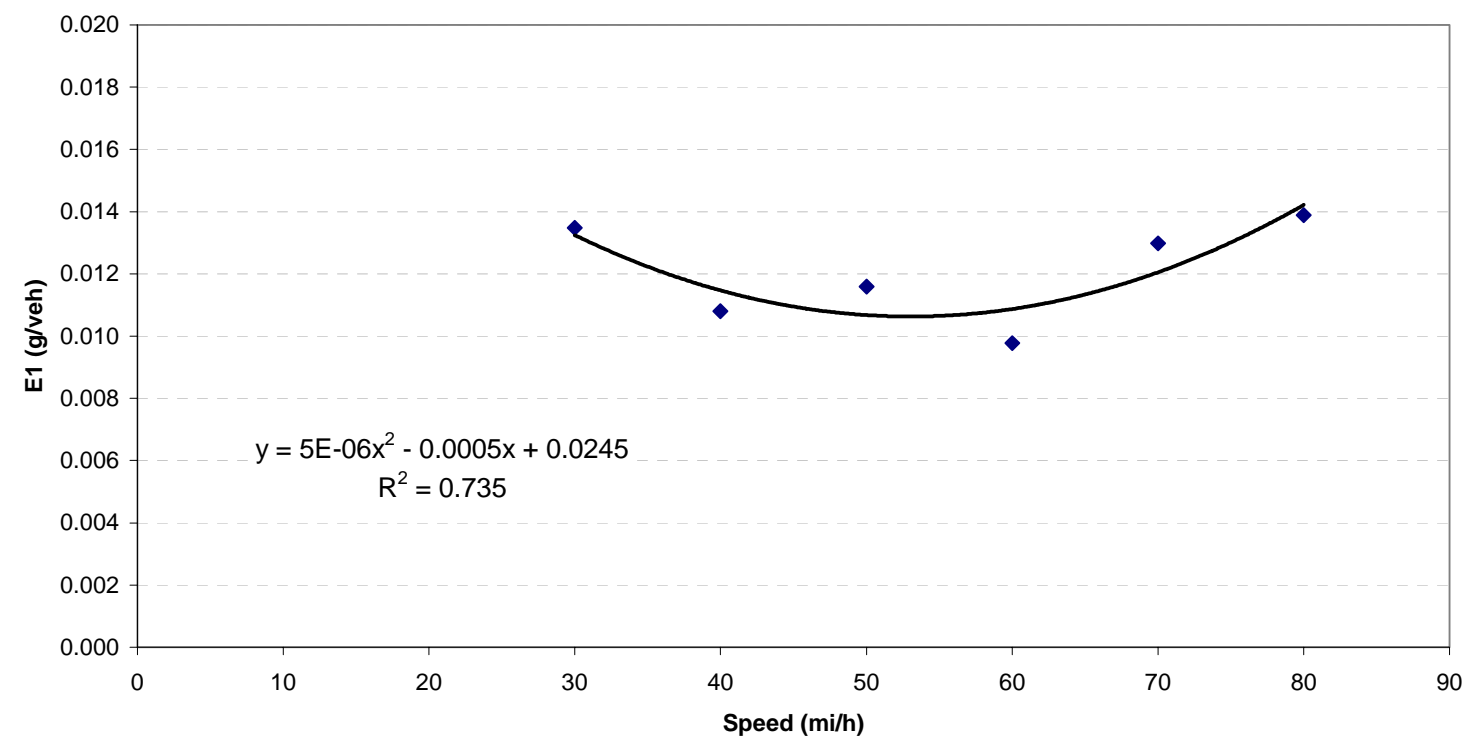

Figure 5-10. Microscopic emission factor $\mathrm{E}_{1}$ as a function of average speed for at a zero acceleration $(-0.01<\mathrm{a}<0.01)$, using the modified mixing volume $\mathrm{V}(\mathrm{SPD})$. February 2005.

Figure 5-10 shows a good correlation between $E_{1}$ and the average speed $\left(\mathrm{R}^{2}=0.735\right)$ and is given by equation $5-3$ :

$$
E_{1}=5 \times 10^{-6} \times S P D^{2}-0.0005 \times S P D+0.0245
$$


Where " $\mathrm{E}_{1}$ " is the microscopic emission factor $[\mathrm{g} / \mathrm{veh}]$, and "SPD" is the average speed at constant acceleration $[\mathrm{mi} / \mathrm{h}]$. The average data points shown in figure 5-10 represent averages of data up to 1700 points per data-point indicating the robustness of the data used in the analysis.

The relation between $E_{1}$ and the average acceleration is shown in figure 5-11. Figure 5-11 shows a good correlation between $E_{1}$ and the average acceleration $\left(\mathrm{R}^{2}=0.931\right)$ and is given by equation $5-4$ :

$$
E_{1}=0.0095 \times A c c^{2}+0.0022 \times A c c+0.0118
$$

Where " $\mathrm{E}_{1}$ " is the microscopic emission factor [g/veh], and "Acc" is the average acceleration $\left[\mathrm{m} / \mathrm{s}^{2}\right]$. The average data points shown in figure 5-11 represent averages of data up to 17000 points per data-point indicating the robustness of the data used in the analysis.

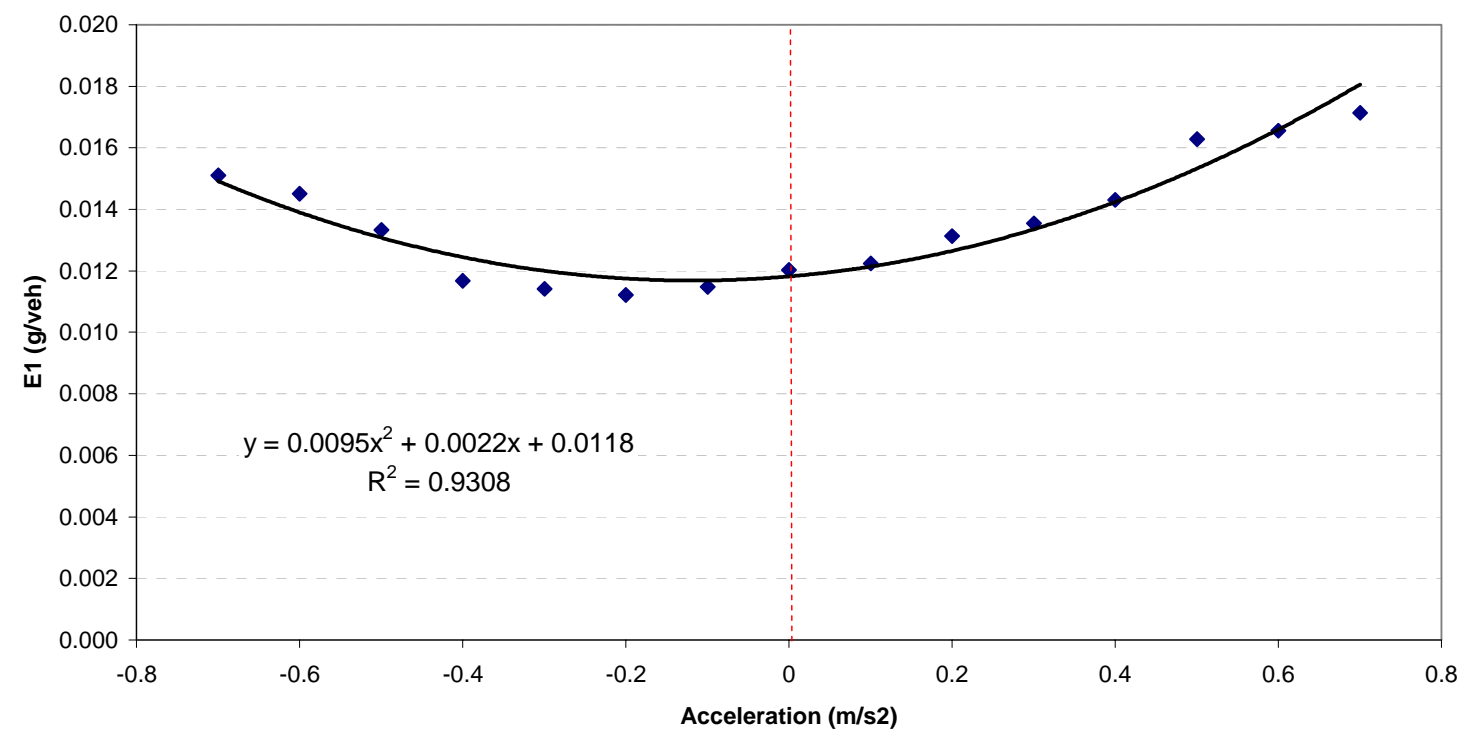

Figure 5-11. Microscopic emission factor $\mathrm{E}_{1}$ as a function of average acceleration for a modified mixing volume V(SPD), February 2005. 
As discussed in chapter four, the constant value shown in equation 5-4 represents the average value of $E_{1}$ at zero acceleration, i.e. the average $E_{1}$ value at the different constant speeds. In order to combine equations 5-3 and 5-4, the constant value of equation 5-4 is replaced by the relation between $E_{1}$ and speed at zero acceleration (-0.01 $<\mathrm{a}<0.01)$. Accordingly, the traffic-air-quality model $\left(\mathrm{E}_{1}(\mathrm{v}, \mathrm{a})\right)$ is then given by:

$$
E_{1}=0.0095 \times A c c^{2}+0.0022 \times A c c+5 \times 10^{-6} \times S P D^{2}-0.0005 \times S P D+0.0245
$$

Equation 5-5, along with the truck density on the road $\left(\mathrm{k}_{\mathrm{T}}\right)$, is used to estimate the value of the macroscopic emission factor $\mathrm{E}_{2}$ according to equation 4-3.

$E_{2}=\left(0.0095 \times A c c^{2}+0.0022 \times A c c+5 \times 10^{-6} \times S P D^{2}-0.0005 \times S P D+0.0245\right) \times k_{T}(5-6)$

The macroscopic emission factor $\mathrm{E}_{2}[\mathrm{~g} / \mathrm{mi}]$ is calculated from the measured values according to equations 4-2, 4-3 and 5-2. The modeled $\mathrm{PM}_{2.5}-\mathrm{E}_{2}$ is estimated according to the schematic diagram of 4-5 from the measured traffic parameters, namely the average speeds and acceleration on the Borman Expressway, equation 5-6. The $\mathrm{E}_{2}$ values are plotted against the average Borman-speed for the months November 2004 through January 2005 and compared to the $\mathrm{PM}_{2.5}$ emission factor estimated by the EPA-PART5 model (Soliman et. al, 2004).

Figures 5-12 through 5-14 show a comparison between the measured, modeled (estimated) and EPA-PART5-estimated macroscopic emission factor $\mathrm{E}_{2}$ [g/mi].

As shown in the figures, the modified Traffic-Air-Quality (TAQ-model) appears to follow the variable nature of the measured emission factor $\mathrm{E}_{2}$ more than EPA-PART5 estimation especially at low speeds, i.e. during congested conditions. 


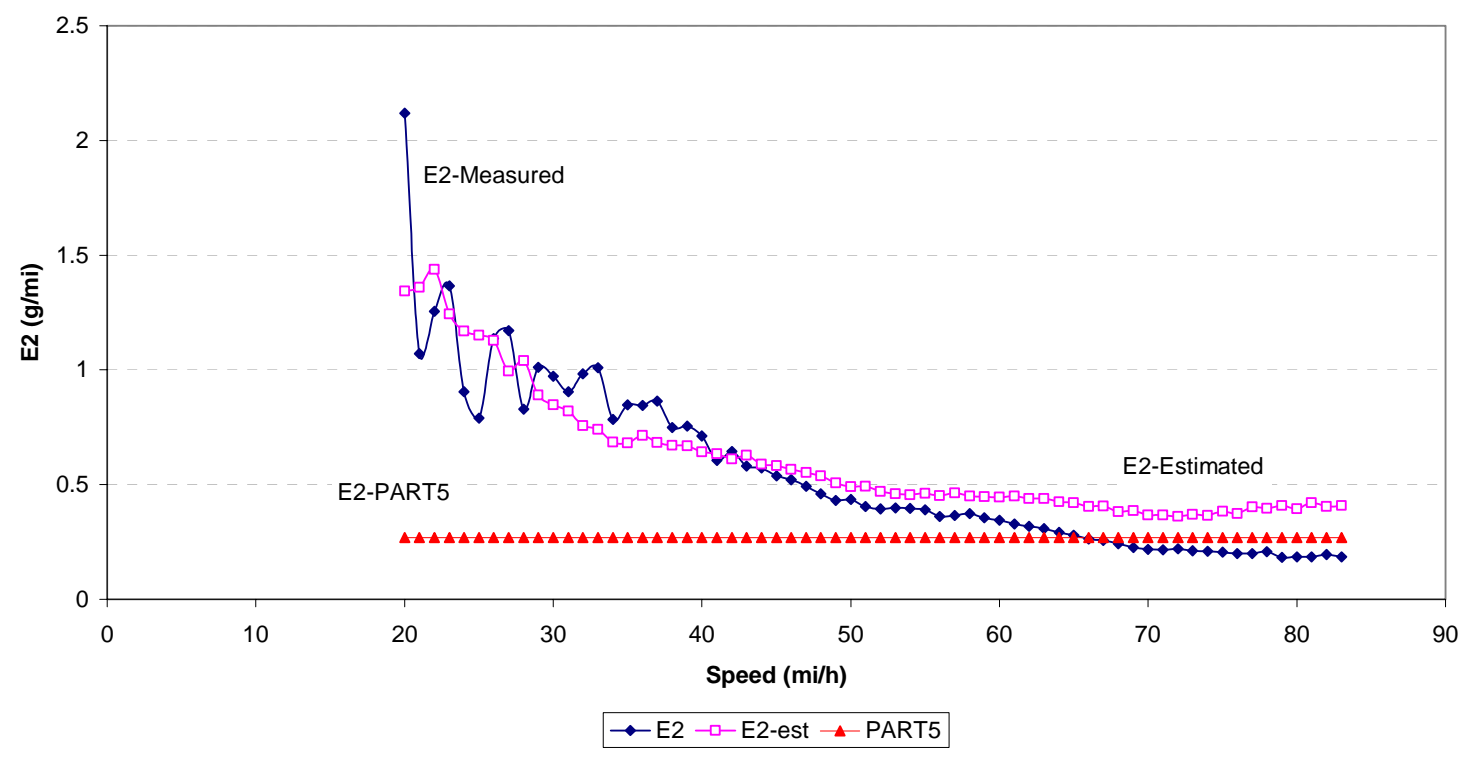

Figure 5-12. The measured, estimated (modified TAQ-model) and PART5-estimated macroscopic $\mathrm{PM}_{2.5}$ emission factor $\mathrm{E}_{2}$ as a function of the Borman average speed, November 2004.

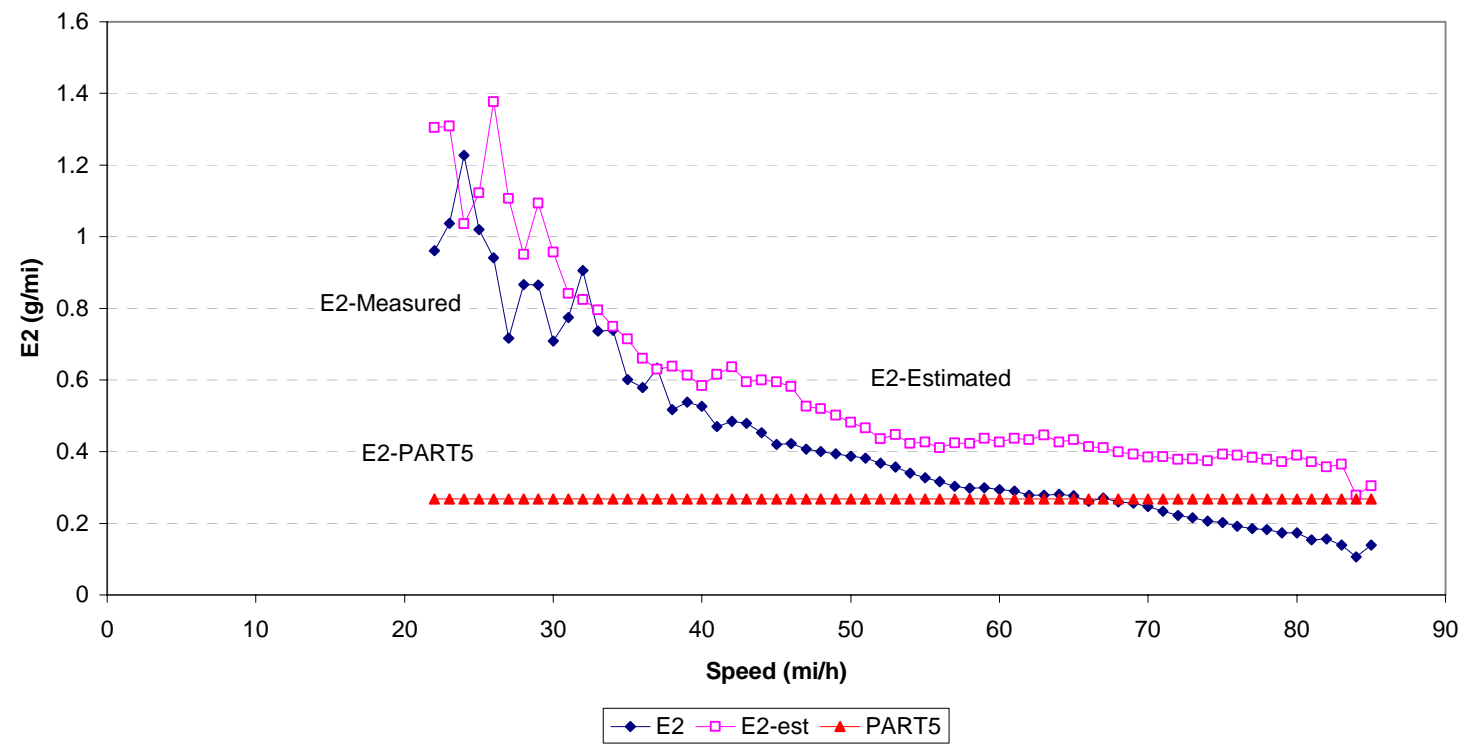

Figure 5-13. The measured, estimated (modified TAQ-model) and PART5-estimated macroscopic $\mathrm{PM}_{2.5}$ emission factor $\mathrm{E}_{2}$ as a function of the Borman average speed, December 2004. 


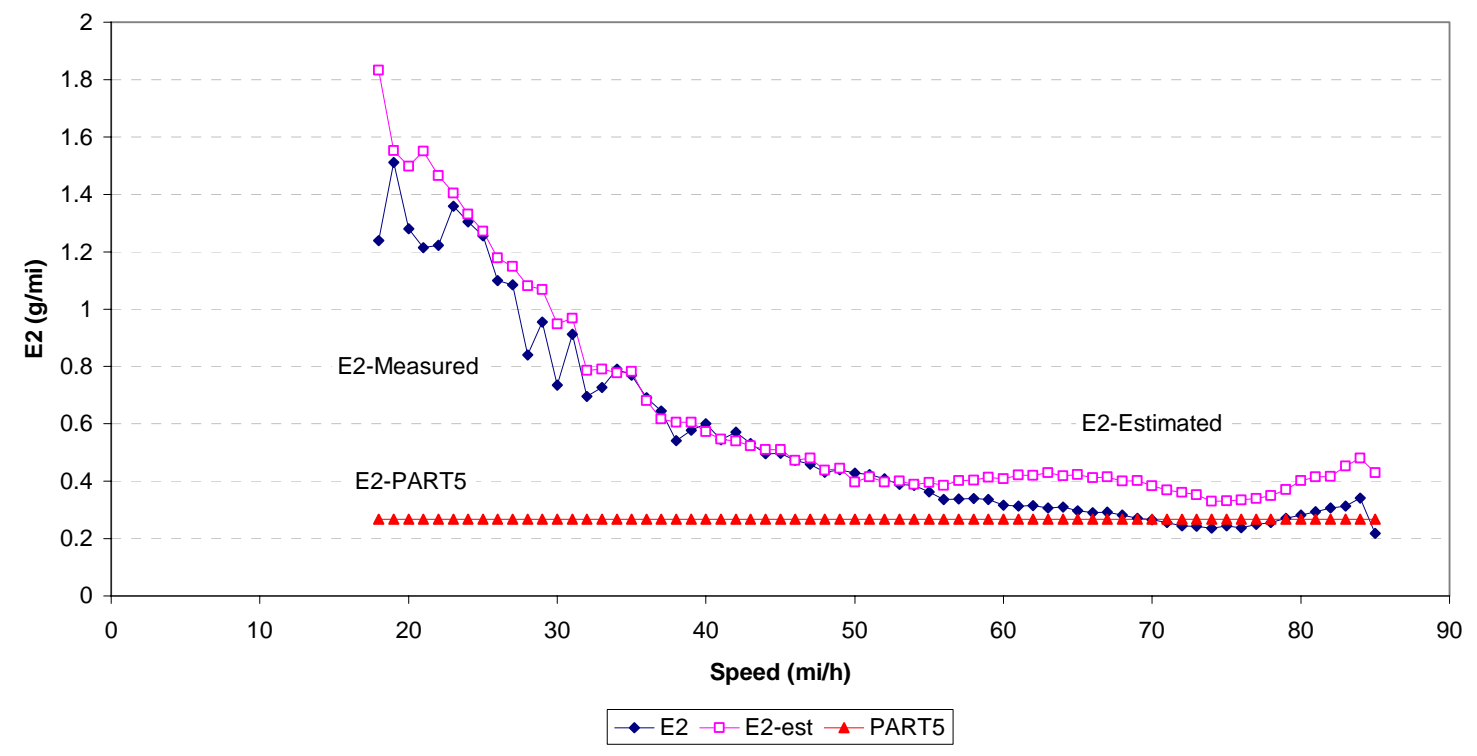

Figure 5-14. The measured, estimated (modified TAQ-model) and PART5-estimated macroscopic $\mathrm{PM}_{2.5}$ emission factor $\mathrm{E}_{2}$ as a function of the Borman average speed, January 2005.

Figure 5-15 shows the ratios between the measured and estimated values of $\mathrm{E}_{2}$ for both the TAQ and the EPA-PART5 models for the periods; November, December 2004 and January 2005.

As shown in figure 5-15, the modified traffic-air-quality model (modified TAQ model, equation 5-6) has performed better than the EPA-PART5 model during congestions, i.e. at low speeds. As mentioned earlier, the discrepancy between the actual (measured) data versus the EPA-PART5-modeled $\mathrm{PM}_{2.5}$ emissions is generally attributed to the inadequate emissions data and outdated assumptions used in the EPA-PART5 model (Ubanwa, 2003). 


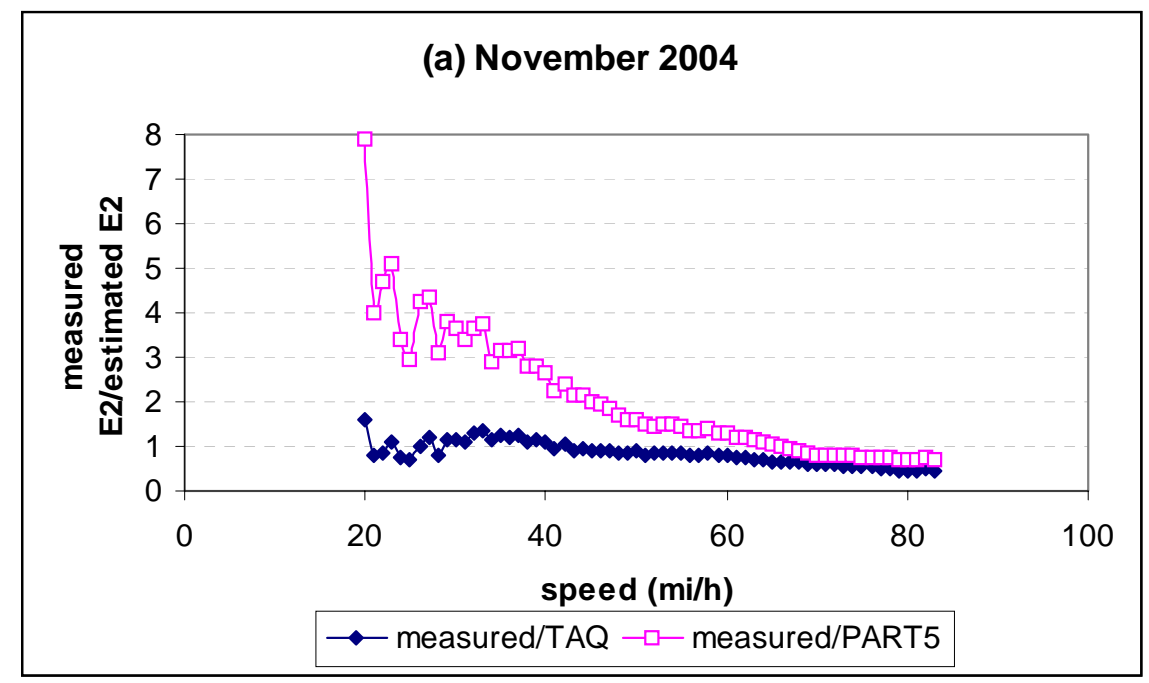

(b) December 2004
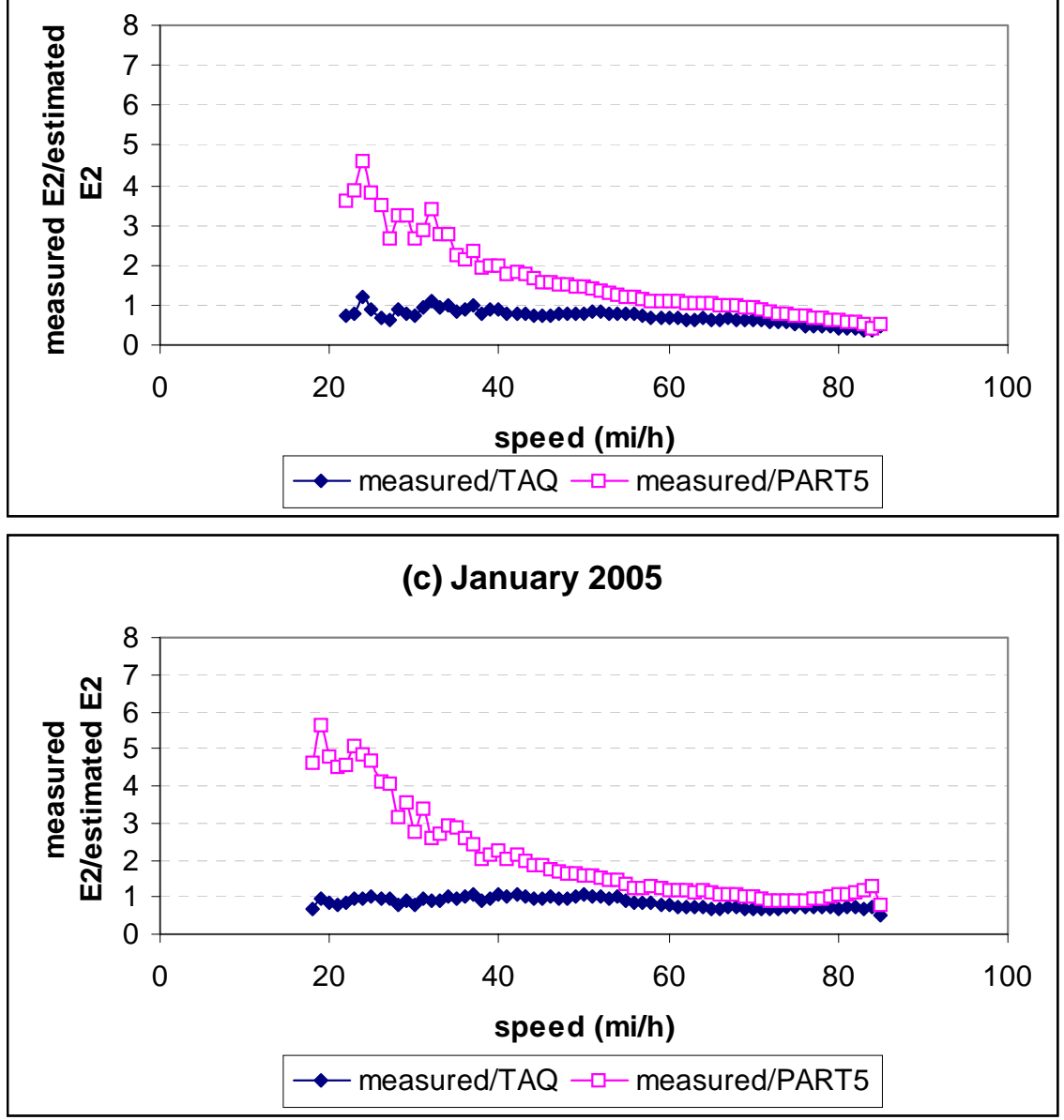

Figure 5-15. The ratio between the measured and estimated values of $E_{2}$ by both TAQmodel and the EPA-PART5 model. a) November 2004, b) December 2004 and c) January 2005. 


\section{CHAPTER SIX}

\section{TRAFFIC-AIR QUALITY TIME SERIES ANALYSIS}

\subsection{Introduction:}

A time-series is a record of observations made at a particular location, of some particular variable $(\mathrm{x})$, that is associated with the evolution of time $(\mathrm{t})$; in other words $\mathrm{x}(\mathrm{t})$. Time Series Analysis (TSA) is the systematic approach to find the correlations between the different values of a single time series (for example; $\mathrm{x}_{\mathrm{i}}(\mathrm{t})$-autocorrelation) or the cross-correlations between variables of different time series (for example; $\mathrm{x}_{\mathrm{i}}(\mathrm{t})$, and

$y_{j}(t)$ ). The analysis can be preformed in either the "time domain" (as in the case of the autocorrelation functions) or in the "frequency-domain" (as in the case of the spectral analysis and the spectral density function). TSA has a variety of applications ranging from economics to physical, health (Schwartz et. al, 1990), and environmental sciences. One of the TSA advantages is, general methodologies can be applied for analysis without the need for any prior knowledge of the underlying casual links between the dependent (y) and the independent (x) variables (i.e. a Black-Box approach) (Scalcedo et. al, 1999).

A time series is commonly described by one of the following models (Chatfield, 1996):

$$
\begin{aligned}
& X_{t}=M_{t}+S_{t}+e_{t} \\
& X_{t}=M_{t} \cdot S_{t}+e_{t} \\
& X_{t}=M_{t} \cdot S_{t} \cdot e_{t}
\end{aligned}
$$

Where, $X_{t}$ is the observed value at time $t, M_{t}$ is the "trend" or the long-term variation of the mean, $S_{t}$ is the cyclical variation component, and $e_{t}$ is the random error (stochastic 
component). Equation 6-1 is called the additive-model, while equations 6-2 and 6-3 are called the multiplicative-model that for simplicity can be transformed into the additivemodel by the logarithmic transformation. $\mathrm{M}_{\mathrm{t}}$ typically can be in the order of years (or shorter depending on the time series length) representing the long term variation of the series, where the time series is of a long-term (years) seasonal change of the variable $\mathrm{X}_{\mathrm{t}}$. Figure 6-1 shows a representation of the additive model of a hypothetical random variable $X_{t}$ (the solid line), as shown in figure, $X_{t}$ has three components, the linear increase "trend" (M; the dashed line), a cyclical component (S; the dotted line) and random noise.

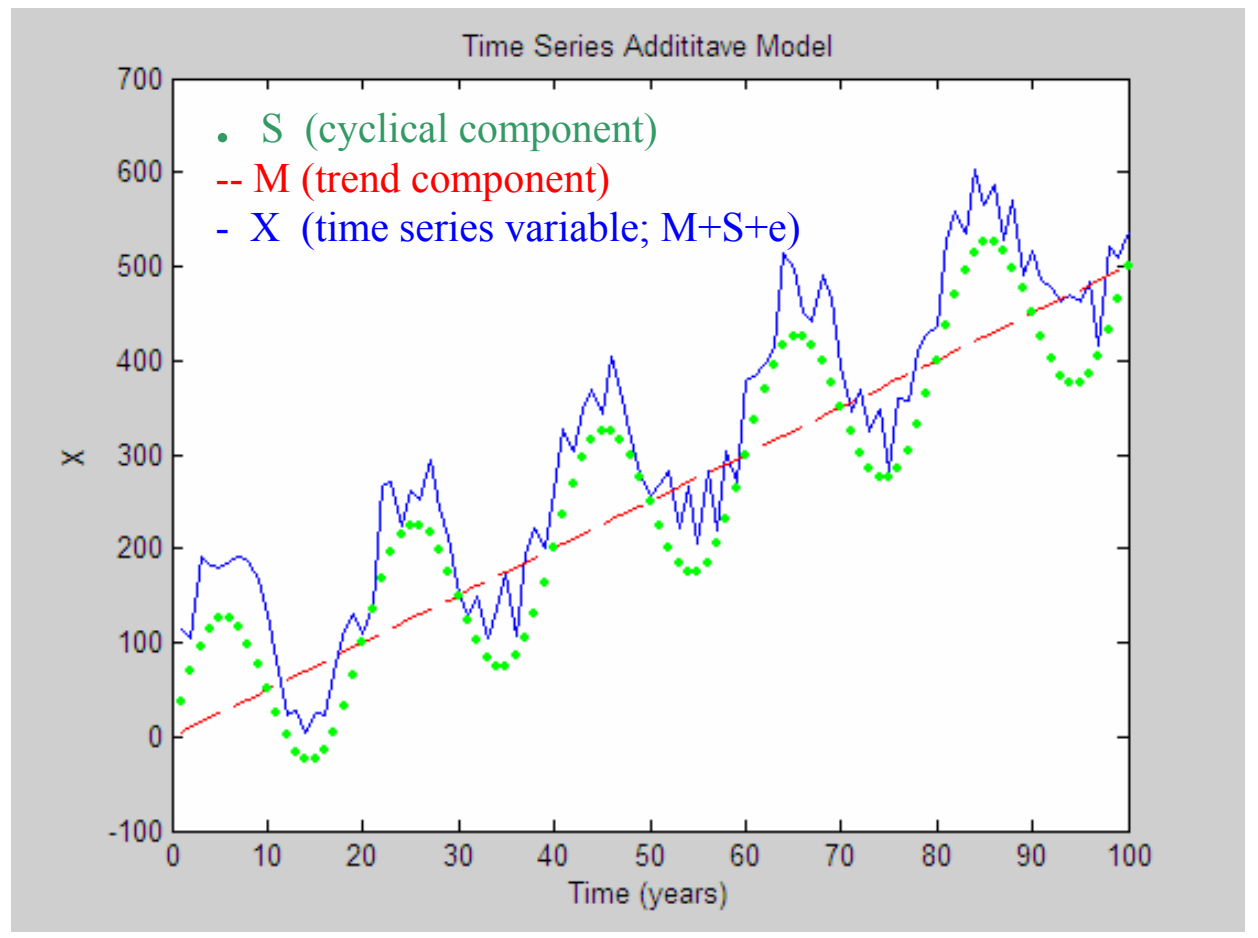

Figure 6-1. A hypothetical representation of an additive time series model.

The time series analysis can be used to achieve several objectives, such as: 1) Description: where the time series is described by a model that represents the different variations within the series. 2) Explanation: where one time series (x(t) for example) can 
be used to explain the variations in another time series $(y(t))$, e.g. how the sea-level time series is affected or explained by the temperature time series. This can be done using either linear systems or non-linear systems (such as neural networks), where a time series $\mathrm{x}(\mathrm{t})$ is an input to the system to give the output time series $\mathrm{y}(\mathrm{t})$. 3) Prediction: where the time series analysis is used to provide a prediction or forecasting of the future values of the series. 4) Control: where a time series is used to measure and control the quality of a process (in manufacturing for example). The observations can be plotted on control charts and the controller takes an action as a result of studying these charts. A more sophisticated method would be fitting a time series model (a stochastic model) to the observations and therefore a series can be predicted and the input variables are then adjusted to keep the process on target (Box, et. al. 1994).

Several studies in the environmental field, particularly in the air pollution field, have used the time series approach in their analyses. The analyses used in these studies were either performed in the time-domain, or in the frequency domain.

Time series analysis performed in urban areas have shown strong correlation between air pollutant concentrations (such as $\mathrm{NO}, \mathrm{NO}_{2}$, and $\mathrm{O}_{3}$ ) and traffic density in the urban area (Mage et. al. 1991). Emissions of air pollutants by motor traffic depend on different factors such as traffic density, driving habits and the ratio of automobiles to trucks. The dispersion and dilution of such air pollutants is mainly influenced by the meteorological conditions which they themselves may acquire a long term trend and cyclical characteristics (Milions ${ }^{\mathrm{a}}$ et. al. 1994, Milions ${ }^{\mathrm{b}}$ et. al. 1994, and Heis et. al. 2000 ), such as wind speed, turbulence, atmospheric stability, and topographical location of such urban area (Nester et. al. 1995, and Simmonds et. al. 1997). A study conducted in 
Stuttgart, Germany (from 1981 to 1993) has shown temporal variability of air pollutants (Mayer 1999). The study has shown that there is an annual cycle for the NO pollutant that has a maximum during the months of November to January and a minimum during the summer months (June and July) due to the favorable atmospheric air mass exchange. Ozone $\left(\mathrm{O}_{3}\right)$ on the other hand since it is partly produced in the lower troposphere by the action of short-wave radiation on anthropogenically (man-made) released precursor substances has shown the opposite behavior, with maximum values in the summer and lower values during winter times. $\mathrm{NO}$ and $\mathrm{O}_{3}$ have also shown diurnal cycles that were strongly influenced by traffic density as well as chemical reactions in the atmosphere (Mayer 1999). A similar study conducted in Munich, Germany (from 1990 to 1993) has shown similar temporal characteristics of the pollutant concentrations and their relations to traffic densities (Mayer et. al. 1999). However, neither of these studies attempted to analytically develop a model correlating the traffic density to air pollution levels.

Holmén et. al. (2001) have conducted time series analyses on the above-road particulate matter (PM) at the Caldecott Tunnel Exit in Orinda, CA on November 18, 1997. Above-road PM concentrations, Heavy-Duty (HD) and Light Duty (LD) vehicle counts were measured simultaneously starting at noon for 2.5 hours-period with a 10 secsampling interval. A LiDAR (Light Detection And Ranging) was used to give indication of the above-road PM concentration (LiDAR signals do not directly give concentration values, however, the signal strength is proportional to the PM concentration). HD and LD vehicles were counted using a video recording of cameras mounted on top of the tunnel exit. The purpose of the study was to measure the relative contributions of LD and HD vehicles to the PM-LiDAR signal under real-world driving conditions. Using the auto- 
correlation function in the time-domain, the time series model results indicated that the LiDAR signal in the sampling period " $\mathrm{t}$ " $\left(\mathrm{PM}_{\mathrm{t}}\right)$ depended on the level recorded at the previous three sampling periods $\left(\mathrm{PM}_{\mathrm{t}-1}, \mathrm{PM}_{\mathrm{t}-2}\right.$, and $\left.\mathrm{PM}_{\mathrm{t}-3}\right)$ where each sampling period is equal to 10 seconds. The cross-correlation function in the time-domain has also shown $\mathrm{PM}_{\mathrm{t}}$ to be dependent also on the number of $\mathrm{LD}$ vehicles in the past seventh-period $\left(\mathrm{LD}_{\mathrm{t}-7}\right)$ and on the number of $\mathrm{HD}$ vehicles in the past eighth-period $\left(\mathrm{HD}_{\mathrm{t}-8}\right)$. Multi-lagged regression analysis was then performed on these observations, and the following model was proposed to calculate the PM at time " $\mathrm{t}$ " from the PM-LiDAR signal at 20 meter height above road:

$\mathrm{PM}_{\mathrm{t}}=104.82+0.52 \mathrm{PM}_{\mathrm{t}-1}+0.11 \mathrm{PM}_{\mathrm{t}-2}+0.06 \mathrm{PM}_{\mathrm{t}-3}+4.79 \mathrm{LD}_{\mathrm{t}-7}+16.28 \mathrm{HD}_{\mathrm{t}-8}+\mathrm{a}_{\mathrm{t}}$

However, the study suggested that the $\mathrm{PM}$ signals produced by $\mathrm{LD}_{\mathrm{t}-7}$ and $\mathrm{HD}_{\mathrm{t}-8}$ is probably due to re-suspended particles recycled by the turbulence caused by the movement of vehicles rather than exhaust coming from vehicle tail pipes.

Comparison between the periodicities (either in the time-domain or the frequencydomain) of the different time series can also be used to identify the source-of-influence to the air pollutant time series, i.e. to identify if it is mainly influenced by meteorological patterns or anthropogenic sources (Scalcedo et. al. 1999, Hies et. al. 2000, and Sebald et. al. 2000).

Frequency-domain spectral analysis is another method used for analyzing air pollution time series. In a study conducted in Berlin, Germany, four stations were used to collect daily concentrations of Elemental Carbon (EC) (Hies et. al. 2000) for a one year period (April $1^{\text {st }}, 1994$ to March $31^{\text {st }}, 1995$ ). The stations were distributed in different 
locations in Berlin to reflect the influence of each area on EC. The locations ranged from heavily populated urban areas with high traffic densities to forests in the outskirts of the city. The purpose of the study was to detect and identify the anthropogenic cyclical patterns (produced by traffic and coal heating) in the EC time series. Power Density Spectra (pds) was used along with the Coherence and Phase spectra functions were used in the analysis. A pds allows detection of periodic components in noisy time series, while coherence and phase spectra functions between EC and meteorological data as well as between EC and traffic data are used to determine the respective source of periodicity. It has been found that domestic-coal-heating has influenced the EC reading on a seasonal bases with a 365-day-period peak, while traffic sources on the other hand has influenced the EC measurements on a smaller period-scale of 2.3-, 4.6-, and 7-day-period peaks. High coherence values between temperature and EC has indicated an indirect temperature influence of 365-days period. Similar analysis was also conducted by the same research group for the Ozone time series (Sebald et. al. 2000). However, neither of these studies attempted to analytically develop a model correlating the traffic density to the air pollution levels.

\subsection{Traffic Time Series Properties:}

The objective of this analysis is to analytically develop a model, using the time series analysis (TSA) to forecast the local air quality adjacent to the Borman Expressway based on the traffic conditions on the Expressway, such as free-flow and congested conditions based on the Traffic-Air-Quality Model (i.e. the TAQ-Model; given by equation 5-6). Such a model may be used as an air-quality index or parameter that can be included in the Intelligent Transportation System (ITS) that is installed in Northwest 
Indiana. Time series analysis is preformed on complete-samples of both traffic and environmental data for the data that were collected during the period of November 2004 to February 2005. The general characteristics of the traffic data-time series were analyzed for their daily and weekly periodicities. An example for a sample chosen for the analysis was for the period of November 8 to November 14, 2004. Figure 6-2 shows the 1-hour averages of the traffic data, such as, average speed $[\mathrm{mi} / \mathrm{h}]$, average class 9 -truck-density [vehicle/mi], total class 9-truck volume [vehicle/h], and average fleet-mix (ratio of class 9-truck-density to total vehicle-density on both bounds) [\%].
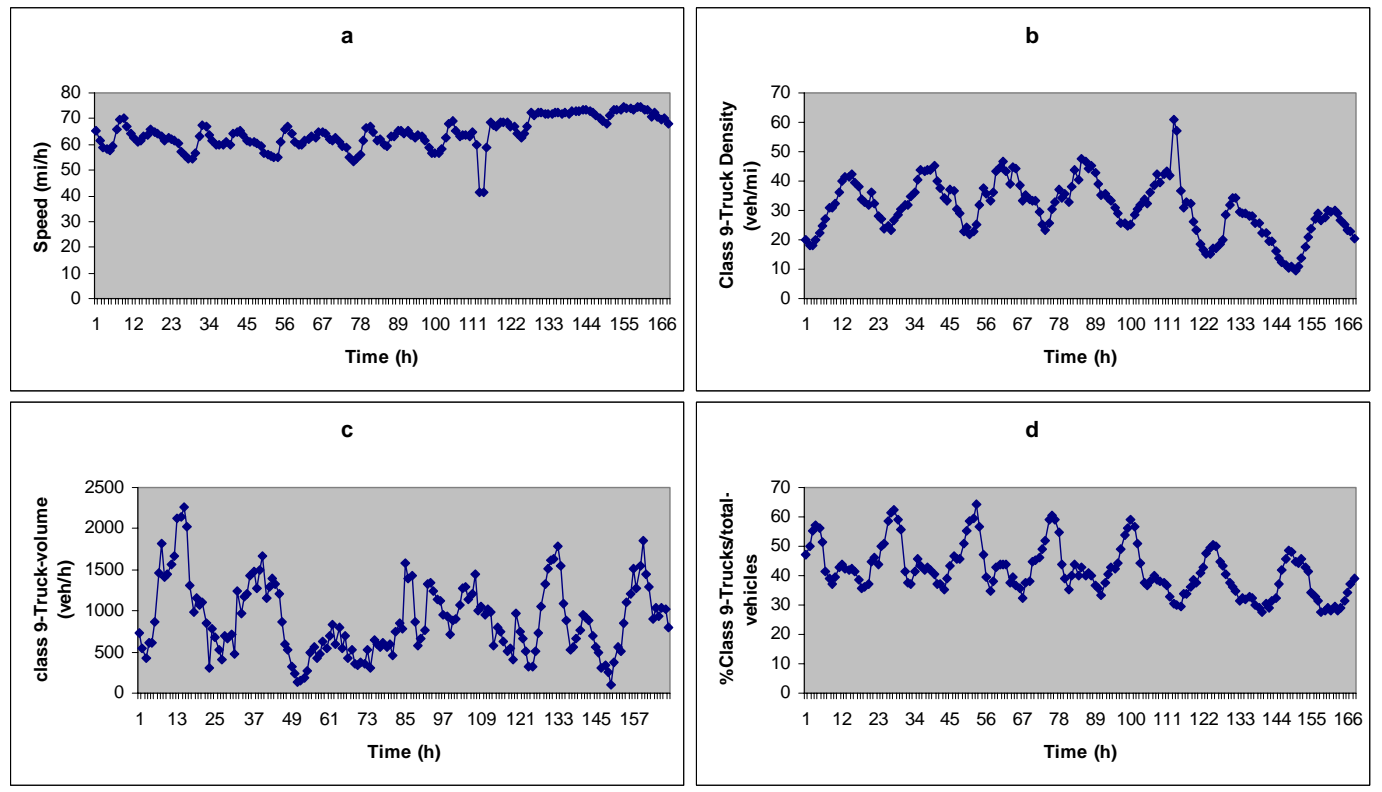

Figure 6-2. 1-hour averages of the traffic data: a) average Borman speed $[\mathrm{mi} / \mathrm{h}], \mathrm{b}$ ) average class 9-truck-density [vehicle/mi], c) total class 9-truck volume [vehicle/h], and d) average fleet-mix [\%]. November 8 to November 14, 2004.

As shown in figure 6-2, the traffic data show a periodic behavior for the time series, a 24-hour period and a weekly period. Such periodicity is also shown using the spectral analysis (Fast-Fourier-Transform analysis, FFT), figure 6-3. 

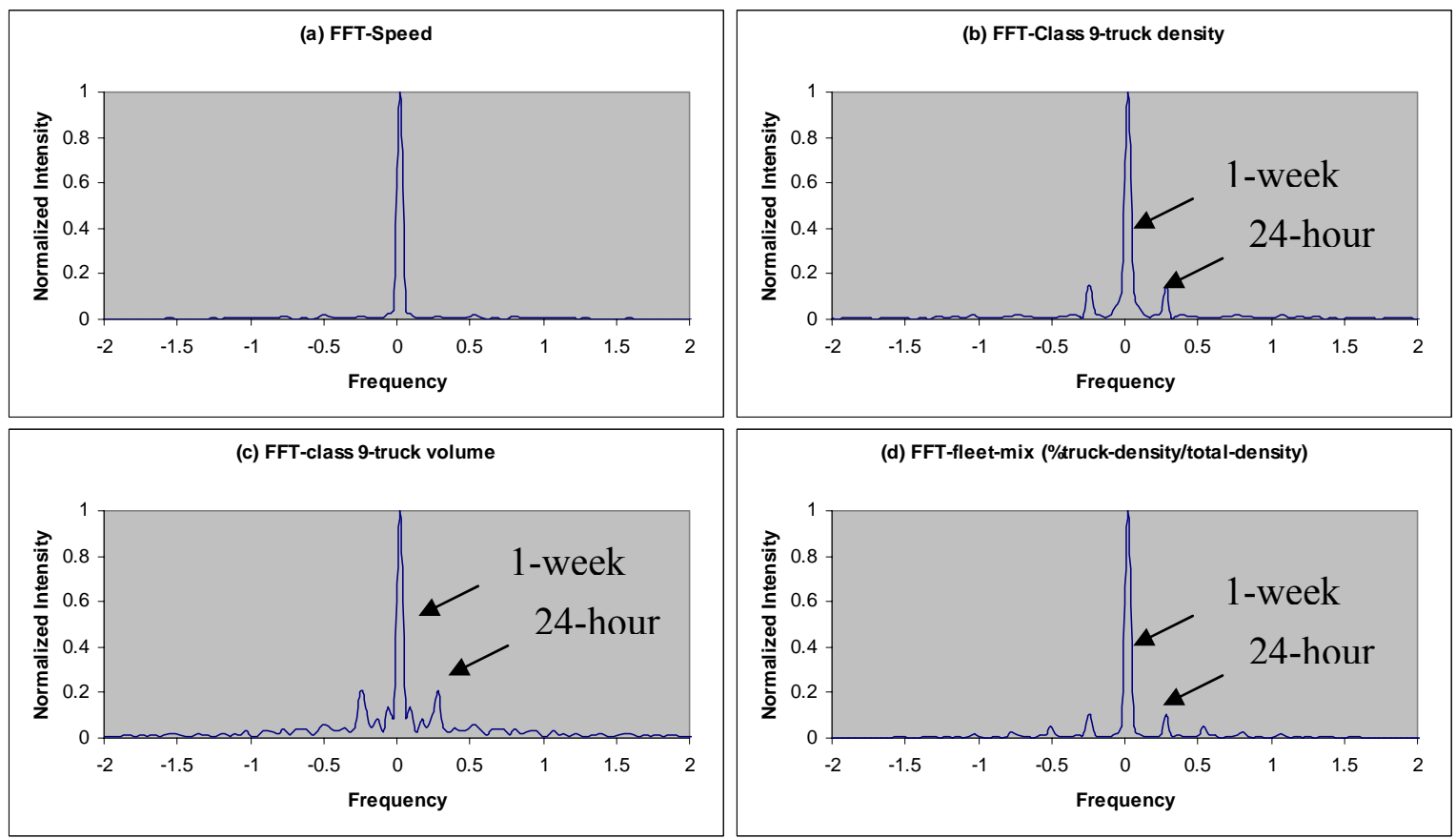

Figure 6-3. Spectral analysis of the traffic data: a) FFT of average Borman speed, b) FFT of average class 9-truck-density, c) FFT of total class 9-truck volume, and d) FFT of average fleet-mix. November 8 to November 14, 2004.

As shown in figure 6-3, with the exception of the speed data, the traffic data show a 24-hour period and a 1-week period (embedded within the zero frequency-peak). The weekly period is also seen by calculating the daily averages of the traffic data.

\subsection{Traffic-Air Quality Forecasting Model:}

Autocorrelation analysis can be used to determine how a time series correlates with itself. Next an Auto-Regressive model (AR model) was developed to be used for forecasting the traffic time series. The forecasted traffic series was then used to estimate the emission factor of a road link using the TAQ model; given by equation 5-6. 
The autoregressive model of order " $p$ " is given by (Chatfield, 1996):

$$
X_{t}=\mu+\sum_{i=1}^{p} \alpha_{i}\left(X_{t-i}-\mu\right)+Z_{t}
$$

Where: "X" is the time series variable at time "t", " $\mu$ " is the mean value of the series, " $\alpha$ " are the autocorrelation parameters, "p" is the order of the AR-model, and " $\mathrm{Z}$ " is the residual at time " $\mathrm{t}$ ".

The autocorrelation parameters matrix can be estimated by the following relation:

$$
\alpha=\mathrm{R}^{-1} \times \mathrm{r}
$$

Where: " $\alpha$ " is a $(\mathrm{p} \times 1)$ autocorrelation parameters matrix, $\alpha^{\mathrm{T}}=\left(\alpha_{1}, \ldots, \alpha_{\mathrm{p}}\right)$, " $\mathrm{r}$ " is a $(\mathrm{p} \times 1)$ autocorrelation coefficients matrix, $r^{\mathrm{T}}=\left(\mathrm{r}_{1}, \ldots, \mathrm{r}_{\mathrm{p}}\right)$, and $\mathrm{R}$ is a $(\mathrm{p} \times \mathrm{p})$ autocorrelation coefficient matrix:

$$
R=\left(\begin{array}{ccccc}
1 & r_{1} & r_{2} & \ldots & r_{p-1} \\
r_{1} & 1 & r_{1} & \ldots & r_{p-2} \\
r_{2} & r_{1} & 1 & \ldots & r_{p-3} \\
\ldots & \ldots & \ldots & \ldots & \ldots \\
r_{p-1} & r_{p-2} & r_{p-3} & \ldots & 1
\end{array}\right)
$$

The autocorrelation coefficients for lag " $k$ " are given by:

$$
r_{k}=\frac{\sum_{t=1}^{N-k}\left(x_{t}-\bar{x}\right)\left(x_{t+k}-\bar{x}\right)}{\sum_{t=1}^{N}\left(x_{t}-\bar{x}\right)^{2}}
$$

Where: "N" is time series length (i.e. total number of data points or variables in the series), " $\mathrm{k}$ " is the lag of the time series during the autocorrelation process 
$(\mathrm{k}=1,2, \ldots, \mathrm{N} / 10)$, " $\mathrm{x}_{\mathrm{t}}$ " is the time series variable at time " $\mathrm{t}$ ", and " $\mathrm{x}$ " is the average of the time series "X".

A MATLAB code was written to produce the forecasting-autoregressive model by calculating equations 6-5 through 6-7 for the traffic data used in the Traffic-AirQuality model (TAQ-model; given by equation 5-6), namely the average speed, average acceleration and average truck density on the Borman Expressway. A sample of data from November 8 to November 14, 2004 was chosen for this analysis.

The first step for calculating the autoregressive model is to calculate the autocorrelation coefficients " $\mathrm{r}_{\mathrm{k}}$ " for the different time-lag " $\mathrm{k}$ ". This is done by shifting the time series $X_{t}$ over itself (autocorrelation) with a lag " $k$ " and calculating equation 6-7 at each lag. The time-lag " $\mathrm{k}$ " is usually chosen as $\mathrm{k}=1,2, \ldots, \mathrm{N} / 10$.

The second step for calculating the autoregressive model of the traffic data is determining the best order "p" to be used in the analysis. This is achieved by calculating equation 6-5 for an arbitrary value of "p" ( $p=10$ in this analysis) and then calculating the sum-of-squares between the autoregressive-model (forecasting-model) and the measured values. Figure 6-4 shows the sum-of-squares $\left(\mathrm{S}^{2}\right)$ of the traffic data as a function of the AR-model order "p". The "p" value is then chosen at the first "bend" of the curve where the $S^{2}$ values drop and remain constant over some "p" values. Note that "p" identifies how many points of the measured data-time-series $\left(\mathrm{x}_{\mathrm{t}-\mathrm{i}}, \mathrm{i}=1,2 \ldots, \mathrm{p}\right)$ are needed to forecast a data variable " $\mathrm{x}_{\mathrm{t}}$ ".

Figure 6-4 shows the sum-of-squares $\left(\mathrm{S}^{2}\right)$ of the traffic data, speed, acceleration and truck density as a function of the AR-model order "p". As shown in the figure, the speed time series can be forecasted using an AR-model of order $\mathrm{p}=3$, the acceleration 
time series can be forecasted using an AR-model of order $\mathrm{p}=8$, and finally the truck density time series can be forecasted using an AR-model of order $\mathrm{p}=2$ (the arrows on the graphs).

The third step is constructing the matrices " $\mathrm{R}$ " and " $\mathrm{r}$ " (defined earlier) and use them in equation 6-6 to estimate the autocorrelation parameters matrix " $\alpha$ ".

Finally, the elements of the matrix " $\alpha$ " are used to calculate the AR-model (forecasting model) of the different traffic data time series (speed, acceleration and truck density time series).

Figure 6-5 shows the measured and forecasted series of the speed data. The order used for the AR-model is $\mathrm{p}=3$, and the autocorrelation coefficient matrix " $\mathrm{r}$ " (as explained above) is given by: $\mathrm{r}^{\mathrm{T}}=\left[\begin{array}{lll}0.8811 & 0.6770 & 0.5306\end{array}\right]$. As shown in figure, the AR-model performed well in estimating the average hourly speed data.

Figure 6-6 shows the measured and forecasted series of the acceleration data. The order used for the AR-model is $\mathrm{p}=8$, and the autocorrelation coefficient matrix " $\mathrm{r}$ " is given by: $\mathrm{r}^{\mathrm{T}}=\left[\begin{array}{llllllll}0.0579 & 0.0827 & 0.0790 & -0.0598 & 0.1531 & 0.0125 & 0.1009 & -0.2099\end{array}\right]$. Since the acceleration time series is not a "well-defined (or well-behaved)" function, the AR-model did not perform as well in estimating the average hourly acceleration data. 

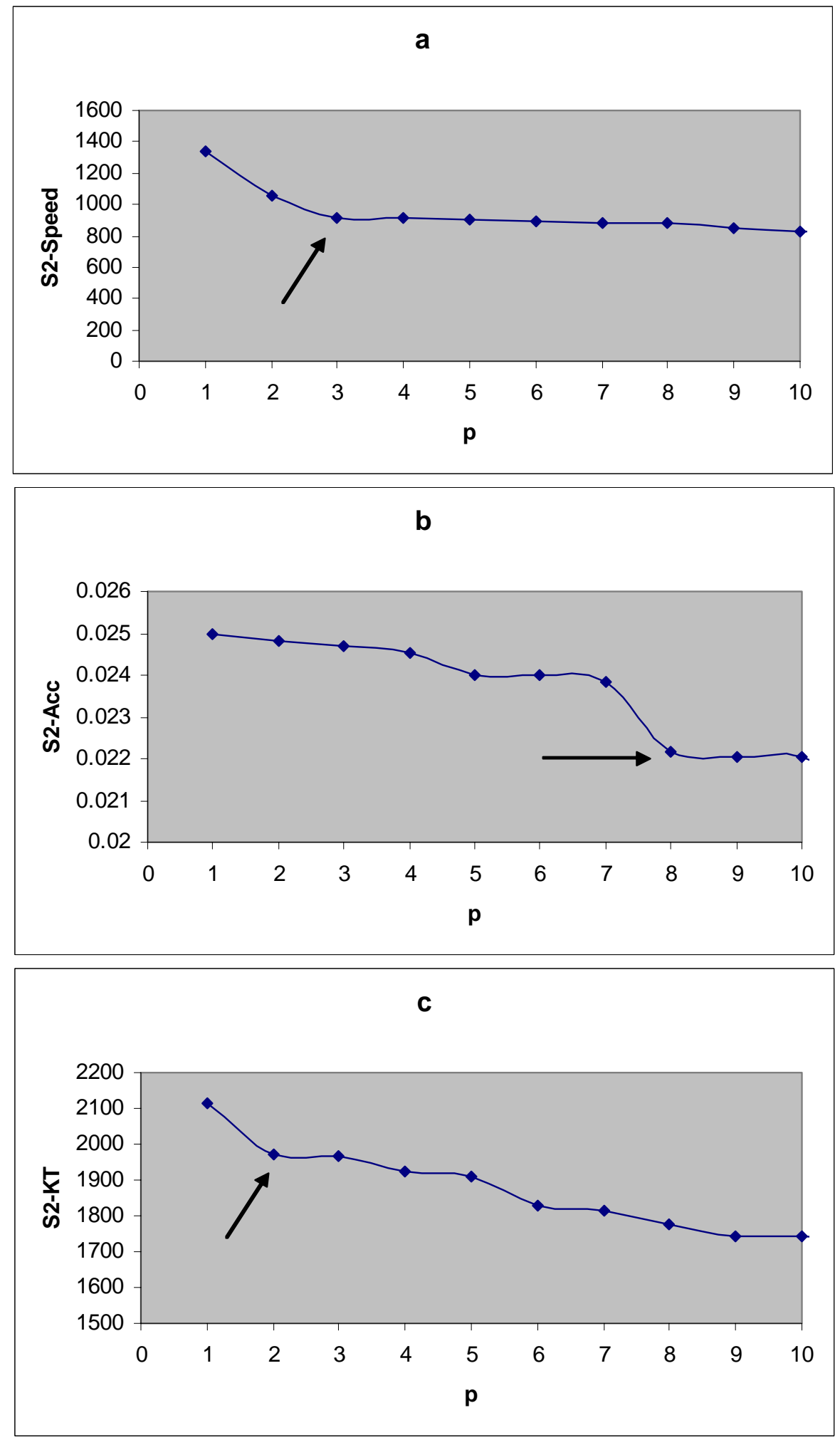

Figure 6-4. The sum-of-squares $\left(\mathrm{S}^{2}\right)$ as a function of the AR-model order "p" for: a) Speed, b) Acceleration and c) class 9-truck density. November 8 to November 14, 2004. 

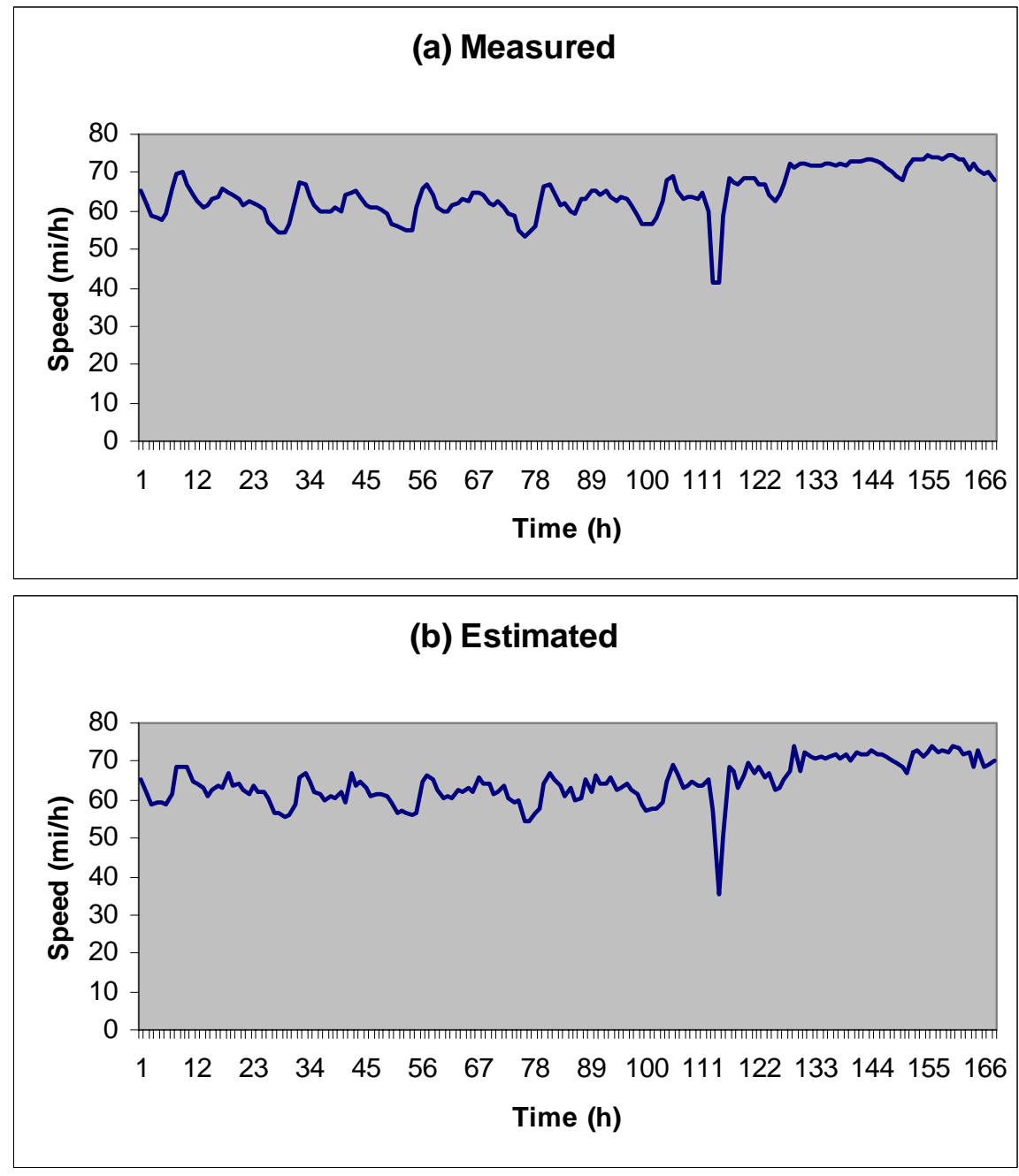

(c) Estimated vs. measured

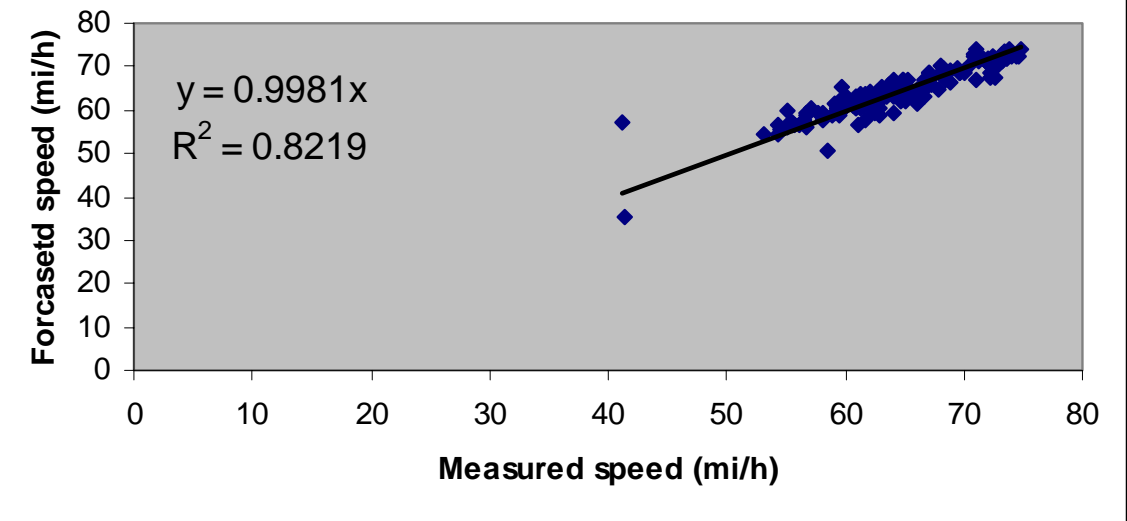

Figure 6-5. a) Measured speed values, and b) estimated speed values using the AR-model of order $3 \mathrm{c}$ ) estimated speed vs. measured speed. November 8 to November 14, 2004. 


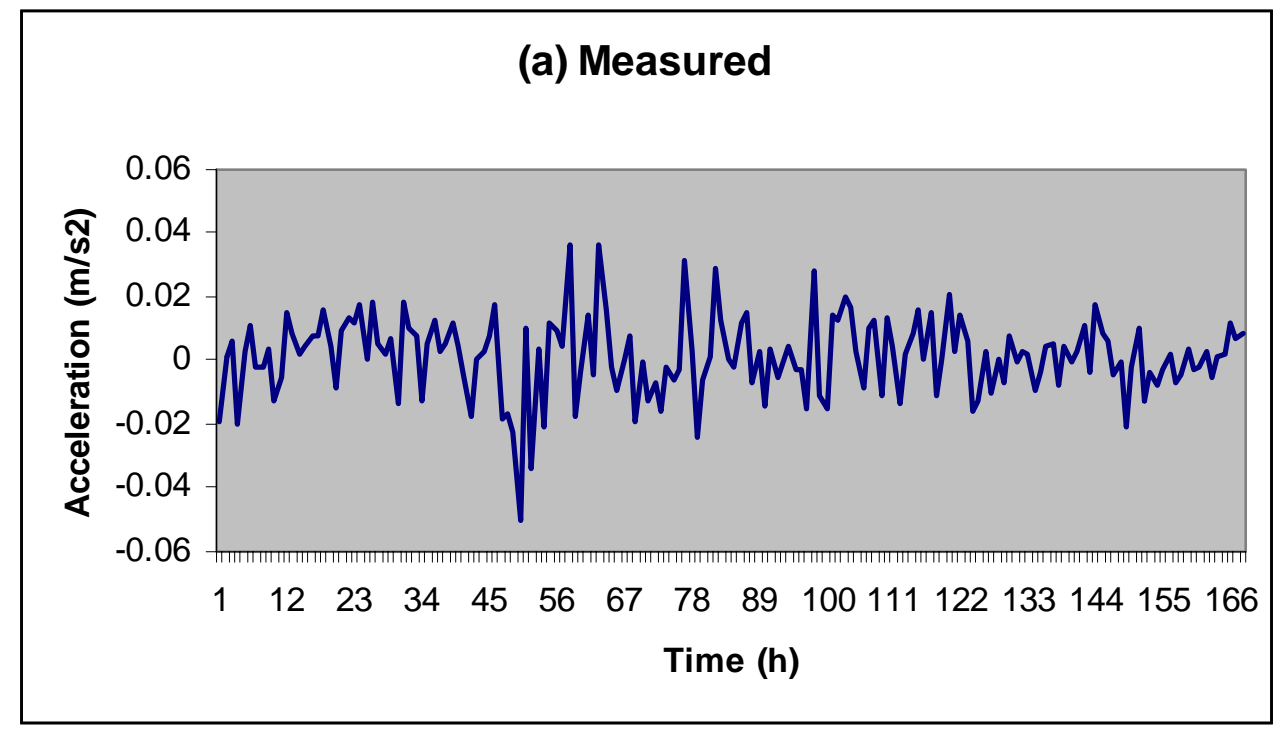

(b) Estimated

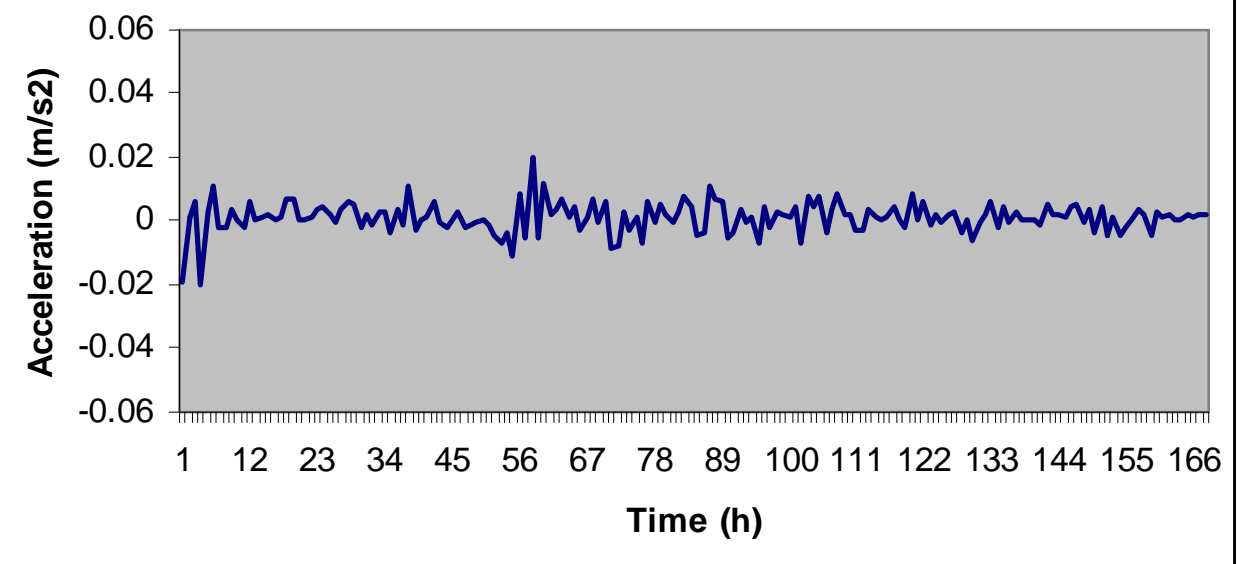

Figure 6-6. a) Measured acceleration values, and b) estimated acceleration values using the AR-model of order 8. November 8 to November 14, 2004.

Figure 6-7 shows the measured and forecasted series of the class 9-truck density data. The order used for the AR-model is $\mathrm{p}=2$, and the autocorrelation coefficient matrix " $\mathrm{r}$ " is given by: $\mathrm{r}^{\mathrm{T}}=\left[\begin{array}{ll}0.9164 & 0.8056\end{array}\right]$. As shown in figure, the AR-model performed well in estimating the average hourly truck density data. 

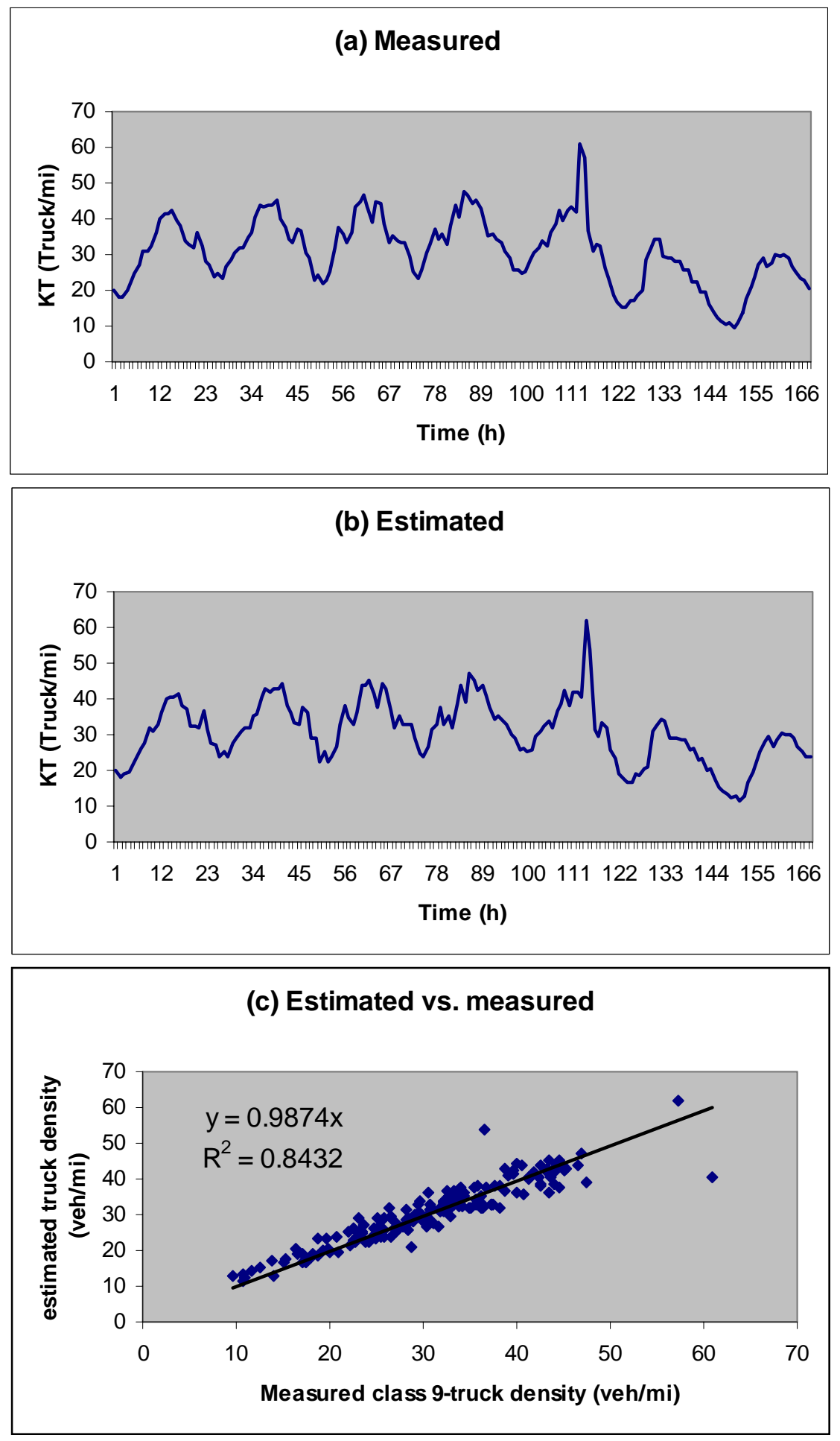

Figure 6-7. a) Measured truck density values, b) estimated truck density values using the AR-model of order 2, and c) estimated (forecasted) vs. measured class 9-truck density. November 8 to November 14, 2004. 
The estimated traffic parameters (speed, acceleration and truck density) are used to forecast the macroscopic $\mathrm{PM}_{2.5}$ emission factors, $\mathrm{E}_{2}$ [g/mi] using the Traffic Air Quality model (TAQ-model, equation 5-6). The forecasted $\mathrm{E}_{2}$ model is then compared with the measured $E_{2}$ values. Both of the measured and estimated $E_{2}$ values are compared against the traffic conditions described by the normalized-travel-time (TRN) to determine how traffic conditions affect $\mathrm{E}_{2}$. Note, TRN values $>1$ indicate traffic congestion, while $\mathrm{TRN} \leq 1$ indicate normal or free traffic flow.

Figure 6-8 shows the measured and forecasted/estimated $E_{2}$ values as a function of time for the period of November 8 to November 14, 2004. The measured $E_{2}$ average value was $0.373 \pm 0.218 \mathrm{~g} / \mathrm{mi}$ while the estimated $\mathrm{E}_{2}$ average value was $0.404 \pm 0.106 \mathrm{~g} / \mathrm{mi}$.

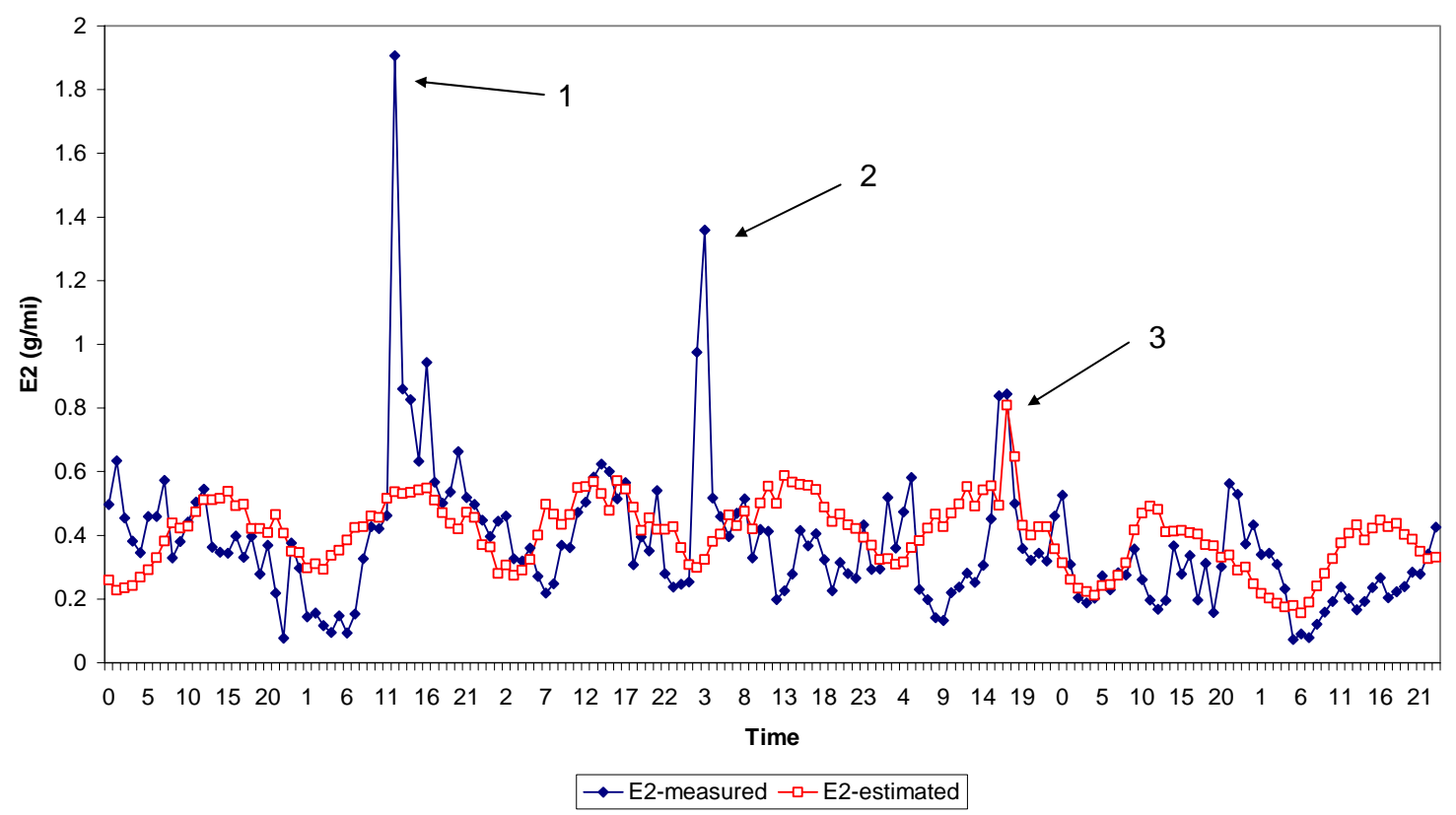

Figure 6-8. Measured and forecasted/estimated $\mathrm{E}_{2}$ values as a function of time for the period of November 8 to November 14, 2004. 
As shown in figure 6-8, the forecasted model did not predict the peaks marked as 1 and 2 of the measured values. A comparison with the traffic condition of the same period, the TRN graph of figure 6-9, show that peaks 1 and 2 were not related to the traffic conditions on the Borman Expressway. Peak 3 on the other hand appears to be due to congestions (TRN value $>1$ ) on the Borman Expressway. Peaks 1 and 2 of the measured values were due to a sudden increase in the measured $\mathrm{PM}_{2.5}$ concentrations; however such increase did not correspond to a traffic jam on the Borman Expressway. No data were available to provide a cause for the $\mathrm{PM}_{2.5}$ concentration increase, it could have been due to congestions on nearby local roads -Kennedy or Cline Ave.- or due to other near by local sources. Hence, it is suggested that peaks 1 and 2 are non-Borman-traffic related increases in the $\mathrm{PM}_{2.5}$ concentrations as indicated by figure 6-9.

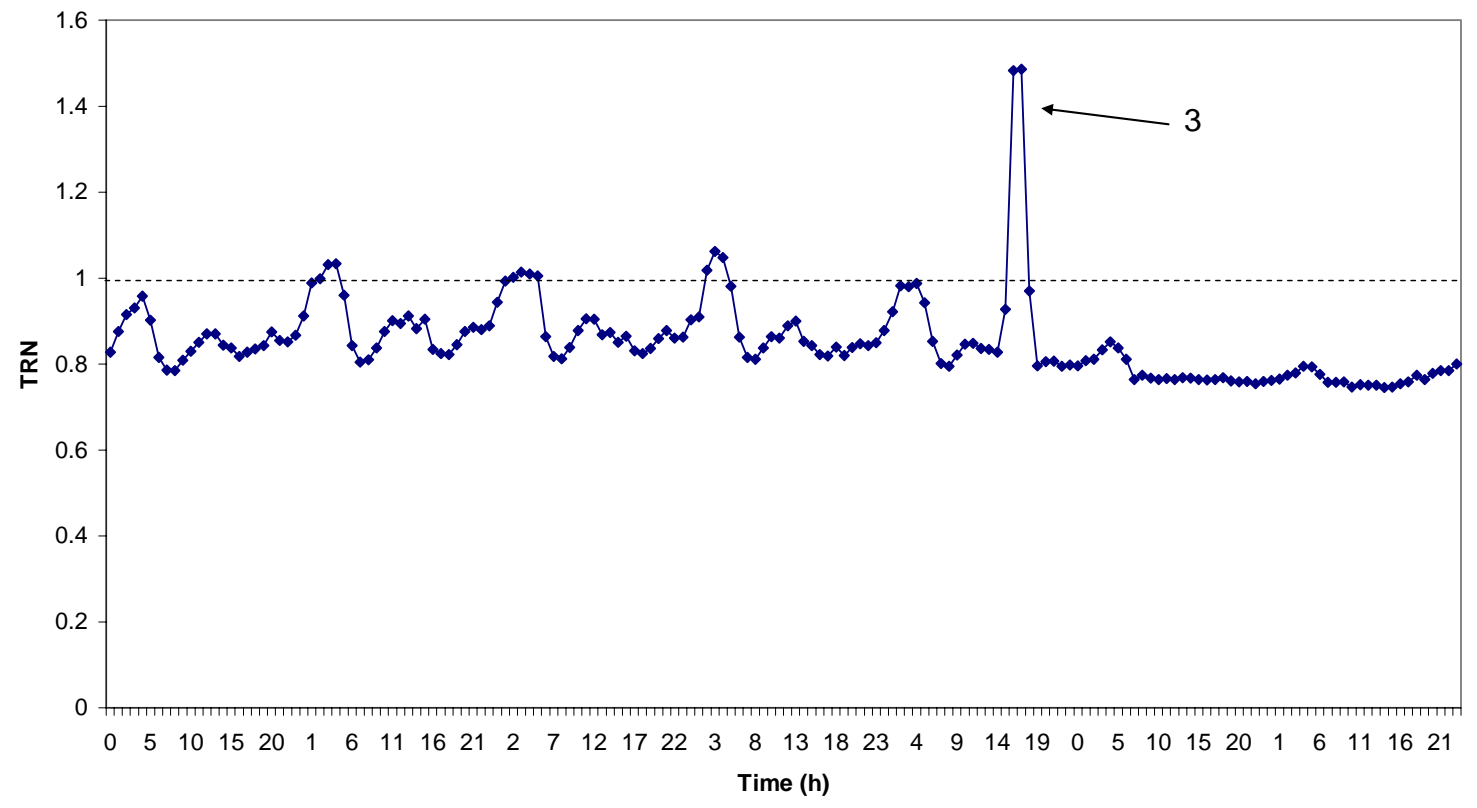

Figure 6-9. Measured normalized-travel-time (TRN) as a function of time for the period of November 8 to November 14, 2004. 
Another example of the traffic and air quality data was chosen in order to further verify the ability of the combined AR-TAQ model to forecast the average hourly $\mathrm{PM}_{2.5}$ emission factors $\left(E_{2}\right)$ using the traffic parameters as input. A two day sample, February 10 and 11, 2005, showed three periods of congested traffic where the TRN values were greater than 1. Figure 6-10 show the measured, forecasted emission factor $\left(\mathrm{E}_{2}\right)$ as well as the traffic condition described by the TRN values. The time period of this sample was for February 10 and 11, 2005.

As shown in figure 6-10, during the period of February 10 and 11 2005, the Borman Expressway experienced three major congestions described by the TRN values greater than 1 . The three peaks appearing on the measured and estimated $E_{2}$ values (figures 6-10-a and -b) correspond to the three peaks of the normalized-travel-time graph (figure 6-10-c) hence showing the effect of traffic congestions on the $\mathrm{PM}_{2.5}$ emission factors. The measured $E_{2}$ average value was $0.314 \pm 0.149 \mathrm{~g} / \mathrm{mi}$ while the estimated $\mathrm{E}_{2}$ average value was $0.458 \pm 0.115 \mathrm{~g} / \mathrm{mi}$. 

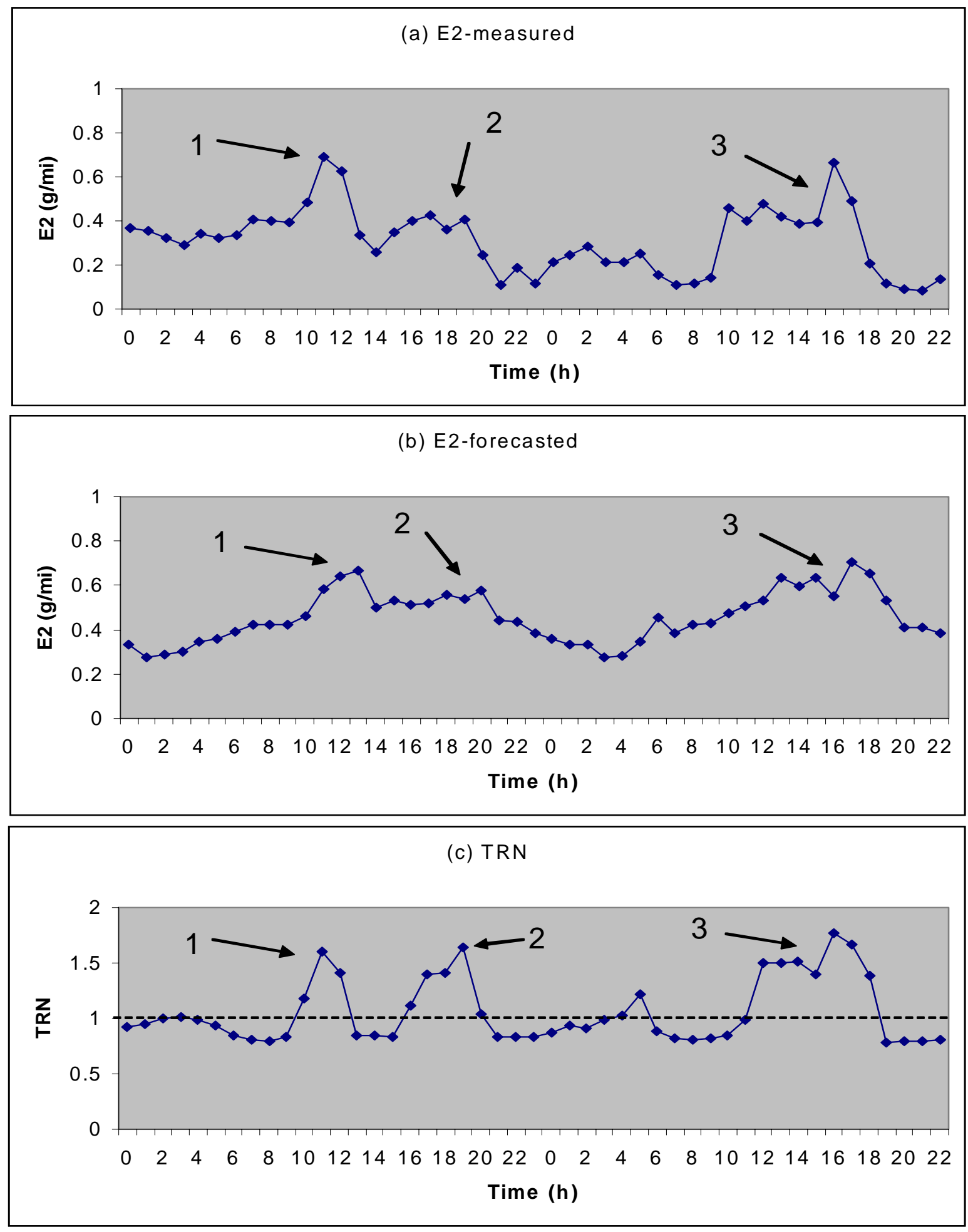

Figure 6-10. a) Measured, b) forecasted emission factors $\left(E_{2}\right)$ and c) The TRN values of the Borman Expressway. February 10 and 11, 2005. 


\section{CHAPTER SEVEN \\ SUMMARY AND IMPLEMENTATION}

\subsection{Summary and Conclusion of The Borman Study:}

The purpose of the study was to quantify the impact of traffic condition such as free flow and congestions on local air quality. The I-94 Expressway in Northwest Indiana, is considered a test-bed for this research due to the high volume of class-9-truck traffic traveling on it, as well as the existing and continuing installation of the Intelligent Transportation System (ITS) to improve the traffic management along the highway stretch.

Two Purdue University air monitoring stations were installed on the Borman Expressway to simultaneously measure both traffic and air quality data adjacent to the expressway. The data analyzed were for the period of November 2004 to February 2005.

$\mathrm{PM}_{2.5}$ concentration and mass accumulation rate analyses have shown a three-fold increase in the $\mathrm{PM}_{2.5}$ mass accumulated per day during road construction in comparison to normal days.

Traffic data were collected using the new technology of SIDEFIRE $^{\circledR}$ WAVETRONIX $^{\mathrm{TM}}$ microwave sensors. The sensors have been calibrated for both speeds and class-9-truck volume for both east and west bounds using video-recorded manual data over a period of 2 hours. The calibration curves showed good correlation between 
the sensor data set and the manual data set. On average, the manual speed readings were $5 \%$ higher than the sensor readings, while the difference in truck volume readings over one hour during congestion ranges from $6 \%$ to $14 \%$ for the east and west bound, respectively.

The concept of microscopic and macroscopic $\mathrm{PM}_{2.5}$ emission factors $\left(\mathrm{E}_{1}\right.$ [g/vehicle], and $E_{2}[\mathrm{~g} / \mathrm{mi}]$, respectively) is introduced in order to quantify and characterize the effect of traffic along the expressway on the local air quality adjacent to the road. Such characterization was done by analytically building a model to estimate the $\mathrm{PM}_{2.5}$ emission factors (mass of pollutant per unit length, $\mathrm{g} / \mathrm{mi}$ ) for the Borman Expressway under the different driving conditions. Such emission factors indicate the pollution emission-strength of a unit length of a road link on the expressway. The higher the emission factor the worse the expected air quality level adjacent to the road.

A Traffic-Air-Quality model (TAQ-model) to predict the macroscopic $\mathrm{PM}_{2.5}$ emission factors $\mathrm{E}_{2}[\mathrm{~g} / \mathrm{mi}]$ by using only traffic parameters as inputs -namely, speed, acceleration and truck density- was developed using two approaches. The first is the constant mixing volume approach, where the turbulent mixing volume around the moving trucks is assumed constant with speed. The second is a more realistic approach, which is the variable mixing volume approach, where the turbulent mixing volume is calculated at different truck speeds and used in the TAQ model. The TAQ model requires only traffic parameters as inputs to estimate the emission factor on a given road link, as shown in the schematic diagram of figure $7-1$.

Wind tunnel experiments using 1/24 scaled class 9-truck-models were used to evaluate the relation between the turbulent mixing volume and the truck speeds. Both 
approaches have shown better predictions that matched the measured emission factor values more than the EPA-PART5 model. The measured values as well as the TAQ model have shown that the $\mathrm{PM}_{2.5}$ emission factors change more aggressively with respect to the average truck speeds on the Borman Expressway more than the EPA-PART5 model predictions which assume constant emission values with respect to speed as shown in the example of figure 7-2-a. Figure 7-2-b shows the good correlation between the $\mathrm{PM}_{2.5}$ emission factors predicted by the TAQ-model and the measured $\mathrm{E}_{2}$ values (slope $=$ 1.12 , and $\mathrm{R}^{2}=0.93$ ) for the example of the month of January 2005 .

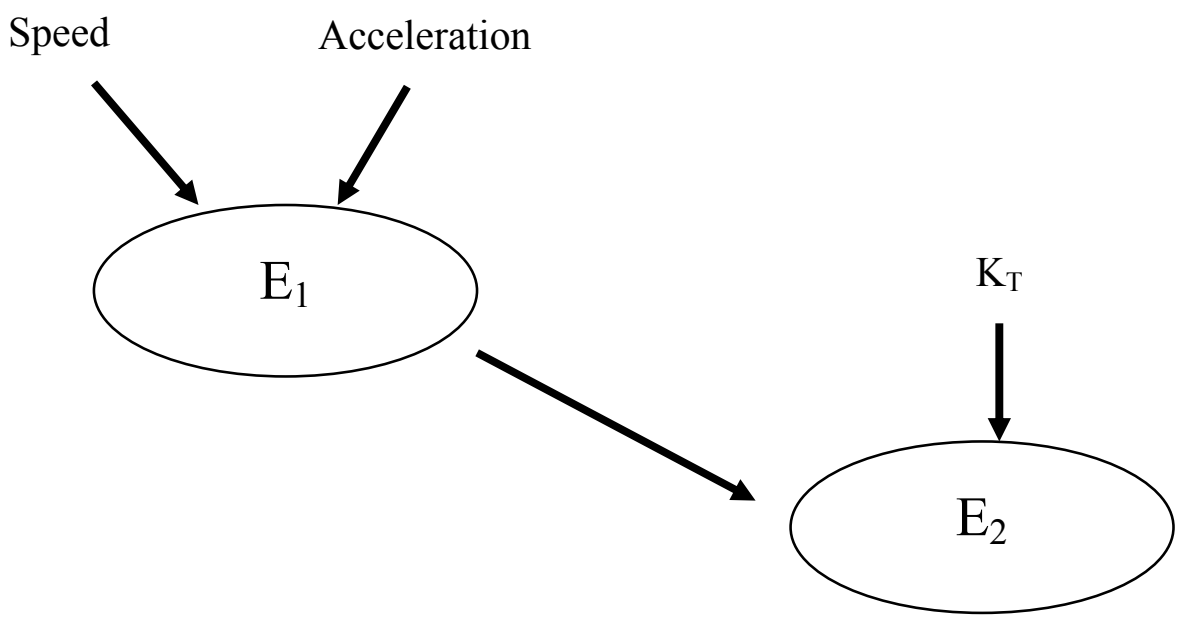

Figure 7-1. A schematic diagram showing the process of estimating E2 from traffic data.

Figure 7-2-a also shows that during congestions (at low speeds) a given road link is expected to emit more pollutant mass than during free flow (at higher speeds). For example, in January 2005 , on average a $73 \%$ improvement in air quality is expected when the average Borman speed range is improved from $<30 \mathrm{mi} / \mathrm{h}$ to $>50 \mathrm{mi} / \mathrm{h}$. 
(a) E2 vs. Speed, January 2005

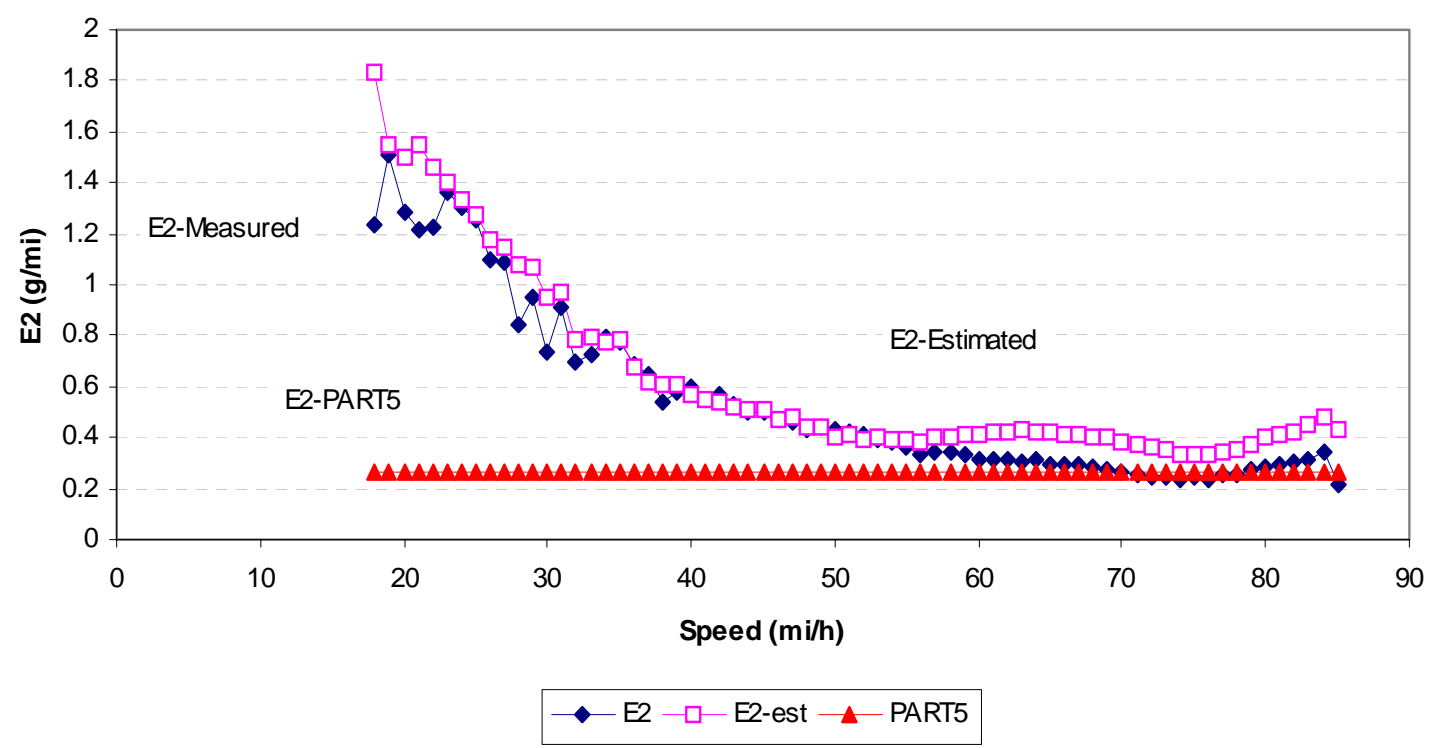

(b) estimated vs. measured E2

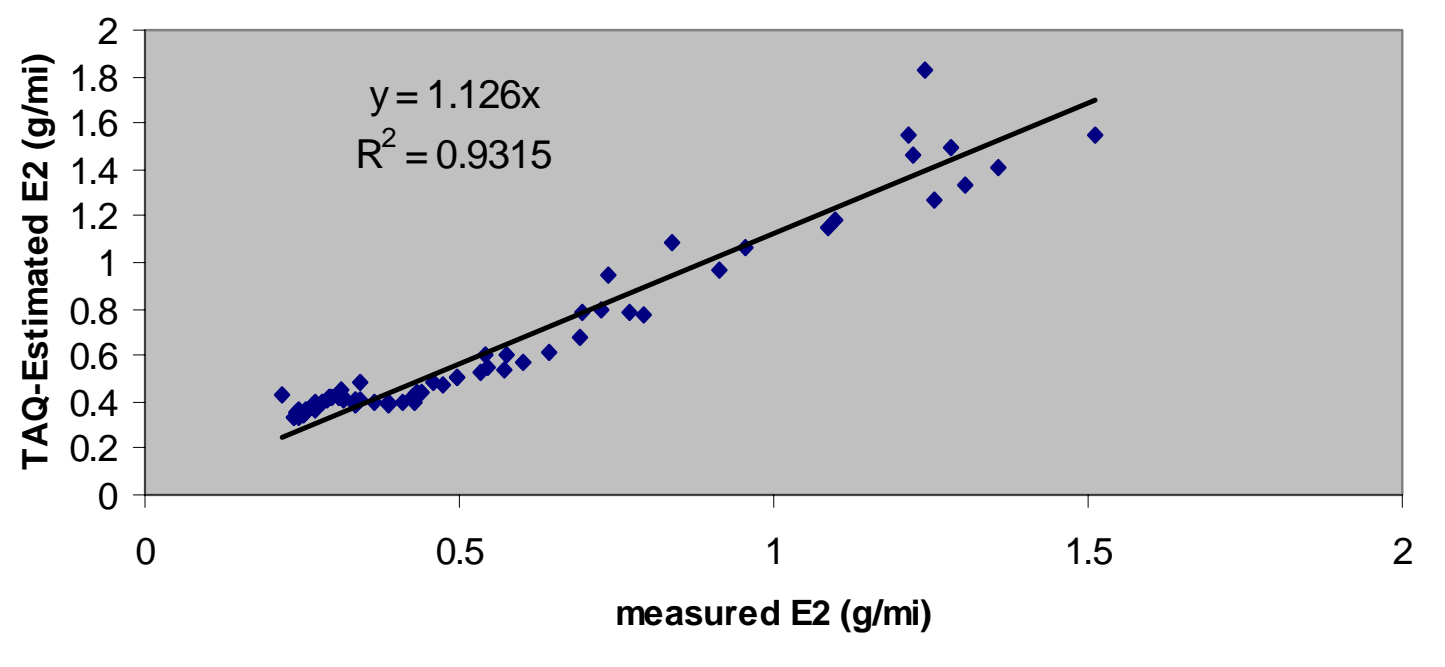

Figure 7-2. a) The measured, estimated (modified TAQ-model) and PART5-estimated macroscopic $\mathrm{PM}_{2.5}$ emission factor $\mathrm{E}_{2}$ as a function of the Borman average speed, and $\mathrm{b}$ ) TAQ-model-estimated $\mathrm{E}_{2}$ vs. the measured values of $\mathrm{E}_{2}$, January 2005. 
Table 7-1 shows the average measured $\mathrm{PM}_{2.5}$ emission factor $\left(\mathrm{E}_{2},[\mathrm{~g} / \mathrm{mi}]\right)$ for the average Borman speed ranges of less than $30 \mathrm{mi} / \mathrm{h}$ and greater than $50 \mathrm{mi} / \mathrm{h}$. As shown in the table, an average of $74 \%$ improvement in air quality is expected when the average Borman speed range is improved from $<30 \mathrm{mi} / \mathrm{h}$ to $>50 \mathrm{mi} / \mathrm{h}$. hence it is of importance to manage the traffic along expressways to maintain low emissions of $\mathrm{PM}_{2.5}$ per road link.

Table 7-1. Measured $\mathrm{E}_{2}$ values for the different average Borman speed ranges.

\begin{tabular}{|c|c|c|c|}
\hline & $\begin{array}{c}\text { E2 for Average } \\
\text { Borman } \\
\text { Speed }<\text { 30 } \\
{[\mathbf{g} / \mathbf{m i}]}\end{array}$ & $\begin{array}{c}\text { E2 for Average } \\
\text { Borman } \\
\text { Speed }>\mathbf{5 0} \\
{[\mathbf{g} / \mathbf{m i}]}\end{array}$ & $\begin{array}{c}\text { \% Decrease in } \\
\text { E2 value } \\
{[\mathbf{\%}]}\end{array}$ \\
\hline November & 1.15 & 0.28 & 75.55 \\
\hline December & 0.93 & 0.25 & 72.89 \\
\hline January & 1.16 & 0.31 & 73.69 \\
\hline Average & 1.08 & 0.28 & 74.12 \\
\hline
\end{tabular}

Additional improvements can be also achieved in the free-flow region where traffic flows at speeds are greater than $50 \mathrm{mi} / \mathrm{h}$. Table $7-2$ shows the percent improvement in air quality from the $\mathrm{PM}_{2.5}$ point of view (i.e. reduction in $\mathrm{PM}_{2.5}$ emission levels [g/mi]) when traffic speed is increased from $55 \mathrm{mi} / \mathrm{h}$ (speed limit) to $75 \mathrm{mi} / \mathrm{h}$ on the Borman Expressway.

Table 7-2. \% Improvement in PM2.5 emission when speeds are changed from $55 \mathrm{mi} / \mathrm{h}$ to $75 \mathrm{mi} / \mathrm{h}$ on the Borman Expressway.

\begin{tabular}{|c|c|}
\hline & $\begin{array}{c}\text { \% Decrease in E2 value } \\
{[\%]}\end{array}$ \\
\hline November & $47 \%$ \\
\hline December & $38 \%$ \\
\hline January & $33 \%$ \\
\hline Average & $39 \%$ \\
\hline
\end{tabular}


As shown in table 7-2, on average there was a $39 \%$ reduction in $\mathrm{PM}_{2.5}$ emission levels when speeds are changed from $55 \mathrm{mi} / \mathrm{h}$ to $75 \mathrm{mi} / \mathrm{h}$ on the Borman Expressway. Similar analyses need to be performed on the different traffic pollutants such as $\mathrm{CO}, \mathrm{NO}_{\mathrm{x}}$, etc. as well as on the fuel-consumption levels as a function of speed to estimate the best (optimum) speed limit for traffic in order to improve the overall air-quality as well as the fuel consumption in the area.

Table 7-3 shows the average ratios of the TAQ-model and PART5 estimation during congestion and free flow with respect to the measured $E_{2}$ values for the months of November 2004 through January 2005 over the speed ranges less than $30 \mathrm{mi} / \mathrm{h}$ and greater than $50 \mathrm{mi} / \mathrm{h}$. Table 7-3-a shows that, on average, during congestions, the TAQmodel has over predicted the measured $E_{2}$ values by 1.2 folds in comparison to the 4.0 fold under-prediction by the EPA-PART5 model. On the other hand, table 7-3-b shows that during free flow, on average, the TAQ model has over predicted the measured $\mathrm{E}_{2}$ values by a factor of 1.5 .

Table 7-3. The average ratios of the TAQ model and PART5 model compared to the measured $\mathrm{E}_{2}$ values, a) during congestions, and b) during free flow.

a) Congestion $\quad(<30 \mathrm{mi} / \mathrm{h})$

\begin{tabular}{|c|c|c|c|c|}
\hline & TAQ/Measured & PART5/Measured & Measured/TAQ & Measured/PART5 \\
\hline November & 1.0 & 0.2 & $\mathbf{1 . 0}$ & $\mathbf{4 . 3}$ \\
\hline December & 1.2 & 0.3 & $\mathbf{0 . 8}$ & $\mathbf{3 . 5}$ \\
\hline January & 1.1 & 0.2 & $\mathbf{0 . 9}$ & $\mathbf{4 . 3}$ \\
\hline Average & 1.1 & 0.3 & $\mathbf{0 . 9}$ & $\mathbf{4 . 0}$ \\
\hline
\end{tabular}

b) Free Flow $\quad(>50 \mathrm{mi} / \mathrm{h})$

\begin{tabular}{|c|c|c|c|c|}
\hline & TAQ/Measured & PART5/Measured & Measured/TAQ & Measured/PART5 \\
\hline November & $\mathbf{1 . 5}$ & $\mathbf{1 . 0}$ & 0.7 & 1.0 \\
\hline December & $\mathbf{1 . 6}$ & $\mathbf{1 . 1}$ & 0.6 & 0.9 \\
\hline January & $\mathbf{1 . 3}$ & $\mathbf{0 . 9}$ & 0.8 & 1.1 \\
\hline Average & $\mathbf{1 . 5}$ & $\mathbf{1 . 0}$ & 0.7 & 1.0 \\
\hline
\end{tabular}


Finally, a simple forecasting model (the Auto-Regressive model) using time series analysis was developed to help predict averaged hourly values of $E_{2}$ based on forecasted hourly averaged traffic parameters (speed, acceleration and truck density). The autoregressive model (AR-model) forecasts time series values at time " $\mathrm{t}$ " $\left(\mathrm{x}_{\mathrm{t}}\right)$ by using previously measured values at time " $\mathrm{t}-\mathrm{i}$ " $\left(\mathrm{x}_{\mathrm{t}-\mathrm{i}}\right)$ as inputs, where $\mathrm{i}=1,2, \ldots, \mathrm{p}$, and $\mathrm{p}$ is the order of the AR-model.

The combined AR-TAQ model have shown good predictions of the emission factor $E_{2}$ when compared to the measured $E_{2}$ values, as shown in figure 7-3.

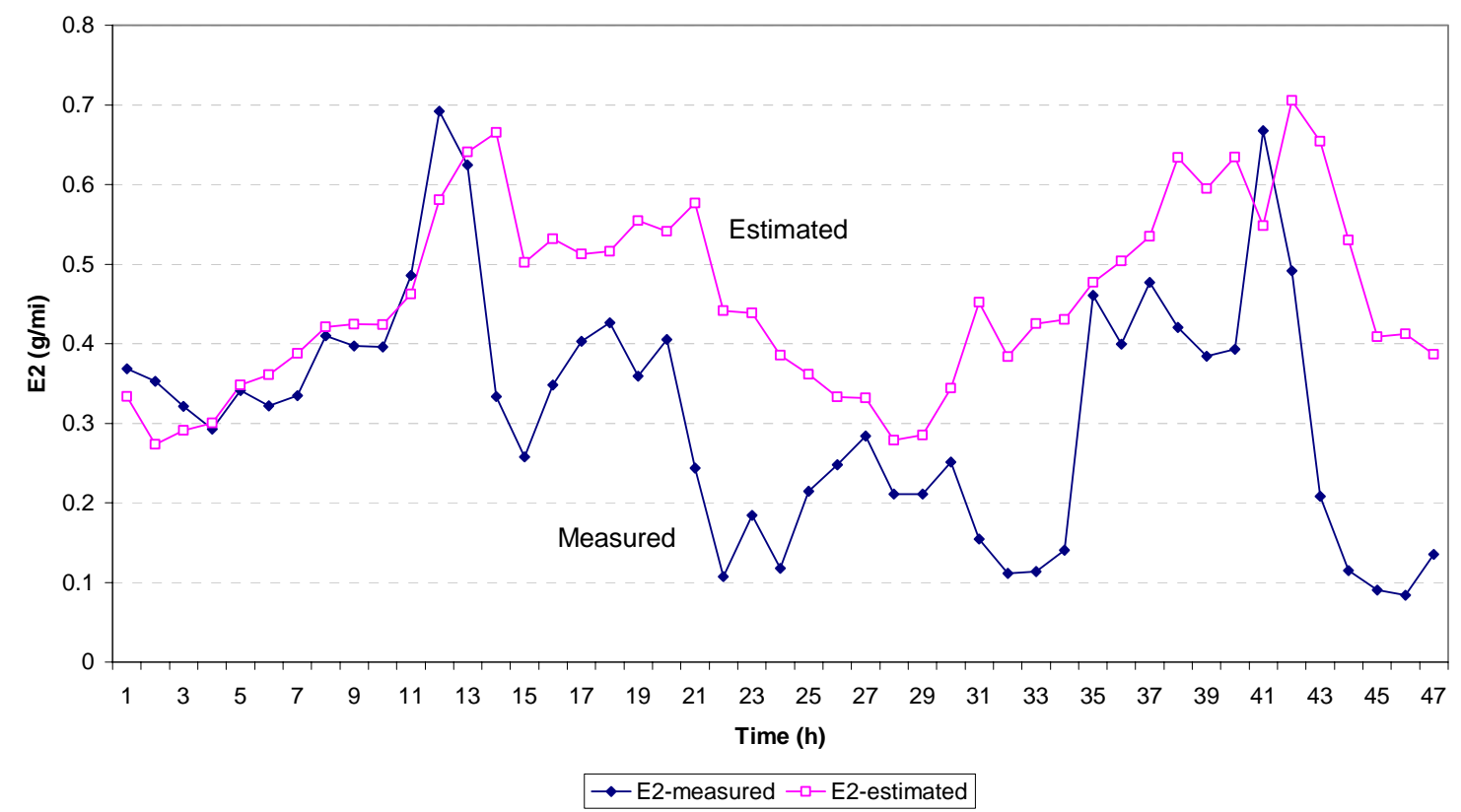

Figure 7-3. Measured and forecasted (estimated) emission factors $\left(\mathrm{E}_{2}, \mathrm{~g} / \mathrm{mi}\right)$ of the Borman Expressway. February 10 and 11, 2005. 


\subsection{Implementation and Future Research:}

The analysis presented in this study is of importance since it quantifies the impact of traffic conditions on the local air quality adjacent to an expressway. The resulting TAQ model is also of special importance to the $\mathrm{PM}_{2.5}$ non-attainment areas and counties, where $\mathrm{PM}_{2.5}$ levels exceed the National Ambient Air Quality Standard (NAAQS) levels. The TAQ model developed at the Borman Expressway sites can assist in managing the traffic conditions on the Borman from an air quality point-of-view to minimize air pollutant impacts utilizing the concept of a traffic-air-quality index.

The proposed Traffic-Air-Quality index is an air quality level (a specific pollutant emission mass per mile) above which local air quality around an expressway (or local roads in urban areas) exceeds the National Ambient Air Quality Standard (NAAQS) levels and the air becomes hazardous to human health. Hence, similar to critical traffic parameters values above which congestion occurs, ITS traffic management protocols and incident-counter-measure strategies can be implemented once the local air quality reach the Traffic-Air-Quality index value and therefore maintain the air quality levels below the NAAQS requirements. This is especially useful in $\mathrm{PM}_{2.5}$ non-attainment counties, for example:

- $\quad$ The Indianapolis area, IN: Hamilton, Hendricks, Marion, Morgan, Johnson.

- The Evansville area, IN: Vanderburgh, Warrick, Dubois and associated satellite townships in Gibson, Pike, \& Spencer Counties.

- The Louisville area, KY: Clark, Floyd and associated township in Jefferson County.

- The Cincinnati area, $\mathrm{OH}$ : a township in Dearborn County. 
From a legislative point of view, up until now, ITS traffic management protocols have not been introduced as a measure to control air quality levels in non-attainment areas (areas where air pollution levels exceed the NAAQS levels) unlike standards used for other sources such as stationary industrial sources, local house holds and businesses, figure 7-4.

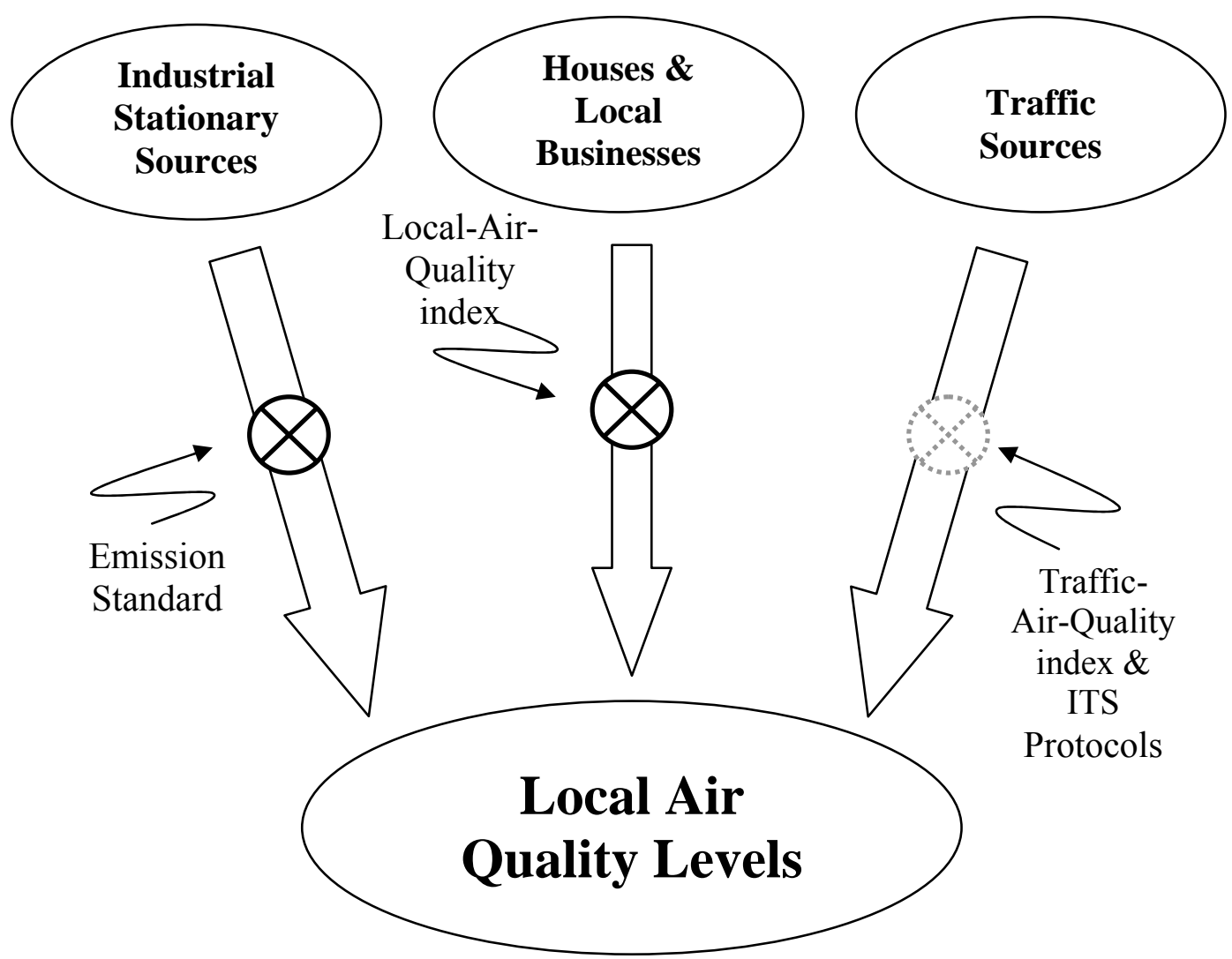

Figure 7-4. Air pollution sources in urban areas and their control measures.

Figure 7-4 is a schematic diagram that shows the different contributors to the local air quality levels in an urban-industrialized area and their control measures (represented with the ON/OFF switches on the arrows) such as the industrial emission 
standards presented by the Clean Air Act of 1970 and its amendments and the EPA localair-quality index Clean Air Act of 1970 and its amendments. However, although traffic is a major contributor of air pollution in urban areas, for example motor vehicles account for more than $60 \%$ (Davis et. al, 1998) of the total world-wide global CO emission, and locally up to $90 \%$ (Chquetto et. al, 1995) in crowded urban areas (no $\mathrm{PM}_{2.5}$ global emission contribution were reported or quantified), there is no attention paid to the importance of traffic management as a tool to control local air quality levels in nonattainment areas.

In summary, the current analysis approach to air quality data obtained from both sides of the Expressway resulted in the following:

1. The TAQ model; which gives the change in air pollutant mass emission levels as a function of traffic conditions.

2. The TAQ model will help develop ITS protocols that would assist in reducing the air pollution impact caused by traffic along the expressway:

a. AR-TAQ model can be used as a short-term prediction tool for the local air-quality adjacent to the Borman Expressway and other expressways.

b. Similar to the industrial processes, where emissions quotas (tons/year) are controlled, the AR-TAQ prediction analysis can be used as an input-index to control the traffic conditions along highways to maintain certain emission quota per road link (g/mi) and consequently improving the local traffic-air quality in the area. 
Hence, when traffic parameters are measured with the ITS sensors, traffic management on a given link of expressway can be executed not only based on traffic conditions but also on the bases of local air quality levels using the TAQ model.

Traffic data from both east and west bounds (going from and to Chicago, IL, respectively) have shown that congestion occur more frequently on the Borman-West bound more than the East bound, due to congestions in the state of Illinois. Hence, the Borman west bound may contribute more to the traffic-air pollution in Northwest Indiana more than the east bound (given equal truck density on both bounds). Therefore, "regional" collaboration between the different states is of importance to improve the traffic flow regionally rather than locally and hence improve air-quality. The GaryChicago-Milwaukee Corridor (GCM-Corridor, http://www.gcmtravel.com/gcm/home.jsp) is an example of such collaboration between the Department Of Transportation (DOT's) in the Indiana, Illinois, and Wisconsin states.

Proposed future work: Install two traffic/ $\mathrm{PM}_{2.5}$ continuous monitoring station at other different locations where counties are deemed $\mathrm{PM}_{2.5}$-non-attainment. The resulting $\mathrm{PM}_{2.5}$ air quality data will be used to verify and generalize the TAQ model created by the current stations along the Borman Expressway, and once verified, the TAQ model can be implemented and integrated in the ITS protocols to produce "tools" to manage traffic from an air-quality point of view. These "tools" can be tested at several locations and generalized, therefore, will be applicable to other expressway links in other parts of the United States. The "tools" will be very helpful for managing traffic, especially in nonattainment areas where the improvement in air quality is critical. 


\section{BIBLIOGRAPHY}

Baker, C.J., Hargreaves, D.M., "Wind Tunnel Evaluation of a Vehicle Pollution Dispersion Model", Journal of Wind Engineering and Industrial Aerodynamics, vol. 89, pp. 187-200, 2001.

Bellasio, Roberto, "Modeling Traffic Air Pollution in Road Tunnels", Atmospheric Environment, vol. 31, no. 10, pp. 1539-1551, 1997.

Bortnick, Steven M., Basil W. Coutant, and Shelly I. Eberly, "Using Continuous $\mathrm{PM}_{2.5}$ Data to Report Air Quality Index", Journal of Air and Waste Management Association, vol. 52, pp. 104-112, January 2002.

Box, G.E.P., Jenkins, G.M., and Reinsel, G.C., Time Series Analysis: Forecasting and Control, $3^{\text {rd }}$ edition (Prentice Hall, NJ, 1994).

Chan, T.L., et. al, "On-Road Remote Sensing of Petrol Vehicle Emissions Measurements and Emission Factors Estimation in Hong Kong", Atmospheric Environment, vol. 38, pp. 2055-2066, 2004.

Chatfield, Chris, The Analysis Of Time Series, $5^{\text {th }}$ edition (Chapman \& Hall, London, 1996).

Chen, Kang-Shin, C. F. Lin, and Youn-Min Chou, "Determination of Source Contributions to Ambient $\mathrm{PM}_{2.5}$ in Kaohsiung, Taiwan, Using a Receptor Model", Journal of Air and Waste Management Association, vol. 51, pp. 4898-498, April 2001.

Chquetto, Sergio, and Roger Mackett "Modeling the Effects of Transport Policies on Air Pollution", The Science of The Total Environment, vol. 169, pp. 265-271, 1995.

Chuersuwan, Nares, Barbara J. Turpin, and Charles Pietarinen, "Evaluation of TimeResolved $\mathrm{PM}_{2.5}$ Data in Urban/Suburban Areas of New Jersey", Journal of Air and Waste Management Association, vol. 50, October 2000, pp. 1780-1789.

Chung, Albert, Daniel P.Y. Chang, Michael J. Kleeman, Kevin D. Perry, Thomas A. Cahill, Dabrina Dutcher, Eric M. McDougall, and Kenneth Stroud, "Comparison of Real-Time Instruments Used To Monitor Air born Particulate Matter", Journal of Air and Waste Management, vol. 51, January, 2001, pp. 109-120.

Coifman, B. "Estimating Density and Lane Inflow on a Freeway Segment", Transportation Research: Part A, vol 37, no 8, pp 689-701, 2003. 
Coifman, B. "Estimating Travel Times and Vehicle Trajectories on Freeways Using Dual Loop Detectors", Transportation Research: Part A, 2002, vol. 36, no 4, pp. 351-364, 2002.

Coifman, B. "Improved Velocity Estimation Using Single Loop Detectors", Transportation Research: Part A, vol 35, no 10, pp. 863-880, 2001.

Coifman, B., and Cassidy, M. "Vehicle Re-identification and Travel Time Measurement on Congested Freeways", Transportation Research: Part A, 2002, vol 36, no 10, pp. 899-917, 2002.

Dab, William et. al. "Air Pollution and Health: Correlation ir Causality? The Case of Relationship between Exposure to Particles and Cardiopulmonary Mortality", Journal of Air and Waste Management Association, vol. 51, pp. 220-235, February 2001.

Davis, Mackenzie L., and David A. Cornwell, Introduction to Environmental Engineering, $3^{\text {rd }}$ edition, p. 471 (WCB/McGraw-Hill, New York, 1998).

Derwent, R. G., Simmonds, P. G., Seuring, S., and Dimmer, C., "Observation and Interpretation of the Seasonal Cycles in the Surface Concentration of Ozone and Carbon Monoxide at Mace head, Ireland", Atmospheric Environment, vol. 32, n 2, pp. 145-157, 1998.

Durbin, Thomas D., Ryan D. Wilson, Joseph M. Norbeck, J. Wayne Miller, Tao Huai, Sam H. Rhee, "Estimates of the emission rates of ammonia from light-duty vehicles using standard chassis dynamometer test cycles", Atmospheric Environment, vol. 36, pp. 1475-1482, 2002.

Ebelt, Stefanie T., A. John Petkau, Sverre Vedal, Teri V. Fisher, and Michael Brauer, "Exposure of Chronic Obstructive Pulmonary Disease Patients to Particulate Matter: Relationships between Personal and Ambient Air Concentrations", Journal of Air and Waste Management Association, vol. 50, pp. 1081-1094, July 2000.

El-Fadel, Mutasem, Majdi Abou Najm, and Hayssam Sbayti“Air Quality Assessment at a Congested Urban Intersection", Journal of Transportation and Statistics, pp. 85-102, September 2000.

Eskridge, Robert E., Hunt, J. C. R., "Highway Modeling, Part 1: Prediction of Velocity Turbulence Fields in the Wake of Vehicles", Journal of Applied Meteorology, vol. 18, no. 4, p 387-400 April 1979.

Eskridge, Robert E., Rao, S. Trivikrama, "Measurements and Prediction of TrafficInduced Turbulence and Velocity Fields Near Roadways", Journal of Climate and Applied Meteorology, vol. 22, no. 8, pp. 1431-1443, Aug 1983. 
Fischer, P.H., et. al. "Traffic-related Differences in Outdoor and Indoor Concentrations of Particles and Volatile Organic Compounds in Amsterdam", Atmospheric Environment, vol. 34, pp. 3713-3722, 2000.

Fu, Lixin, Jiming Hao,Ole Hertel, and Ruwim Berkowicz, "Modeling TrafficRelated Air Pollution in Street Canyons of Beijing", Journal of the Air \& Waste Management Association, vol. 50, pp. 2060-2066, December 2000.

Garber, Nicholas J., and Lester A. Hoel, Traffic and Highway Engineering, Third Edition (Brooks/Cole Inc., California, 2002).

Gramotnev, G. et. al, "Determination of Average Emission Factors for Vehicles on a Busy Road”, Atmospheric Environment, vol. 37, pp. 465-474, 2003.

Greenberg, J.M., A. Klar, and M. Rascle, "Congestion on Multilane Highways", Society of Industrial and Applied Mathematics, vol. 63, no. 3, pp. 818-833, 2003.

Helbing, Dirk, Davide Bactic, Martin Schönhof, and Martin Treiber, "Modeling Widely Scattered States in Synchronized traffic flow and Possible Relevance for Stock Market Dynamics”, Physica A, vol. 303, pp. 251-260, 2002.

Helmut, Mayer, "Air Pollution in Cities", Atmospheric Environment, vol. 33, pp. 4029-4037, 1999.

Hider, Z. E., S. Hibberd, and C. J. Baker, "Modeling Particulate Dispersion in the Wake of a Vehicle", Journal of Wind Engineering and Industrial Aerodynamics, vol. 67\&68, pp. 733-744, 1997.

Holmen, Britt A., Debbie A. Niemeier, and Yu Meng, "Time-Series Analysis of Above Road Particulate Matter at the Caldecott Tunnel Exit", Journal of Air and Waste Management Association, vol. 51, pp. 601-615, April 2001.

Jamriska, M., Morawska, L., "A Model for Determination of Motor Vehicle Emission Factors From On-Road Measurements With a Focus on Sub-micrometer Particles", The Science of Total Environment, vol. 264, pp. 241-255, 2001.

Janssen, Nicole A.H., et. al. "Personal Exposure to Fine Particulate Matter in Elderly Subjects: Relation Between Personal, Indoor, and Outdoor Concentrations", Journal of Air and Waste Management Association, vol. 50, July 2000, pp. 1133-1143.

John, Christian, Rainer Friedrich, Johannes Staehelin, Kurt Schläpfer, and Warner A. Stahel, "Comparison of Emission Factors of Road Traffic From a Tunnel Study (Gubrist Tunnel, Switzerland) and From Emission Modeling", Atmospheric Environment, vol. 33, pp. 3367-3376, 1999. 
Kachroo, P; Ozbay, K.; Hobeika, A.G., "Real-time travel time estimation using macroscopic traffic flow models", IEEE Conference on Intelligent Transportation Systems, Proceedings, ITSC, p 132-137, 2001.

Kerner, B.S., and H. Rehborn, "Experimental Properties of Phase Transitions in Traffic Flow", PHYSICAL REVIEW LETTERS, vol. 79, no. 20, pp. 4030-4033, 1997.

Kerner, Boris S., Hubert Rehborn, Mario Aleksic, and Andreas Haug," Recognition and tracking of spatial-temporal congested traffic patterns on freeways", Transportation Research Part C, vol. 12, pp. 369-400, 2004.

Ketzel, M., Wahlin, P., Berkowicz, R., "Particle and Trace Gas Emission Factors Under Urban Driving Conditions in Copenhagen Based on Street and Roof Level Observation”, Atmospheric Environment, vol. 37, pp. 2735-2749, 2003.

Kristensson, Adam, et. al, "Real World Traffic Emission Factors of Gasses and Particles Measured in a Road Tunnel in Stockholm, Sweden", Atmospheric Environment, vol. 38, pp. 657-673, 2004.

Kristensson, Adam, et. al, "Real-World Emission Factors of Gases and Particles Measured in a Road Tunnel in Stockholm, Sweden", Atmospheric Environment, vol. 38, pp. 657-673, 2004.

Künzli, N., "Health Costs Due To Outdoor Air Pollution by Traffic", The LANCET, vol. 356, September 2, pp. 782, 783, 2002.

Lloyd, Alan C., and Thomas A. Cackette, "Diesel Engines: Environmental Impact and Control", Journal of Air and Waste Management Association, vol. 51, pp. 809847, June 2001.

Lubashevsky, Ihor, Mahnke, Reinhard; Wagner, Peter; Kalenkov, Sergey, "LongLived States in Synchronized Traffic Flow: Empirical Prompt and Dynamical Trap Model", Physical Review E - Statistical Physics, Plasmas, Fluids, and Related Interdisciplinary Topics, vol. 66, no. 12, pp. 1-13, July 2002

Mage, David, Guntis Ozolins, Peter Peterson, Anthony Webster, Rudi Orthofer, Veerle Vandeweerd, and Michael Gwynne, "Urban Air Pollution in Megacities of the World”, Atmospheric Environment, vol. 30, n 5, pp. 681-686, 1991.

Mayer, H. Haustein, Ch., and Matzarakis, A., "Urban Air Pollution Caused by Motor-Traffic", Advances in Air Pollution, vol. 6, pp. 251-260, 1999.

Mayer, Helmut, "Air Pollution in Cities", Atmospheric Environment, vol. 33, pp. 4029-4037, 1999. 
Milions", A. E., Davies, T. D., "Regression and Stochastic Models For Air PollutionI. Review, Comments and Suggestions", Atmospheric Environment, vol. 28, n 17, pp. 2801-2810, 1994.

Milions"b, A. E., Davies, T. D., "Regression and Stochastic Models For Air Pollution-II. Application of Stochastic Models to Examine The Links Between Ground-Level Smoke Concentrations and Temperature Inversions", Atmospheric Environment, vol. 28, n 17, pp. 2811-2822, 1994.

Nester, K., "Influence of Sea Breeze Flows on Air Pollution Over the Attica Peninsula", Atmospheric Environment, vol. 29, n 24, pp. 3655-3670, 1995.

Noll, Kenneth E., and Terry L. Miller, Air Monitoring Survey Design, p. 67 (Ann Arbor Science Publishers Inc., Michigan, 1977).

Pang, Yanbo, Yuan Ren, Fida Obeidi, Robert Hastings, Delbert J. Eatough, and William E. Willson, "Semi-Volatile Species in $\mathrm{PM}_{2.5}$ : Comparison of Integrated and Continuous Sampler for $\mathrm{PM}_{2.5}$ Research or Monitoring”, Journal of Air and Waste Management, vol. 51, pp. 25-36, January 2001.

Parsons, B., and L.F. Salter, "Air Quality Effects of Traffic in a Canyon-Like Street, Falmouth, UK", Environmental Monitoring and Assessment, vol. 38, pp. 67-73, 2003.

Premo, Todd A., "Acceleration Effect on Vehicle Emission Measured Real-Time Using Fourier Transform Infrared Spectroscopy". M.S. Thesis, Purdue University, May 1998.

Rao, K.S., Gunter, R.L.; White, J.R.; Hosker, R.P., "Turbulence and dispersion modeling near highways", Atmospheric Environment, vol. 36, no. 27, pp. 43374346, September 2002.

Robinson, N.F., W.R. Pierson, A.W. Gertler, J.C. Sagebiel, "Comparison of MOBILE4.1 and MOBILE5 Predictions With the Measurements of Vehicle Emission Factors in Fort Mc. Henry and Tuscarora Mountain Tunnels", Atmospheric Environment, vol. 30, pp. 2257-2267, 1996.

Scalcedo, R.L.R., Alvim Ferraz, M.C.M., Alves, C.A., and Martins, F.G., "Time Series Analysis of Air Pollution Data", Atmospheric Environment, vol. 33, pp. 23612372, 1999.

Schlink, Uwe, Olf Herbarth, and Gred Tetzalff, "A Component Time-Series Model for $\mathrm{SO}_{2}$ Data: Forecasting, Interpretation and Modification", Atmospheric Environment, vol. 31, n 9, pp. 1285-1295, 1997. 
Schneider IV, William, "The Long Term Measurements of Carbon Monoxide and Particulate Matter $\mathrm{PM}_{2.5}$ Adjacent to the Borman Expressway". M.S. Thesis, Purdue University, May 2001.

Schneider IV, William, "Development of an Empirical Based Air Quality Traffic Management Tool and Strategies for the Borman Expressway". Ph.D. Thesis, Purdue University, December 2003.

Schwartz, J., Marcus, A., "Mortality and Air Pollution in London: A Time-Series Analysis", American Journal of Epidemiology, vol. 131, pp. 185-194, 1990.

Sebald, Ludwig, Renate Treffeisen, Eberhard Reimer, and Thomas Hies, "Spectral Analysis of Air Pollutants, Part 2: Ozone Time Series", Atmospheric Environment, vol. 34, pp. 3503-3509, 2000.

Seigneur, Christian "Current Status of Air Quality Models for Particulate Matter", Journal of the Air \& Waste Management Association, vol. 51, pp. 1508-1521, November 2001.

Shimizu, H.; Kobayashi, M.; and Yonezawa, Y., "Analysis of mean link travel time for urban traffic networks", IEEE Vehicular Technology Conference, vol. 1, p 318$322,2000$.

Simmonds, Ian, and Kevin Keay, "Weekly Cycle of Meteorological Variations in Melbourne and the Role of Pollution and Anthropogenic Heat Release", Atmospheric Environment, vol. 31, n 11, pp. 1589-1603, 1997.

Soliman, Ahmed S.M., "Local Carbon Monoxide and Particulate Matter 2.5 Modeling in Northwest Indiana Adjacent To The Borman Expressway". M.S. Thesis, Purdue University, May 2002.

Soliman, Ahmed S.M., Robert B. Jacko, Barry Partridge, "Effect of the Borman Expressway on the Air Quality in Urban Northwest Indiana: Time Series Analysis of Traffic and Air Quality Data-I”, Air \& Waste Management Association Annual conference Proceedings, June 2004.

Thomas Hies, Renate Treffeisen, Ludwig Sebald, and Eberhard Reimer, "Spectral Analysis of Air Pollutants, Part 1: Elemental Carbon Time Series", Atmospheric Environment, vol. 34, pp. 3495-3502, 2000.

Tsai, Jiun-Horng, Yih-Chyun Hsu, Hung-Cheng Weng, Wen-Yinn Lin, Fu-Tien Jeng, "Air pollutant emission factors from new and in-use motorcycles", Atmospheric Environment, vol. 34, pp. 4747-4754, 2000. 
Ubanwa, B. , A. Burnette, S. Kishan, S. G. Fritz, "Exhaust Particulate Matter Emission Factors and Deterioration Rate for In-Use Motor Vehicles", Journal of Engineering for Gas Turbines and Power, vol. 125, no. 2, pp. 513-523, April 2003.

Vardoulakis, Sotiris, et. al, "Modeling Air Quality in Street Canyons: A Review", Atmospheric Environment, vol. 37, pp. 155-182, 2003.

Veurman, J., N.L.J. Gense, I.R. Wilmink, and H.I. Baarbe, "Emissions at Different Conditions of Traffic Flow", Proceeding of the seventh Inernational Conference on Urban Transport and the Environment, pp. 571-580, 2002.

Wark, Kenneth, Cecil F. Warner, and Wayne T. Davis, Air Pollution, its Origin and Control, $3^{\text {rd }}$ edition, pp. 70, 189 (Addison-Wesley, California, 1998).

Windover, J.R. and Cassidy, M.J., "Some observed details of freeway traffic evolution", Transportation Research A, vol. 35 no.10, 881-894, 2001.

Windover, J.R., "Empirical Studies of the Dynamic Features of freeway traffic", Ph.D. Thesis, University of California, Berkley, USA, 1998. 